BNL-98524-2012-IR

\title{
Accident analysis for the NIST Research Reactor Before and After Fuel Conversion
}

J-S. Baek, A. Cuadra, A.L. Hanson, L-Y. Cheng, N.R. Brown and D.J. Diamond

September 2012

Nuclear Science \& Technology Department

\author{
Brookhaven National Laboratory \\ U.S Department of Energy \\ National Nuclear Security Administration
}

Notice: This manuscript has been authored by employees of Brookhaven Science Associates, LLC under Contract No. DE-AC02-98CH10886 with the U.S. Department of Energy. The publisher by accepting the manuscript for publication acknowledges that the United States Government retains a non-exclusive, paid-up, irrevocable, world-wide license to publish or reproduce the published form of this manuscript, or allow others to do so, for United States Government purposes. 


\section{DISCLAIMER}

This report was prepared as an account of work sponsored by an agency of the United States Government. Neither the United States Government nor any agency thereof, nor any of their employees, nor any of their contractors, subcontractors, or their employees, makes any warranty, express or implied, or assumes any legal liability or responsibility for the accuracy, completeness, or any third party's use or the results of such use of any information, apparatus, product, or process disclosed, or represents that its use would not infringe privately owned rights. Reference herein to any specific commercial product, process, or service by trade name, trademark, manufacturer, or otherwise, does not necessarily constitute or imply its endorsement, recommendation, or favoring by the United States Government or any agency thereof or its contractors or subcontractors. The views and opinions of authors expressed herein do not necessarily state or reflect those of the United States Government or any agency thereof. 


\section{Accident Analysis for the NIST Research Reactor Before and After Fuel Conversion}

Manuscript Completed: September 6, 2012

Prepared by:

J. S. Baek, A. Cuadra, A.L. Hanson, L-Y. Cheng, N.R. Brown, and D.J. Diamond

Nuclear Science and Technology Department

Brookhaven National Laboratory

Upton, NY 11973-5000

Prepared for:

National Institute of Standards and Technology (NIST)

National Nuclear Security Administration 



\begin{abstract}
Postulated accidents have been analyzed for the $20 \mathrm{MW} \mathrm{D} 2 \mathrm{O}$-moderated research reactor (NBSR) at the National Institute of Standards and Technology (NIST). The analysis has been carried out for the present core, which contains high enriched uranium (HEU) fuel and for a proposed equilibrium core with low enriched uranium (LEU) fuel. The analyses employ stateof-the-art calculational methods. Three-dimensional Monte Carlo neutron transport calculations were performed with the MCNPX code to determine homogenized fuel compositions in the lower and upper halves of each fuel element and to determine the resulting neutronic properties of the core. The accident analysis employed a model of the primary loop with the RELAP5 code. The model includes the primary pumps, shutdown pumps outlet valves, heat exchanger, fuel elements, and flow channels for both the six inner and twenty-four outer fuel elements.

Evaluations were performed for the following accidents: (1) control rod withdrawal startup accident, (2) maximum reactivity insertion accident, (3) loss-of-flow accident resulting from loss of electrical power with an assumption of failure of shutdown cooling pumps, (4) loss-of-flow accident resulting from a primary pump seizure, and (5) loss-of-flow accident resulting from inadvertent throttling of a flow control valve. In addition, natural circulation cooling at low power operation was analyzed. The analysis shows that the conversion will not lead to significant changes in the safety analysis and the calculated minimum critical heat flux ratio and maximum clad temperature assure that there is adequate margin to fuel failure.
\end{abstract}




\section{TABLE OF CONTENTS}

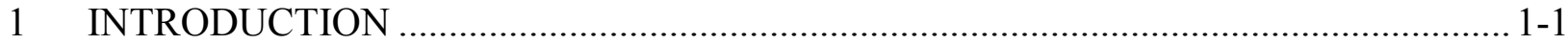

2 NIST RESEARCH REACTOR DESCRIPTION …….................................................... $2-3$

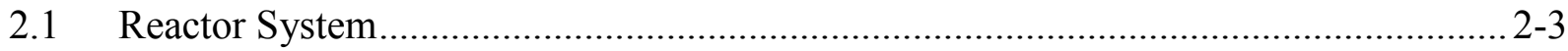

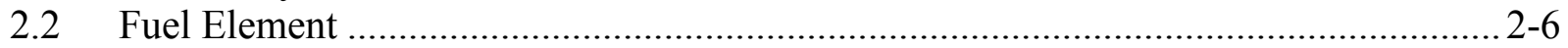

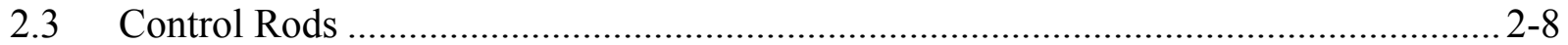

3 METHODOLOGY FOR TRANSIENT ANALYSIS ……………..................................

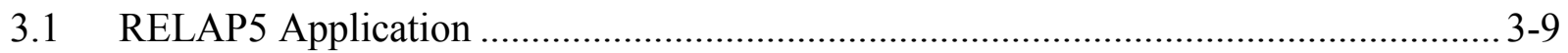

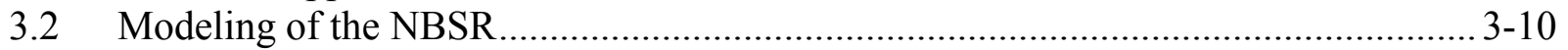

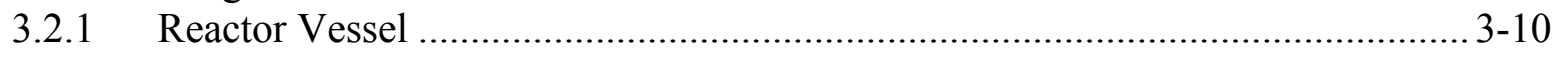

3.2.2 Primary Coolant Loop.......................................................................... 3-12

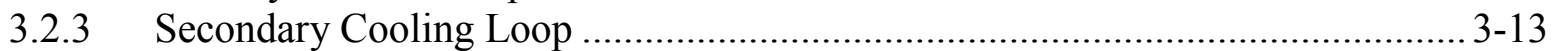

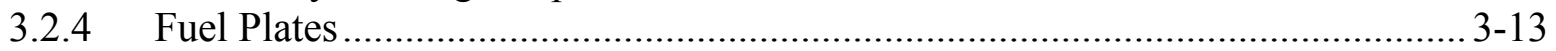

3.2.5 Modeling of Valve at Inlet of Outer Plenum ................................................... 3-13

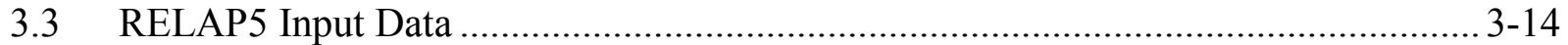

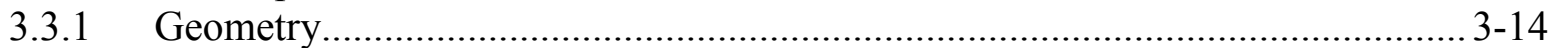

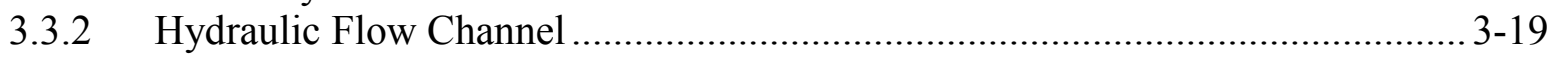

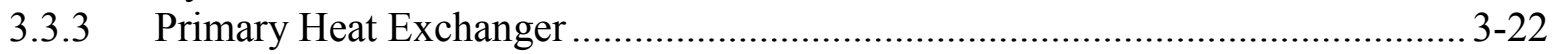

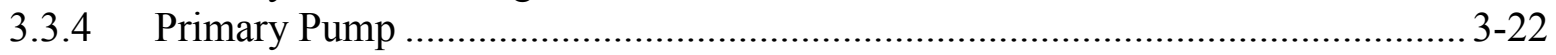

3.3.5 Inner Emergency Cooling Tank Orifice …….............................................. 3-24

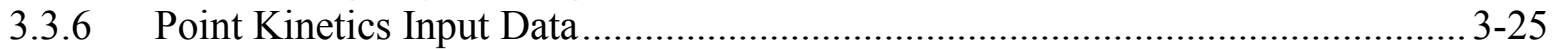

3.3.6.1 Reactor Physics Parameters ...................................................................... 3-25

3.3.6.2 Reactivity Effects ………………………........................................... 3-27

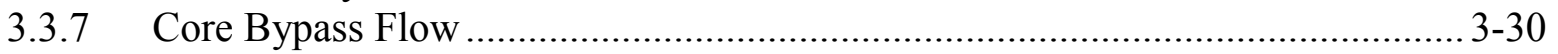

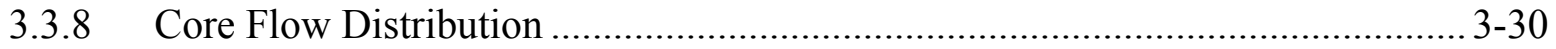

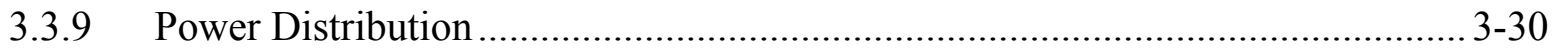

3.3.9.1 Power Distribution for Hottest-Cell Stripe ……......................................... 3-30

3.3.9.2 Power Distribution for Hottest Stripe ………............................................... 3-31

3.3.9.3 Power Distribution for Non-Hot Stripes ……….......................................... 3-31

3.3.9.4 Modeling of Heat Structures ……………................................................. 3-32

3.3.10 Control Variables and Variable and Logic Trips ................................................. 3-36

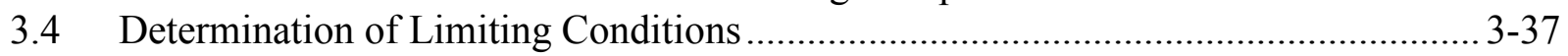

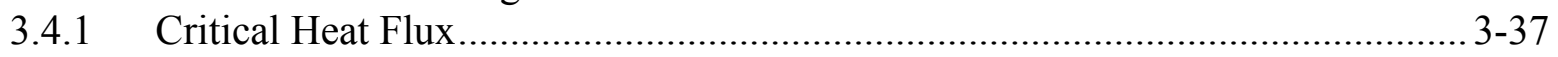

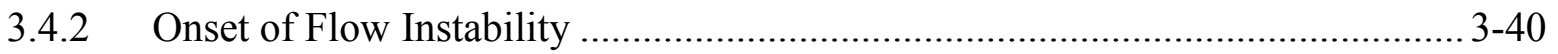

3.5 Statistical Hot Channel Limits Analysis ............................................................... 3-41

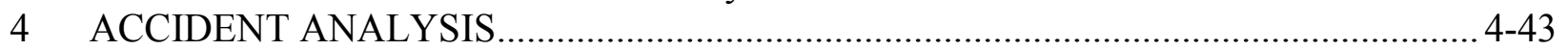

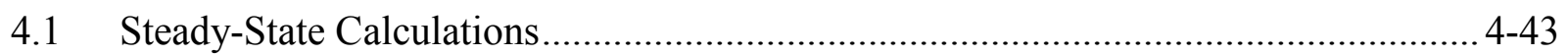

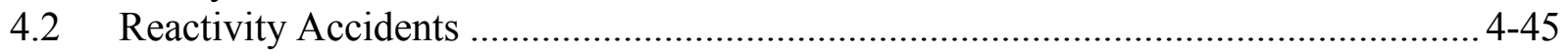

4.2.1 Startup Accident .................................................................................. 4-45

4.2.1.1 Simulation of Accident................................................................................ 4-45

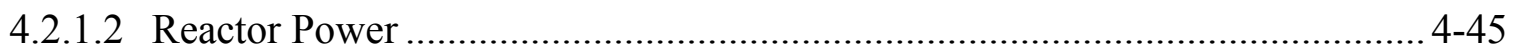

4.2.1.3 Fuel Temperature ……………………….......................................... $4-47$

4.2.1.4 Minimum CHFR ……………........................................................ 4-49

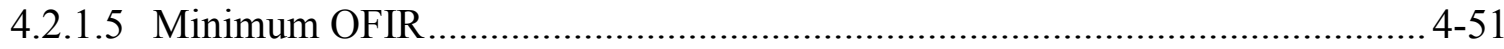

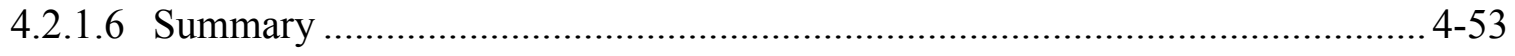


4.2.2 Maximum Reactivity Insertion Accident .................................................... 4-53

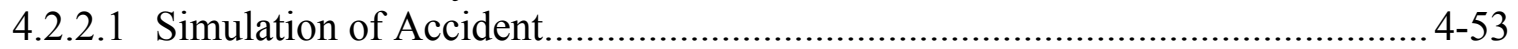

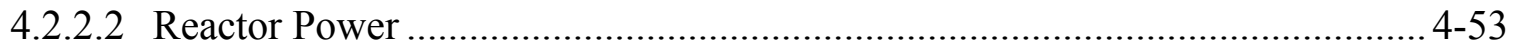

4.2.2.3 Fuel Temperature …………................................................................ 4-55

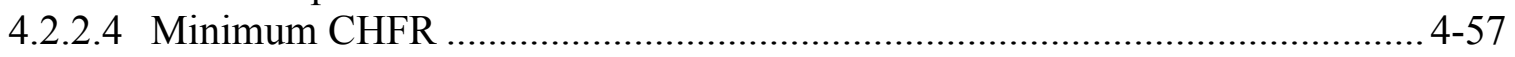

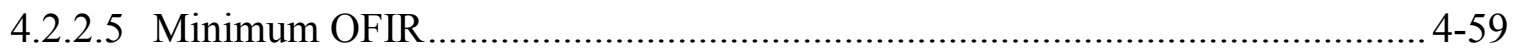

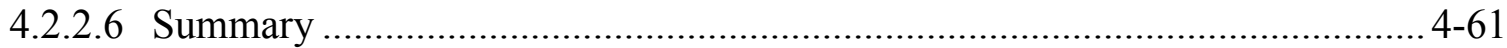

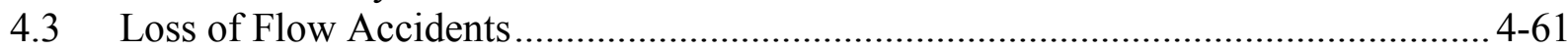

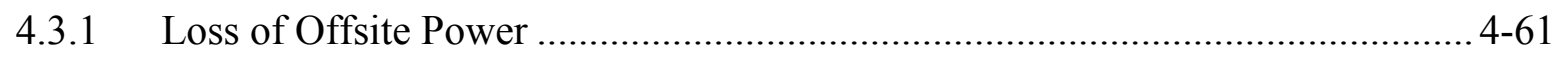

4.3.1.1 Simulation of Accident............................................................................... 4-61

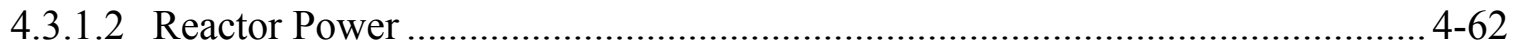

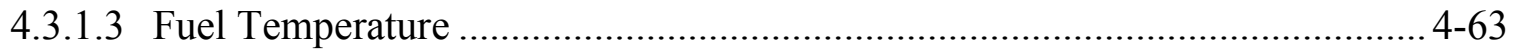

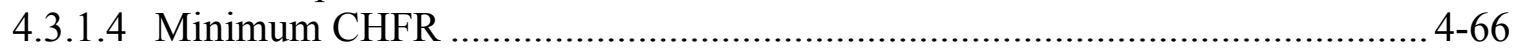

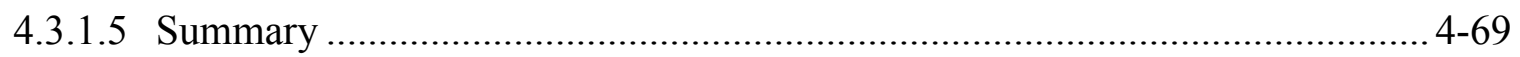

4.3.2 Seizure of One Primary Pump ………….................................................. 4-69

4.3.2.1 Simulation of Accident............................................................................... 4-69

4.3.2.2 Reactor Power ……............................................................................ 4-70

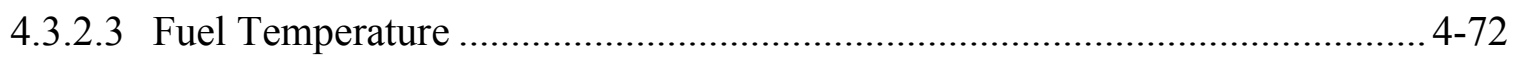

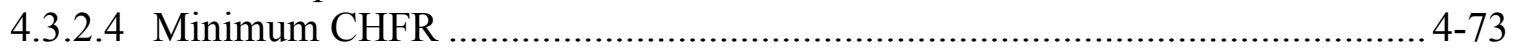

4.3.2.5 Minimum OFIR ................................................................................... 4-75

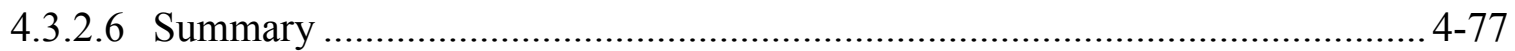

4.3.3 Throttling of Coolant Flow to Outer Plenum................................................... 4-77

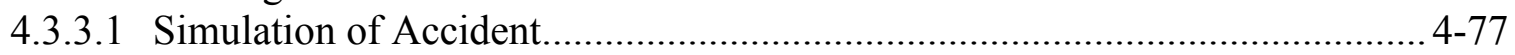

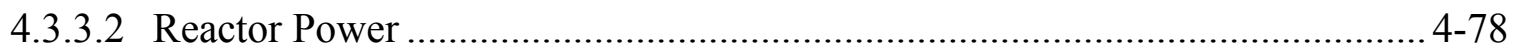

4.3.3.3 Fuel Temperature …………............................................................. 4-79

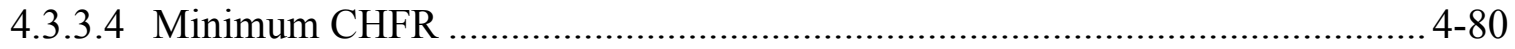

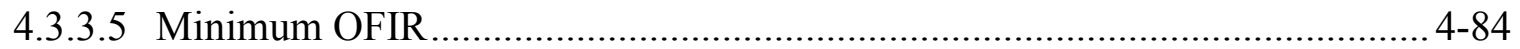

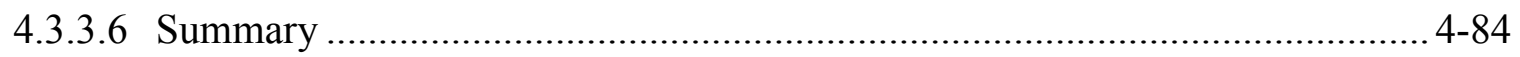

4.3.4 Throttling of Coolant Flow to Inner Plenum .................................................. 4-85

4.3.4.1 Simulation of Accident........................................................................... 4-85

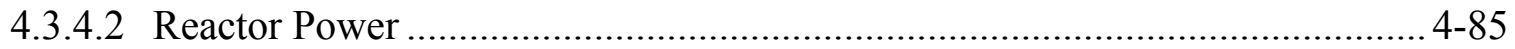

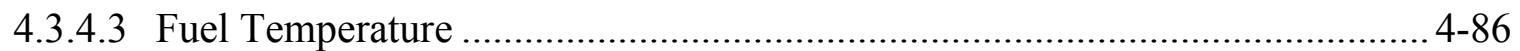

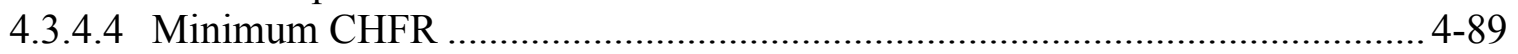

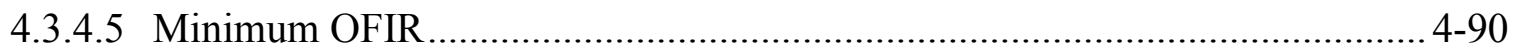

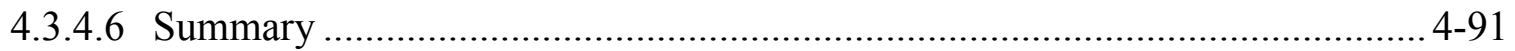

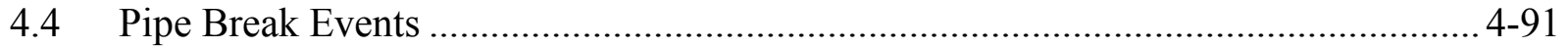

4.5 Natural Circulation Cooling at Low Power Operation.............................................. 4-92

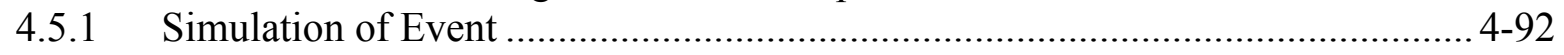

4.5.2 Flow Behavior in Primary System ................................................................. 4-93

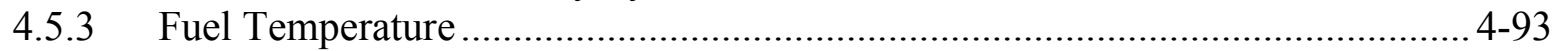

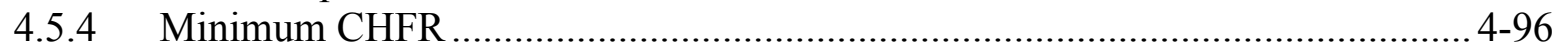

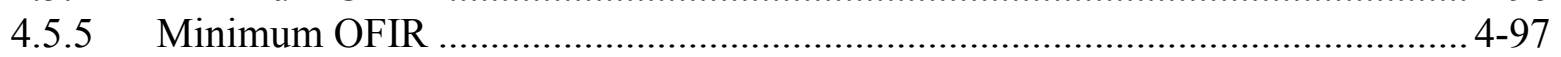

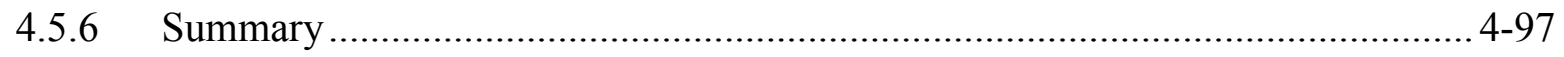

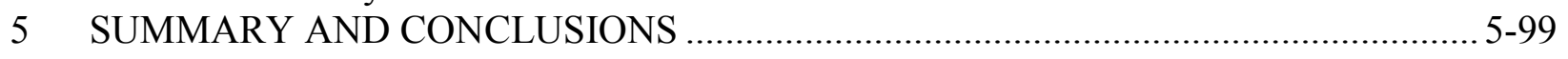

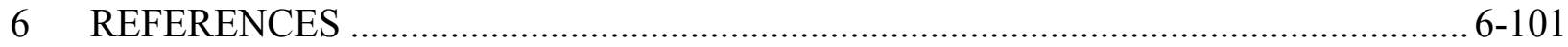




\section{LIST OF FIGURES}

Figure 2-1 NBSR Primary System (NIST, 2010) ............................................................. 2-4

Figure 2-2 Reactor Elevation View (NIST, 2010) ........................................................... 2-5

Figure 2-3 Cutaway Isometric Drawing of NBSR Fuel Element (NIST, 2010)......................2 2-6

Figure 2-4 Cross Sectional View of NBSR Fuel Element ....................................................2-7

Figure 3-1 Nodal Diagram of NBSR ........................................................................... 3-11

Figure 3-2 Schematic of Coolant Channels of Fuel Elements ............................................. 3-12

Figure 3-3 Top-View of Single Coolant Channel with Fuel Plates ........................................ 3-13

Figure 3-4 Nodal Diagram of NBSR with VALVE at Piping to Outer Plenum...................... 3-14

Figure 3-5 Primary System Piping - Hot Leg (Cheng, 2004) .............................................. 3-15

Figure 3-6 Primary System Piping - Cold Leg (Cheng, 2004) ......................................... 3-16

Figure 3-7 Elevations of Fuel Element .......................................................................... 3-17

Figure 3-8 Hydraulic Flow Channel between Two Half Fuel Plates...................................... 3-19

Figure 3-9 Modeling of Heat Transfer to Hydraulic Flow Channel ....................................... 3-20

Figure 3-10 Primary Pump Performance Curves (Cheng, 2004) .......................................... 3-23

Figure 3-11 Comparison of Pump Coastdown Calculation with Plant Data (Cheng, 2004) ..... 3-24

Figure 3-12 Predictions of Draining of Inner Emergency Cooling Tank (Cheng, 2004) .......... 3-25

Figure 3-13 Reactivity Worth of Shim Arms at SU with HEU and LEU Fuels .......................3-28

Figure 3-14 Reactivity Worth of Shim Arms at EOC with HEU and LEU Fuels ................... 3-29

Figure 3-15 Shim Arm Travel after Scram Initiation (Cheng, 2004) .................................... 3-29

Figure 3-16 Modeling of Power Distribution in RELAP5 Input Model................................ 3-31

Figure 3-17 Power Distribution in Inner Core with HEU and LEU Fuels at SU ....................3-34

Figure 3-18 Power Distribution in Inner Core with HEU and LEU Fuels at EOC ................. 3-35

Figure 3-19 Power Distribution in Outer Core with HEU and LEU Fuels at SU................... 3-35

Figure 3-20 Power Distribution in Outer Core with HEU and LEU Fuels at EOC ................. 3-36

Figure 3-21 Sudo-Kaminaga Correlation Scheme (Cuadra, 2011) ........................................ 3-39

Figure 4-1 Reactor Power Responses in Startup Accident: Wide Range ............................... 4-46

Figure 4-2 Reactor Power Responses in Startup Accident: Narrow Range............................ 4-46

Figure 4-3 Cladding Temperatures in Startup Accident: Wide Range .................................. 4-48

Figure 4-4 Cladding Temperatures in Startup Accident: Narrow Range .............................. 4-48

Figure 4-5 Critical-Heat-Flux Ratios in Startup Accident: Wide Range ................................. 4-49

Figure 4-6 Critical-Heat-Flux Ratios in Startup Accident: Narrow Range ............................. 4-50

Figure 4-7 Onset-of-Flow-Instability Ratios in Startup Accident: Narrow Range................... 4-51

Figure 4-8 Onset-of-Flow-Instability Ratios in Startup Accident: Narrow Range.................. 4-52

Figure 4-9 Reactor Powers Responses in Maximum Reactivity Insertion Accident: Wide Range

Figure 4-10 Reactor Power Responses in Maximum Reactivity Insertion Accident: Narrow

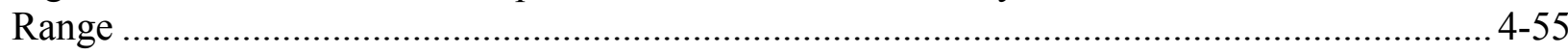

Figure 4-11 Cladding Temperatures in Maximum Reactivity Insertion Accident: Wide Range ... 4-56

Figure 4-12 Cladding Temperatures in Maximum Reactivity Insertion Accident: Narrow Range

4-56

Figure 4-13 Critical-Heat-Flux Ratios in Maximum Reactivity Insertion Accident: Narrow Range 
Figure 4-14 Critical-Heat-Flux Ratios in Maximum Reactivity Insertion Accident: Narrow Range 4-58

Figure 4-15 Onset-of-Flow-Instability Ratios in Maximum Reactivity Insertion Accident: Wide

Range ..... 4-59

Figure 4-16 Onset-of-Flow-Instability Ratios in Maximum Reactivity Insertion Accident:

Narrow Range. 4-60

Figure 4-17 Reactor Power Responses in Accident of Loss of Offsite Power with Shutdown

Pump Trip: Wide Range ..... 4-62

Figure 4-18 Reactor Power Responses in Accident of Loss of Offsite Power with Shutdown

Pump Trip: Narrow Range .......................................................................................... 4-63

Figure 4-19 Cladding Temperatures in Accident of Loss of Offsite Power with Shutdown Pump

Trip: Wide Range. 4-64

Figure 4-20 Cladding Temperatures in Accident of Loss of Offsite Power with Shutdown Pump

Trip: Narrow Range ...................................................................................................... 4-64

Figure 4-21 Mass Flow Rate in Hottest Channel in Accident of Loss of Offsite Power with

Shutdown Pump Trip of NBSR with HEU fuel at EOC

Figure 4-22 Critical Heat Flux Ratios in Accident of Loss of Offsite Power with Shutdown Pump

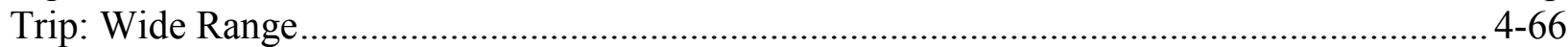

Figure 4-23 Critical Heat Flux Ratios in Accident of Loss of Offsite Power with Shutdown Pump

Trip: Narrow Range 4-67

Figure 4-24 Void Fraction in Powered-Top Node of Hottest Channel in Accident of Loss of

Offsite Power with Shutdown Pump Trip. 4-69

Figure 4-25 Reactor Power Responses in Accident of Seizure of One Primary Pump: Wide

Range

Figure 4-26 Reactor Power Responses in Accident of Seizure of One Primary Pump: Narrow

Range

Figure 4-27 Cladding Temperatures in Accident of Seizure of One Primary Pump: Wide Range472

Figure 4-28 Cladding Temperatures in Accident of Seizure of One Primary Pump: Narrow

Range

Figure 4-29 Critical Heat Flux Ratios in Accident of Seizure of One Primary Pump: Wide Range

Figure 4-30 Critical Heat Flux Ratios in Accident of Seizure of One Primary Pump: Narrow

Range

Figure 4-31 Onset-of-Flow-Instability Ratios in Accident of Seizure of One Primary Pump: Wide

Range 4-76

Figure 4-32 Onset-of-Flow-Instability Ratios in Accident of Seizure of One Primary Pump:

Narrow Range $4-76$

Figure 4-33 Reactor Power Responses in Accident of Throttling of Coolant Flow to Outer

Plenum 4-78

Figure 4-34 Cladding Temperatures in Accident of Throttling of Coolant Flow to Outer Plenum

Figure 4-35 Critical Heat Flux Ratios in Accident of Throttling of Coolant Flow to Outer Plenum Figure 4-36 Reactor Power Responses in Accident of Throttling of Coolant Flow to Inner Plenum 
Figure 4-37 Cladding Temperatures in Accident of Throttling of Coolant Flow to Inner Plenum .. 4-87

Figure 4-38 Critical Heat Flux Ratios in Accident of Throttling of Coolant Flow to Inner Plenum

Figure 4-39 Comparison of Boil-Off and Flow from Inner Emergency Cooling Tank.

(Cheng, 2004)

Figure 4-40 Coolant Flows inside Core in Event of Natural Circulation Cooling at Low Power

Operation

Figure 4-41 Cladding Temperatures in Event of Natural Circulation Cooling at Low Power

Operation...

Figure 4-42 Critical Heat Flux Ratios in Event of Natural Circulation Cooling at Low Power

Operation.....

Figure 4-43 Onset-of-Flow-Instability Ratios in Event of Natural Circulation Cooling at Low

Power Operation 


\section{LIST OF TABLES}

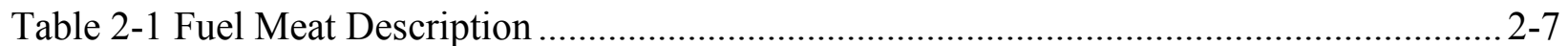

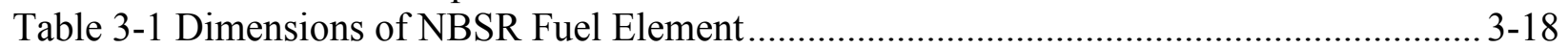

Table 3-2 Dimensions of coolant channel between fuel plates........................................... 3-18

Table 3-3 Nodal Scheme for Flow Channels ............................................................... 3-20

Table 3-4 Dimensions of Various Coolant Channel Types in Fueled Region............................ 3-21

Table 3-5 Percent of Fissions as Calculated by MCNPX and RELAP5 Input Values ............... 3-26

Table 3-6 Recommended Delayed Neutron Parameters for the HEU and LEU..........................3-26

Table 3-7 Delayed Neutrons from the ${ }^{2} \mathrm{H}(\gamma, \mathrm{n})^{1} \mathrm{H}$ Nuclear Reaction........................................ 3-27

Table 3-8 Effective Total Delayed Neutron Fraction Used in RELAP5 ................................. 3-27

Table 3-9 Prompt Neutron Lifetime for HEU and LEU cores and RELAP5 Input Values....... 3-27

Table 3-10 Heat Structures of Fuel Plates ..................................................................... 3-32

Table 3-11 Setpoints for Reactor Trip ............................................................................ 3-37

Table 3-12 Ratio of Nominal Value to Random Value of CHFR, CHFRnCHFRr .................... 3-42

Table 3-13 Ratio of Nominal Value to Random Value of OFIR, OFIRn OFIRr ........................ 3-42

Table 4-1 Steady-State Operating Conditions ....................................................................... 4-43

Table 4-2 Comparison of Steady-State Operating Conditions ............................................... 4-44

Table 4-3 Reactor Trips and Occurring Times in Startup Accident ........................................ 4-47

Table 4-4 Reactor Peak Powers and Occurring Times in Startup Accident ............................. 4-47

Table 4-5 Peak Cladding Temperatures and Cladding Temperature Increases in Startup Accident

Table 4-6 Minimum CHFRs in Startup Accident ............................................................ 4-50

Table 4-7 Minimum OFIRs in Startup Accident .................................................................... 4-52

Table 4-8 Reactor Trips and Occurring Times in Maximum Reactivity Insertion Accident .... 4-55

Table 4-9 Reactor Peak Powers and Occurring Times in Maximum Reactivity Insertion Accident

Table 4-10 Peak Cladding Temperatures and Cladding Temperature Increases in Maximum

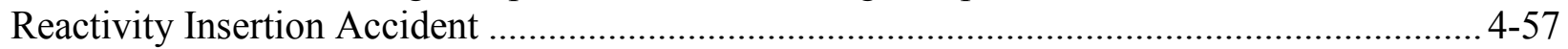

Table 4-11 Minimum CHFRs in Maximum Reactivity Insertion Accident ………….............. 4-58

Table 4-12 Minimum OFIRs in Maximum Reactivity Insertion Accident................................ 4-60

Table 4-13 Reactor Trips and Occurring Times in Accident of Loss of Offsite Power

with Shutdown Pump Trip ...................................................................................................... 4-63

Table 4-14 Peak Cladding Temperatures and Cladding Temperature Increases in Accident of

Loss of Offsite Power with Shutdown Pump Trip ................................................................ 4-65

Table 4-15 Minimum CHFRs in Accident of Loss of Offsite Power with Shutdown Pump Trip

Table 4-16 Reactor Trips and Occurring Times in Accident of Seizure of One Primary Pump4-71

Table 4-17 Peak Cladding Temperatures and Cladding Temperature Increases in Accident of

Seizure of One Primary Pump ............................................................................................ 4-73

Table 4-18 Minimum CHFRs in Accident of Seizure of One Primary Pump ............................ 4-75

Table 4-19 Minimum OFIRs in Accident of Seizure of One Primary Pump ........................... 4-77

Table 4-20 Reactor Trips and Occurring Times in Accident of Throttling of Coolant Flow to

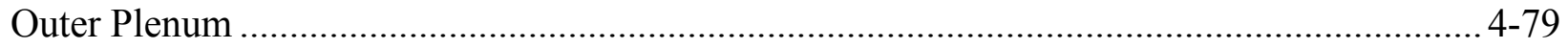

Table 4-21 Peak Cladding Temperatures and Cladding Temperature Increases in Accident of

Throttling of Coolant Flow to Outer Plenum....................................................................... 4-80 
Table 4-22 Minimum CHFRs in Accident of Throttling of Coolant Flow to Outer Plenum .... 4-84 Table 4-23 Reactor Trips and Occurring Times in Accident of Throttling of Coolant Flow to

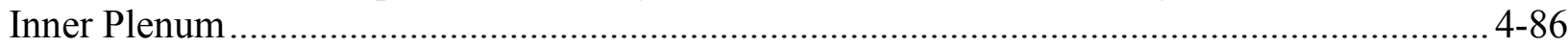

Table 4-24 Peak Cladding Temperatures and Cladding Temperature Increases in Accident of Throttling of Coolant Flow to Inner Plenum ...................................................................... 4-89 Table 4-25 Minimum CHFRs in Accident of Throttling of Coolant Flow to Inner Plenum ..... 4-90 Table 4-26 Peak Cladding Temperatures and Cladding Temperature Increases in Event of Natural Circulation Cooling at Low Power Operation 


\section{ACKNOWLEDGEMENTS}

The authors benefitted greatly from the close support of the staff at the NIST Center for Neutron Research, which runs the NBSR. Thank you Sean O'Kelly, Robert Williams, and Michael Rowe for your close collaboration. The authors appreciate the financial support of the National Nuclear Security Administration. Thanks also to Lynda Fitz who ably performed all the administrative work for this report. 


\section{INTRODUCTION}

A plan is being developed for the conversion of the NIST research reactor (NBSR) from highenriched uranium (HEU) fuel to low-enriched uranium (LEU) fuel. The design of the LEU fuel and neutronic characteristics of the equilibrium core have been determined (Hanson, 2011). The converted core will provide the users of the NBSR with the same cycle length as exists for the current HEU-fueled reactor although with some loss of neutrons at radial beam tube locations. The next step is to perform safety analyses with the LEU fuel to assure that the reactor can be operated safely.

One objective of the current study is to provide that portion of the safety analysis that requires the use of the systems analysis (thermal-hydraulic) code RELAP5. The code simulates the time dependent behavior after different initiating events. Ancillary objectives are to compare these results to those obtained for the current HEU-fuelled reactor (using the same methodology) and assure that the results are acceptable in terms of safety margin. The study is for the equilibrium LEU core; transition cores will be treated in a separate study.

Calculations have been performed for accidents involving

1) excessive positive reactivity insertions (startup withdrawal of rods and rapid withdrawal of large reactivity worth experiments), and

2) power-cooling mismatches (loss of electrical power for primary pumps, pump seizure, closure of throttling valve and loss of both shutdown coolant pumps).

A detailed three-dimensional Monte Carlo model for both MCNPX and MCNP5 (Hanson, 2011 and Hanson, 2012) was used to calculate physics parameters for the HEU- and LEU-fuelled cores for use in the accident analysis; namely, the startup and end-of-cycle power distributions, neutron kinetics parameters, and the reactivity worth of the shim arms. The model includes a plate-by-plate representation of each fuel element, the water gap at the axial mid-plane, beam tubes, shim arms, regulating rod, axial and radial reflectors, cold neutron sources, and other structures internal to the NBSR.

The RELAP5 model includes the primary piping from vessel inlet to outlet, primary pump and shut-down pump flow paths, heat exchanger, fuel element geometry and flow area, and flow channels for the six inner and twenty-four outer fuel elements. The initial operating parameters (flows, temperatures, power level and distribution, etc.) were assumed to be at their most limiting values or at the Limiting Safety System Setpoints (LSSSs). The NBSR reactor protection system logic was modeled and initiated a reactor trip, upon reaching a setpoint and after the appropriate instrumentation response delay. The limiting fuel temperature and critical heat flux ratio (CHFR) have been investigated. In addition, onset of flow instability ratio (OFIR) has been evaluated as a supplementary parameter to examine integrity of fuel elements.

The RELAP5 model used differs from that used for the current Safety Analysis Report (NIST, 2010). Two hot-channels are added in the core region (one in the inner core and the other in the outer core) to examine the effect of the highest total power, in one stripe of a fuel plate, on the critical heat flux and onset of flow instability. More realistic geometric configurations of some 
components are considered and the valves at the outlets of the primary and shutdown pumps as well as at the inlet of the inner and outer plena are newly modeled. The geometries and material properties of the heat structures modeling the fuel elements have been modified with more accurate and appropriate information about thermal properties and power distributions. These improvements increase the fidelity of the present thermal hydraulic analyses relative to that utilized in (NIST, 2010).

The details of these analyses are presented in the following chapters. A brief description of the NBSR is presented in Chapter 2. The methodology to perform the safety analysis is discussed in Chapter 3. The assumptions made in developing the accident scenario and the consequences predicted for each accident are provided in Chapter Error! Reference source not found.. A summary of conclusions is given in Chapter Error! Reference source not found. and references are in Chapter Error! Reference source not found. 


\section{NIST RESEARCH REACTOR DESCRIPTION}

\section{$2.1 \quad$ Reactor System}

The NBSR is a heavy water $\left(\mathrm{D}_{2} \mathrm{O}\right)$ cooled, moderated, and reflected tank type research reactor that operates at a design power of $20 \mathrm{MWth}$. The NBSR is cooled by forced upward circulation through two concentric plenums below the lower grid plate of the reactor. There is no pulsing capability in the NBSR. There are thirty fuel elements in the core on a triangular pitch. The fuel elements are split axially into two halves with a 7 in $(17.8 \mathrm{~cm})$ gap located between the two halves at the mid-plane. This mid-plane gap allows thermal neutrons to be used in the beam tubes for thermal and cold neutron scattering research while minimizing "contamination" from fast neutrons and gamma rays. Each half-element encapsulates seventeen curved fuel plates. The control elements within the NBSR consist of four semaphore-type shim safety arms and a single automatic regulating rod.

The large volume and spacing within the core provides flexible capabilities for thermal neutron irradiation. Insertion of eight radial beam tubes and two cold neutron sources into the plane of the fuel gap allows high intensity, low energy beams of neutrons to be extracted. A pneumatic rabbit system provides researchers with the ability to automatically and rapidly inject samples into and out of the core region of the reactor while in-core irradiation thimbles provide for manual sample irradiation.

In normal operation the NBSR is cooled by forced convection of the $\mathrm{D}_{2} \mathrm{O}$ coolant. A large $\mathrm{D}_{2} \mathrm{O}$ hold-up tank and a $\mathrm{D}_{2} \mathrm{O}$ hold-up pan around the lower half of the core, ensure adequate backup coolant supply in the event of a piping rupture. The inner reserve tank is located in the top reflector and is drained through two non-isolable pipes at the bottom of the tank. These pipes feed a flow distributor that routes emergency cooling to the individual fuel elements. The secondary hold up pan keeps the bottom half of the individual fuel elements immersed in coolant and collects water from the inner reserve tank that splashes out of the distributor pan or runs down the outside of the fuel elements.

There are several $\mathrm{D}_{2} \mathrm{O}$ reflectors in the NBSR. The side reflector is $50.8 \mathrm{~cm}$ (20 in) thick and the top reflector is $300 \mathrm{~cm}$ (118 in) thick. Coarse adjustment of the $\mathrm{D}_{2} \mathrm{O}$ moderator level in the top reflector is provided by several overflow pipes. During refueling, the low-level overflow pipe is utilized to drain the moderator level to just above the height of the upper grid plate. During abnormal operation, another overflow pipe serves as a moderator dump that will drop the $\mathrm{D}_{2} \mathrm{O}$ level to $2.5 \mathrm{~cm}$ ( $1 \mathrm{in})$ above the active core for emergency shutdown.

A complete description of the NBSR reactor and support facility is provided in the current Safety Analysis Report (NIST, 2010). The only change that will be made in the NBSR reactor under conversion is the change in the fuel meat composition within the fuel plates and the thickness of the fuel meat and clad. The external dimensions of the fuel plates remain the same.

The schematic of the NBSR primary system and a reactor view are shown in Figure 2-1 and Figure 2-2, respectively. The NBSR core is contained in an aluminum tank $2.13 \mathrm{~m}(7 \mathrm{ft})$ in

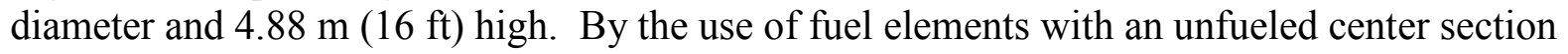


(depicted in Figure 2-3), the core is split into an upper and lower section. Each of these fueled sections is $1.12 \mathrm{~m}$ (44 in) in diameter and $0.279 \mathrm{~m}$ (11 in) high. The unfueled gap between the two fueled sections is $0.178 \mathrm{~m}$ (7 in). The overall dimensions of the core are $1.12 \mathrm{~m}$ (44 in) in diameter by $0.737 \mathrm{~m}$ ( 29 in) high.

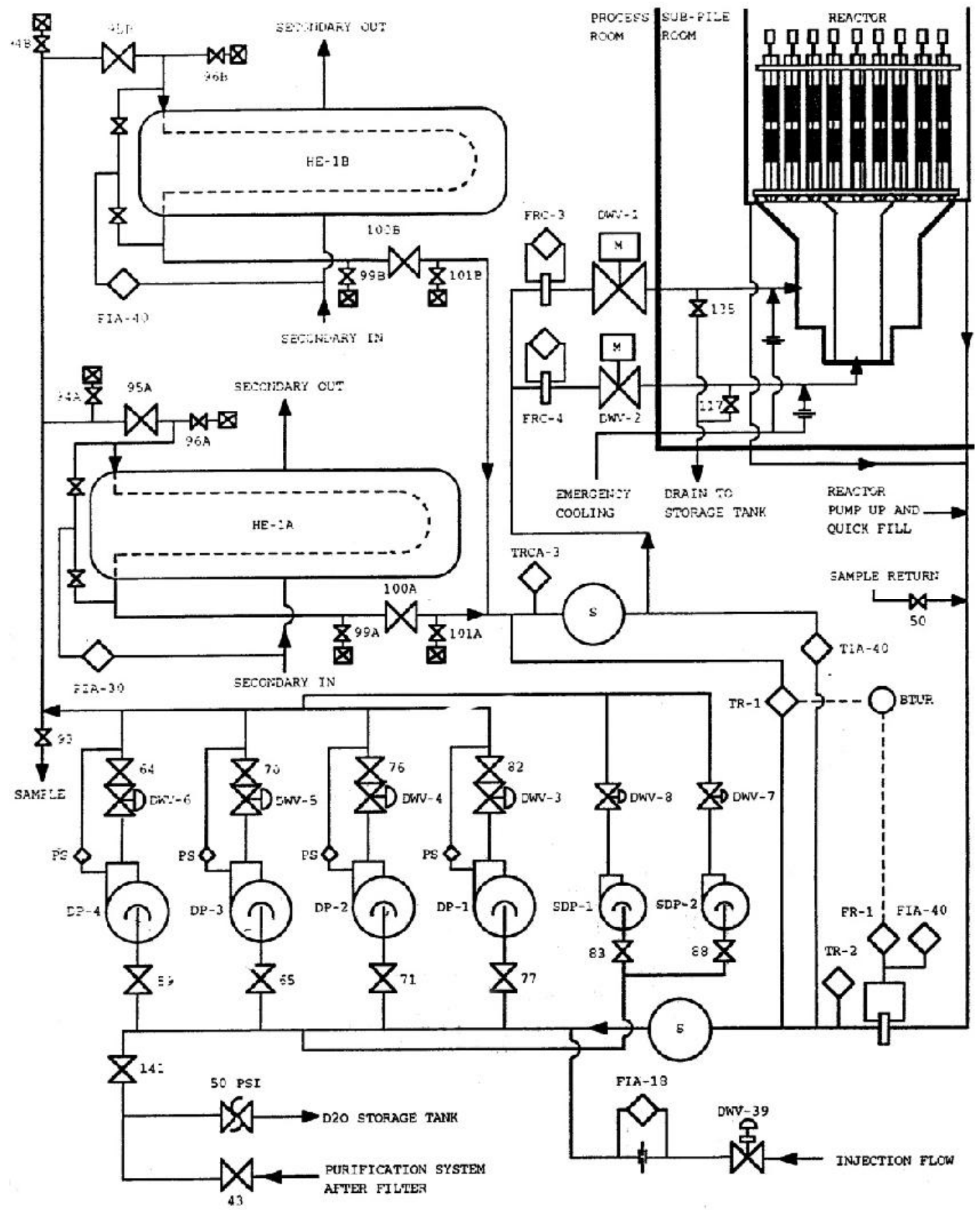

Figure 2-1 NBSR Primary System (NIST, 2010) 


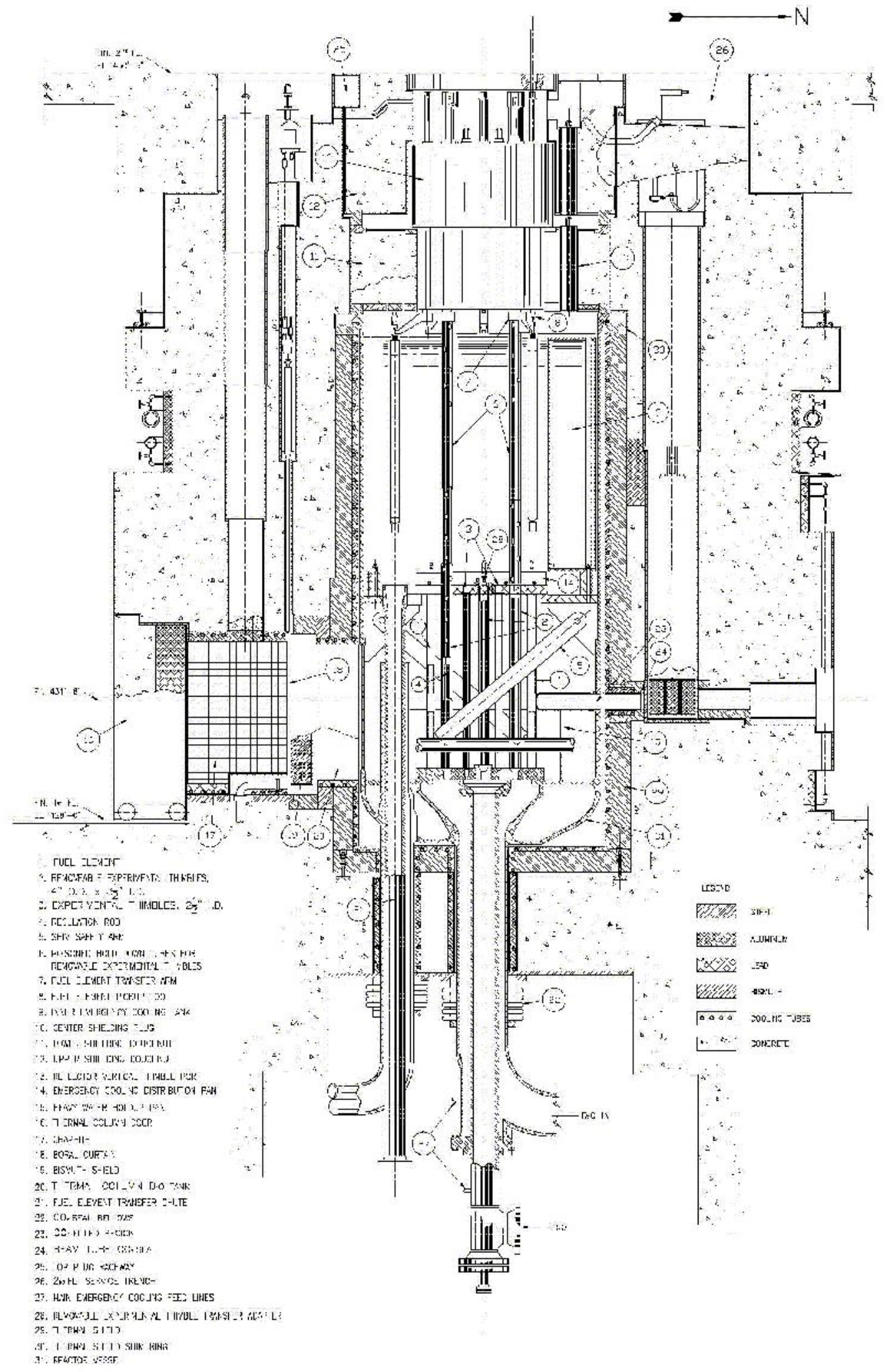

Figure 2-2 Reactor Elevation View (NIST, 2010) 


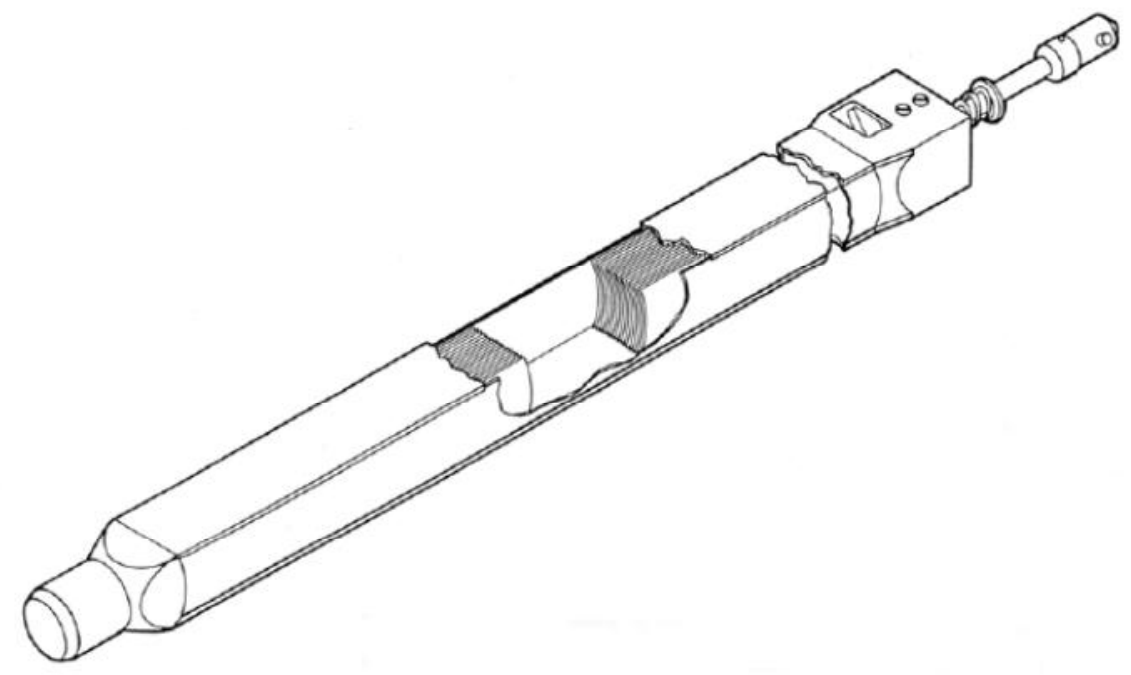

Figure 2-3 Cutaway Isometric Drawing of NBSR Fuel Element (NIST, 2010)

\subsection{Fuel Element}

Presently the NBSR is fueled with high-enriched uranium (HEU) with a nominal ${ }^{235} \mathrm{U}$ enrichment of $93 \%$. The fuel is $\mathrm{U}_{3} \mathrm{O}_{8}$ in an aluminum oxide dispersion that is clad in aluminum. Each fuel element is constructed of 17 fuel plates in each upper and lower half (34 plates per fuel element) with two unfueled plates at each end-side and is constructed in the material test reactor (MTR) curved plate geometry as shown in Figure 2-4. The dimensions are given in inches in the figure. Each plate is $0.3302 \mathrm{~cm}$ (13 in) long with $0.279 \mathrm{~cm}(11 \mathrm{in})$ of active fuel length. The thickness of fuel in each plate is $0.0508 \mathrm{~cm}(0.02 \mathrm{in})$, equivalent to a volume of $148 \mathrm{~cm}^{3}(9.05$ $\left.\mathrm{in}^{3}\right)$ of fuel per half-element. The gap that is noticeable in Figure 2-3 is 6 in $(15.24 \mathrm{~cm})$ long but the unfueled region is 7 in $(17.8 \mathrm{~cm})$ long. Each HEU fuel element has a mass of $350 \pm 3.4 \mathrm{~g}$ of ${ }^{235} \mathrm{U}$. The aluminum cladding is $0.0381 \mathrm{~cm}(0.015 \mathrm{in})$ thick on each side.

The fuel meat for the low-enriched uranium (LEU) conversion of the NBSR is U10Mo metal foils with aluminum cladding. Details of the U10Mo fuel are given in Table 2-1. The thickness of the LEU fuel foils is $0.0216 \mathrm{~cm}(0.0085 \mathrm{in})$ with a total volume of $63.08 \mathrm{~cm}^{3}\left(3.8 \mathrm{in}^{3}\right)$ per halfelement. The engineering specification on fuel foil thickness is $0.0085 \mathrm{in}$. The rolling tolerance of the fuel foils is $\pm 0.001 \mathrm{in}$, so the fuel thickness is specified as $0.0085 \pm 0.001 \mathrm{in}$. The ${ }^{235} \mathrm{U}$ content of each LEU fuel element is $386 \pm 4 \mathrm{~g}$. The uncertainty is due to the uncertain molybdenum content of the LEU fuel; the $10 \%$ weight specification for molybdenum has an uncertainty of $\pm 1 \%$. The thickness of the aluminum cladding for the LEU fuel is $0.0503 \mathrm{~cm}$ ( $0.0198 \mathrm{in})$ on each side. There is a $0.00254 \mathrm{~cm}(0.001 \mathrm{in})$ layer of zirconium between the cladding and the fuel to improve fuel behavior under irradiation and this is also taken into account in the modeling. 


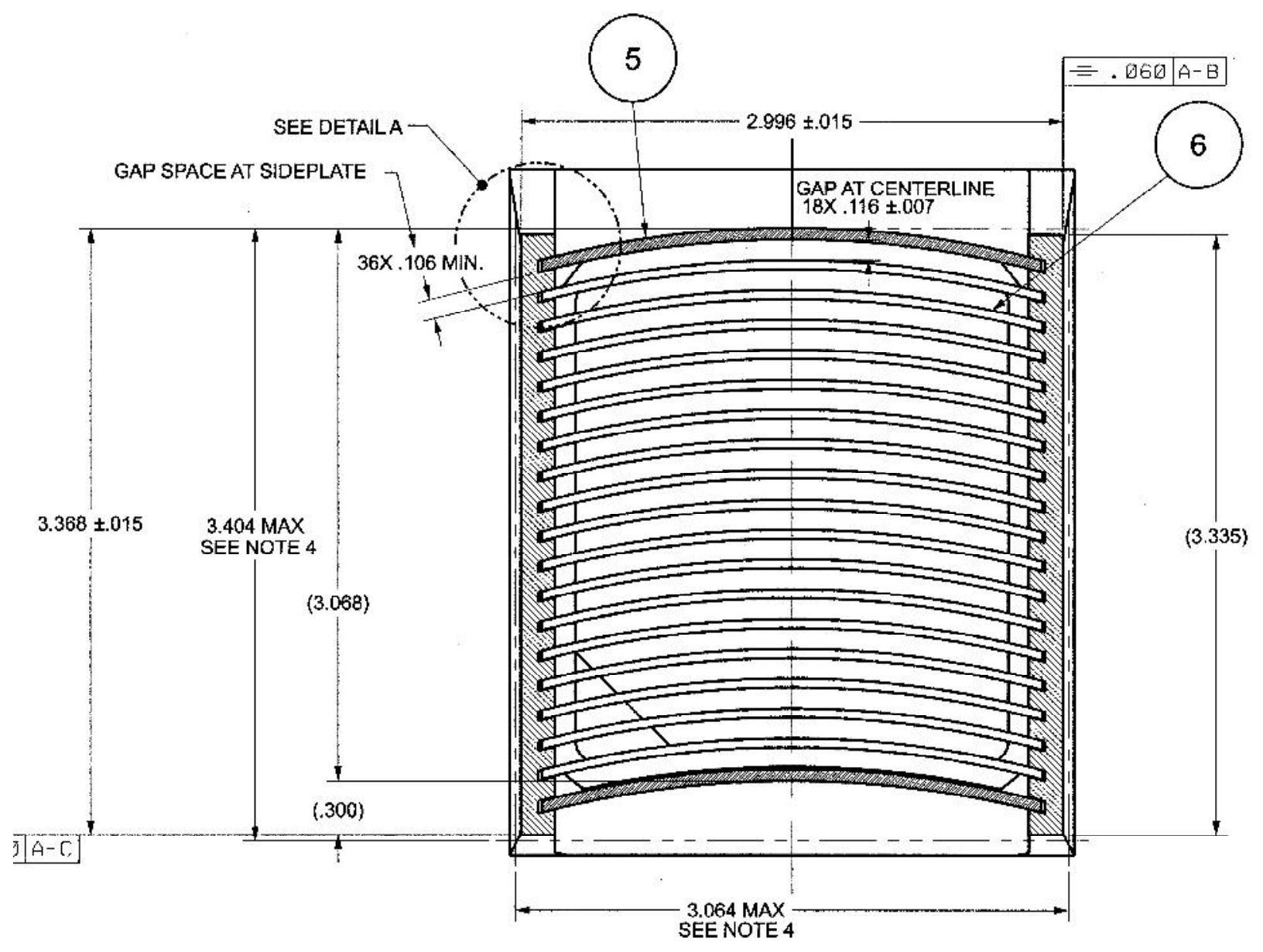

Figure 2-4 Cross Sectional View of NBSR Fuel Element

Table 2-1 Fuel Meat Description

\begin{tabular}{|l|c|c|}
\hline & HEU & LEU \\
\hline${ }^{235}$ U grams & 350 & 386 \\
\hline${ }^{238}$ U grams & 26 & 1567 \\
\hline O grams & 68 & 0 \\
\hline Al grams & 625 & 0 \\
\hline Mo grams & 0 & 217 \\
\hline Total grams & 1069 & 2170 \\
\hline \multicolumn{2}{|c|}{} \\
\hline Fuel density $\left(\mathrm{g} / \mathrm{cm}^{3}\right)$ & 3.61 & 17.2 \\
\hline Fuel thickness $\left(\mathrm{cm}^{3}\right)$ & 0.0508 & 0.0216 \\
\hline Fuel volume $\left(\mathrm{cm}^{3}\right)$ & 148 & 63.1 \\
\hline
\end{tabular}




\subsection{Control Rods}

The NBSR has two types of control rods. Primary control of the reactor is accomplished by use of four "semaphore" shim safety arms. Fine control is provided by the use of a single vertical regulating rod.

The four shim safety arms are each $2.54 \mathrm{~cm}(1 \mathrm{in})$ thick by $12.7 \mathrm{~cm}(5 \mathrm{in})$ wide and have a 1.32 $\mathrm{m}$ (52 in) poisoned length. The hollow interior is filled with helium and the $1.02 \mathrm{~mm}$. (0.040 in) thick cadmium poisoned volume is clad with aluminum on both the outside and inside. The arms pivot on hanger brackets just under the upper grid plate, with drive mechanisms penetrating the vessel through rotating leak-tight seals. The total reactivity worth of the four shim safety arms is about $26 \%$ and the worth of a single arm is about $6.5 \%$.

The regulating rod consists of a solid aluminum cylinder, $6.35 \mathrm{~cm}(2.50 \mathrm{in})$ in diameter by 0.737 $\mathrm{m}$ (29 in) long. It is located in an off-center vertical thimble. The vertical drive mechanism is mounted in the top plug and is of standard commercial design. The volume of the regulating rod void combined with its aluminum structure as a poison is designed to make the reactivity worth approximately $0.6 \%$. 


\section{METHODOLOGY FOR TRANSIENT ANALYSIS}

The potential for fuel damage has been evaluated for various accidents and transients postulated for the NBSR. The criterion for fuel damage, which is the basis for the safety limits found in the Technical Specifications (NIST, 2009), is that the clad temperature must not reach the blister temperature $\left(723 \mathrm{~K}\left(450^{\circ} \mathrm{C}\right)\right.$ for $\mathrm{HEU}$ fuel and as yet undetermined for LEU fuel).

To assure that there is sufficient margin to this criterion, several events are analyzed using criteria for the critical heat flux ratio (CHFR) and, in some cases, the onset of flow instability ratio (OFIR) as surrogates for clad temperature. The value of the critical heat flux (CHF) is generally associated with the phenomenon of boiling transition in which a sudden reduction in the heat transfer rate (from the heated wall to the coolant) results in a rapid increase in the wall temperature. The local heat flux in a fuel plate is a function of the reactor power and the power distribution in the core. The determination of the CHF for the NBSR in an accident or transient requires the evaluation of the thermal-hydraulics of the coolant. This is performed by using the computer code RELAP5/MOD3.3 (ISL, 2001). Flow instabilities can be followed by CHF and therefore, it is also of interest to follow the OFIR. The evaluations of CHF and OFIR are performed using the Sudo-Kaminaga correlation (Kaminaga, 1998) and Saha-Zuber (Saha, 1974) criteria, respectively.

Based on previous experience, the calculations are carried out for only the startup (SU) and endof-cycle (EOC) state points during a fuel cycle. At SU there are four fresh fuel elements in the core and the short-lived fission product poisons such as ${ }^{135}$ Xe have decayed away during the refueling period since the previous cycle. The power peaking is highest at this state point making it the limiting point for some events. However, some events are most limiting at EOC because differential shim arm worth is lowest when the shim arms are inserted from the fully withdrawn position.

\subsection{RELAP5 Application}

RELAP5 is a light and heavy water reactor transient analysis code developed for the U.S. Nuclear Regulatory Commission (NRC). It is capable of analyzing a wide variety of thermalhydraulic transients in nuclear and non-nuclear systems involving mixtures of steam, water (light/heavy), non-condensables, and solute. RELAP5 is one of the most widely used system codes for analyzing power and research reactor accidents/transients. The Department of Energy (DOE) research/test reactors ATR (Advanced Test Reactor) and HFIR (High Flux Isotope Reactor) used RELAP5 to analyze design basis accidents in their Safety Analysis Reports (SARs). RELAP5 also has been applied to the HFBR (High Flux Beam Reactor), which was similar to the NBSR in many respects, especially with respect to the coolant (heavy water) and the geometry of the fuel element (MTR, Materials Testing Reactor, plate type).

The hydrodynamic model in RELAP5 is a one-dimensional, transient, two-fluid model for flow of a two-phase steam-water mixture. The non-equilibrium transient two-fluid model is represented by the conservation equations of mass, momentum, and energy for each phase. The steam phase can contain non-condensable components and the water phase can have a solute 
component. Special process models are available to handle choked flow, abrupt area changes, and counter-current flow.

Metal components are modeled by heat structures with internal heat generation. Heat transfer within the structures is by one-dimensional heat conduction. A full boiling curve is implemented in the code for modeling heat transfer between heat structures and the coolant. Reactor power and decay power are calculated by a point kinetics model with no reactivity feedback. In RELAP5 a hydraulic system is constructed by connecting fluid components, such as pipes, valves, pumps, etc., in series or in parallel. Geometric data and the initial thermodynamic state of the fluid are required for the interconnecting components. The initial flow rate is required at the junctions between two components. Heat structures are defined with the heat transfer surface facing the coolant in a hydraulic component. Time varying boundary conditions can be specified in terms of fluid flow rate or the thermodynamic state of the fluid. Control system components are available in RELAP5 to model system dynamic behavior such as component trips and the evaluation of system variables.

The following sections summarize the modeling; detailed information is found in the calculation notebooks (Baek, 2012a) and (Baek, 2012b).

\subsection{Modeling of the NBSR}

The RELAP5/MOD3.3 model of the NBSR simulates the transport of heat and coolant in the primary system. The reactor vessel and the primary coolant loop are represented by a series of hydrodynamic volumes. Fuel plates in the core region are represented by heat structures. Fission and decay power are calculated by using the point kinetics model with negative thermalhydraulic feedback neglected. A schematic diagram showing the main components of the NBSR primary system is shown in Figure 2-1.

\subsubsection{Reactor Vessel}

Figure 3-1 shows a nodal diagram of the NBSR. The reactor vessel is divided into a number of interconnected hydrodynamic volumes and heat structures with internal heat generation are used to model the fuel plates. In the nodal diagram, hydraulic components are described by numbers with the background color of light gray and heat structures are represented by the red background color. The numbers after " $H$ " depict heat structure node numbers and "-1" and "-2" illustrate the heat structures associated with hydraulic flow channels in the lower and upper cores, respectively.

It is unnecessary to model each of the 17 fuel plates and 18 coolant channels in each of the upper and lower halves of the thirty fuel elements. A comprehensive, representative, and conservative safety analysis is performed by simplifying the problem and focusing on the limiting cases.

The inner six fuel elements are modeled as an inner group and the outer 24 fuel elements as an outer group. The inner group is divided into five different channel types, each with a different heating rate and flow area. The five types of channels are the hottest cell channel and hottest stripe channel with no mixing of coolant in the mid-plane (central unfueled) gap (e.g., see 
volumes 103, 105, 107, 113, 115, and 117 in Figure 3-1); the hottest cell channel with mixing of coolant from the other channels in the fuel element (e.g., see volumes 203, 205, and 207 in Figure 3-1); channel for 16 non-hot fuel plate channels with mixing of coolant from the hottest cell channel in the hot fuel element (e.g., see volumes 213, 205, and 217 in Figure 3-1); and a channel for non-hot (average) channels in five elements (volumes 303, 305, and 307 in Figure 3-1). Similarly, the outer group is divided into five channel types, and three additional channels correspond to eighteen average elements in subsets of eight fuel elements.

Figure 3-2 is a schematic representation of the five types of flow channels. The hottest cell channel, the hottest stripe channel, and the average element channel are similar in their composition of hydraulic volumes that constitute the flow path for the coolant in a fuel element. Another hottest cell channel is modeled with a mid-plane gap shared with hot element channel as shown in Figure 3-2. This arrangement is to simulate the effects of coolant mixing in the midplane flow areas of a fuel element.

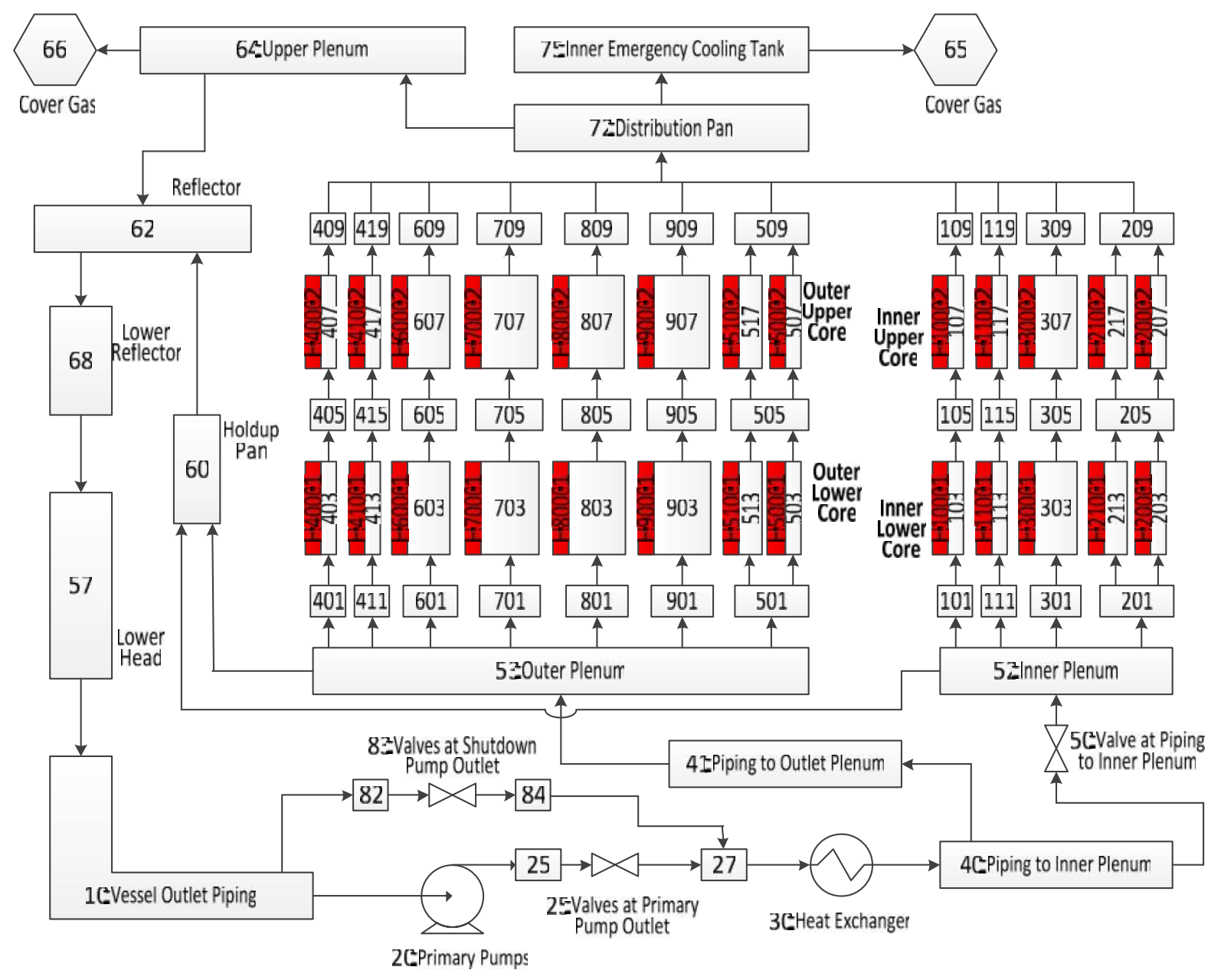

Figure 3-1 Nodal Diagram of NBSR 


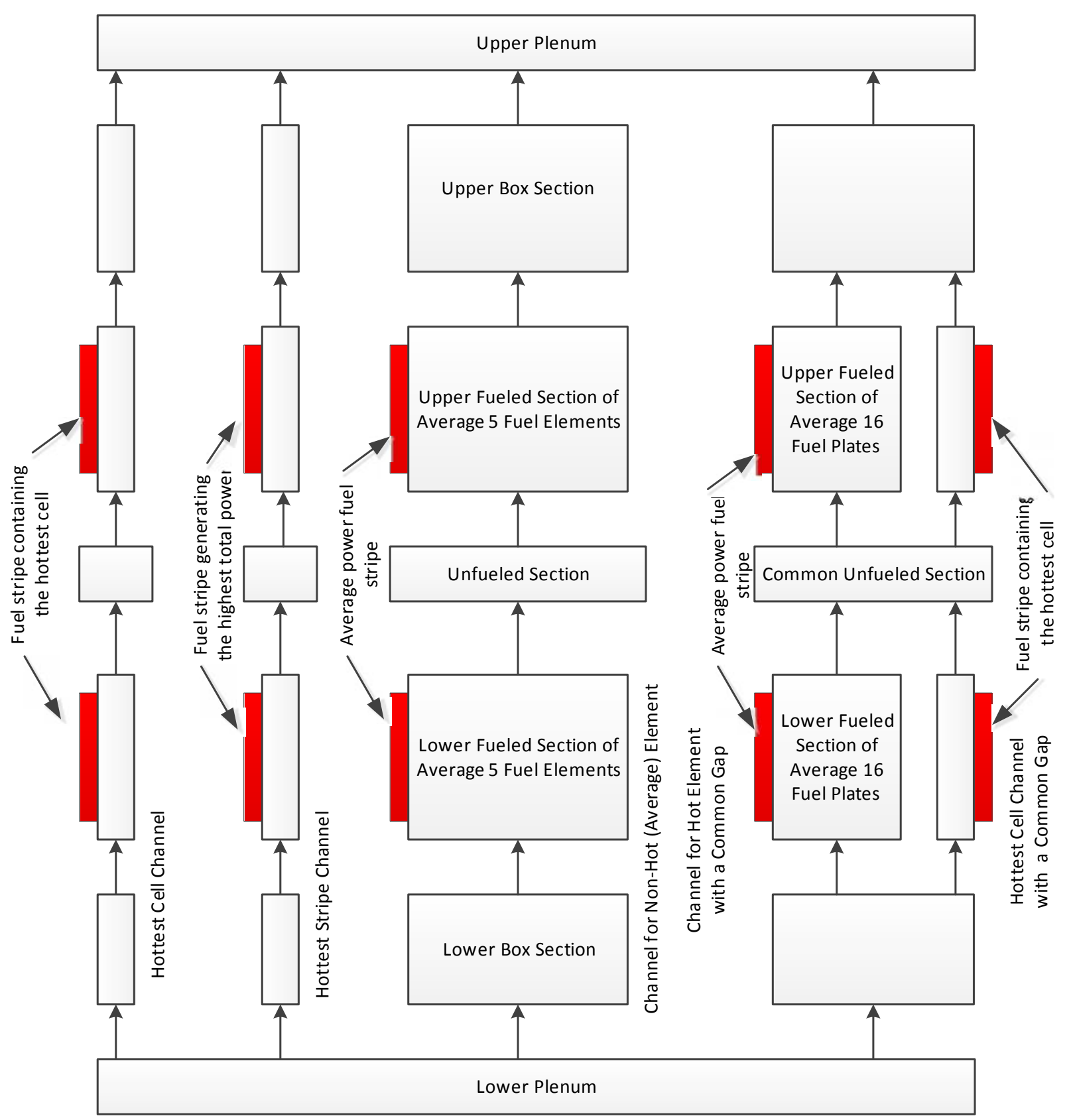

Figure 3-2 Schematic of Coolant Channels of Fuel Elements

\subsubsection{Primary Coolant Loop}

Parallel flow paths in the NBSR primary coolant loop are modeled by combining them into a single effective flow path. This applies to the two outlet pipes from the reactor vessel, the three branches going into and out of the three primary pumps, and the two branches of the shutdown pumps as well as two primary heat exchangers. This simplification does not have a significant effect on the RELAP5 analysis since the parallel flow paths are thermally and hydraulically similar. 


\subsubsection{Secondary Cooling Loop}

The secondary cooling loop is modeled simply as a once through circuit. At one end a source supplies the cooling water to the primary heat exchangers. After the heat exchangers the secondary coolant (light water) flows to a sink.

\subsubsection{Fuel Plates}

Rectangular heat structures are used to represent the NBSR fuel plates. As discussed earlier, each channel type is associated with a different heat structure (the hottest cell element has two heat structures for the two parallel flow channels in the core region). The power generated by fission and fission product decay is assumed to deposit in the fuel meat with no direct heating of the coolant/moderator assumed. Energy deposition outside the fuel (Hanson, 2005) lowers the local power peaking in the fuel meat and thus, neglecting this effect is conservative.

Since each fuel plate is cooled on both sides, it is reasonable to model only the half thickness of a plate as shown in Figure 3-3 to give the correct wall heat flux into the coolant channel. The fuel is modeled as a volumetric heat source and thermal energy is transferred by conduction in the fuel meat (a half thickness of $0.0254 \mathrm{~cm}(0.01 \mathrm{in})$ for the HEU fuel and of $0.0108 \mathrm{~cm}(0.0042 \mathrm{in})$ for the LEU fuel) and the cladding (a thickness of $0.0381 \mathrm{~cm}(0.015 \mathrm{in})$ for the HEU fuel and of $0.0528 \mathrm{~cm}(0.0208 \mathrm{in})$ for the LEU fuel). The fuelled portion of a NBSR fuel plate has a height of $27.94 \mathrm{~cm}$ (11 in) and a width (flattened plate) of $6.028 \mathrm{~cm}$ (2.3734 in). In the RELAP5 model, each NBSR fuel plate is assumed to have a heat transfer surface that has the same height as the fuel meat. Figure 3-3 shows the RELAP5 model of a NBSR fuel plate and the corresponding coolant channel. The assignment of power and axial power profile to each heat structure is discussed in Section 3.3.

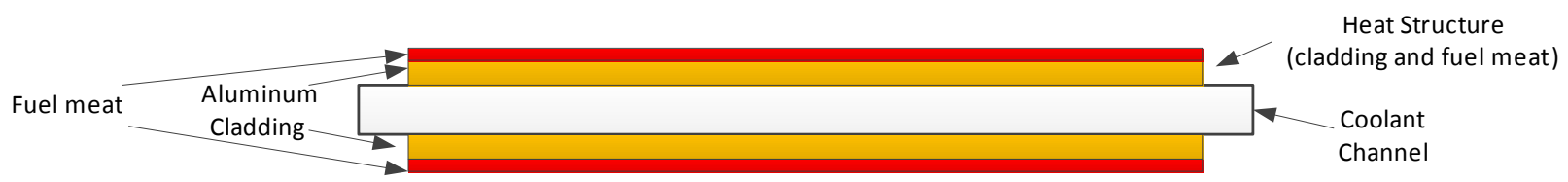

Figure 3-3 Top-View of Single Coolant Channel with Fuel Plates

\subsubsection{Modeling of Valve at Inlet of Outer Plenum}

In order to simulate the throttling of coolant flow to the outer plenum, the basic RELAP5 input model (Figure 3-1) has been modified as shown in Figure 3-4. The difference between the two models is a new valve (VALVE-51) at the inlet to the outer plenum and the old valve (VALVE50) replaced with a single junction SNGLJUN-50 (although it is not shown in Figure 3-4). The valve characteristics of VALVE-51 are assumed to be the same as those of VALVE-50. It should be noted that this input model is used only to analyze the accident with throttling of coolant flow to outer plenum. 


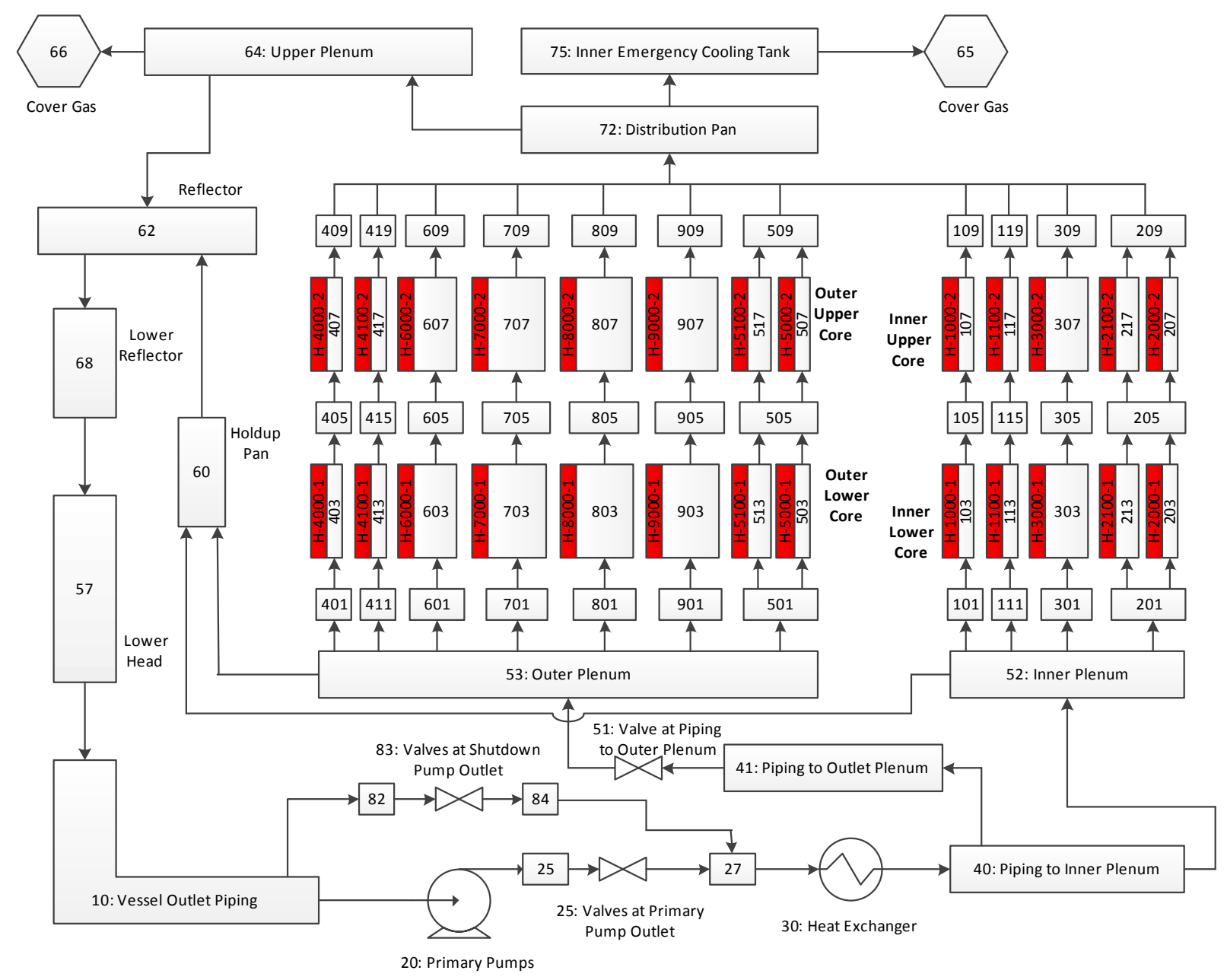

Figure 3-4 Nodal Diagram of NBSR with VALVE at Piping to Outer Plenum

\subsection{RELAP5 Input Data}

\subsubsection{Geometry}

The geometric inputs for the NBSR are based on plant drawings and on-site walk-downs.

Figure 3-5 and Figure 3-6 summarize the dimensions of the primary loop piping.

Elevations of the fuel element are indicated in Figure 3-7 and other fuel element dimensions are given in Table 3-1 and

Table 3-2. For simplicity, the lower and upper ends of a fuel element are assumed to be flush with the bottom of the lower grid plate and the top of the upper grid plate, respectively. This approximation has a negligible effect on the results of these analyses, since in the lower core the $27.9 \mathrm{~cm}$ (11 in) fueled region starts $22.9 \mathrm{~cm}$ (9 in) above the lower grid plate. The fuel region in the upper core ends $61 \mathrm{~cm}$ (24 in) below the upper grid plate. The water level in the reactor is 
measured from the bottom of the lower grid plate. The core mid-plane corresponds to a level of $69.8 \mathrm{~cm}$ (27.5 in).

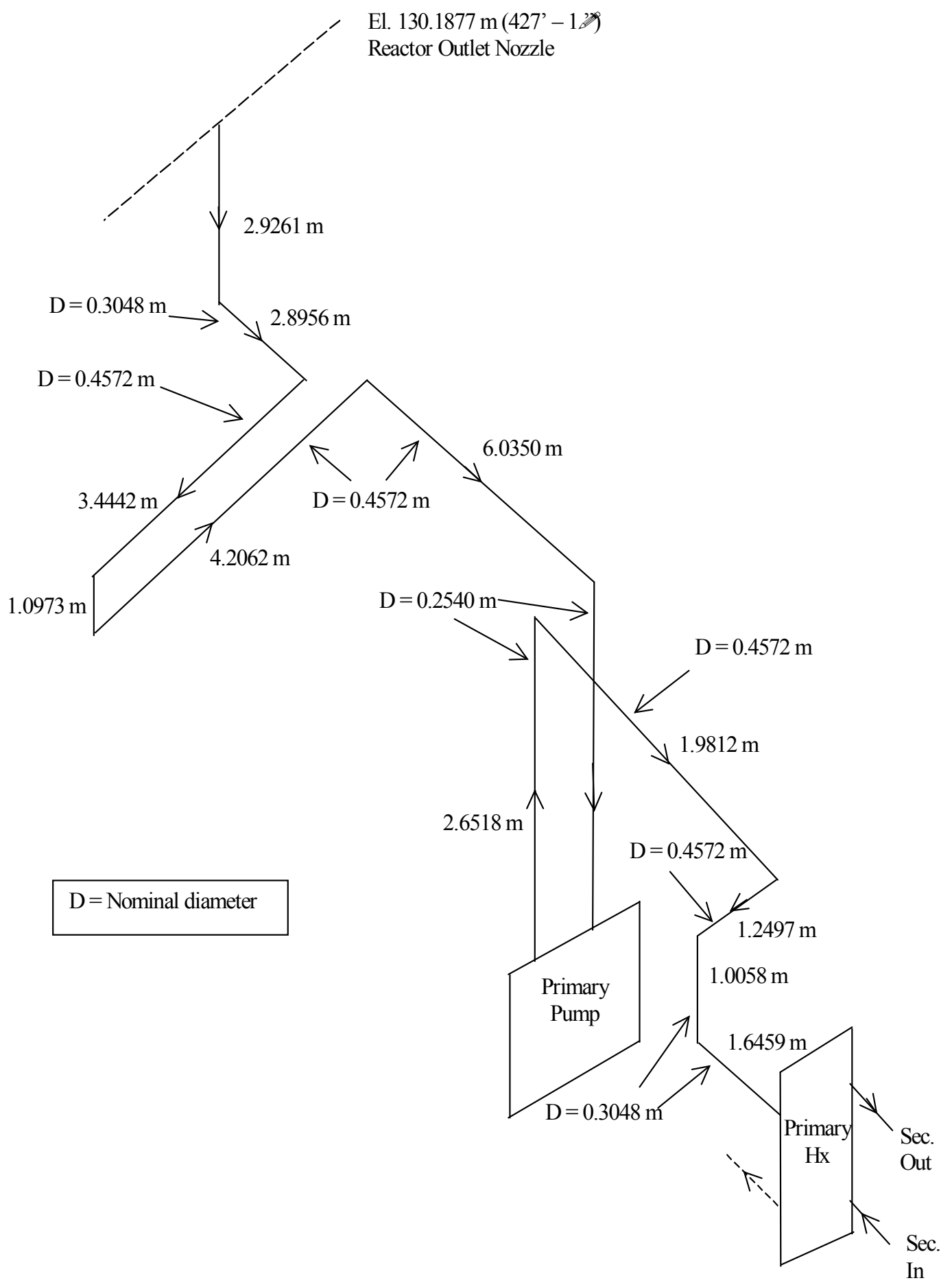

Figure 3-5 Primary System Piping - Hot Leg (Cheng, 2004) 


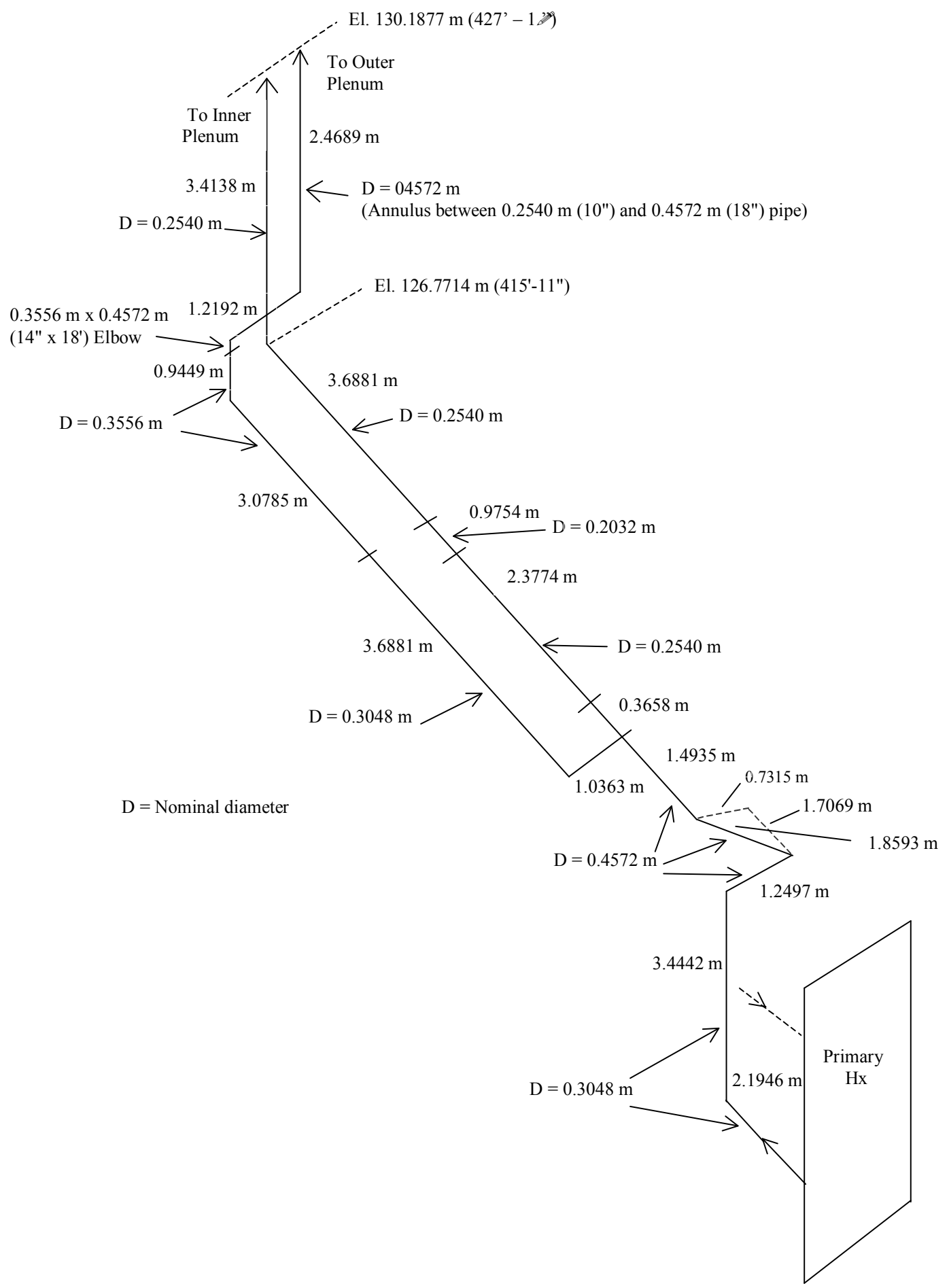

Figure 3-6 Primary System Piping - Cold Leg (Cheng, 2004) 


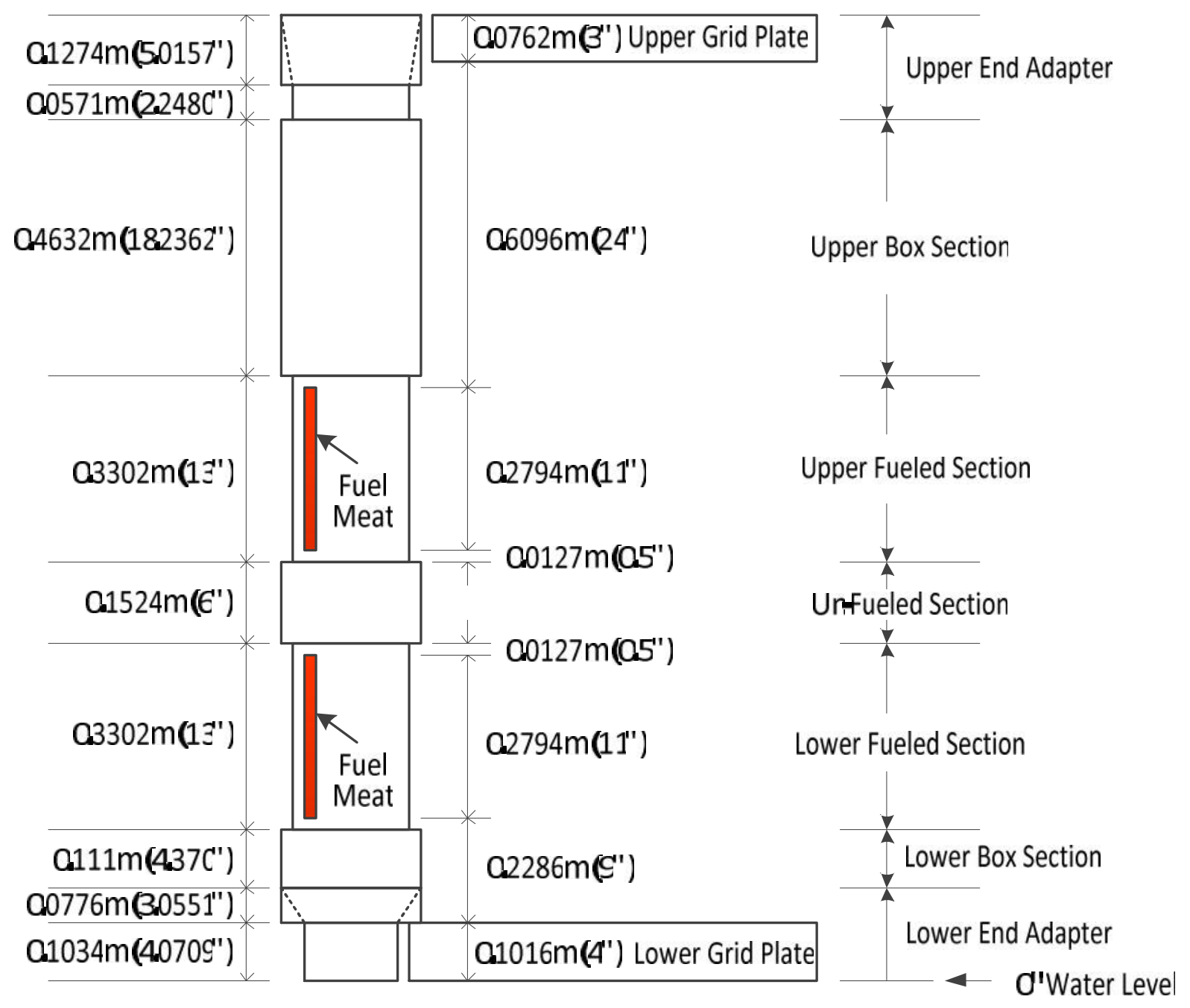

Figure 3-7 Elevations of Fuel Element 
Table 3-1 Dimensions of NBSR Fuel Element

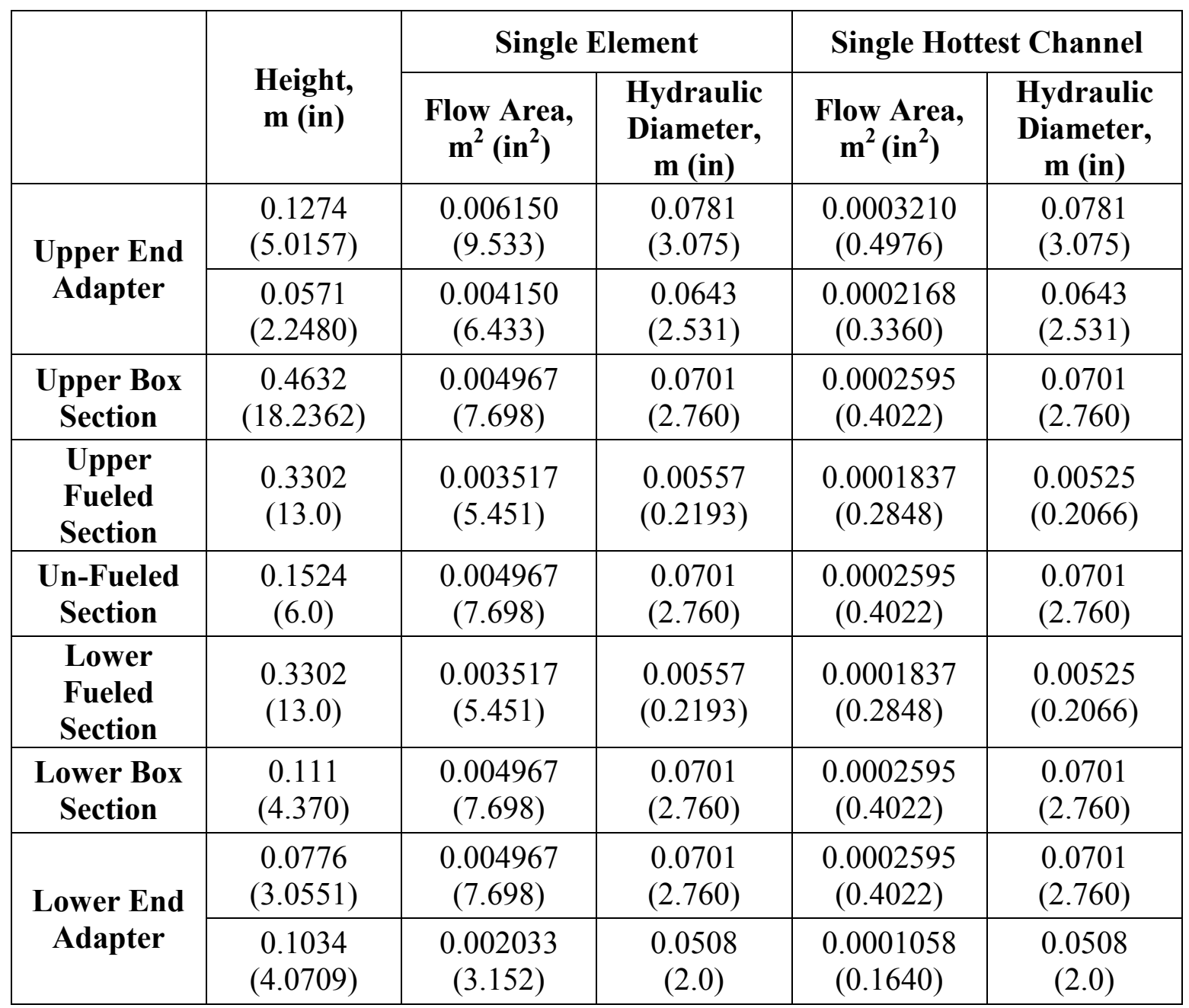

Table 3-2 Dimensions of coolant channel between fuel plates

\begin{tabular}{|c|c|c|c|}
\hline $\begin{array}{c}\text { Average Single } \\
\text { Channel }\end{array}$ & $\begin{array}{c}\text { Flow Area, } \mathbf{~ m}^{2}\left(_{\left(\mathbf{n}^{2}\right)}\right. \\
\left(.8371 \times 10^{4}\right. \\
(0.28475)\end{array}$ & Width, m (in) & Gap, m (in) \\
\hline Hottest Cell Channel & $\begin{array}{c}1.9556 \times 10^{4} \\
(0.30312)\end{array}$ & $0.0673(2.6495)$ & $0.002906(0.1144)$ \\
\hline
\end{tabular}

Notes: There are 18 coolant channels in the plated region per fuel element.

Channel flow area is the area between two curved fuel plates and two straight side plates.

Channel width is the average of the two curved plates when flattened.

Channel gap is the flow area divided by the width.

Average channel has a centerline gap of 0.002946 m (0.116 in) shown in Figure 2-4.

Hottest cell channel is assumed to have a centerline gap of $0.002769 \mathrm{~m}$ (0.109 in) shown in Figure 2-4. 


\subsubsection{Hydraulic Flow Channel}

Figure 3-1 shows the nodal-diagram of the RELAP5 model of the NIST research reactor. This figure depicts the five flow channels used to model the six inner fuel elements and the eight channels representing the twenty four outer fuel elements, on the right and left sides, respectively. A hydraulic flow channel (shown horizontally) is defined as shown in Figure 3-8 (see also Figure 3-3).

\section{Figure 3-8 Hydraulic Flow Channel between Two Half Fuel Plates}

The heat generated in a fuel plate is transferred to the two adjacent flow channels. In the analysis it is assumed that the power generated in the hottest plate is transferred into one common flow channel as shown in the lower diagram in

Figure 3-9. This is conservative for two reasons. Firstly, the hottest plate, by definition, is adjacent to a plate that is less hot (plate $\mathrm{A}$ in

Figure 3-9) and secondly, it is observed that the hottest plate is at the edge in all analysis cases. The latter means that one side of the hottest plate faces a channel that has an aluminum plate on the other side (plate B in

Figure 3-9) and hence, has cooler water on that side. The heat flux into this cooler outside channel is more than the average heat flux from the hottest plate and the heat flux into the hot channel will actually be less than the average heat flux ( ) from that plate.

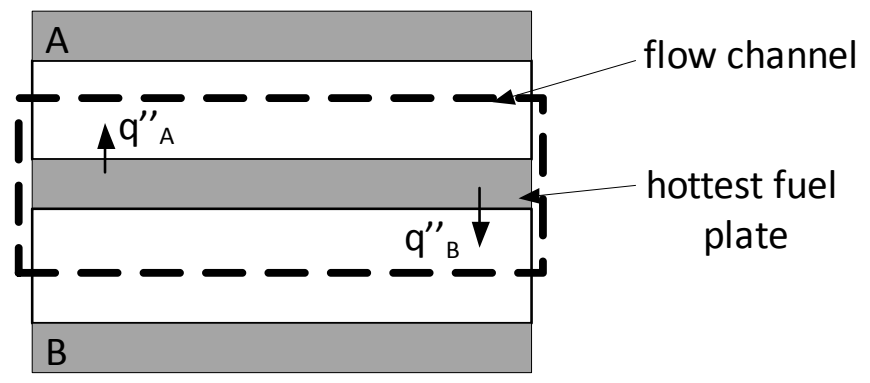

$\downarrow$ Modeling

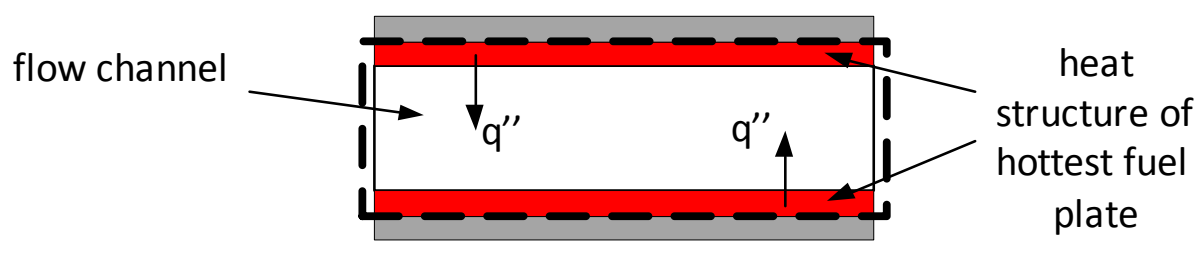




\section{Figure 3-9 Modeling of Heat Transfer to Hydraulic Flow Channel}

Table 3-3 and Table 3-4 summarize the nodal scheme for the hydraulic flow channels of the RELAP5 model and the dimensions of the flow channels, respectively.

Table 3-3 Nodal Scheme for Flow Channels

\begin{tabular}{|c|c|}
\hline \multicolumn{2}{|r|}{ Inner Core } \\
\hline Node \# & Description \\
\hline $\begin{array}{l}103 \text { (lower) }^{(1)} \\
\& \\
107 \text { (upper) }^{(2)}\end{array}$ & $\begin{array}{l}\text { Hottest cell flow channels. One of the heat structure cells associated with these } \\
\text { flow channels has the maximum MCNP nodal power for the inner core. }\end{array}$ \\
\hline $\begin{array}{l}113 \text { (lower) \& } \\
117 \text { (upper) }\end{array}$ & $\begin{array}{l}\text { Hottest stripe flow channels. Flow channels into which the maximum MCNP } \\
\text { total (for the whole stripe }{ }^{(3)} \text { ) power is transferred from the heat structure. }\end{array}$ \\
\hline $\begin{array}{l}203 \text { (lower) \& } \\
207 \text { (upper) }\end{array}$ & $\begin{array}{l}\text { Hottest cell flow channels with a mid-plane gap in hot fuel element. The power } \\
\text { distribution is the same as that for Nodes } 103 \& 107 \text {. These flow channels are } \\
\text { in the fuel element containing the heat structure with the maximum MCNP } \\
\text { nodal power for the inner core. }\end{array}$ \\
\hline $\begin{array}{l}213 \text { (lower) \& } \\
217 \text { (upper) }\end{array}$ & $\begin{array}{l}\text { Flow channels of hot fuel element for the remaining } 16 \text { fuel plates of the fuel } \\
\text { element for Nodes } 203 \& 207 \text {. All of the flow channels in each core (lower or } \\
\text { upper) are lumped together into an effective channel. These flow channels } \\
\text { share a mid-plane gap with Nodes } 203 \text { and } 207 \text {. }\end{array}$ \\
\hline $\begin{array}{l}303 \text { (lower) \& } \\
307 \text { (upper) }\end{array}$ & $\begin{array}{l}\text { Flow channels for the remaining five non-hot (average) fuel elements in the } \\
\text { inner core. All of the flow channels in each core (lower or upper) are lumped } \\
\text { together into an effective channel. }\end{array}$ \\
\hline \multicolumn{2}{|r|}{ Outer Core } \\
\hline Node \# & Description \\
\hline $\begin{array}{l}403 \text { (lower) \& } \\
407 \text { (upper) }\end{array}$ & $\begin{array}{l}\text { Hottest cell flow channels. One of the heat structure cells associated with these } \\
\text { flow channels has the maximum MCNP nodal power for the outer core. }\end{array}$ \\
\hline $\begin{array}{l}413 \text { (lower) \& } \\
417 \text { (upper) } \\
\end{array}$ & $\begin{array}{l}\text { Hottest stripe flow channels into which the maximum MCNP total (for the } \\
\text { whole stripe) power is transferred from the heat structure. }\end{array}$ \\
\hline $\begin{array}{l}503 \text { (lower) \& } \\
507 \text { (upper) }\end{array}$ & $\begin{array}{l}\text { Hottest cell flow channels with a mid-plane gap. The power distribution is the } \\
\text { same as that for Nodes } 403 \& 407 \text {. These flow channels are in the fuel element } \\
\text { containing the heat structure with the maximum MCNP nodal power for the } \\
\text { outer core. }\end{array}$ \\
\hline $\begin{array}{l}513 \text { (lower) \& } \\
517 \text { (upper) }\end{array}$ & $\begin{array}{l}\text { Flow channels of hot fuel element for the remaining } 16 \text { fuel plates of the fuel } \\
\text { element for Nodes } 503 \& 507 \text {. All of the flow channels in each core (lower or } \\
\text { upper) are lumped together into an effective channel. These flow channels } \\
\text { share a mid-plane gap with Nodes } 503 \text { and } 507 .\end{array}$ \\
\hline $\begin{array}{c}603 \text { (lower) \& } \\
607 \text { (upper) }\end{array}$ & $\begin{array}{l}\text { Flow channels for the first five fuel non-hot elements among the remaining } 23 \\
\text { elements in the outer core. All of the flow channels in each core (lower or } \\
\text { upper) are lumped together into an effective channel. }\end{array}$ \\
\hline $\begin{array}{c}703 \text { (lower) \& } \\
707 \text { (upper) }\end{array}$ & $\begin{array}{l}\text { Flow channels for the first six non-hot fuel elements among the remaining } 18 \\
\text { elements in the outer core. All of the flow channels in each core (lower or } \\
\text { upper) are lumped together into an effective channel. }\end{array}$ \\
\hline 803 (lower) \& & Flow channels for another six non-hot fuel elements among the remaining 12 \\
\hline
\end{tabular}




\begin{tabular}{|c|l|}
\hline 807 (upper) & $\begin{array}{l}\text { elements in the outer core. All of the flow channels in each core (lower or } \\
\text { upper) are lumped together into an effective channel. }\end{array}$ \\
\hline $\begin{array}{c}903 \text { (lower) \& } \\
907 \text { (upper) }\end{array}$ & $\begin{array}{l}\text { Flow channels for the remaining six non-hot fuel elements in the outer core. } \\
\text { an effective channel. }\end{array}$ \\
\hline
\end{tabular}

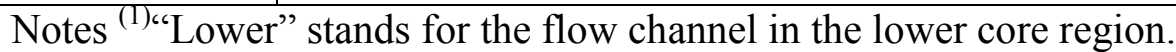

(2)“Upper" represents the flow channel in the upper core region.

${ }^{(3)}$ Definition of fuel stripe is given in Section 3.3.9.1.

Table 3-4 Dimensions of Various Coolant Channel Types in Fueled Region

\begin{tabular}{|c|c|c|c|}
\hline & $\begin{array}{c}\text { Flow Area, } \mathrm{m}^{2} \\
\left(\text { in }^{2}\right)\end{array}$ & $\begin{array}{c}\text { Hydraulic } \\
\text { Diameter, m (in) }\end{array}$ & $\begin{array}{c}\text { Heated } \\
\text { Diameter, m (in) }\end{array}$ \\
\hline \multicolumn{4}{|c|}{ Inner Core Group } \\
\hline Hottest Cell Flow Channel & $\begin{array}{c}0.0001837 \\
(0.2848)\end{array}$ & $\begin{array}{l}0.00525 \\
(0.2066)\end{array}$ & $\begin{array}{c}0.006095 \\
(0.240)\end{array}$ \\
\hline Hottest Stripe Flow Channel & $\begin{array}{c}0.0001837 \\
(0.2848) \\
\end{array}$ & $\begin{array}{l}0.00525 \\
(0.2066)\end{array}$ & $\begin{array}{c}0.006095 \\
(0.240) \\
\end{array}$ \\
\hline $\begin{array}{l}\text { Hottest Cell Flow Channel with a } \\
\text { Mid-Plane Gap in Hot Fuel } \\
\text { Element }\end{array}$ & $\begin{array}{l}0.0001837 \\
(0.2848)\end{array}$ & $\begin{array}{l}0.00525 \\
(0.2066)\end{array}$ & $\begin{array}{l}0.006095 \\
(0.240)\end{array}$ \\
\hline $\begin{array}{l}\text { Flow Channels of Non-Hot } \\
\text { Stripes in Hot Fuel Element }\end{array}$ & $\begin{array}{c}0.0033364 \\
(5.1714)\end{array}$ & $\begin{array}{l}0.00559 \\
(0.2201)\end{array}$ & $\begin{array}{c}0.006919 \\
(0.2724)\end{array}$ \\
\hline $\begin{array}{l}\text { Flow Channels for Non-Hot } \\
\text { (Average) Fuel Elements }\end{array}$ & $\begin{array}{l}0.0172330 \\
(26.7112) \\
\end{array}$ & $\begin{array}{l}0.00558 \\
(0.2196) \\
\end{array}$ & $\begin{array}{l}0.006889 \\
(0.2712)\end{array}$ \\
\hline \multicolumn{4}{|c|}{ Outer Core Group } \\
\hline Hottest Cell Flow Channel & $\begin{array}{c}0.0001837 \\
(0.2848)\end{array}$ & $\begin{array}{l}0.00525 \\
(0.2066)\end{array}$ & $\begin{array}{c}0.006095 \\
(0.240)\end{array}$ \\
\hline Hottest Stripe Flow Channel & $\begin{array}{c}0.0001837 \\
(0.2848) \\
\end{array}$ & $\begin{array}{l}0.00525 \\
(0.2066) \\
\end{array}$ & $\begin{array}{l}0.006095 \\
(0.240) \\
\end{array}$ \\
\hline $\begin{array}{l}\text { Hottest Cell Flow Channel with a } \\
\text { Mid-Plane Gap in Hot Fuel } \\
\text { Element }\end{array}$ & $\begin{array}{c}0.0001837 \\
(0.2848)\end{array}$ & $\begin{array}{l}0.00525 \\
(0.2066)\end{array}$ & $\begin{array}{l}0.006095 \\
(0.240)\end{array}$ \\
\hline $\begin{array}{l}\text { Flow Channels of Non-Hot } \\
\text { Stripes in Hot Fuel Element }\end{array}$ & $\begin{array}{c}0.0033364 \\
(5.1714)\end{array}$ & $\begin{array}{l}0.00559 \\
(0.2201)\end{array}$ & $\begin{array}{c}0.006919 \\
(0.2724)\end{array}$ \\
\hline $\begin{array}{l}\text { Flow Channels for Non-Hot } \\
\text { (Average) Fuel Elements \#1 }\end{array}$ & $\begin{array}{l}0.0172330 \\
(26.7112)\end{array}$ & $\begin{array}{l}0.00558 \\
(0.2196)\end{array}$ & $\begin{array}{c}0.006889 \\
(0.2712)\end{array}$ \\
\hline $\begin{array}{l}\text { Flow Channels for Non-Hot } \\
\text { (Average) Fuel Elements \#2 }\end{array}$ & $\begin{array}{l}0.0211205 \\
(32.7368) \\
\end{array}$ & $\begin{array}{l}0.00557 \\
(0.2193) \\
\end{array}$ & $\begin{array}{l}0.006870 \\
(0.2705)\end{array}$ \\
\hline $\begin{array}{l}\text { Flow Channels for Non-Hot } \\
\text { (Average) Fuel Elements \#3 }\end{array}$ & $\begin{array}{l}0.0211205 \\
(32.7368)\end{array}$ & $\begin{array}{l}0.00557 \\
(0.2193)\end{array}$ & $\begin{array}{l}0.006870 \\
(0.2705)\end{array}$ \\
\hline $\begin{array}{l}\text { Flow Channels for Non-Hot } \\
\text { (Average) Fuel Elements \#4 }\end{array}$ & $\begin{array}{l}0.0211205 \\
(32.7368)\end{array}$ & $\begin{array}{l}0.00557 \\
(0.2193)\end{array}$ & $\begin{array}{l}0.006870 \\
(0.2705)\end{array}$ \\
\hline
\end{tabular}




\subsubsection{Primary Heat Exchanger}

The two NBSR primary heat exchangers are combined into one unit. All heat transfer plates are lumped into a single rectangular plate with the appropriate total heat transfer area and a rectangular coolant channel on each side of the plate. Primary and secondary coolant flows counter-currently in the rectangular channels. A fouling factor is applied to the heat transfer surface to maintain a heat exchanger heat removal rate that agrees with the initial reactor power. The inputs for the heat exchangers are based on plant drawings and vendor specifications.

\subsubsection{Primary Pump}

The three primary pumps are lumped into one effective pump. The pump characteristics are developed from vendor diagrams. Figure 3-10 shows the pump head and pump efficiency as a function of flow in one pump. In RELAP5 the pump performance is specified in the form of 16 homologous curves, eight head curves and eight torque curves. Vendor data are insufficient to define all 16 curves. For completeness, as required by RELAP5, the missing parts are filled in by data built into the code for a Bingham pump. The homologous curves are normalized to a rated flow of $140 \mathrm{l} / \mathrm{s}$ ( $2180 \mathrm{gpm}$ ) per pump that corresponds to the maximum pump efficiency as determined from the vendor data. This is equivalent to approximately $1 / 3$ the rated flow of one HFBR pump. Since the moment of inertia of the pump impeller and the motor shaft are unknown, the combined moment of inertia of three NBSR primary pumps is therefore assumed to equal the moment of inertia of one HFBR pump (excluding the flywheel). The pump inertia is important in the calculation of the pump coastdown. Figure 3-11 provides a comparison between actual NBSR plant data and the RELAP5 prediction of pump coastdown. The differences during the first few seconds are believed to be due to the inertia of the flow instrumentation; due to this the pump coastdown prediction is conservative when compared to the measured data. The friction torque coefficient for the pump in the RELAP5 input has been adjusted to obtain good agreement with the data in the later part of the coastdown, which is most important in the transient analysis. 


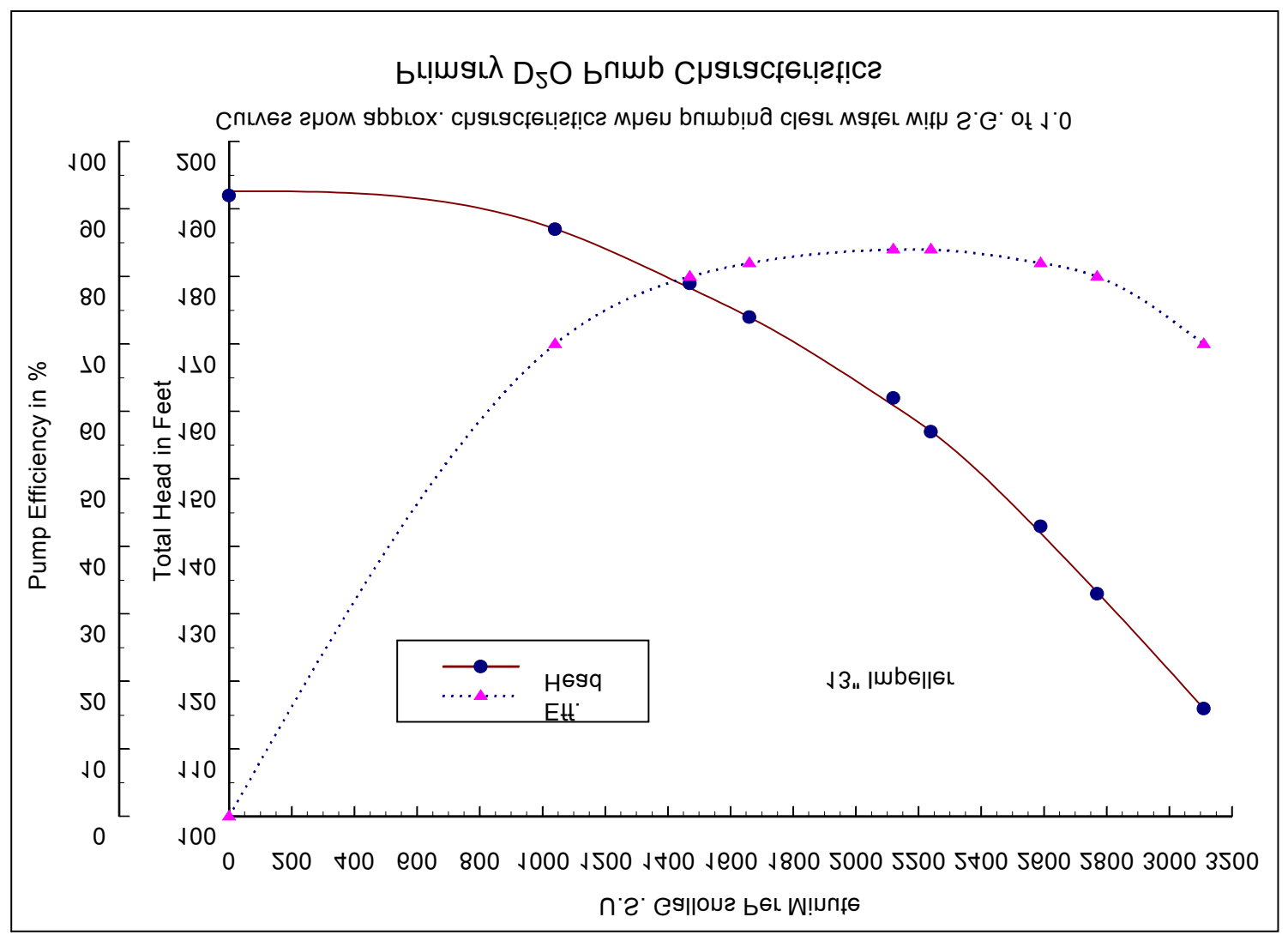

Figure 3-10 Primary Pump Performance Curves (Cheng, 2004) 


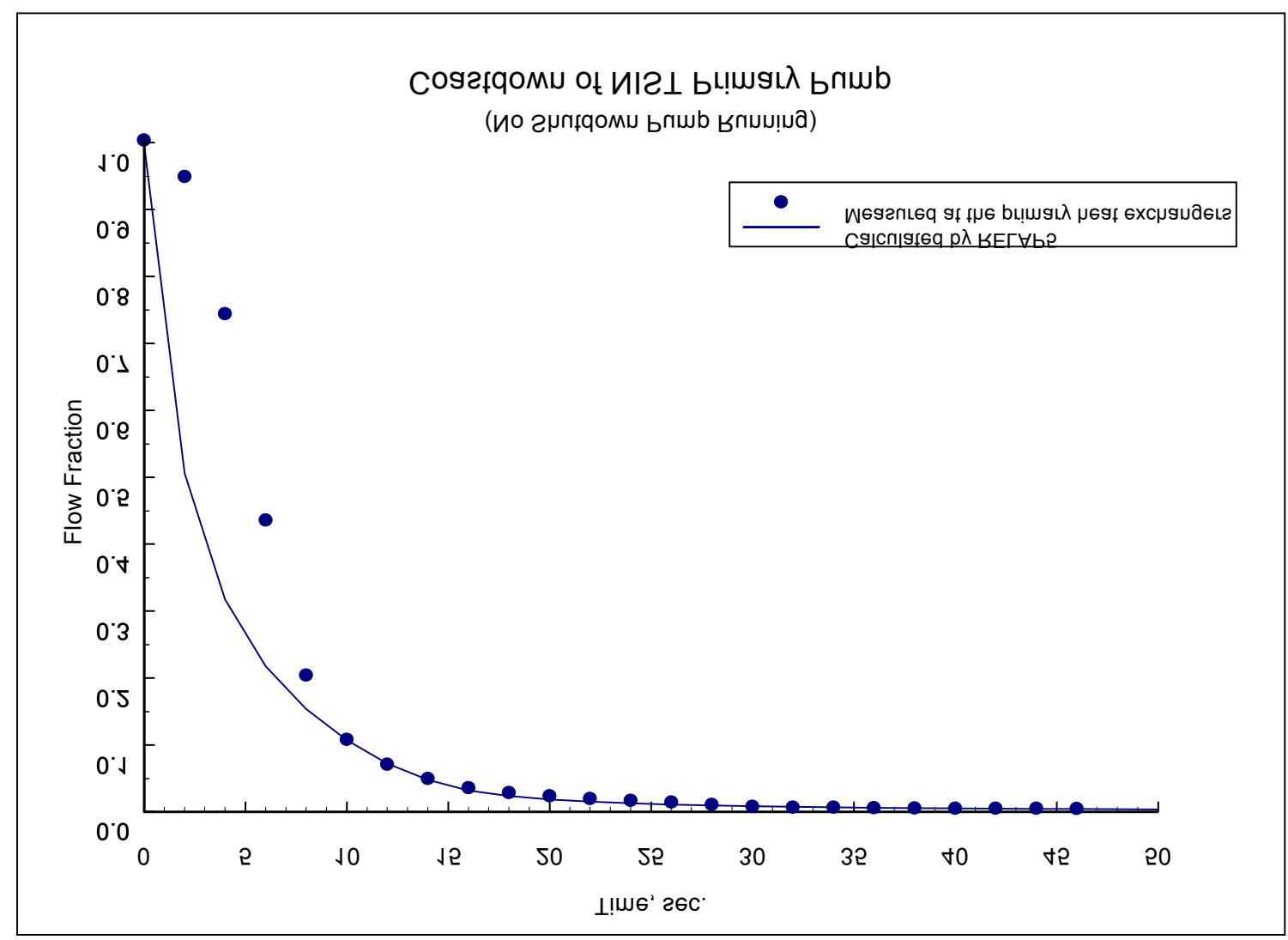

Figure 3-11 Comparison of Pump Coastdown Calculation with Plant Data (Cheng, 2004)

\subsubsection{Inner Emergency Cooling Tank Orifice}

It takes 30 minutes to completely drain the inner emergency cooling tank under gravity. The required orifice size was calculated analytically (Cheng, 2004) by applying the mechanical energy balance to the water in the tank with an orifice in the bottom. The corresponding initial mass flow rate through the orifice was also calculated analytically. A RELAP5 model of the inner emergency cooling tank was set up and the orifice was modeled as a junction with an abrupt area change. The orifice area was adjusted in the RELAP5 input until the initial orifice flow agreed with the analytical result. Using this orifice area, a RELAP5 calculation was performed to calculate the water level in the emergency tank as a function of time. The results of this calculation were then compared to an analytical solution. Figure 3-12 illustrates the excellent agreement between the RELAP5 results and the analytical solution. The performance of the inner emergency cooling tank in a postulated loss of coolant accident is discussed in Section 4.4 . 


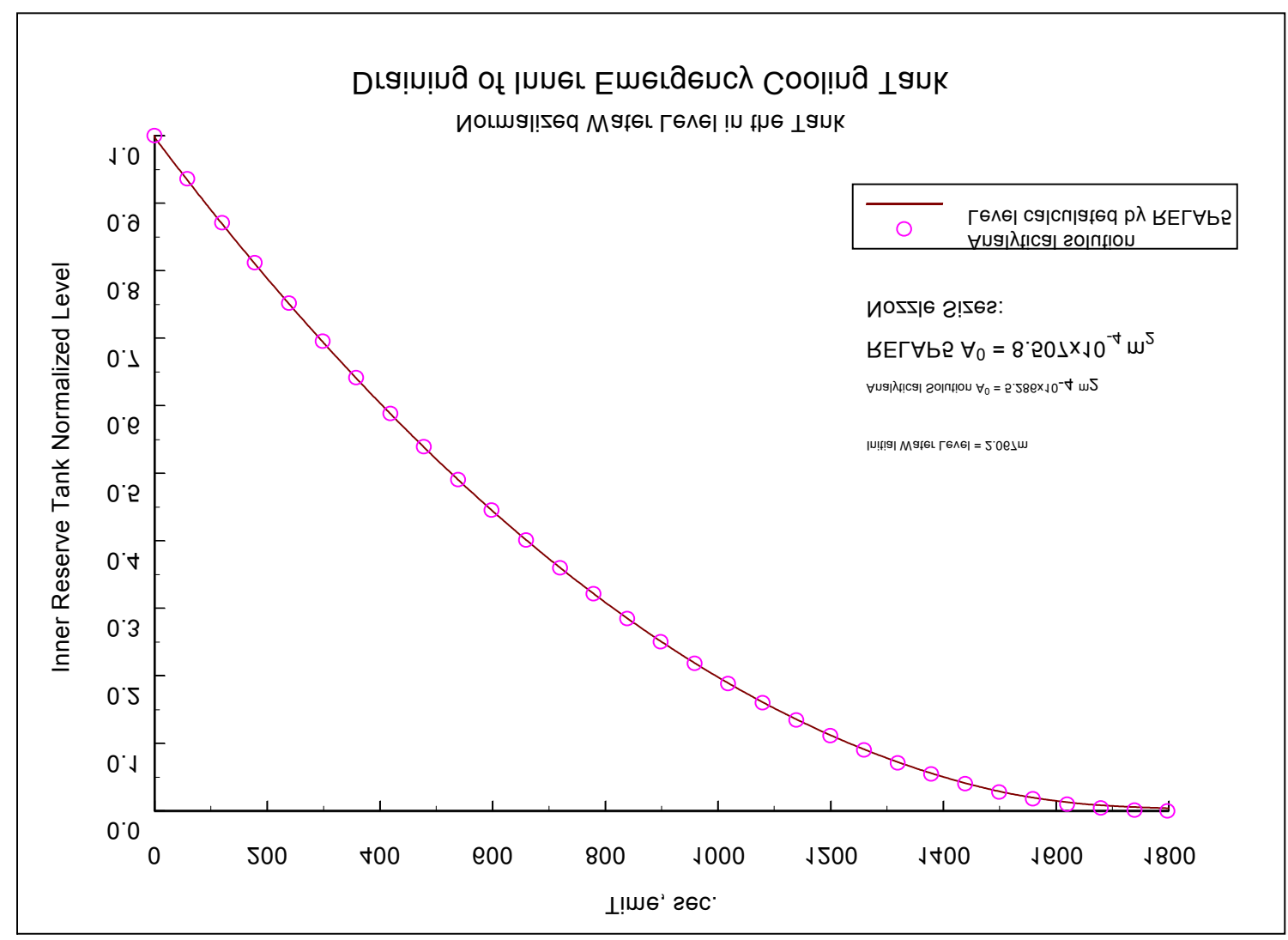

Figure 3-12 Predictions of Draining of Inner Emergency Cooling Tank (Cheng, 2004)

\subsubsection{Point Kinetics Input Data}

\subsubsection{Reactor Physics Parameters}

The RELAP5 model calculates the total reactor power as the sum of fission power and fission product decay power. Fission power is calculated from the point kinetics model and decay power is calculated using decay heat data as a function of fissionable isotope using data from the 1994 ANS Standard (ANS, 1994) for four isotopes $\left({ }^{235} \mathrm{U},{ }^{238} \mathrm{U},{ }^{23} \mathrm{Pu}\right.$, and $\left.{ }^{241} \mathrm{Pu}\right)$ and input values for the isotopic fission fractions. The fraction of fissions from each isotope is based on neutronic studies (Hanson, 2012). Table 3-5 shows the contributions to the fission process from each major actinide ( $\geq 0.01 \%$ contribution) using the inventories calculated by MCNPX. In the RELAP5 input the fraction of ${ }^{236} \mathrm{U}$ is added to that of ${ }^{238} \mathrm{U}$ and adjusted to make the total fraction sum to $100 \%$. 
Table 3-5 Percent of Fissions as Calculated by MCNPX and RELAP5 Input Values

\begin{tabular}{|c|c|c|c|c|c|c|c|c|}
\hline \multirow{2}{*}{ Actinide } & \multicolumn{4}{|c|}{ MCNPX Calculation } & \multicolumn{4}{c|}{ RELAP5 Input Value } \\
\cline { 2 - 9 } & \multicolumn{2}{|c|}{ HEU } & \multicolumn{2}{c|}{ LEU } & \multicolumn{2}{c|}{ HEU } & \multicolumn{2}{c|}{ LEU } \\
\cline { 2 - 9 } & SU & EOC & SU & EOC & SU & EOC & SU & EOC \\
\hline${ }^{235} \mathrm{U}$ & 99.73 & 99.67 & 96.35 & 95.71 & 99.73 & 99.67 & 96.35 & 95.71 \\
\hline${ }^{236} \mathrm{U}$ & 0.02 & 0.02 & 0.02 & 0.02 & \multicolumn{5}{c|}{ Not modeled } \\
\hline${ }^{238} \mathrm{U}$ & 0.01 & 0.01 & 0.49 & 0.49 & 0.02 & 0.04 & 0.50 & 0.51 \\
\hline${ }^{239} \mathrm{Pu}$ & 0.23 & 0.27 & 2.99 & 3.54 & 0.23 & 0.27 & 2.99 & 3.54 \\
\hline${ }^{241} \mathrm{Pu}$ & 0.02 & 0.02 & 0.16 & 0.24 & 0.02 & 0.02 & 0.16 & 0.24 \\
\hline
\end{tabular}

The delayed neutron contribution directly from fission products uses six delayed neutron groups each having its own delayed neutron precursor fraction and decay constant and the delayed neutron contribution from photoneutrons (the ${ }^{2} \mathrm{H}(\gamma, \mathrm{n})^{1} \mathrm{H}$ reaction) is divided into eight delayed neutron groups. The delayed neutron fractions and decay constants for the two sets of groups are given in Table 3-6 and Table 3-7, respectively. The calculation of the delayed neutron parameters is explained in (Hanson, 2012). The calculation was performed utilizing adjointweighted tallies; a feature of MCNP5-1.60 using the data sets from ENDF/B-VII. The effective delayed neutron fraction used in the reactor power evaluation is the sum of the delayed neutron fractions of the 14 groups as shown in Table 3-8.

Table 3-6 Recommended Delayed Neutron Parameters for the HEU and LEU

\begin{tabular}{|c|c|c|c|c|c|c|}
\hline \multicolumn{7}{|c|}{ SU } \\
\hline \multirow{2}{*}{ Group } & \multicolumn{3}{|c|}{ HEU } & \multicolumn{3}{|c|}{ LEU } \\
\hline & $\lambda_{i}(1 / s)$ & $\beta_{i}$ & $\beta_{\mathbf{i}} / \boldsymbol{\beta}$ & $\lambda_{i}(1 / s)$ & $\beta_{i}$ & $\beta_{i} / \beta$ \\
\hline 1 & 0.01249 & 0.00022 & 0.03158 & 0.01249 & 0.00020 & 0.02938 \\
\hline 2 & 0.03182 & 0.00111 & 0.15934 & 0.03177 & 0.00108 & 0.15868 \\
\hline 3 & 0.10938 & 0.00107 & 0.15360 & 0.10942 & 0.00105 & 0.15427 \\
\hline 4 & 0.31700 & 0.00301 & 0.43208 & 0.31731 & 0.00301 & 0.44224 \\
\hline 5 & 1.35386 & 0.00092 & 0.13206 & 1.35205 & 0.00085 & 0.12488 \\
\hline 6 & 8.63611 & 0.00032 & 0.04594 & 8.65543 & 0.00030 & 0.04408 \\
\hline$\beta=\Sigma \beta_{\mathrm{i}}$ & \multicolumn{3}{|c|}{0.00665} & \multicolumn{3}{|c|}{0.00650} \\
\hline \multicolumn{7}{|c|}{ EOC } \\
\hline \multirow{2}{*}{ Group } & \multicolumn{3}{|c|}{ HEU } & \multicolumn{3}{|c|}{ LEU } \\
\hline & $\lambda_{i}(1 / s)$ & $\beta_{i}$ & $\beta_{i} / \beta$ & $\lambda_{\mathrm{i}}(1 / \mathrm{s})$ & $\beta_{i}$ & $\beta_{i} / \beta$ \\
\hline 1 & 0.01249 & 0.00021 & 0.03028 & 0.01249 & 0.00020 & 0.02938 \\
\hline 2 & 0.03182 & 0.00112 & 0.16147 & 0.03176 & 0.00109 & 0.16015 \\
\hline 3 & 0.10938 & 0.00110 & 0.15859 & 0.10942 & 0.00102 & 0.14986 \\
\hline 4 & 0.31700 & 0.00302 & 0.43539 & 0.31730 & 0.00301 & 0.44224 \\
\hline 5 & 1.35374 & 0.00087 & 0.12543 & 1.35118 & 0.00087 & 0.12782 \\
\hline 6 & 8.63558 & 0.00030 & 0.04325 & 8.65038 & 0.00030 & 0.04408 \\
\hline$\beta=\Sigma \beta_{\mathrm{i}}$ & \multicolumn{3}{|c|}{0.00661} & \multicolumn{3}{|c|}{0.00648} \\
\hline
\end{tabular}

$\lambda_{\mathrm{i}}$ : average decay constant of group $\mathrm{i}$ 
$\beta_{\mathrm{i}}$ : delayed neutron fraction of group $\mathrm{i}$

$\beta$ : effective delayed neutron fraction

$\beta_{\mathrm{i}} / \beta$ : delayed neutron precursor yield ratio (RELAP5 input format)

Table 3-7 Delayed Neutrons from the ${ }^{2} H(\gamma, n)^{1} H$ Nuclear Reaction

\begin{tabular}{|c|l|l|}
\hline Group & \multicolumn{1}{|c|}{$\boldsymbol{\lambda}_{\mathbf{i}} \mathbf{( 1 / \mathbf { s } )}$} & \multicolumn{1}{|c|}{$\boldsymbol{\beta}_{\mathbf{i}}$} \\
\hline 7 & 0.278 & 0.000203 \\
\hline 8 & 0.0169 & 0.000065 \\
\hline 9 & 0.0049 & 0.0000223 \\
\hline 10 & 0.00152 & 0.0000107 \\
\hline 11 & $4.27 \times 10-4$ & 0.0000066 \\
\hline 12 & $1.16 \times 10-4$ & 0.0000074 \\
\hline 13 & $4.41 \times 10-5$ & 0.000001 \\
\hline 14 & $3.65 \times 10-6$ & 0.00000033 \\
\hline \multicolumn{2}{|c|}{$\beta=\Sigma \beta_{i}$} & 0.000316 \\
\hline
\end{tabular}

Table 3-8 Effective Total Delayed Neutron Fraction Used in RELAP5

\begin{tabular}{|c|c|c|}
\hline Fuel Cycle & \multicolumn{3}{|c|}{$\boldsymbol{\beta}=\boldsymbol{\Sigma} \boldsymbol{\beta}_{\text {6-groups }}+\boldsymbol{\Sigma} \boldsymbol{\beta}_{\text {8-photoneutrons }}$} \\
\hline & HEU & LEU \\
\hline SU & 0.006966 & 0.006806 \\
\hline EOC & 0.006936 & 0.006806 \\
\hline
\end{tabular}

The neutron lifetimes (or the prompt neutron generation times, as used in RELAP5) calculated using the adjoint-weighted tally methodology as used for the calculation of delayed neutron data (Hanson, 2012) are shown in Table 3-9 with recommended conservative values for use in RELAP5.

Table 3-9 Prompt Neutron Lifetime for HEU and LEU cores and RELAP5 Input Values

\begin{tabular}{|c|c|c|c|c|}
\hline \multirow{2}{*}{} & \multicolumn{2}{|c|}{ HEU } & \multicolumn{2}{c|}{ LEU } \\
\cline { 2 - 5 } & $\mathbf{S U}(\boldsymbol{\mu} \mathbf{s})$ & EOC $(\boldsymbol{\mu} \mathbf{s})$ & SU $(\mu \mathbf{s})$ & EOC $(\mu \mathbf{s})$ \\
\hline MCNP & 698 & 802 & 651 & 730 \\
\hline RELAP5 & 650 & 750 & 600 & 700 \\
\hline
\end{tabular}

\subsubsection{Reactivity Effects}

In the present analysis, no credit is taken for the moderator density and temperature feedback nor for fuel temperature feedback. This is conservative since these are negative reactivity feedbacks, 
which act in the opposite direction to the inserted accident reactivity and tend to reduce the transient power excursion.

The reactivity curve for the four shim arms as a function of position is shown in Figure 3-13 at SU for both the HEU and LEU cores and similarly, in Figure 3-14 at EOC. Initial position of the shim arms is $22.61^{\circ}$ at SU with the HEU fuel, $23.31^{\circ}$ at SU with the LEU fuel, and $41^{\circ}$ at EOC with both the HEU and LEU fuels. The shim arm worth is defined as zero at its initial positions as shown in the two figures.

The shim arm travel as a function of time after scram is shown in Figure 3-15. The assumed scram motion of the shim arms is in the form of a nonlinear fit developed from measured data. A conservative time delay of $0.0983 \mathrm{~s}$ has been incorporated in the start of shim arm motion after the initiation of a scram. It is assumed that starting from any position the first $5^{\circ}$ insertion will take $240 \mathrm{~ms}$. The scram motion is described by the following relation:

$$
\Delta \theta=\left\{\begin{array}{l}
a(t-\delta)^{2}, \text { if } t \geq 0.0983 \mathrm{~s} \\
0.0, \text { otherwise }
\end{array}\right.
$$

where $\Delta \theta$ is the shim arm travel in degrees, $t$ is the time from scram initiation in seconds, and

$$
\begin{aligned}
& a=248.9 \text { and } \\
& \delta=0.0983 .
\end{aligned}
$$

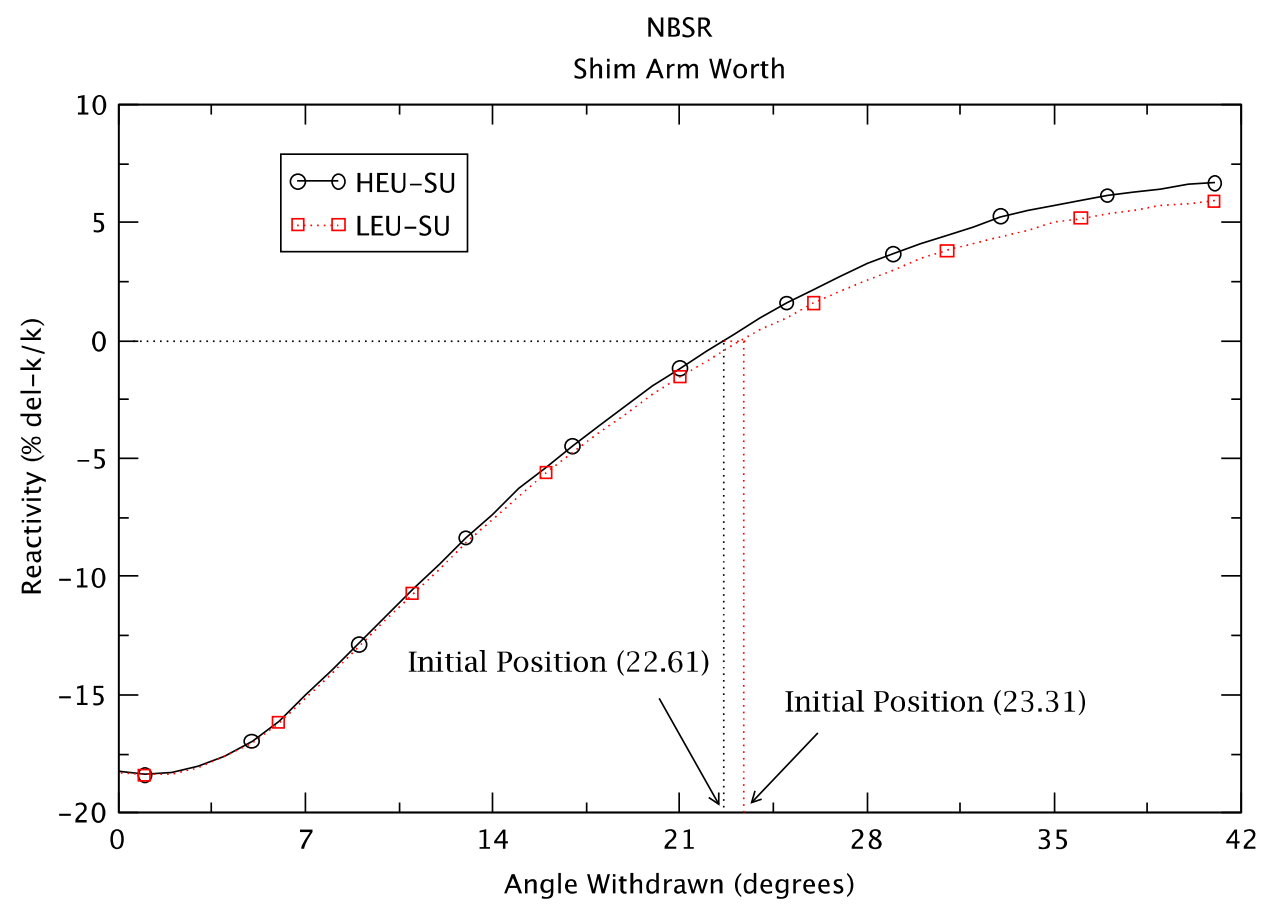

Figure 3-13 Reactivity Worth of Shim Arms at SU with HEU and LEU Fuels 


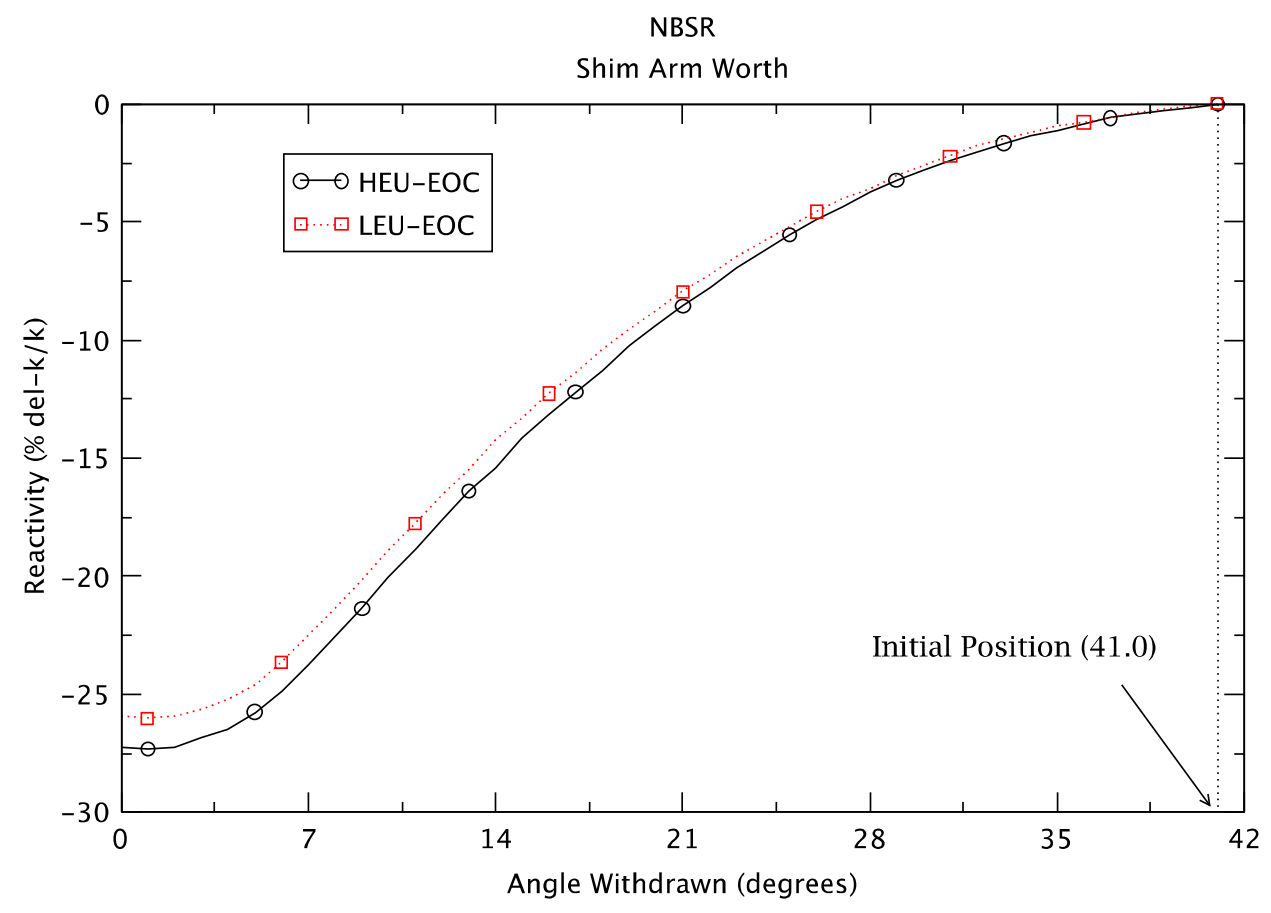

Figure 3-14 Reactivity Worth of Shim Arms at EOC with HEU and LEU Fuels

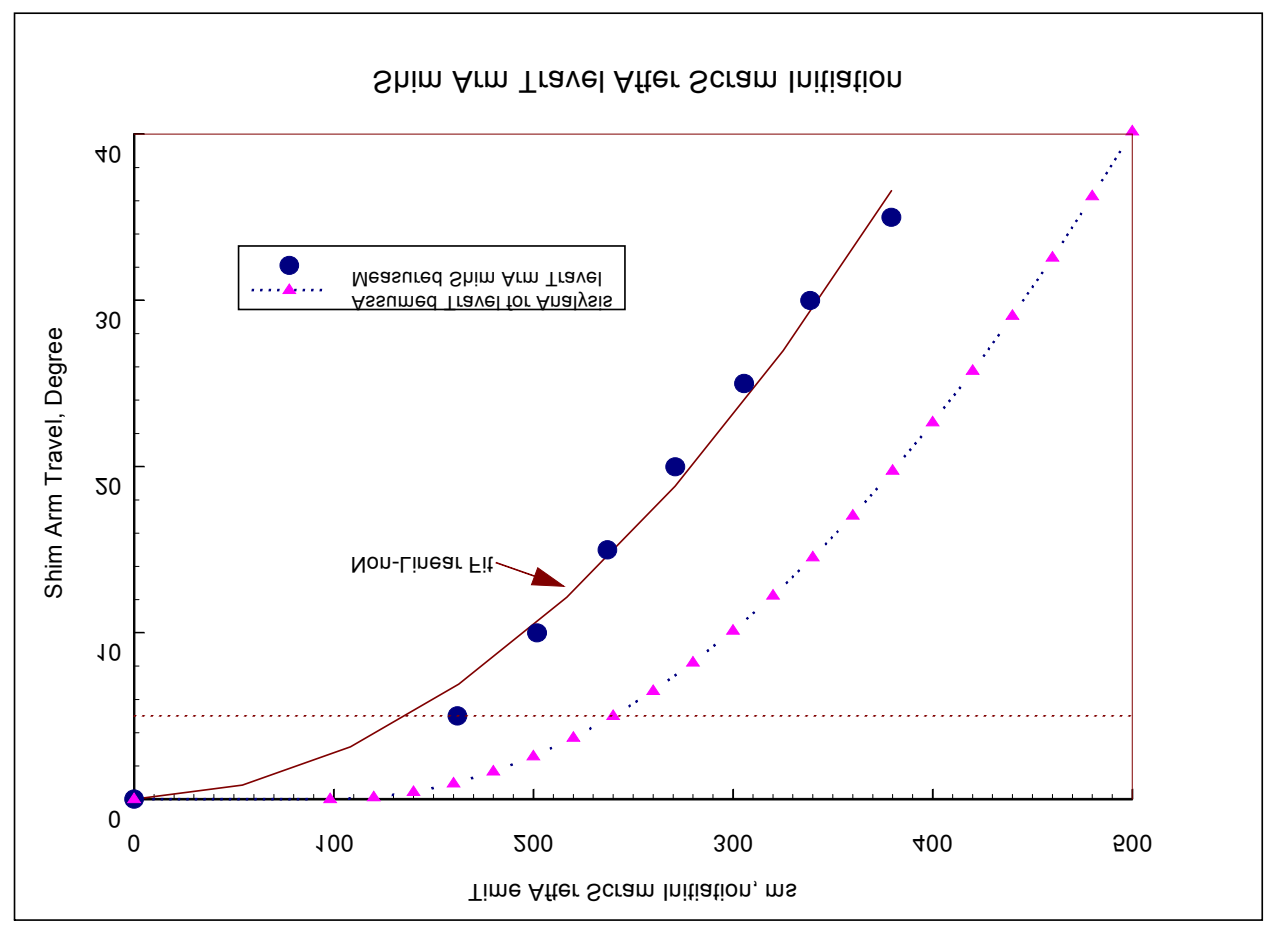

Figure 3-15 Shim Arm Travel after Scram Initiation (Cheng, 2004) 


\subsubsection{Core Bypass Flow}

About $4 \%$ of the total primary flow bypasses the fuel elements. In RELAP5 the areas of the bypass flow junctions have been adjusted so that $4 \%$ of flow to the inner and outer plenums is bypassed.

\subsubsection{Core Flow Distribution}

The flow distribution between the inner and outer plenums is derived from actual plant measurements. At a primary flow of $560 \mathrm{l} / \mathrm{s}(8700 \mathrm{gpm})$, the respective distributed flow values are148 l/s (2300 gpm) and $412 \mathrm{l} / \mathrm{s}$ (6400 gpm). This flow split is accomplished in the RELAP5 model by adjusting a junction loss coefficient in the outer plenum inlet pipe (Component 41). In simulating a flow control valve throttling accident, a motor valve (Component 50 or Component 51 ) is assumed to be closed at the inner (or outer) plenum inlet of the reactor.

\subsubsection{Power Distribution}

\subsubsection{Power Distribution for Hottest-Cell Stripe}

In Section 3.2.1 the channels represented in the model were explained. To provide the power distributions from the neutronics analysis needed by RELAP5, ancillary calculations and data reduction must be performed. A FORTRAN program has been developed to read the fission rate in each (approximately) $2 \mathrm{~cm} \times 2 \mathrm{~cm}$ fuel plate cell calculated by MCNPX. The program examines the "hottest" cells with the highest fission rate power in the inner and outer cores as shown on the left hand side of Figure 3-16. The three stripes in a fuel element shown in the figure correspond to the mesh in the transverse direction across a fuel plate. After finding the stripe with the hottest cell, the same power distribution along the axial cells (representing a fuel stripe) which include the hottest cell is assumed in the remaining two lateral stripes as illustrated on the right hand side of Figure 3-16. This method is conservative in terms of minimum CHFR.

Figure 3-16 shows that the hottest heat structure is divided into two half-plates and the highest power is transferred into one common flow channel (see

Figure 3-9), rather than into two adjacent flow channels. This kind of power distribution is modeled for the hottest cell flow channels (Nodes $103 \& 107$ and Nodes $403 \&$ 407) and the hottest cell flow channels with a sharing water from the mid-plane gap in hot fuel element (Nodes $203 \& 207$ and Nodes $503 \&$ 507). This approach increases the conservatism of power distribution modeling. 

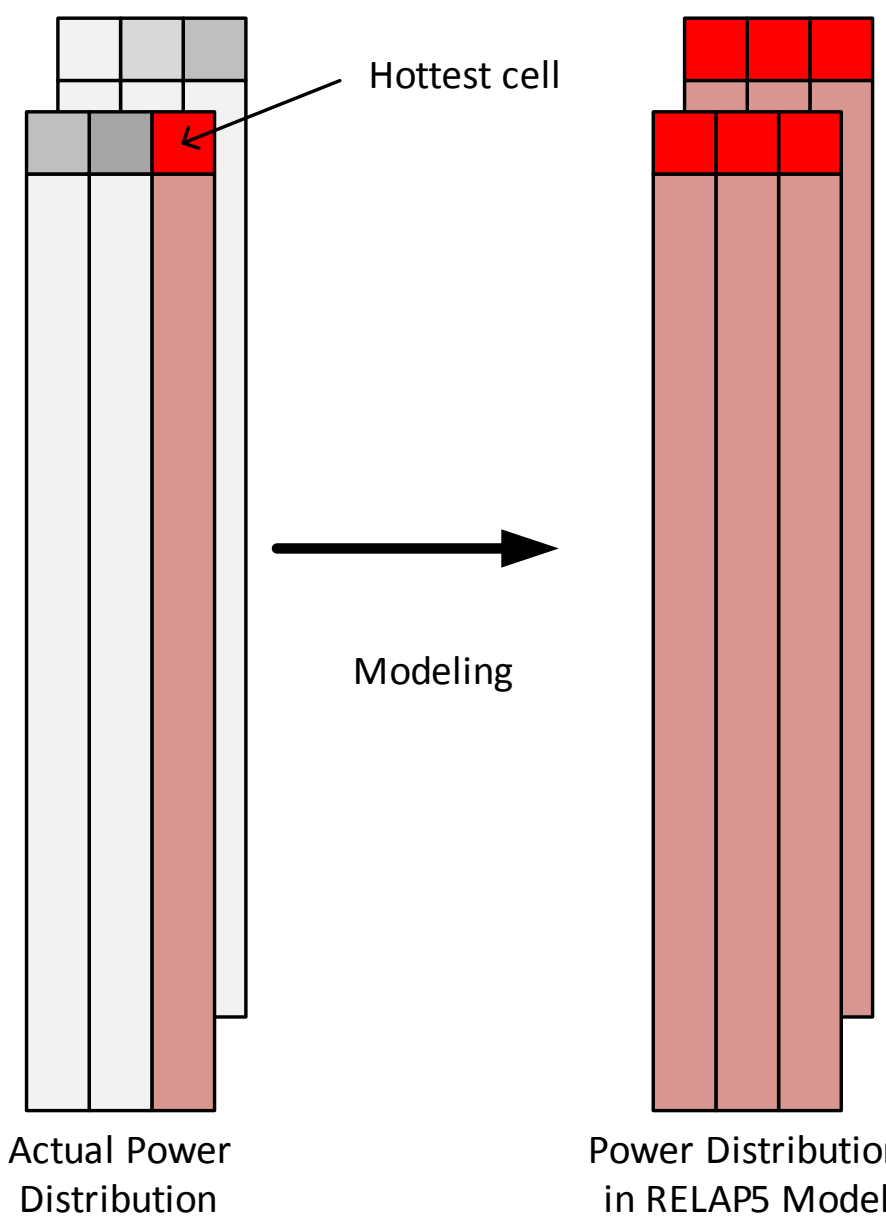

Power Distribution

in RELAP5 Model

\section{Figure 3-16 Modeling of Power Distribution in RELAP5 Input Model}

\subsubsection{Power Distribution for Hottest Stripe}

As mentioned above, a fuel stripe represents one-third of a fuel plate which is divided vertically as shown in Figure 3-16. The FORTRAN program also examines all fuel stripes to determine which one produces the highest total stripe power in the inner and outer cores. After examining the hottest fuel stripes, the same power distribution along the stripe is assumed in the remaining two lateral stripes as the one done with the hottest cells in Section 3.3.9.1. This kind of power distribution is modeled for the hottest stripe flow channels (Nodes $113 \& 117$ and Nodes $413 \&$ 417).

\subsubsection{Power Distribution for Non-Hot Stripes}

For fuel elements that don't include the hottest cell or hottest stripe discussed in the previous sections, all of the stripes are lumped together into one effective heat structure. The power for each axial node of the effective heat structure is the sum of the nodal power at the same axial location for all fuel stripes represented by the heat structure. Discussions of how the average stripes are lumped together are given in Table 3-10. 


\subsubsection{Modeling of Heat Structures}

Heat structures are used to model the power distribution in the NBSR core for the RELAP5 analysis. Table 3-10 provides descriptions of the power distributions which have been determined by the method discussed in the previous sections. Table 3-10 also illustrates the relation between the hydraulic nodes (flow channels) and heat structures. For example, the power generated in the heat structure HTSTR-1000 is transferred to the hydraulic nodes of Node 103 (lower core region) and Node 107 (upper core region) as indicated in the nodal-diagram of Figure 3-1. Each heat structure only accounts for the fueled section of a fuel plate (or fuel plates). The unfueled portions (the edges) of a fuel plate are conservatively neglected (Cheng, 2010) in the RELAP5 model. The hydraulic channel, however, accounts for the full width of a fuel plate exposed to the coolant, i.e. the wetted surface of a fuel plate including the unfueled portions.

Table 3-10 Heat Structures of Fuel Plates

\begin{tabular}{|c|c|c|}
\hline \multicolumn{3}{|r|}{ Inner Core } \\
\hline HTSTR \# & Node \# & Description \\
\hline $1000^{(1)}$ & $103 \& 107$ & $\begin{array}{l}\text { Power distribution along a fuel stripe which includes the hottest } \\
\text { cell in the inner core. Additionally, the other fuel stripe in the } \\
\text { same fuel stripe location is modeled (i.e. the fuel stripe directly } \\
\text { above or below the stripe with the hottest cell) as shown in Figure } \\
\text { 3-7. }\end{array}$ \\
\hline $1100^{(1)}$ & $113 \& 117$ & $\begin{array}{l}\text { Power distribution along a fuel stripe which produces the highest } \\
\text { total stripe power in the inner core. Additionally, the other fuel } \\
\text { stripe in the same fuel plate location is modeled (i.e. the fuel stripe } \\
\text { directly above or below the hottest stripe). }\end{array}$ \\
\hline $2000^{(1)}$ & $203 \& 207$ & $\begin{array}{l}\text { Power distribution along a fuel stripe which includes the hottest } \\
\text { cell in the inner core. The power distribution is the same as that } \\
\text { for HTSTR } 1000 \text {. Additionally, the other fuel stripe in the same } \\
\text { fuel stripe location is modeled (i.e. the fuel stripe directly above or } \\
\text { below the stripe with the hottest cell). }\end{array}$ \\
\hline 2100 & $213 \& 217$ & $\begin{array}{l}\text { Power distribution for the remaining } 32 \text { fuel plates of the hottest } \\
\text { fuel element containing HTSTR } 2000 \text {. Thirty two fuel plates ( } 16 \\
\text { lower plates and } 16 \text { upper plates) are modeled. }\end{array}$ \\
\hline 3000 & $303 \& 307$ & $\begin{array}{l}\text { Power distribution for the remaining } 5 \text { fuel elements in the inner } \\
\text { core. Power of HTSTR } 1000 \text { and HTSTR } 1100 \text { are subtracted } \\
\text { from the power of these remaining } 5 \text { fuel elements. One hundred } \\
\text { and sixty six fuel plates ( } 83 \text { lower plates and } 83 \text { upper plates) are } \\
\text { modeled. }\end{array}$ \\
\hline \multicolumn{3}{|r|}{ Outer Core } \\
\hline HTSTR \# & Node \# & Description \\
\hline $4000^{(1)}$ & $403 \& 407$ & $\begin{array}{l}\text { Power distribution along a fuel stripe which includes the hottest } \\
\text { cell in the outer core. Additionally, the other fuel stripe in the } \\
\text { same fuel stripe location is modeled (i.e. the fuel stripe directly } \\
\text { above or below the stripe with the hottest cell). }\end{array}$ \\
\hline $4100^{(1)}$ & $413 \& 417$ & Power distribution along a fuel stripe which produces the highest \\
\hline
\end{tabular}




\begin{tabular}{|c|c|c|}
\hline & & $\begin{array}{l}\text { total stripe power in the outer core. Additionally, the other fuel } \\
\text { stripe in the same fuel stripe location is modeled (i.e. the fuel } \\
\text { stripe directly above or below the hottest stripe). }\end{array}$ \\
\hline $5000^{(1)}$ & $503 \& 507$ & $\begin{array}{l}\text { Power distribution along a fuel stripe which includes the hottest } \\
\text { cell in the outer core. The power distribution is the same as that } \\
\text { for HTSTR } 4000 \text {. Additionally, the other fuel stripe in the same } \\
\text { fuel stripe location is modeled (i.e. the fuel stripe directly above or } \\
\text { below the stripe with the hottest cell). }\end{array}$ \\
\hline 5100 & $513 \& 517$ & $\begin{array}{l}\text { Power distribution for the remaining } 32 \text { fuel plates of the hottest } \\
\text { fuel element containing HTSTR } 4000 \text {. Thirty two fuel plates (16 } \\
\text { lower plates and } 16 \text { upper plates) are modeled. }\end{array}$ \\
\hline 6000 & $603 \& 607$ & $\begin{array}{l}\text { Power distribution for the first five fuel elements among the } \\
\text { remaining } 23 \text { fuel elements in the outer core. Power of HTSTR } \\
4000 \text { and HTSTR } 4100 \text { are subtracted from the power of these five } \\
\text { fuel elements. One hundred and sixty six fuel plates ( } 83 \text { lower } \\
\text { plates and } 83 \text { upper plates) are modeled. }\end{array}$ \\
\hline 7000 & $703 \& 707$ & $\begin{array}{l}\text { Power distribution for the next six fuel elements among the } \\
\text { remaining } 18 \text { fuel elements in the outer core. Two hundred and } \\
\text { four fuel plates ( } 102 \text { lower plates and } 102 \text { upper plates) are } \\
\text { modeled. }\end{array}$ \\
\hline 8000 & $803 \& 807$ & $\begin{array}{l}\text { Power distribution for the next six fuel elements among the } \\
\text { remaining } 12 \text { fuel elements in the outer core. Two hundred and } \\
\text { four fuel plates ( } 102 \text { lower plates and } 102 \text { upper plates) are } \\
\text { modeled. }\end{array}$ \\
\hline 9000 & $903 \& 907$ & $\begin{array}{l}\text { Power distribution for the remaining six fuel elements in the outer } \\
\text { core. Two hundred and four fuel plates ( } 102 \text { lower plates and } 102 \\
\text { upper plates) are modeled. }\end{array}$ \\
\hline
\end{tabular}

Note ${ }^{(1)}$ Explanation of heat structure power is given only for a single stripe but the same power distribution along the stripe is given to the two remaining lateral stripes of the same fuel plate for conservatism (see the right hand side of Figure 3-16).

RELAP5 calculates the NBSR total core power using the point kinetics model and then evaluates the power of each heat structure according to the power distribution discussed in Table 3-10. In the following, power distributions are shown for the limiting two channels (the hottest cell channels) in the inner and outer cores.

Figure 3-17 illustrates the normalized steady-state power distribution in the inner core at SU. In the legend a number with "HTSTR" represents the heat structure number. The power shown in Figure 3-17 has been normalized to the total reactor power. The origin at $0.0 \mathrm{~cm}$ represents the central plane of the core and is in the unfueled gap between the lower and upper fuel plates. Negative distance is measured downward from the centre. The coolant flow is upward through the core, from the negative to the positive direction in Figure 3-17.

The normalized powers shown in Figure 3-17 are plotted at the 14 points at the centers of the heat structure nodes (identifying symbols on the figures are given at fewer points). Two adjacent 
data points are connected by a straight line rather than by fitting a curve. Since the data points have statistical errors from the MCNP calculations, the straight lines have seemingly erratic slopes.

From Figure 3-17, it can be observed that at SU the hottest cell is located in the hottest stripe in the case of HEU fuel while the hottest stripe does not contain the hottest cell in the case of LEU fuel. It can also be observed that the steady-state power in the hottest cell channel as well as the channel including the hottest stripe is higher in the inner core with the LEU fuel than with the HEU fuel at SU.

Similarly, Figure 3-18 shows the normalized steady-state power distribution in the inner core at EOC and Figure 3-19 and Figure 3-20 depict the normalized steady-state power distribution in the outer core at SU and EOC, respectively. By examining Figure 3-17 through Figure 3-20, it can be seen that the highest power density (hottest cell) always occurs at the top cell of the lower plate or bottom cell of the upper plate.

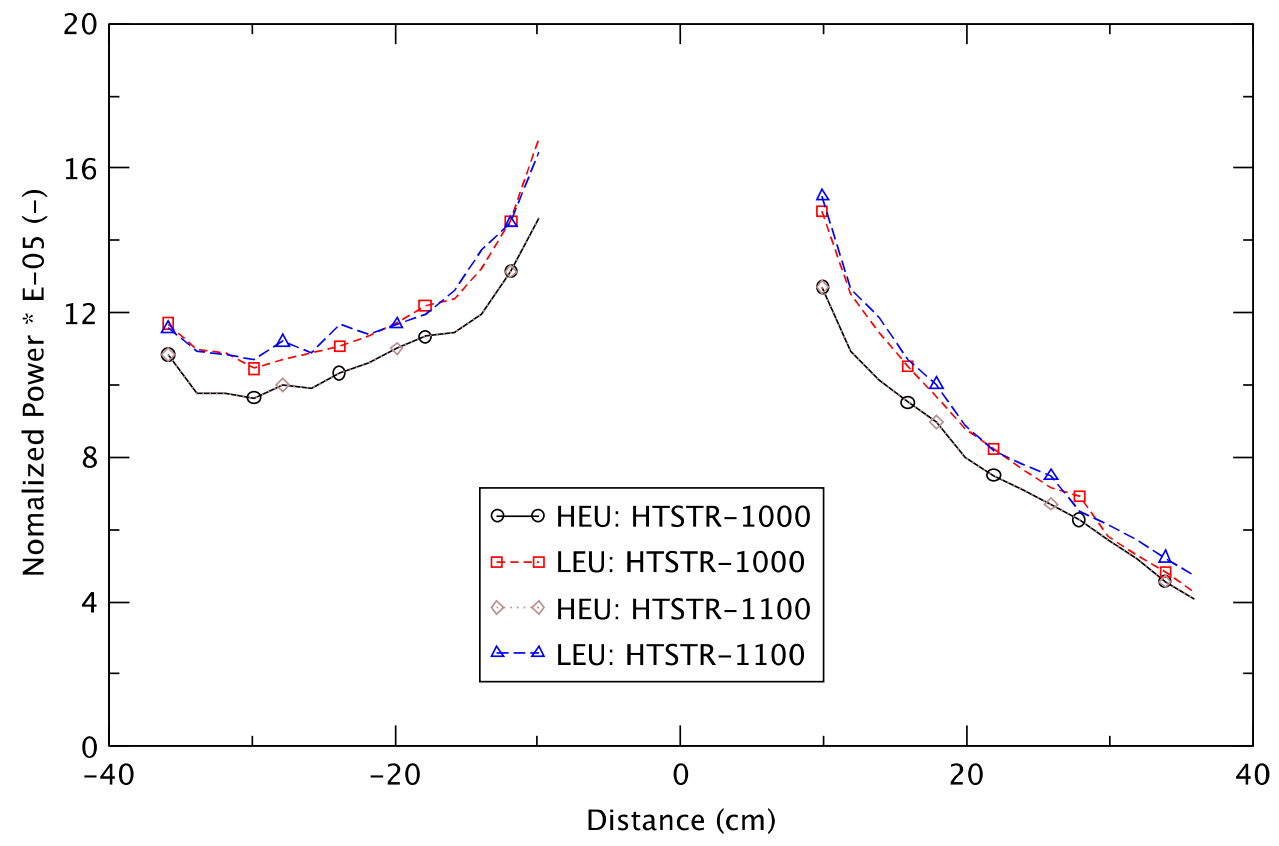

Figure 3-17 Power Distribution in Inner Core with HEU and LEU Fuels at SU 


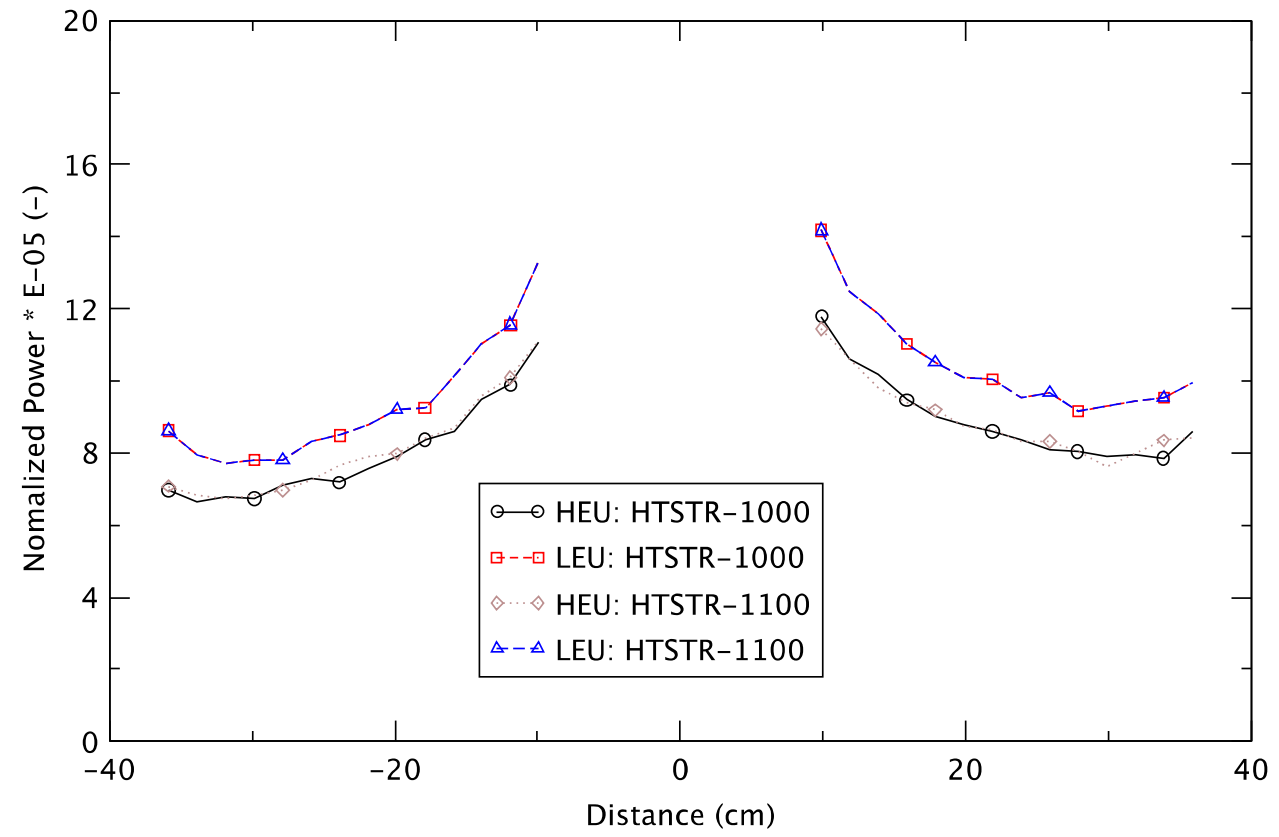

Figure 3-18 Power Distribution in Inner Core with HEU and LEU Fuels at EOC

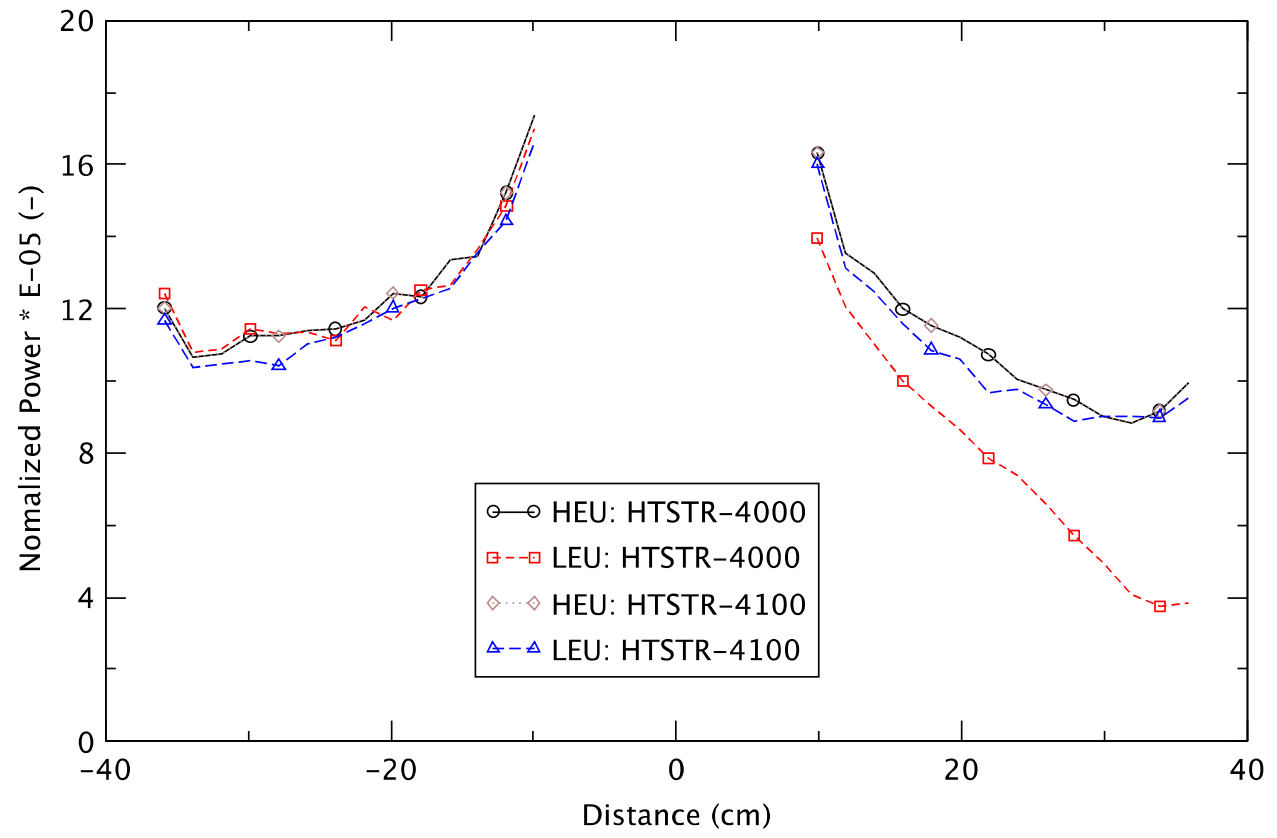

Figure 3-19 Power Distribution in Outer Core with HEU and LEU Fuels at SU 


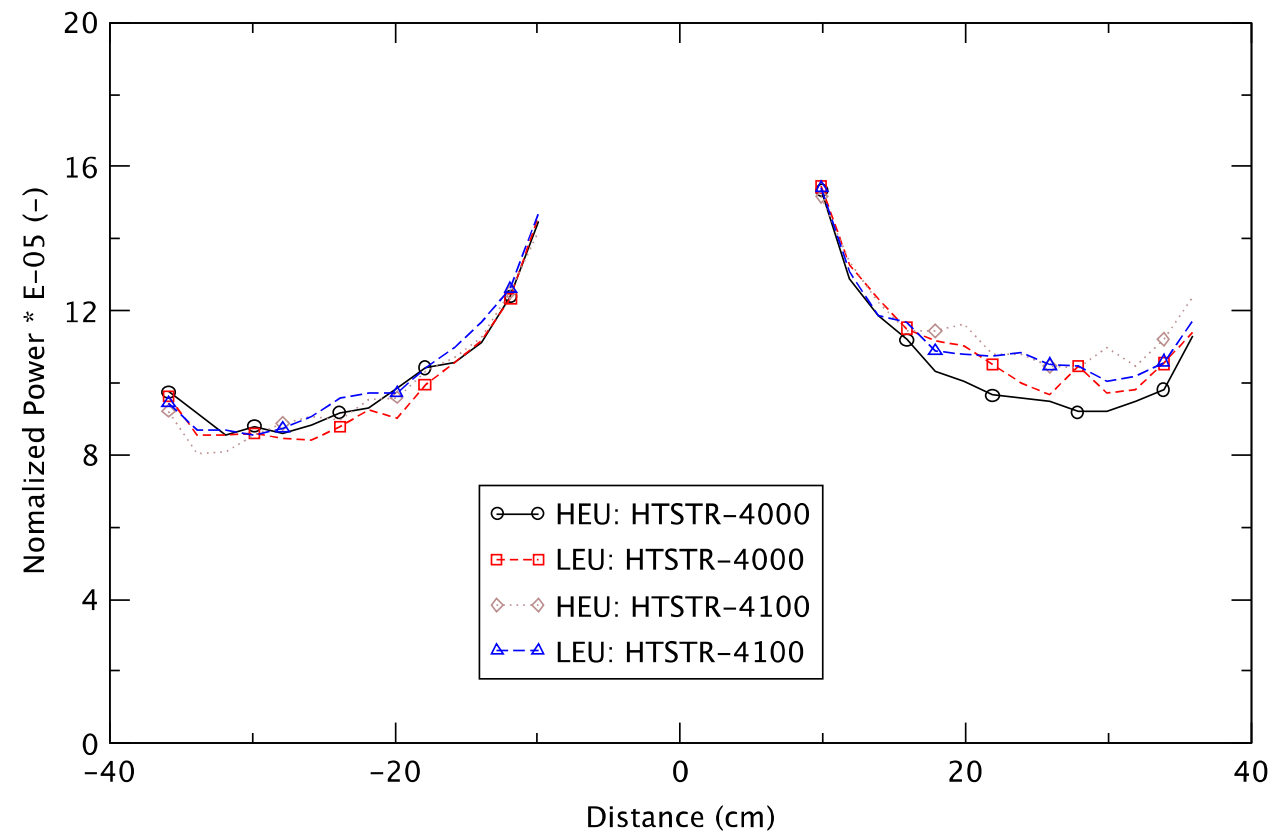

Figure 3-20 Power Distribution in Outer Core with HEU and LEU Fuels at EOC

\subsubsection{Control Variables and Variable and Logic Trips}

In the RELAP5 computer code, control variables are functions defined in the input deck to calculate process parameters. Each control variable is identified by a number and an alphanumeric name. The more important control variables used in the NBSR transient analyses are listed in (Baek, 2012a).

The initiation of safety systems is defined in RELAP5 in the form of trip variables. Each trip is identified by a number. The NBSR input deck uses three types of trips; pump trip, reactor trip and valve trip (open and close). A pump trip is usually initiated at time zero according to the accident scenario. A reactor trip or scram can be initiated by a number of conditions in the reactor. The reactor trips that have been modeled for the analysis of the NBSR accidents are the power and flow trips. This may be conservative for some events where trip on reactor period may be earlier. Table 3-11 lists the scram values and the corresponding time delays as assumed in the RELAP5 model. A complete listing of each of the different types of trips used in RELAP5 model is provided in (Baek, 2012a) 
Table 3-11 Setpoints for Reactor Trip

\begin{tabular}{|c|c|c|}
\hline Reactor Trip & Setpoint & Instrument Delay Time (s) \\
\hline Total Primary Flow & 372 //s $(5900 \mathrm{gpm})$ & 0.4 \\
\hline Outer Plenum Flow & $297 \ell / \mathrm{s}(4700 \mathrm{gpm})$ & 0.4 \\
\hline Inner Plenum Flow & $75.7 \ell / \mathrm{s}(1200 \mathrm{gpm})$ & 0.4 \\
\hline Reactor Power & $26 \mathrm{MW}^{(1)}$ & 0.0 \\
\hline
\end{tabular}

Notes: ${ }^{(1)}$ The Limiting Safety System Setpoint (LSSS) value for reactor power is $130 \%$.

\subsection{Determination of Limiting Conditions}

Fuel damage is examined by investigating the minimum CHFR in the core during the course of the transient. The OFIR is also evaluated as a supplementary parameter to examine the potential for fuel damage in some cases.

\subsubsection{Critical Heat Flux}

The Sudo-Kaminaga correlation (Kaminaga, 1998) was selected for evaluation of the CHF. In the previous SAR (NIST, 2010), the Mirshak correlation was used, however, the Sudo-Kaminaga correlation represents an improvement due to the enhanced geometric similarity, increased dependence on the full range of actual operating conditions in the NBSR, and an overall approach that is more mechanistic.

The Sudo-Kaminaga correlation was developed for vertical rectangular channels in JRR-3 (Japan Research Reactor unit 3). The CHF experiments included the effect of mass flux, inlet subcooling, outlet subcooling, flow direction, pressure, as well as the channel configuration. Experiments were carried out within the range of pressure of 0.1 to $4 \mathrm{MPa}$, mass flux of $-25,800$ to $6250 \mathrm{~kg} / \mathrm{m}^{3}$, including stagnant flow conditions, inlet subcooling of 1 to $213 \mathrm{~K}$, outlet condition with subcooling of 0 to $74 \mathrm{~K}$ and quality of 0 to 1.0 , and the ratio of heated length to equivalent hydraulic diameter L/De of 8 to 240. The correlations proposed by Sudo and Kaminaga are mass flux and flow direction dependent and there are three separate regions, based on the dimensionless mass flux $\mathrm{G}^{*}$, as depicted in Figure 3-21.

The three mass flux regions, low, medium and high, are categorized by a dimensionless mass flux:

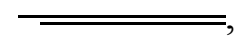

where $\lambda$ is the critical wave length defined as:

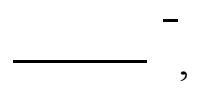


and:

$G$ : mass flux $\left(\mathrm{kg} / \mathrm{m}^{2} . \mathrm{s}\right)$

$\sigma$ : surface tension $(\mathrm{N} / \mathrm{m})$

$f_{g}$ and $\rho_{l}$ : density of gas and liquid $\left(\mathrm{kg} / \mathrm{m}^{3}\right)$

$g$ : acceleration of gravity $\left(\mathrm{m} / \mathrm{s}^{2}\right)$.

The boundary values $\mathrm{G}_{1}{ }^{*}, \mathrm{G}_{2}{ }^{*}$, and $\mathrm{G}_{3}{ }^{*}$ in Figure 3-21 are,

$$
G_{1}^{*}=\left|\frac{\frac{A}{f_{H}} \Delta T_{\text {Subin }}^{*}}{{ }^{*}}\right|^{\frac{1}{0389}},
$$

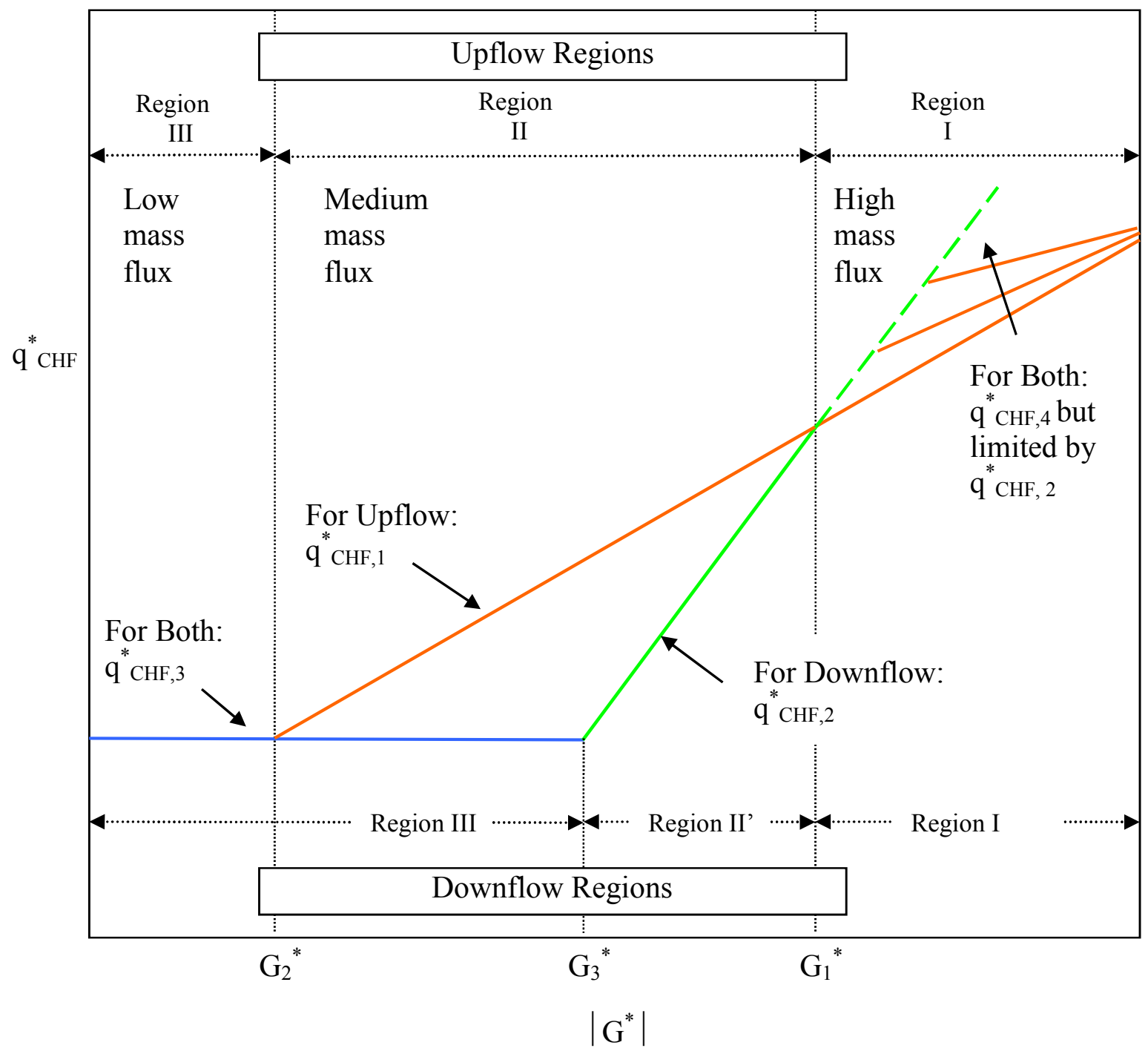




$$
G_{2}^{*}=\left|\div 40 \frac{A}{A_{H}} \frac{\bar{W}}{\left\{1+\left|\frac{\rho g}{f l}\right|^{025}{ }^{2}\right.}\left(i+3.0 \cdot \Delta T_{\text {Subin }}^{*}\right)\right|^{\frac{1}{0611}},
$$

and

$$
G_{3}^{*}=0.7 \frac{\bar{W}}{\left\{1+\left|\frac{\bar{\alpha}}{\rho l}\right|^{4}\right\}} \overline{2}\left(3.0+\frac{1}{\Delta T_{\text {subin }}^{*}}\right) .
$$

where the dimensionless subcooling at the inlet (in) or the outlet $(\mathrm{O})$ is defined as:

$$
\Delta T_{S u b}^{*}=\frac{C_{p f \cdot \Delta T_{S u b}}}{h_{f g}}
$$

and:

$A$ : flow area $\left(\mathrm{m}^{2}\right)$

$A_{H}:$ heated area $\left(\mathrm{m}^{2}\right)$

$W$ : channel width of rectangular channel (m)

$C_{p f}$ : specific heat at constant pressure of the liquid $(\mathrm{kJ} / \mathrm{kg} . \mathrm{K})$

$r_{f g}$ : latent heat of evaporation $(\mathrm{kJ} / \mathrm{kg})$.

The correlation scheme proposed is applicable for both upflow and downflow:

$$
\begin{aligned}
& q_{C H F 4}^{*}=0.005\left|G^{*}\right|^{0611}\left(1+\frac{5000}{\left|G^{*}\right|} \Delta T_{S u b O}^{*}\right), \\
& q_{C H F 1}^{*}=0.005\left|G^{*}\right|^{0611}, \\
& q_{C H F 2}^{*}=\frac{A}{A_{H}}\left|G^{*}\right| \cdot \Delta T_{\text {Subin }}^{*}, \\
& q_{C H F 3}^{*}=0.7 \cdot \frac{A}{A_{H}} \frac{\frac{\bar{W}}{\lambda}}{\left\{1+\left|\frac{E G}{f l}\right|^{4}\right\}} \overline{2} \cdot\left(1.0+3.0 \cdot \Delta T_{\text {subin }}^{*}\right),
\end{aligned}
$$

where the dimensionless critical heat flux $\mathrm{q}^{*} \mathrm{CHF}$ is defined as: 
The dimensionless critical heat flux for both up-flow and down-flow in Region I is predicted by , whereas , and are used for the up-flow and down-flow CHFs respectively in Regions II and II'. Finally, is applied for Region III, where the thermal limit is dictated by counter-current flow limitation (CCFL). It is, however, noted that in region I, limits the maximum value of

Critical heat flux and CHFR are evaluated as below.

and

where stands for the heat flux predicted by RELAP5.

\subsubsection{Onset of Flow Instability}

The most relevant instability for the NBSR, the Ledinegg static instability, has its origin in a simple effect. As water flow in a heated channel is reduced, a point will be reached where boiling will occur. At a later point significant amounts of vapor will be present in the channel. The presence of this vapor will increase the pressure drop, and when this effect is large enough, this increase will overwhelm the decrease in pressure drop arising from the flow decrease. This is known as the Onset of Flow Instability (OFI). At this point, the overall pressure drop in the hot channel of a fuel element will increase, and flow will be reduced (if the channel spans an inlet and outlet header, with other, lower power channels in parallel). This condition causes a flow instability, which will result in rapid loss of adequate cooling for that channel.

The onset of flow instability is determined by assuming that the onset of net vapor generation is a conservative threshold for OFI, and the Saha-Zuber criteria (Saha, 1974) are used. The use of the low and high mass flow rate criteria is based on the Péclet number:

where:

: hydraulic diameter

: thermal conductivity of liquid 
: mass flow

: specific heat at constant pressure of the liquid

For low mass flow rates, the Péclet number is less than 70,000, and the Saha-Zuber criterion is:

where:

: heat flux

: saturation temperature of liquid

: temperature of liquid at the point of net vapor generation

For high mass flow rates, the Péclet number is greater than 70,000 , and the criterion is:

Heat flux for OFI and OFIR are evaluated as below.

and

where $\quad$ stands for the heat flux predicted by RELAP5.

\subsection{Statistical Hot Channel Limits Analysis}

A statistical analysis (Cuadra, 2011) was performed to account for the effects of uncertainties in the hot channel variables (i.e., CHFR, OFIR, coolant bulk temperature rise, film temperature rise, and local heat flux). The calculation of cumulative probability distribution functions (PDF) for CHFR and OFIR determines the probability of reaching those limits. The analysis accounts for the uncertainty in each parameter used in the determination of the hot channel variables, either by a random sampling of the parameter or by applying a conservative bias to the parameter. The probability distributions were determined using a direct Monte Carlo simulation of the uncertainty propagation.

Parameter uncertainties were sampled from normal distributions having standard deviations based on estimates of the uncertainty in the individual parameters. For each hot channel variable, the PDF was used to determine the limiting value such that there was a $95 \%$ (or $90 \%$ or $99.9 \%$ ) probability of not exceeding this value. For LEU fuel the analysis was of a preliminary nature as all the fuel parameter uncertainties are not yet exactly known. The results for HEU and LEU 
fuels are shown in Table 3-12 for the normalized random value for CHFR, $(\mathrm{CHFR})_{\mathrm{n}^{\prime}}(\mathrm{CHFR}) \mathrm{r}$ (ratio of the nominal value to the random (or limit) value) for three different probability levels for not reaching $\mathrm{CHF}$.

Table 3-12 Ratio of Nominal Value to Random Value of CHFR, $(\text { CHFR })_{n^{\prime}}($ CHFR $)$ r

\begin{tabular}{|c|c|c|}
\hline Probability Level & HEU & LEU \\
\hline $90 \%$ & 1.30 & 1.32 \\
\hline $95 \%$ & 1.39 & 1.42 \\
\hline $99.9 \%$ & 1.78 & 1.86 \\
\hline
\end{tabular}

The same statistical analysis was performed for the OFI using the Saha-Zuber correlation. The results for HEU and LEU fuels are shown in Table 3-13 for the normalized random value for OFIR, (OFIR) $n^{\prime}($ OFIR $) r$ (ratio of the nominal value to the random (or limit) value) for three different probability levels for not reaching onset of flow instability.

Table 3-13 Ratio of Nominal Value to Random Value of OFIR, $($ OFIR)n' $($ OFIR)r

\begin{tabular}{|c|c|c|}
\hline Probability Level & HEU & LEU \\
\hline $90 \%$ & 1.22 & 1.27 \\
\hline $95 \%$ & 1.28 & 1.35 \\
\hline $99.9 \%$ & 1.58 & 1.73 \\
\hline
\end{tabular}




\section{ACCIDENT ANALYSIS}

This chapter presents the analysis performed for postulated hypothetical accidents. They bound all possible events, and result in a range of probability of fuel damage and hence, potential release of radioactive isotopes to the environment. The consequences of each accident are analyzed to the extent necessary to determine the degree of potential hazard. In addition, the results of the accidents with the HEU and LEU fuels are compared in order to see how the responses of the NBSR reactor are affected by fuel conversion.

\subsection{Steady-State Calculations}

The steady-state operating conditions are summarized in Table 4-1. This table shows the anticipated range and the design basis values that are used in the accident and transient analysis. In all cases the design basis value represents the conservative end of the range. For the thermalhydraulic analysis the primary flow is assumed to split between the inner and outer plenums at $145.1 \mathrm{l} / \mathrm{s}(2,300 \mathrm{gpm})$ and $403.8 \mathrm{l} / \mathrm{s}(6,400 \mathrm{gpm})$, respectively. This flow distribution is based on historic flow measurements that indicated a minimum flow of 6,411 gpm to the outer plenum, where the most limiting fuel element is located. The pressure of the cover gas above the core is only slightly above atmospheric and for simplicity all analyses are done with the assumption that the pressure in the cover gas region is constant at one atmosphere.

Table 4-1 Steady-State Operating Conditions

\begin{tabular}{|c|c|c|c|}
\hline Parameter & Alarm & Normal Operating Range & $\begin{array}{c}\text { Design Basis } \\
\text { Value }\end{array}$ \\
\hline \multirow{3}{*}{ Reactor Power ${ }^{(1)}$} & High & $102 \%$ (Alarm - servo deviation) & \multirow{3}{*}{$\begin{array}{c}20.4 \mathrm{MW} \\
(102 \%)\end{array}$} \\
\hline & Normal & $100 \%$ (Normal - servo deviation: $\pm 0.5 \%$ ) & \\
\hline & Low & $98 \%$ (Alarm - servo deviation) & \\
\hline \multirow{3}{*}{$\begin{array}{c}\text { Reactor Water } \\
\text { Level }^{(2)}\end{array}$} & High & 164 in (Alarm) & \multirow{3}{*}{$\begin{array}{l}3.81 \mathrm{~m} \\
(150 \mathrm{in})\end{array}$} \\
\hline & Normal & 159 in (Normal) & \\
\hline & Low & 150 in (Alarm) & \\
\hline \multirow{3}{*}{$\begin{array}{c}\text { Core Inlet } \\
\text { Temperature }\end{array}$} & High & $110^{\circ} \mathrm{F}$ (Alarm) & \multirow{3}{*}{$\begin{array}{l}316.5 \mathrm{~K} \\
\left(110^{\circ} \mathrm{F}\right)\end{array}$} \\
\hline & Normal & $100^{\circ} \mathrm{F}$ (Normal) & \\
\hline & Low & $80^{\circ} \mathrm{F}$ (Alarm) & \\
\hline \multirow{3}{*}{ Primary Flow ${ }^{(3)}$} & High & $9,000 \mathrm{gpm}$ & \multirow{3}{*}{$\begin{array}{c}548.9 \mathrm{l} / \mathrm{s} \\
(8,700 \mathrm{gpm})\end{array}$} \\
\hline & Normal & $8,800 \mathrm{gpm}$ & \\
\hline & Low & $8,700 \mathrm{gpm}$ & \\
\hline \multirow{3}{*}{$\begin{array}{l}\text { Pressure Above } \\
\text { Core }^{(4)}\end{array}$} & High & $0.37 \mathrm{psig}$ & \multirow{3}{*}{$\begin{array}{c}1.01 \mathrm{kPa} \\
(0.0 \mathrm{psig})\end{array}$} \\
\hline & Normal & $0.15 \mathrm{psig}$ & \\
\hline & Low & $0.00 \mathrm{psig}$ & \\
\hline
\end{tabular}

Notes ${ }^{(1)}$ Rated reactor power is $20 \mathrm{MW}$.

${ }^{(2)}$ Reactor water level is referenced to the bottom of the lower grid plate.

${ }^{(3)}$ There is no alarm on primary flow. The range of flow is defined by different combinations of main pumps. The ideal and high operating flow is $2,300 \mathrm{gpm}$ to the 
inner plenum and 6,700 gpm to the outer plenum while the actual total flow with three pumps is 8,800 gpm.

${ }^{(4)}$ This is the pressure of the helium cover gas.

RELAP5 has been run to establish the steady-state operating conditions which are used as initial conditions in the postulated NBSR accident analysis. The reactor is assumed to be operating with all critical parameters at the most unfavorable extreme value of their normal range. This assures that the analysis for each accident scenario uses the worst case initial conditions that might be anticipated, within the normal limits of operation.

Two types of fuel, HEU and LEU, are considered in the analysis and two conditions in the equilibrium fuel cycle; startup (SU) and end-of-cycle (EOC). The steady-state operating conditions predicted by RELAP5 are compared to the design values (see Table 4-1) in Table 4-2. As shown in Table 4-2, calculated steady state values are in good agreement with the reference ones and conservative in the reactor water level.

Table 4-2 Comparison of Steady-State Operating Conditions

\begin{tabular}{|c|c|c|c|c|c|}
\hline \multirow{3}{*}{ Parameters } & \multirow{3}{*}{$\begin{array}{c}\text { Design } \\
\text { Basis Value }\end{array}$} & \multicolumn{4}{|c|}{ RELAP5 Predictions } \\
\hline & & \multicolumn{2}{|c|}{ HEU } & \multicolumn{2}{|c|}{ LEU } \\
\hline & & SU Core & EOC Core & SU Core & EOC Core \\
\hline Reactor Power & $\begin{array}{c}20.4 \mathrm{MW} \\
(102 \%)\end{array}$ & $\begin{array}{c}20.4 \mathrm{MW} \\
(\Delta=0.0 \%)\end{array}$ & $\begin{array}{c}20.4 \mathrm{MW} \\
(\Delta=0.0 \%)\end{array}$ & $\begin{array}{c}20.4 \mathrm{MW} \\
(\Delta=0.0 \%)\end{array}$ & $\begin{array}{c}20.4 \mathrm{MW} \\
(\Delta=0.0 \%)\end{array}$ \\
\hline $\begin{array}{l}\text { Reactor Water } \\
\text { Level }\end{array}$ & $\begin{array}{l}3.81 \mathrm{~m} \\
(150 \mathrm{in})\end{array}$ & $\begin{array}{c}3.64^{(1)} \mathrm{m} \\
(\Delta=-4.4 \%)\end{array}$ & $\begin{array}{c}3.64^{(1)} \mathrm{m} \\
(\Delta=-4.4 \%)\end{array}$ & $\begin{array}{c}3.64^{(1)} \mathrm{m} \\
(\Delta=-4.4 \%)\end{array}$ & $\begin{array}{c}3.64^{(1)} \mathrm{m} \\
(\Delta=-4.4 \%)\end{array}$ \\
\hline $\begin{array}{l}\text { Core Inlet } \\
\text { Temperature }\end{array}$ & $\begin{array}{l}316.5 \mathrm{~K} \\
\left(110^{\circ} \mathrm{F}\right)\end{array}$ & $\begin{array}{c}316.7 \mathrm{~K} \\
(\Delta=0.1 \%)\end{array}$ & $\begin{array}{c}316.7 \mathrm{~K} \\
(\Delta=0.1 \%)\end{array}$ & $\begin{array}{c}316.7 \mathrm{~K} \\
(\Delta=0.1 \%)\end{array}$ & $\begin{array}{c}316.7 \mathrm{~K} \\
(\Delta=0.1 \%)\end{array}$ \\
\hline $\begin{array}{l}\text { Primary Flow to } \\
\text { Inner Plenum }\end{array}$ & $\begin{array}{c}145.1 \mathrm{l} / \mathrm{s} \\
(2,300 \mathrm{gpm})\end{array}$ & $\begin{array}{c}144.6 \ell / \mathrm{s} \\
(\Delta=-0.3 \%)\end{array}$ & $\begin{array}{c}144.6 \ell / \mathrm{s} \\
(\Delta=-0.3 \%)\end{array}$ & $\begin{array}{c}144.6 \ell / \mathrm{s} \\
(\Delta=-0.3 \%)\end{array}$ & $\begin{array}{c}144.6 \ell / \mathrm{s} \\
(\Delta=-0.3 \%)\end{array}$ \\
\hline $\begin{array}{l}\text { Primary Flow to } \\
\text { Outer Plenum }\end{array}$ & $\begin{array}{c}403.8 \mathrm{l} / \mathrm{s} \\
(6,400 \mathrm{gpm})\end{array}$ & $\begin{array}{c}402.9 \ell / \mathrm{s} \\
(\Delta=-0.2 \%)\end{array}$ & $\begin{array}{c}402.9 \ell / \mathrm{s} \\
(\Delta=-0.2 \%)\end{array}$ & $\begin{array}{c}402.9 \ell / \mathrm{s} \\
(\Delta=-0.2 \%)\end{array}$ & $\begin{array}{c}402.9 \ell / \mathrm{s} \\
(\Delta=-0.2 \%)\end{array}$ \\
\hline $\begin{array}{l}\text { Pressure Above } \\
\text { Core }\end{array}$ & $\begin{array}{l}1.01 \mathrm{kPa} \\
(0.0 \mathrm{psig})\end{array}$ & $\begin{array}{c}1.01 \mathrm{kPa} \\
(\Delta=0.0 \%)\end{array}$ & $\begin{array}{c}1.01 \mathrm{kPa} \\
(\Delta=0.0 \%)\end{array}$ & $\begin{array}{c}1.01 \mathrm{kPa} \\
(\Delta=0.0 \%)\end{array}$ & $\begin{array}{c}1.01 \mathrm{kPa} \\
(\Delta=0.0 \%)\end{array}$ \\
\hline
\end{tabular}

Note ${ }^{(1)}$ While the design basis value of the reactor water level is $3.81 \mathrm{~m}$, the RELAP5 only extends to a level of $3.64 \mathrm{~m}$. This has an insignificant effect but, where relevant, it is conservative because it means less coolant inventory in the reactor. 


\subsection{Reactivity Accidents}

\subsubsection{Startup Accident}

\subsubsection{Simulation of Accident}

A startup accident model was modeled using assumptions to maximize the reactivity insertion. The reactor is assumed to be initially critical at a power level of $100 \mathrm{~W}$. Contrary to operating procedures and all previous training and experience, the operator is then assumed to withdraw the shim arms steadily without any pause, until the reactor is scrammed by a high power level trip. The accident model uses a reactivity insertion rate for the shim arm withdrawal equal to $5 \times 10^{-4} \Delta \mathrm{k} / \mathrm{k} / \mathrm{s}$. This rate is greater than the maximum measured and calculated (from the results shown in Figure 3-13 and Figure 3-14) rate at any shim arm initial position.

The shim arms are assumed to trip from what would be their initial critical position at full power (22. $6^{\circ}$ with the HEU fuel at the SU equilibrium core, $23.3^{\circ}$ with the LEU fuel at SU, and $41^{\circ}$ with the HEU and LEU fuels at EOC as shown in Figure 3-13 and Figure 3-14). The trip is due to a high power signal. The high power level trip is set to $26 \mathrm{MW}$ (130\% of full power). This is conservative because the setting is actually at $125 \%$ of power. For conservatism the calculation does not consider any fuel or moderator reactivity feedback and does not consider the period scram which is active below $2 \mathrm{MW}$.

\subsubsection{Reactor Power}

The predicted reactor power is shown in Figure 4-1 from time zero to $300 \mathrm{~s}$ and in Figure 4-2 from 12 to $18 \mathrm{~s}$. The power increases exponentially and its increase becomes significant after 15 $\mathrm{s}$ in all cases. After reaching its peak, the power decreases suddenly as the shim arm is inserted after the reactor trip signal is generated and after a $0.0983 \mathrm{~s}$ delay. Reactor trips occur at $16.34 \mathrm{~s}$ with the HEU core at EOC, 16.02 with the HEU core at SU, $15.97 \mathrm{~s}$ with the LEU core at EOC, and $15.66 \mathrm{~s}$ with the LEU core at SU, when reactor power reaches $26 \mathrm{MW}$. Table 4-3 and Table 4-4 show the predicted reactor trip times and the predicted reactor peak powers, respectively.

From Figure 4-2 and Table 4-3 it can be observed that the significant power increase starts earlier with the LEU fuels than with the HEU fuels. This is the result of the smaller delayed neutron fraction and shorter neutron lifetime with the LEU fuel. It is also observed that the power rises faster at SU than at EOC; a result primarily of the difference in neutron lifetime as a result of the shim arm presence at SU and absence at EOC.

Higher peak powers are predicted at EOC with both the HEU and LEU fuels. This results from the fact that the initial shim arm positions are different, and at EOC the rate of reactivity insertion from the shim arms after trip is lower. 
NBSR

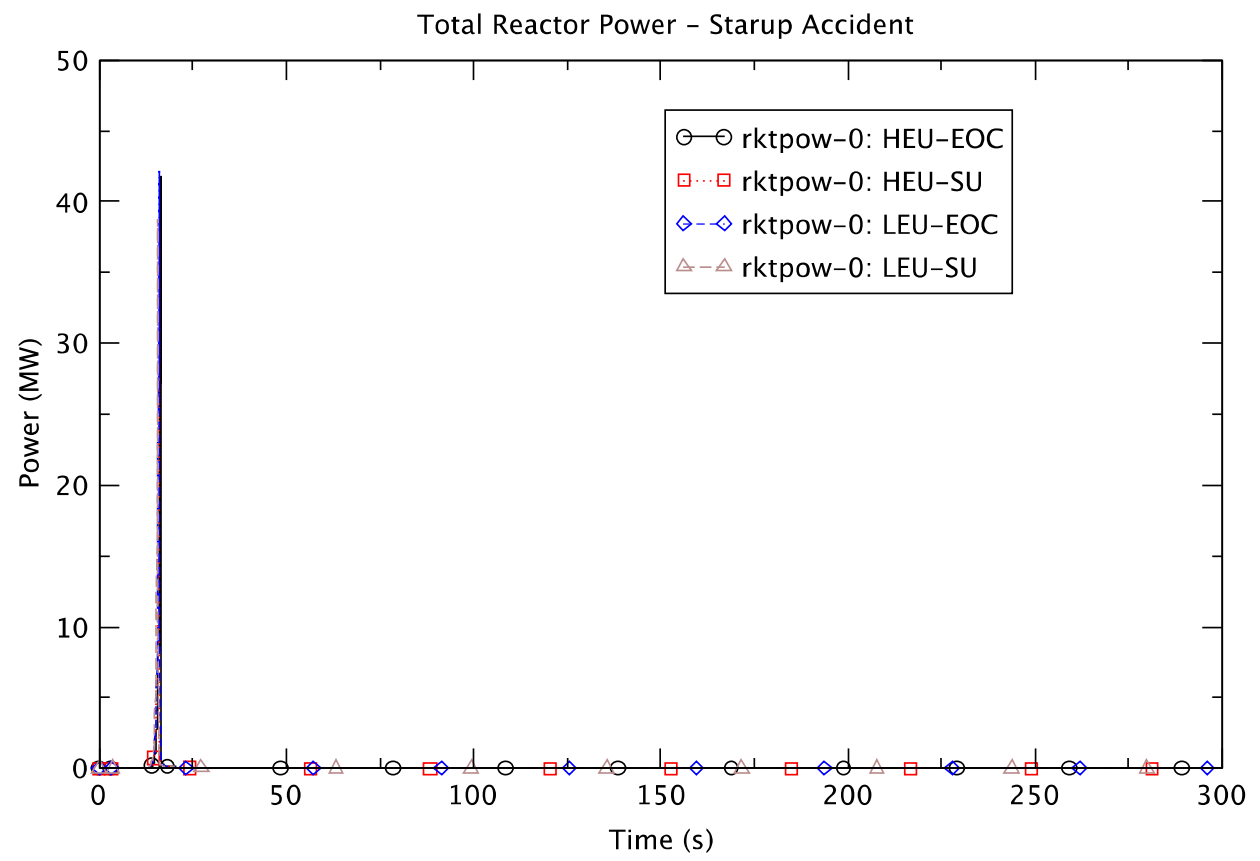

Figure 4-1 Reactor Power Responses in Startup Accident: Wide Range

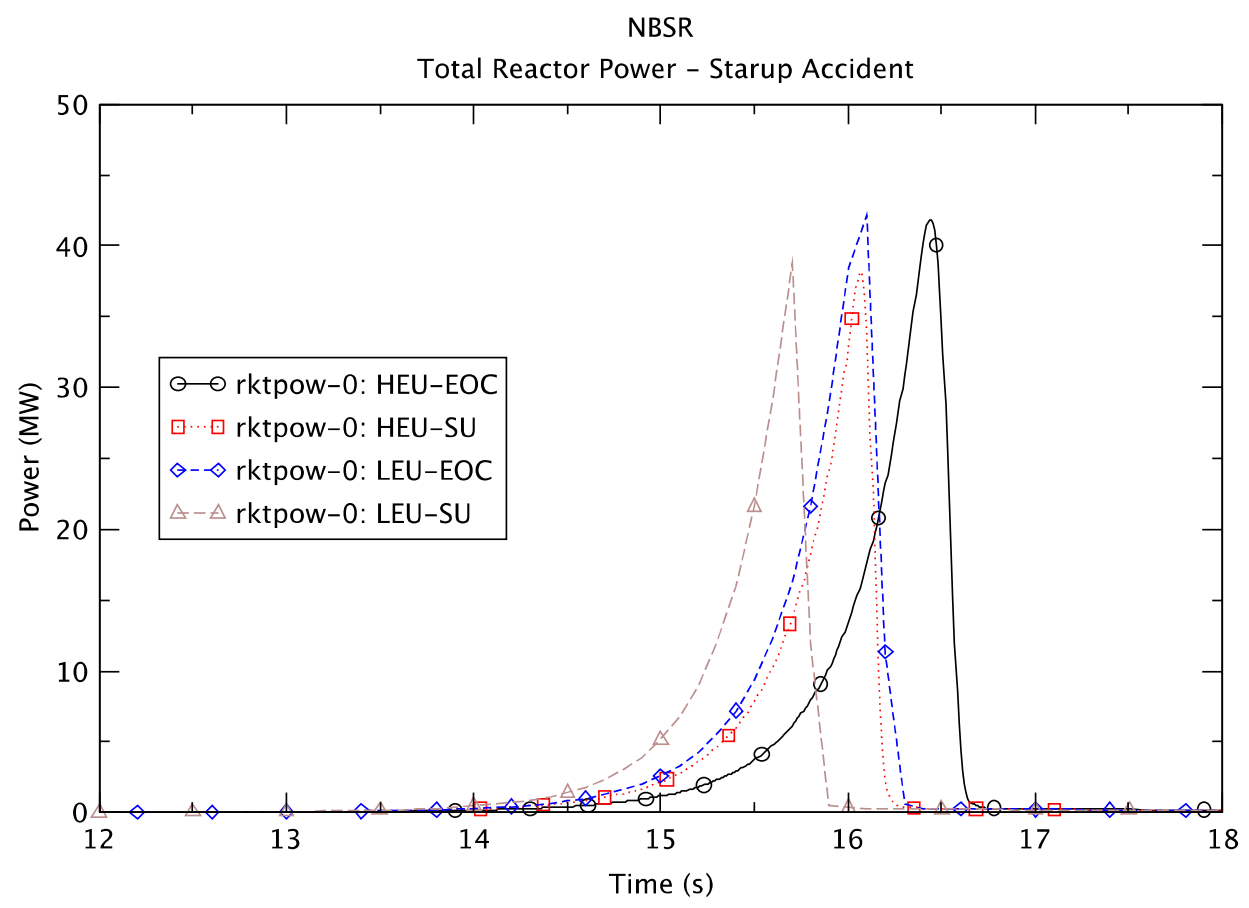

Figure 4-2 Reactor Power Responses in Startup Accident: Narrow Range 
Table 4-3 Reactor Trips and Occurring Times in Startup Accident

\begin{tabular}{|c|c|l|}
\hline Case & Time $(\mathrm{s})$ & Trip Type \\
\hline HEU EOC & 16.34 & High reactor power level \\
\hline HEU SU & 16.02 & High reactor power level \\
\hline LEU EOC & 15.97 & High reactor power level \\
\hline LEU SU & 15.66 & High reactor power level \\
\hline
\end{tabular}

Table 4-4 Reactor Peak Powers and Occurring Times in Startup Accident

\begin{tabular}{|c|c|c|}
\hline Case & Peak Power (MW) & Time (s) \\
\hline HEU EOC & 41.84 & 16.44 \\
\hline HEU SU & 38.15 & 16.06 \\
\hline LEU EOC & 42.15 & 16.10 \\
\hline LEU SU & 38.75 & 15.70 \\
\hline
\end{tabular}

\subsubsection{Fuel Temperature}

Figure 4-3 and Figure 4-4 show the cladding temperatures from time zero to $300 \mathrm{~s}$ and from 12 to $18 \mathrm{~s}$, respectively, in the fuel element nodes corresponding to where minimum CHFR occurs. As expected, the cladding temperature behavior is very similar to the power behavior shown in Figure 4-1 and Figure 4-2. The cladding temperatures start increasing exponentially from time zero. After reaching peak values between $15.7 \mathrm{~s}$ and $16.5 \mathrm{~s}$, they decrease rapidly due to the insertion of shim arms after reactor trip. The peak cladding temperatures and the temperature rises from the initial values are shown in Table 4-5 and they are less than $405 \mathrm{~K}$ (much lower than the expected blister temperatures) and $102 \mathrm{~K}$, respectively, in all cases. From these observations it can be deduced that the NBSR reactor is safe without fuel element damage. 
NBSR

Cladding Temperature Behavior - Startup Accident

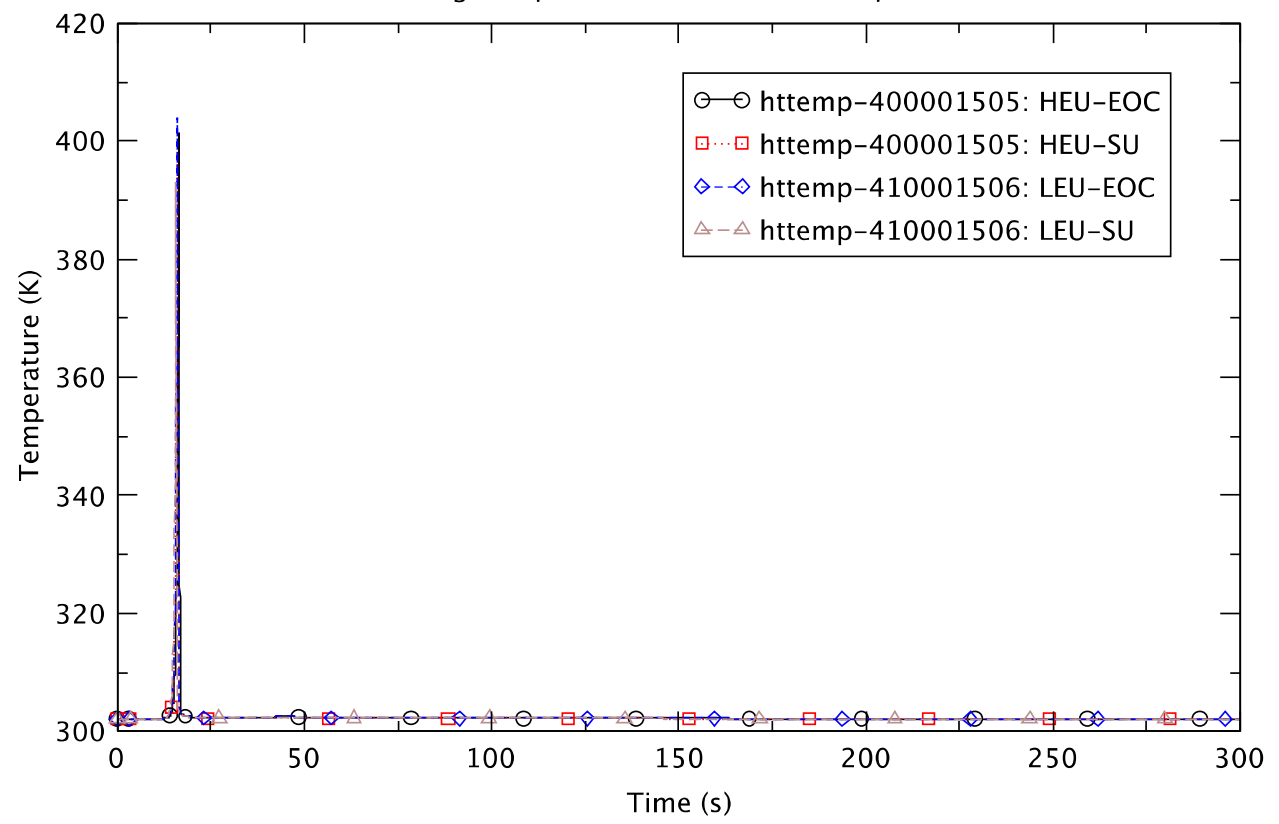

Figure 4-3 Cladding Temperatures in Startup Accident: Wide Range

NBSR

Cladding Temperature Behavior - Startup Accident

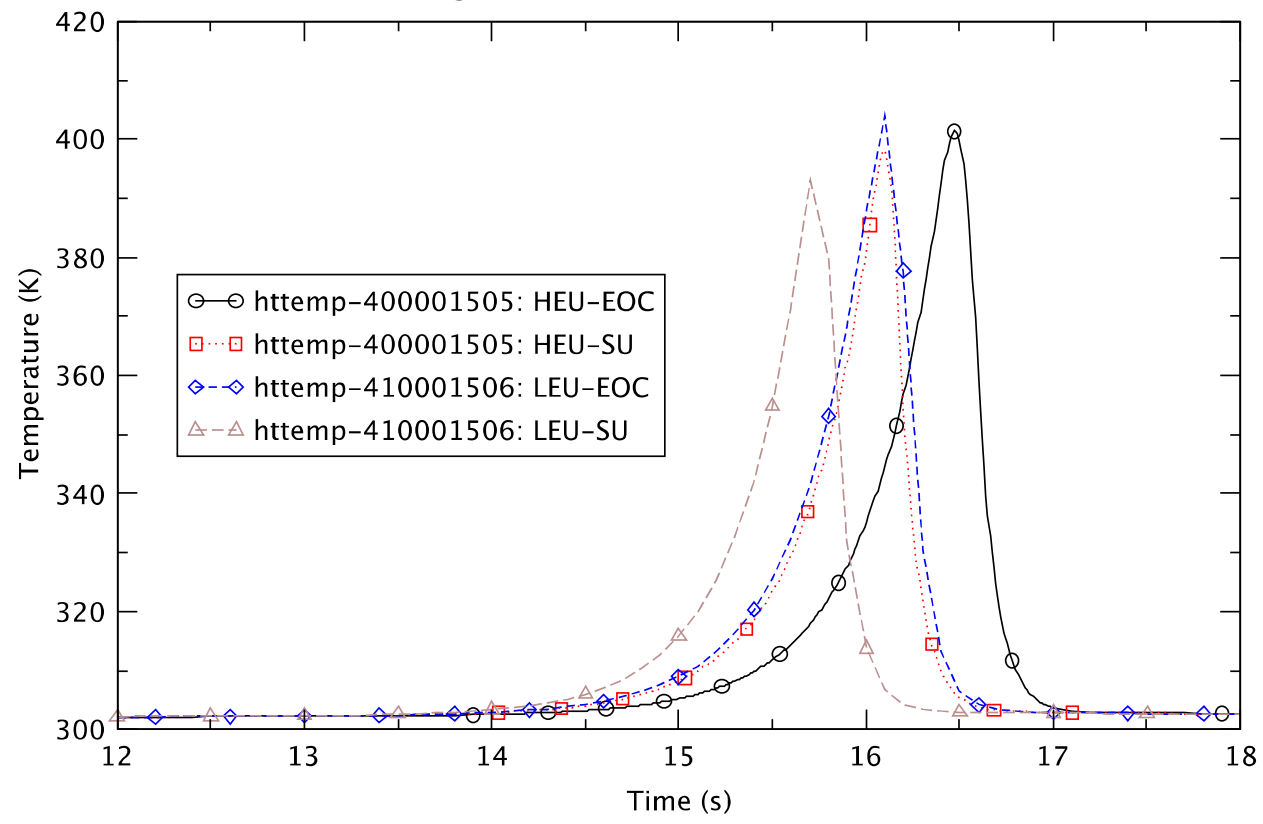

Figure 4-4 Cladding Temperatures in Startup Accident: Narrow Range 
Table 4-5 Peak Cladding Temperatures and Cladding Temperature Increases in Startup Accident

\begin{tabular}{|c|c|c|c|}
\hline Case & $\begin{array}{c}\text { Peak Cladding } \\
\text { Temperature (K) }\end{array}$ & Time (s) & $\begin{array}{c}\text { Temperature } \\
\text { Increase }(\mathrm{K})\end{array}$ \\
\hline HEU EOC & 401.4 & 16.47 & 99.3 \\
\hline HEU SU & 398.1 & 16.09 & 96.0 \\
\hline LEU EOC & 404.1 & 16.10 & 102.0 \\
\hline LEU SU & 392.9 & 15.70 & 90.8 \\
\hline
\end{tabular}

\subsubsection{Minimum CHFR}

Critical-heat-flux ratios are evaluated using Sudo-Kaminaga correlations (see Section 3.4.1) and are shown in Figure 4-5 from time zero to $300 \mathrm{~s}$ and in Figure 4-6 from 12 to $20 \mathrm{~s}$, respectively. The CHFR is very large initially because the initial power is only $100 \mathrm{~W}$. When the CHFR is larger than 1000, its value remains at 1000 in the figures. The nodes in the figures are the ones where minimum CHFR takes place among all the hydraulic nodes in the core region. As shown in those figures, the CHFRs reach minimum values between $15.5 \mathrm{~s}$ and $16.5 \mathrm{~s}$. Then they increase very rapidly and becomes larger than 1000 from about $19.5 \mathrm{~s}$ in all cases. The calculated minimum CHFRs are shown in Table 4-6.

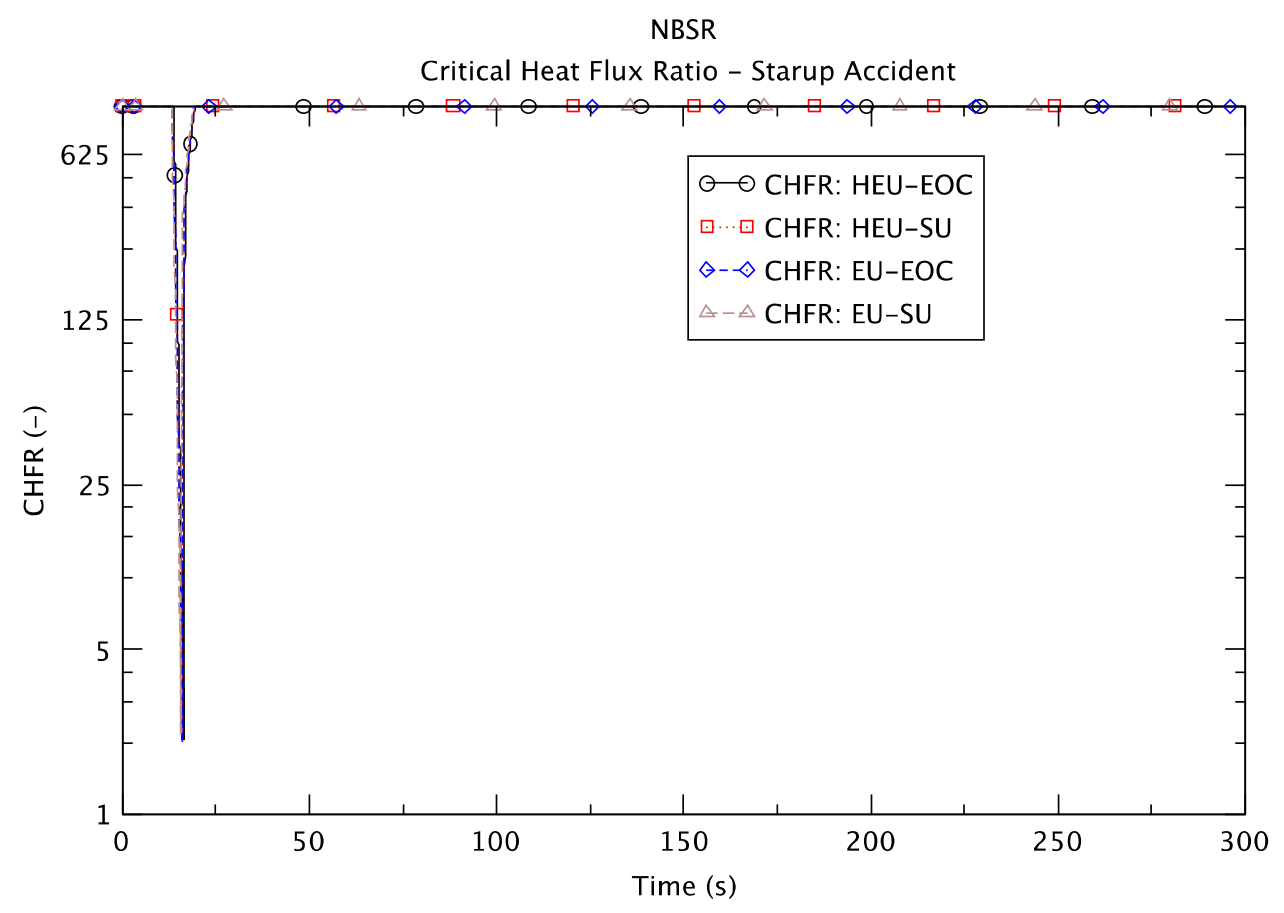

Figure 4-5 Critical-Heat-Flux Ratios in Startup Accident: Wide Range 


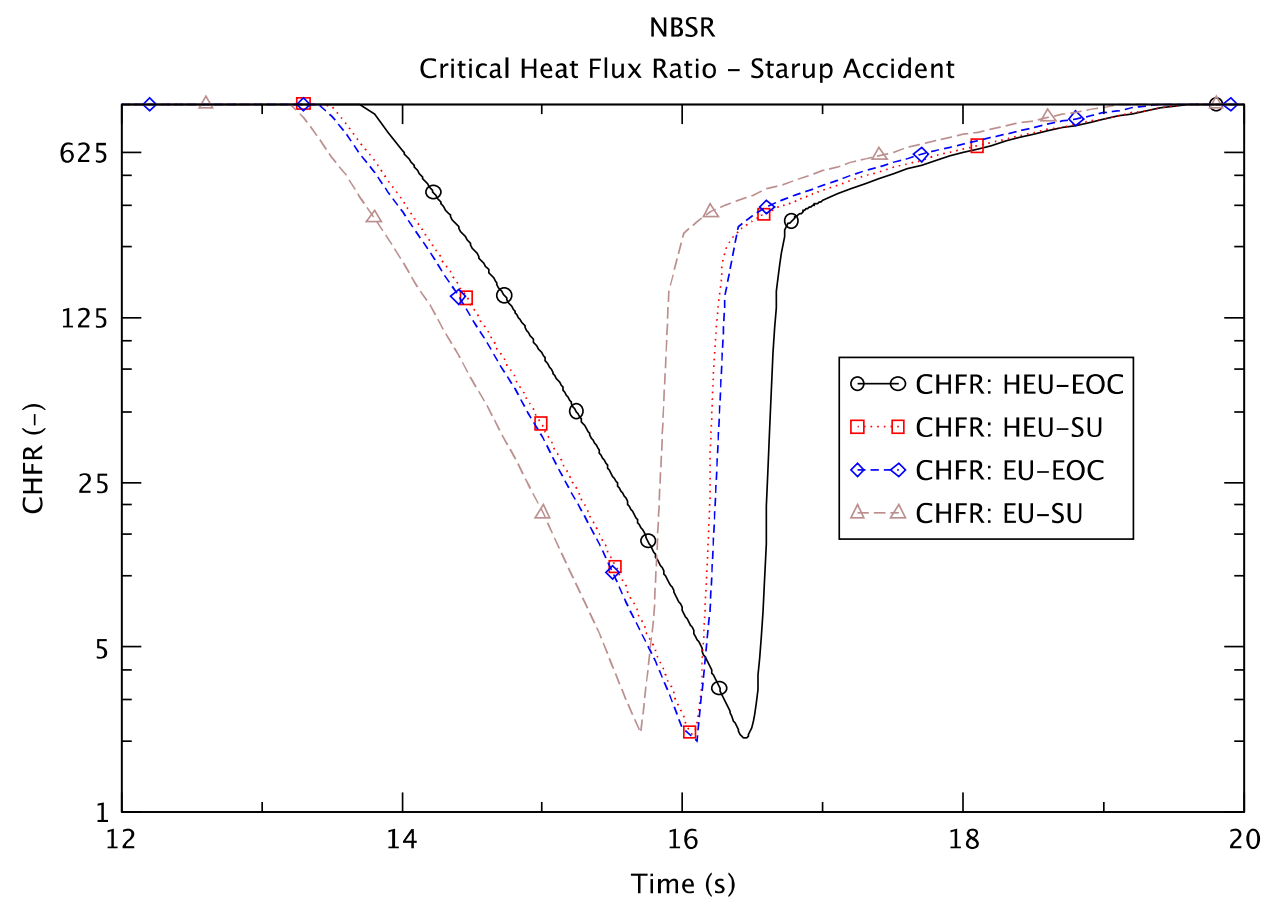

Figure 4-6 Critical-Heat-Flux Ratios in Startup Accident: Narrow Range

Table 4-6 Minimum CHFRs in Startup Accident

\begin{tabular}{|c|c|c|c|}
\hline Case & $\begin{array}{c}\text { Minimum } \\
\text { CHFR (-) }\end{array}$ & Time (s) & Hydraulic Node No. \\
\hline HEU EOC & 2.07 & 16.44 & $407-02^{(1)}$ \\
\hline HEU SU & 2.15 & 16.07 & $407-02^{(2)}$ \\
\hline LEU EOC & 2.00 & 16.10 & $417-02^{(3)}$ \\
\hline LEU SU & 2.18 & 15.70 & $417-02^{(4)}$ \\
\hline
\end{tabular}

Notes ${ }^{(1)}$ The minimum CHFR occurs in the node where the hottest cell (highest power cell in the core region) is located.

${ }^{(2)}$ The minimum CHFR occurs in the next heated (or powered) node above the one where the hottest cell is located.

${ }^{(3)}$ The minimum CHFR occurs in the node where the highest power cell in the hottest fuel stripe is located. This cell is different from the hottest cell among all cells in the core region.

${ }^{(4)}$ The minimum CHFR occurs in the next heated (or powered) node above the one where the highest power cell in the hottest fuel stripe is located.

It can be seen from Table 4-6 that the minimum CHFRs take place when the reactor power becomes highest (see Table 4-4) and are slightly larger at SU than at EOC with both of the HEU and LEU fuels. In the cases of the HEU fuel the minimum CHFR takes place in the flow channel where the hottest cell is located while in the cases of the LEU fuel it happens in the flow channel 
where the sum of each cell power of a fuel strip becomes highest. (See Table 3-3 for the nodalization scheme and Table 3-10 for the heat structure modeling.) The minimum CHFR occurs in the hottest hydraulic cell of the given flow channel at EOC while it happens in the next powered node above the hottest hydraulic cell of the given flow channel at SU.

It is observed from Figure 4-6 and Table 4-6 that the minimum CHFRs are all larger than 1.78 for the HEU fuel and 1.86 for the LEU fuel. This means that with either HEU or LEU fuel the probability of precluding CHF in this accident is greater than $99.9 \%$ (see Table 3-12).

\subsubsection{Minimum OFIR}

Onset-of-flow-instability ratios, evaluated using the Saha-Zuber criteria (see Section 3.4.2), are shown in Figure 4-7 from time zero to $300 \mathrm{~s}$ and in Figure 4-8 from 12 to $20 \mathrm{~s}$, respectively. When the OFIR is larger than 1000, its value remains to be 1000 in the figures. The nodes in the figures are the ones where minimum OFIRs take place among all hydraulic nodes in the core region. As shown in those figures, the OFIRs reach minimum values between $15.5 \mathrm{~s}$ and $16.5 \mathrm{~s}$. Then they increase very rapidly and becomes larger than 1000 from about $19.5 \mathrm{~s}$ in all cases. The minimum OFIRs are shown in Table 4-7.

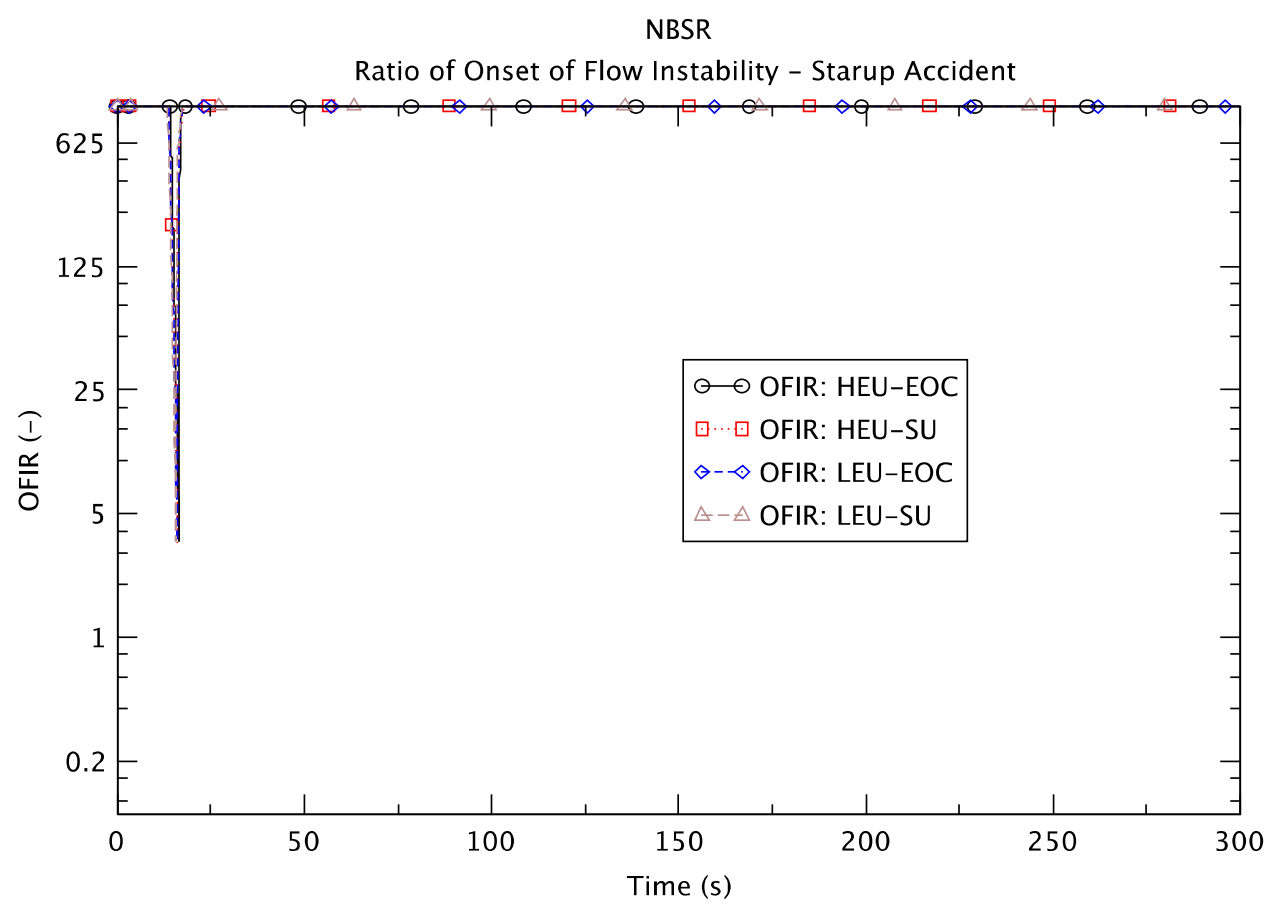

Figure 4-7 Onset-of-Flow-Instability Ratios in Startup Accident: Narrow Range 


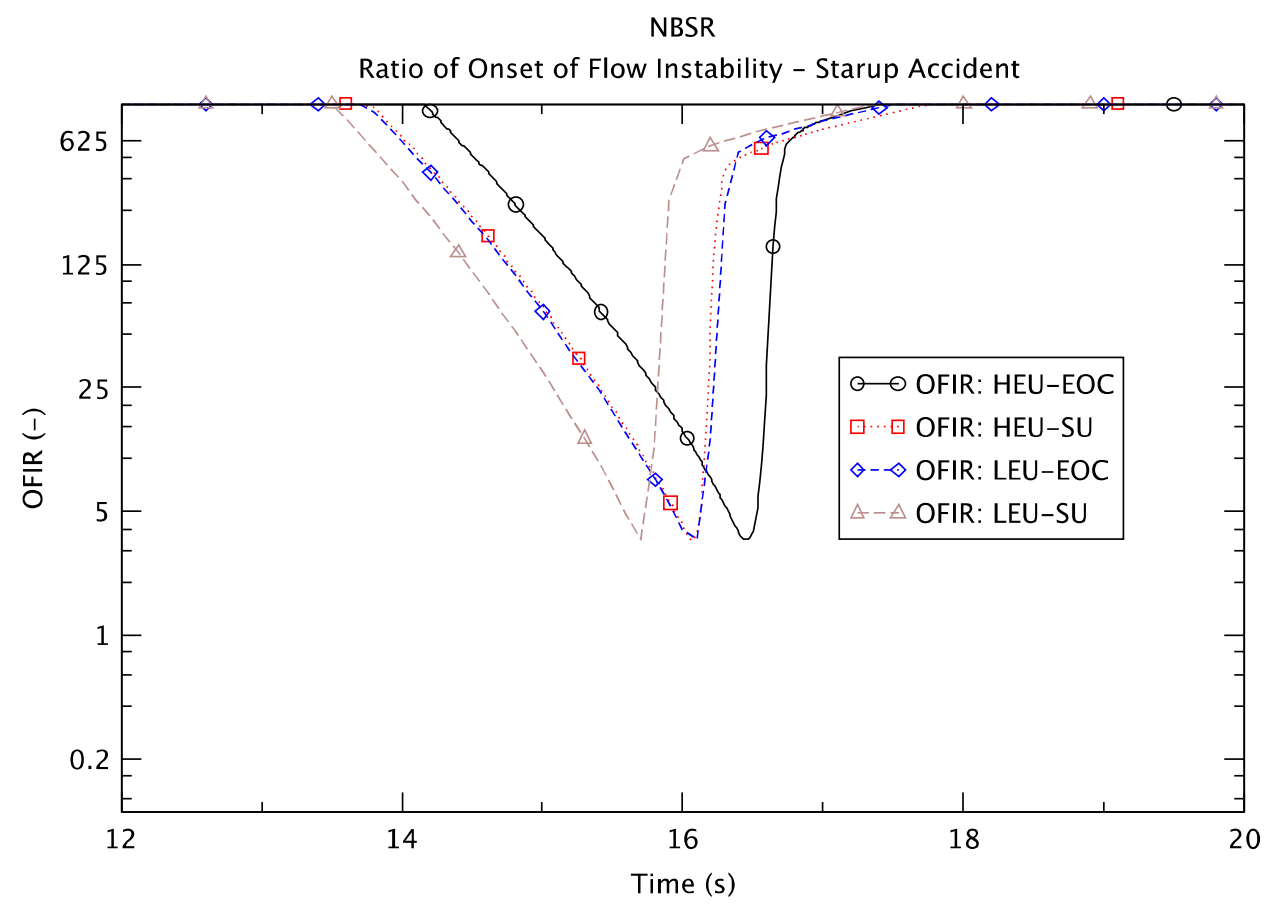

Figure 4-8 Onset-of-Flow-Instability Ratios in Startup Accident: Narrow Range

Table 4-7 Minimum OFIRs in Startup Accident

\begin{tabular}{|c|c|c|c|}
\hline Case & $\begin{array}{c}\text { Minimum } \\
\text { OFIR (-) }\end{array}$ & Time (s) & Hydraulic Node No. \\
\hline HEU EOC & 3.45 & 16.45 & $417-15^{(1)}$ \\
\hline HEU SU & 3.43 & 16.07 & $503-15^{(2)}$ \\
\hline LEU EOC & 3.46 & 16.10 & $417-02^{(3)}$ \\
\hline LEU SU & 3.46 & 15.70 & $503-15^{(2)}$ \\
\hline
\end{tabular}

Notes ${ }^{(1)}$ The minimum OFIR occurs in the powered top node of the flow channel with the hottest fuel stripe.

${ }^{(2)}$ The minimum OFIR occurs in the hottest node (highest power cell in the core region). The flow channel with this node has a mid-plane gap shared with the flow channel for 16 average fuel plates.

${ }^{(3)}$ The minimum OFIR occurs in the hottest node of the hottest stripe channel.

Table 4-7 shows that the minimum OFIR takes place when the reactor power is highest and the calculated values are very similar in all cases. In the case of the HEU fuel at EOC the minimum OFIR occurs in the powered top node of the flow channel for the hottest fuel stripe while in the case of the LEU fuel at EOC it happens in the highest power node in the channel containing the hottest fuel stripe. In the SU cases with either HEU or LEU fuel, the minimum OFIR occurs in the hottest node but its flow channel contains a mid-plane gap as shown in Figure 3-1 and 
explained in Table 3-3. From this observation it can be deduced that there is no favorable place for minimum OFIR to occur.

It is observed from Figure 4-8 and Table 4-7 that the evaluated minimum OFIRs are all much larger than 1.58 for the HEU fuel and 1.73 for the LEU fuel. This means that with either HEU or LEU fuel onset-of-flow-instability is precluded with a probability greater than $99.9 \%$ (see Table 3-13).

\subsubsection{Summary}

In the startup accident, the general system behavior with LEU fuel is very similar to that with HEU fuel. The reactor power increases exponentially due to the constant positive reactivity insertion of $\quad \Delta \mathrm{k} / \mathrm{k} / \mathrm{s}$ and drops very rapidly after shim arms are inserted after a reactor trip signal. Cladding temperature rises owing to the power increase. The highest peak cladding temperature occurs in the case of the LEU fuel at EOC and is $404 \mathrm{~K}$ (much lower than the expected blister temperatures) corresponding to a temperature rise of about $102 \mathrm{~K}$. Hence, no fuel damage is expected in the startup accident with either HEU or LEU fuel.

Minimum CHFR and OFIR are evaluated in all hydraulic nodes in the core region and they are all higher than the value needed to assure no problem with a probability of $99.9 \%$.

\subsubsection{Maximum Reactivity Insertion Accident}

\subsubsection{Simulation of Accident}

The maximum reactivity insertion accident is analyzed using the RELAP5 point kinetics model discussed in Section 3.3.6. For conservatism the calculation does not consider any fuel or moderator reactivity feedback. For this accident a ramp reactivity insertion of $0.005 \Delta \mathrm{k} / \mathrm{k}$ is assumed to occur in $0.5 \mathrm{~s}$. This amount of reactivity is the Technical Specification limit for the reactivity of any experiement.

\subsubsection{Reactor Power}

The predicted reactor powers are shown in Figure 4-9 from time zero to $300 \mathrm{~s}$ and Figure 4-10 from time zero to $2 \mathrm{~s}$. The power increases exponentially from $20.4 \mathrm{MW}$ at time zero and reaches its peak at $0.39 \mathrm{~s}$ in both SU cases and at $0.46 \mathrm{~s}$ in both EOC cases. Then the power decreases suddenly as the shim arms are inserted into the core region after reactor trip signal is generated. Reactor trip at $26 \mathrm{MW}$ occurs for the HEU core at $0.37 \mathrm{~s}$ at EOC and $0.36 \mathrm{~s}$ at SU, and for the LEU core at $0.36 \mathrm{~s}$ at EOC and $0.35 \mathrm{~s}$ at SU.

Table 4-8 and Table 4-9 show the predicted reactor trip times and the predicted reactor peak powers, respectively.

From Figure 4-10 it can be observed that the power increase starts slightly earlier with the LEU fuels than with the HEU fuels. It is also observed that the power rises slightly faster at SU at EOC. These results are similar to what was observed for the startup accident. 


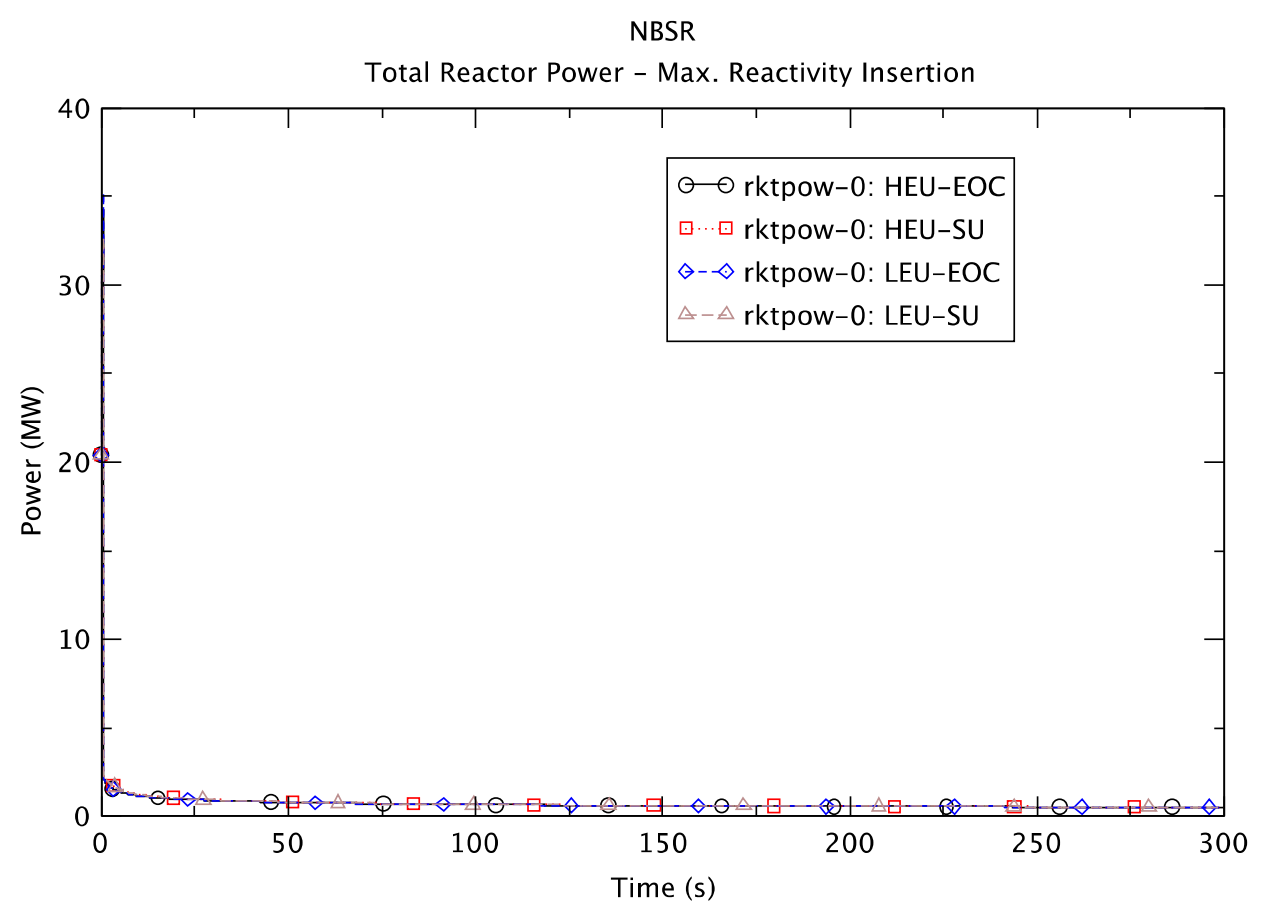

Figure 4-9 Reactor Powers Responses in Maximum Reactivity Insertion Accident: Wide Range

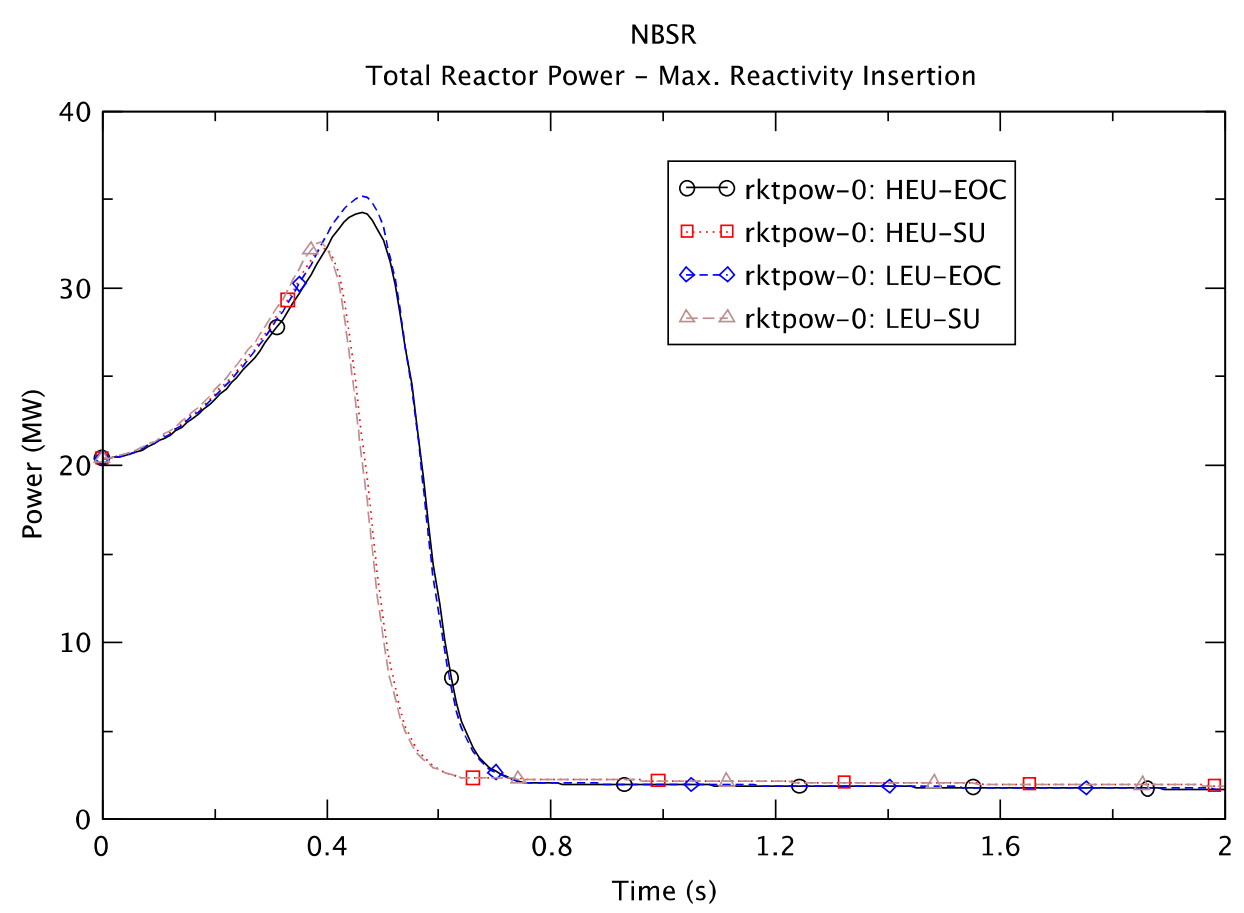




\section{Figure 4-10 Reactor Power Responses in Maximum Reactivity Insertion Accident: Narrow Range}

As shown in Table 4-9 higher peak powers are predicted at EOC than at SU with both of the HEU and LEU fuels and this results from the fact that the initial shim arm positions are different, $41^{\circ}$ at EOC and about $23^{\circ}$ at SU as shown in Figure 3-13 and Figure 3-14, and this causes smaller initial negative reactivity insertion rate after the reactor tip at EOC.

Table 4-8 Reactor Trips and Occurring Times in Maximum Reactivity Insertion Accident

\begin{tabular}{|c|c|l|}
\hline Case & Time $(\mathrm{s})$ & \multicolumn{1}{c|}{ Trip Type } \\
\hline HEU EOC & 0.37 & High reactor power level \\
\hline HEU SU & 0.36 & High reactor power level \\
\hline LEU EOC & 0.36 & High reactor power level \\
\hline LEU SU & 0.35 & High reactor power level \\
\hline
\end{tabular}

Table 4-9 Reactor Peak Powers and Occurring Times in Maximum Reactivity Insertion Accident

\begin{tabular}{|c|c|c|}
\hline Case & Peak Power (MW) & Time (s) \\
\hline HEU EOC & 34.3 & 0.46 \\
\hline HEU SU & 32.3 & 0.39 \\
\hline LEU EOC & 35.2 & 0.46 \\
\hline LEU SU & 32.6 & 0.39 \\
\hline
\end{tabular}

\subsubsection{Fuel Temperature}

Figure 4-11 and Figure 4-12 compare the cladding temperatures from time zero to $300 \mathrm{~s}$ and from time zero to $2 \mathrm{~s}$, respectively, in the fuel element nodes corresponding to where minimum CHFRs occurs. As expected, the cladding temperature behavior is very similar to the power behavior shown in Figure 4-9 and Figure 4-10. The cladding temperatures start increasing exponentially from time zero. After reaching peak values between $0.42 \mathrm{~s}$ and $0.5 \mathrm{~s}$, they decrease rapidly due to the insertion of shim arms after the reactor trip signal. The peak cladding temperatures and the cladding temperature increases from the initial values are shown in Table 4-10 and they are less than $399 \mathrm{~K}$ (much lower than the expected blister temperatures) and $29 \mathrm{~K}$, respectively, in all cases. From these observations it can be deduced that the NBSR reactor would not experience fuel element damage during this event. 
NBSR

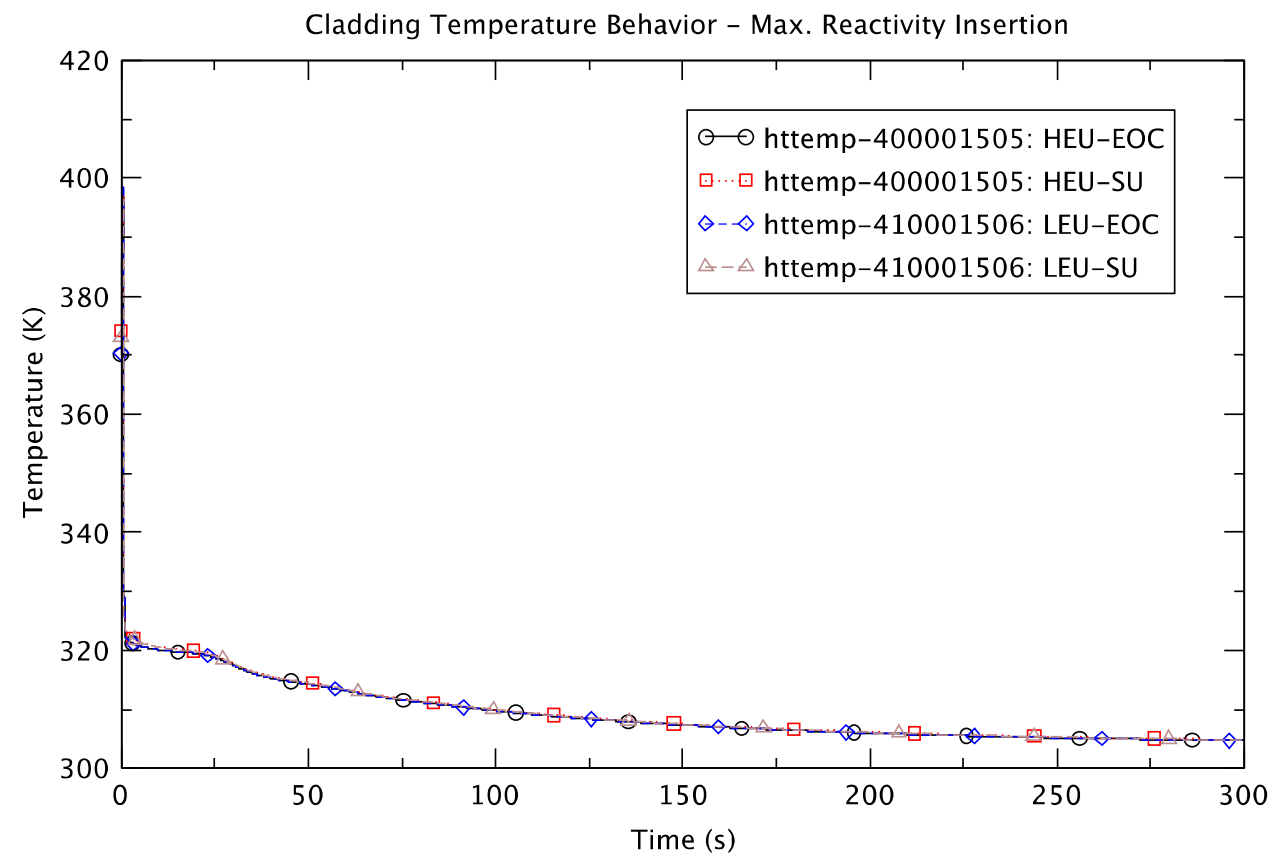

Figure 4-11 Cladding Temperatures in Maximum Reactivity Insertion Accident: Wide Range

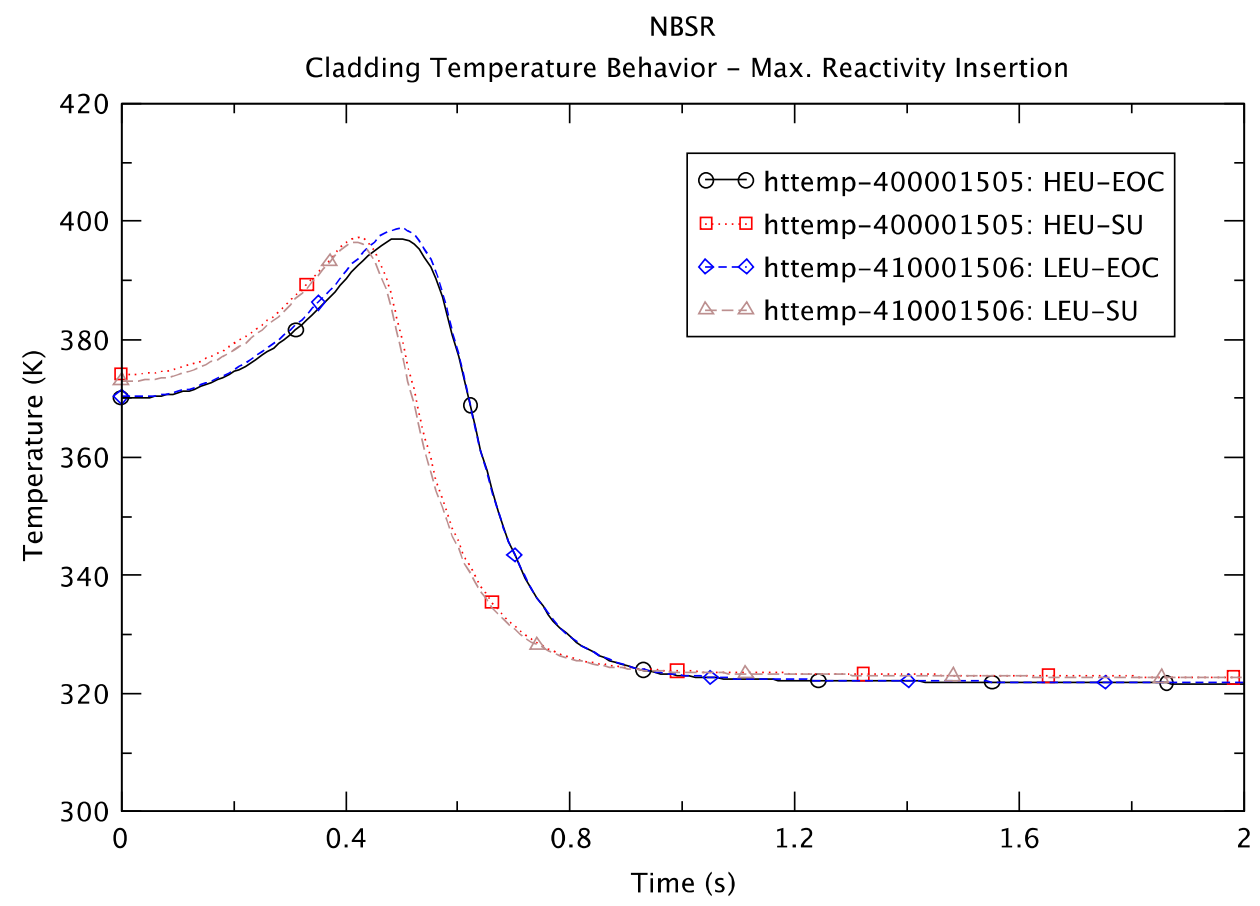

Figure 4-12 Cladding Temperatures in Maximum Reactivity Insertion Accident: Narrow Range 
Table 4-10 Peak Cladding Temperatures and Cladding Temperature Increases in Maximum Reactivity Insertion Accident

\begin{tabular}{|c|c|c|c|}
\hline Case & $\begin{array}{c}\text { Peak Cladding } \\
\text { Temperature }(\mathrm{K})\end{array}$ & Time $(\mathrm{s})$ & $\begin{array}{c}\text { Temperature } \\
\text { Increase }(\mathrm{K})\end{array}$ \\
\hline HEU EOC & 397.1 & 0.49 & 27.1 \\
\hline HEU SU & 397.3 & 0.42 & 23.2 \\
\hline LEU EOC & 398.8 & 0.50 & 28.6 \\
\hline LEU SU & 396.5 & 0.42 & 23.5 \\
\hline
\end{tabular}

\subsubsection{Minimum CHFR}

Critical-heat-flux ratios are evaluated using Sudo-Kaminaga correlations (see Section 3.4.1) and the evaluated CHFR behaviors are shown in Figure 4-13 from time zero to $300 \mathrm{~s}$ and in Figure 4-14 from time zero to $2 \mathrm{~s}$. The nodes in the figures are where minimum CHFR takes place among all the hydraulic nodes in the core region. As shown in those figures, the CHFRs reach minimum values between $0.39 \mathrm{~s}$ and $0.47 \mathrm{~s}$. Then they increase very rapidly and become larger than 37 from $1.0 \mathrm{~s}$ in all cases. The calculated minimum CHFRs are shown in Table 4-11.

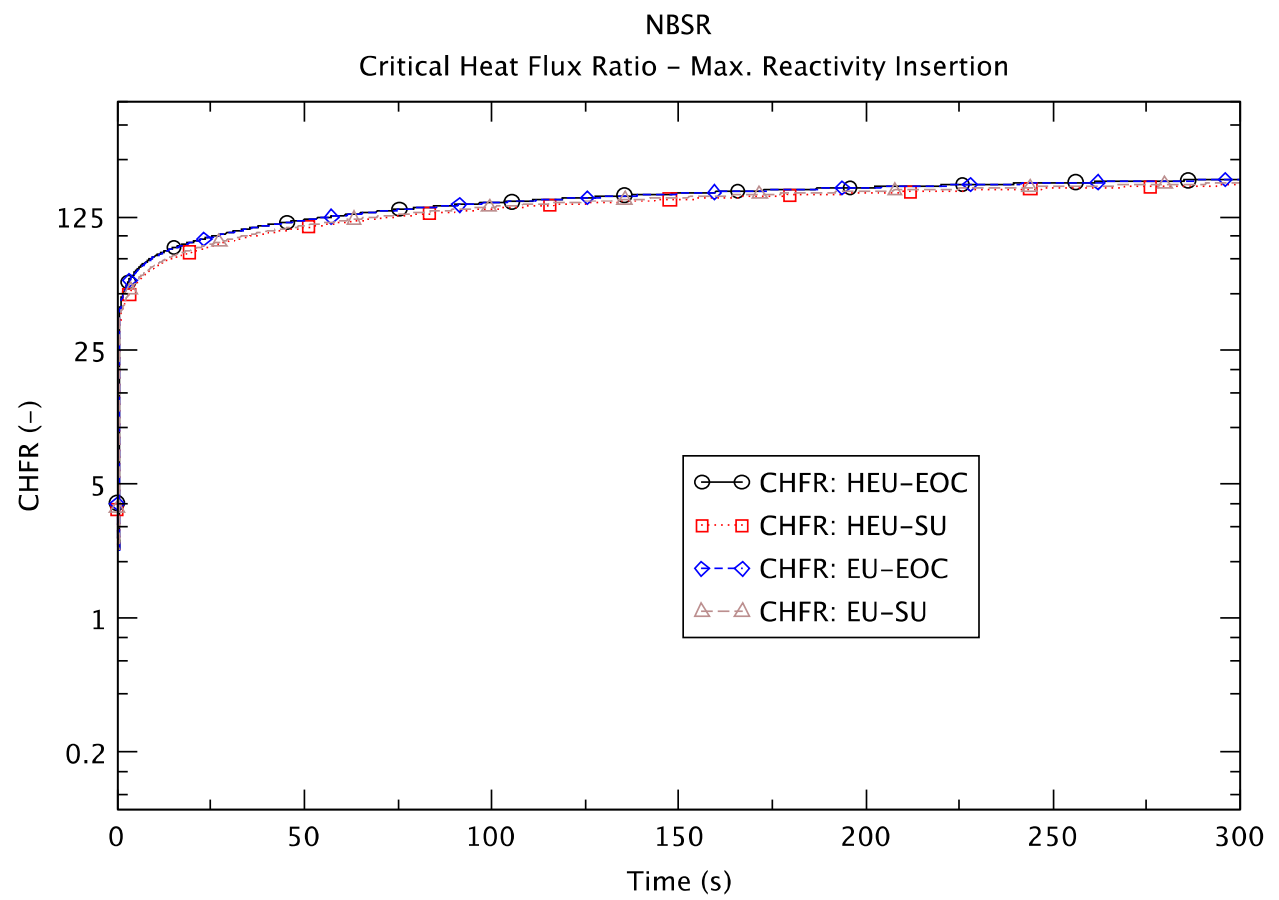

Figure 4-13 Critical-Heat-Flux Ratios in Maximum Reactivity Insertion Accident: Wide Range 


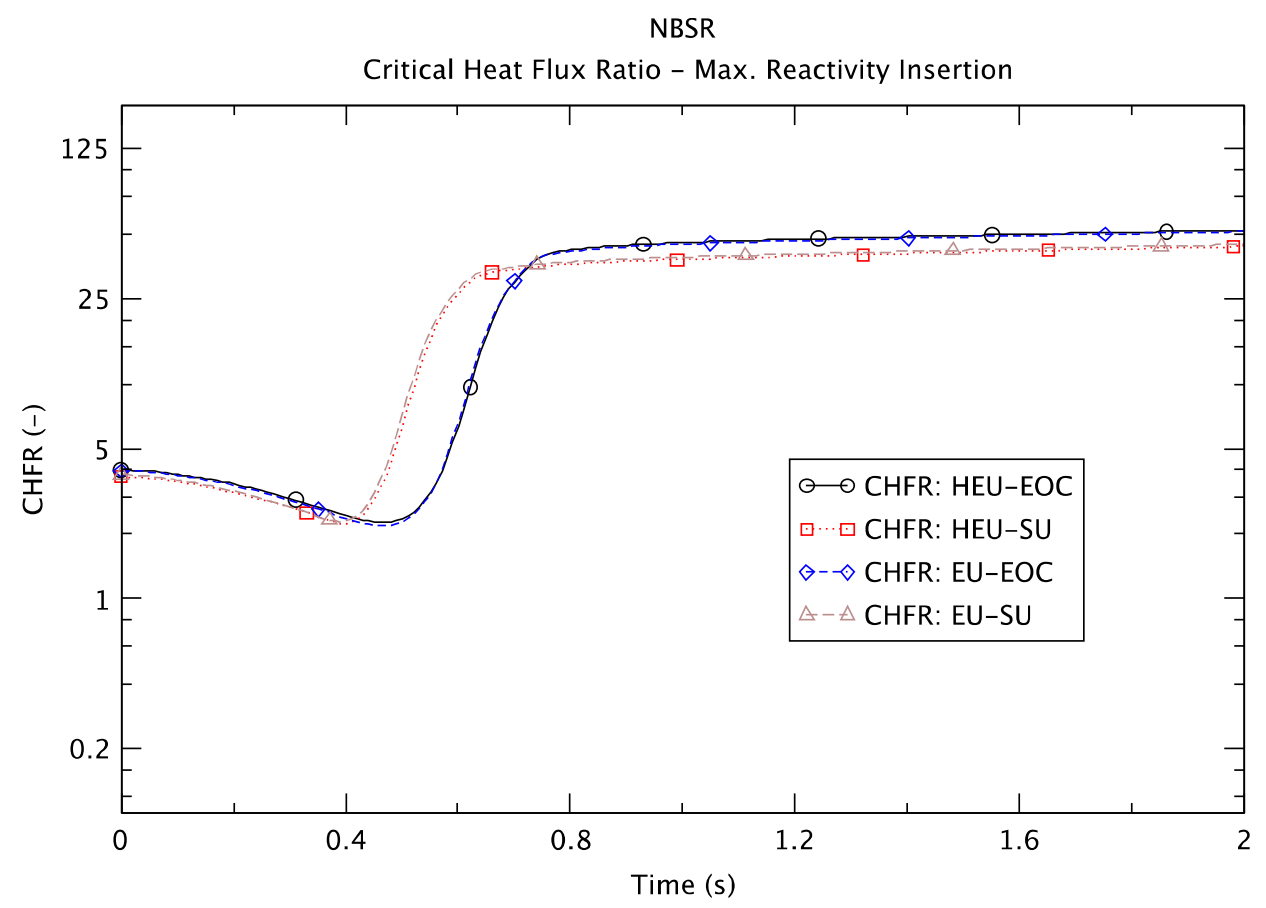

Figure 4-14 Critical-Heat-Flux Ratios in Maximum Reactivity Insertion Accident: Narrow Range

Table 4-11 Minimum CHFRs in Maximum Reactivity Insertion Accident

\begin{tabular}{|c|c|c|c|}
\hline Case & $\begin{array}{c}\text { Minimum } \\
\text { CHFR (-) }\end{array}$ & Time (s) & Hydraulic Node No. \\
\hline HEU EOC & 2.27 & 0.46 & $407-02^{(1)}$ \\
\hline HEU SU & 2.26 & 0.40 & $407-02^{(2)}$ \\
\hline LEU EOC & 2.19 & 0.47 & $417-02^{(3)}$ \\
\hline LEU SU & 2.29 & 0.39 & $417-02^{(4)}$ \\
\hline
\end{tabular}

Notes ${ }^{(1)}$ The minimum CHFR occurs in the node where the hottest cell (highest power cell in the core region) is located.

${ }^{(2)}$ The minimum CHFR occurs in the next heated (or powered) node above the one where the hottest cell is located.

${ }^{(3)}$ The minimum CHFR occurs in the node where the highest power cell in the hottest fuel stripe is located. This cell is different from the hottest cell among all cells in the core region.

${ }^{(4)}$ The minimum CHFR occurs in the next heated (or powered) node above the one where the highest power cell in the hottest fuel stripe is located.

It can be seen from Table 4-11 that the minimum CHFRs take place when the reactor power becomes highest (see Table 4-9) and are very similar with HEU and LEU fuel. It is observed from Figure 4-14 and Table 4-11 that the minimum CHFRs are all much larger than 1.78 for the 
HEU fuel and 1.86 for the LEU fuel. This indicates that with either HEU or LEU fuel the probability of precluding CHF is greater than $99.9 \%$ (see Table $3-12$ ).

\subsubsection{Minimum OFIR}

Onset-of-flow-instability ratios are evaluated using Saha-Zuber criteria (see Section 3.4.2) and are shown in Figure 4-15 from time zero to $300 \mathrm{~s}$ and in Figure 4-16 from time zero to $2 \mathrm{~s}$. The nodes in the figures are the ones where minimum OFIR occurs among all hydraulic nodes in the core region. The OFIRs reach minimum values between $0.39 \mathrm{~s}$ and $0.48 \mathrm{~s}$. Then they increase very rapidly and become larger than 38 from $1.0 \mathrm{~s}$ in all cases. The minimum OFIRs are shown in Table 4-12.

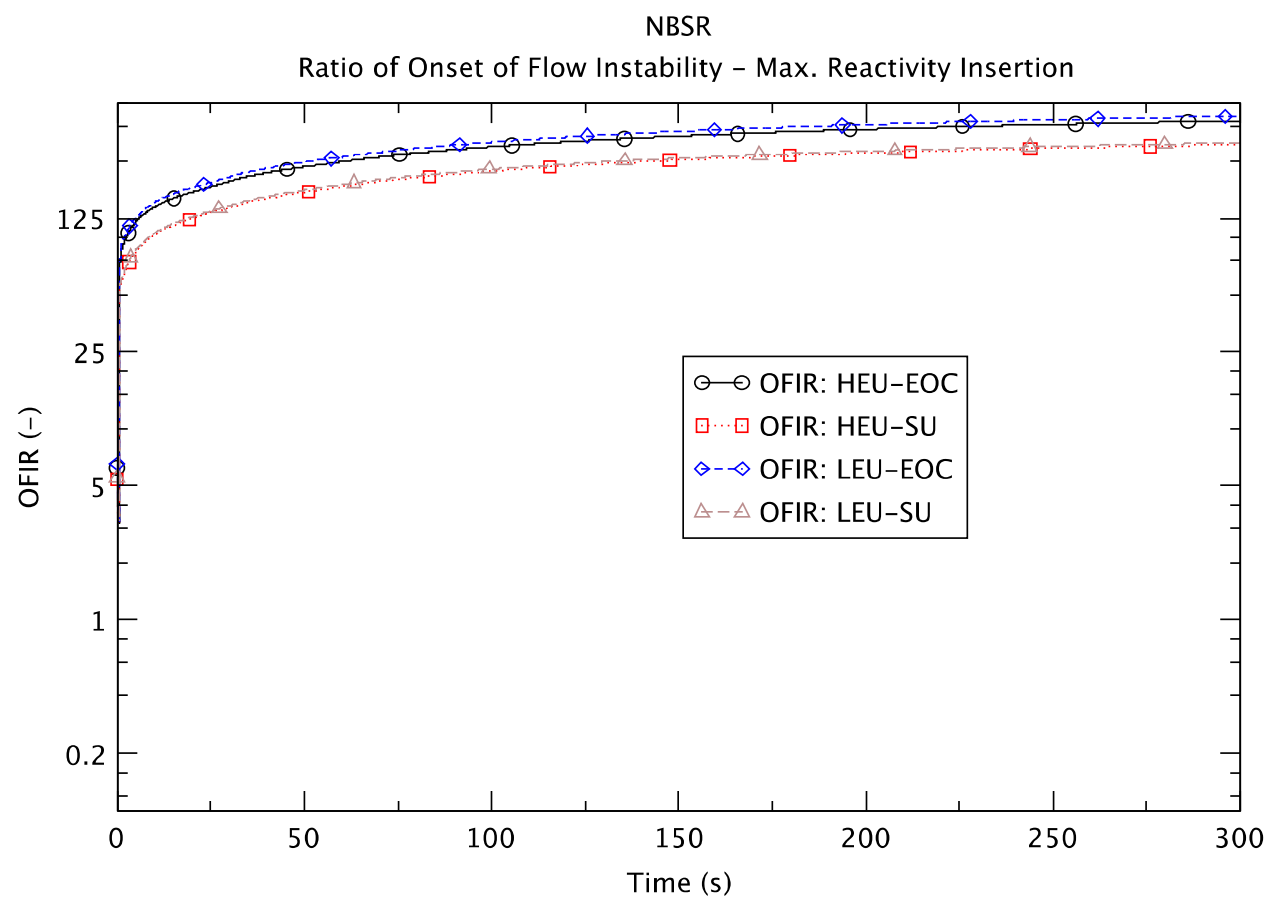

Figure 4-15 Onset-of-Flow-Instability Ratios in Maximum Reactivity Insertion Accident: Wide Range 


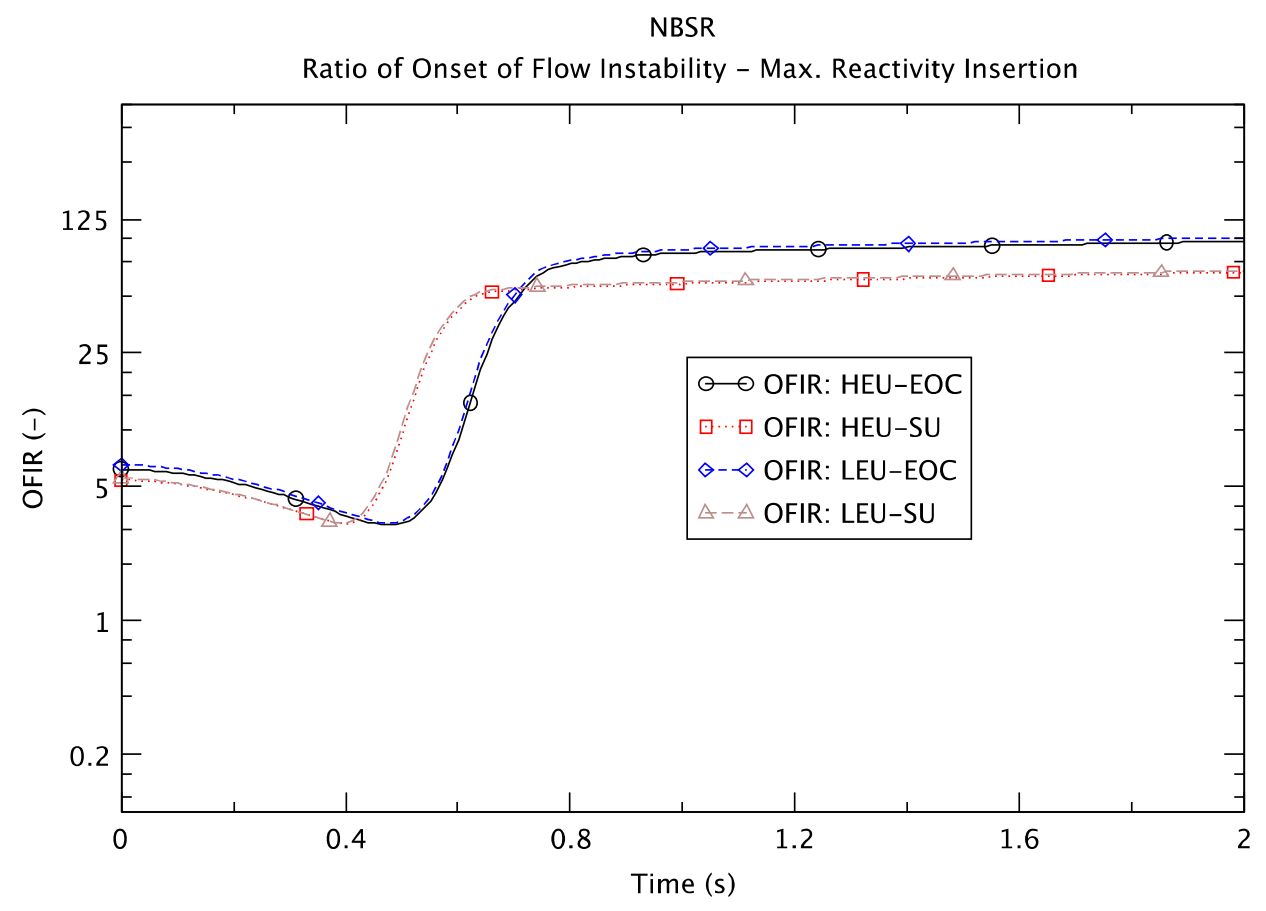

Figure 4-16 Onset-of-Flow-Instability Ratios in Maximum Reactivity Insertion Accident: Narrow Range

Table 4-12 Minimum OFIRs in Maximum Reactivity Insertion Accident

\begin{tabular}{|c|c|c|c|}
\hline Case & $\begin{array}{c}\text { Minimum } \\
\text { OFIR (-) }\end{array}$ & Time (s) & Hydraulic Node No. \\
\hline HEU EOC & 3.18 & 0.47 & $417-15^{(1)}$ \\
\hline HEU SU & 3.16 & 0.40 & $503-15^{(2)}$ \\
\hline LEU EOC & 3.24 & 0.48 & $417-15^{(1)}$ \\
\hline LEU SU & 3.25 & 0.39 & $503-15^{(2)}$ \\
\hline
\end{tabular}

Notes ${ }^{(1)}$ : The minimum OFIR occurs in the powered top node of the flow channel with the hottest fuel stripe.

(2): The minimum OFIR occurs in the hottest node (highest power cell in the core region). The flow channel with this node has a mid-plane gap shared with the flow channel for 16 average fuel plates.

Table 4-12 shows that the minimum OFIR takes place when the reactor power is highest (see Table 4-9) and the calculated values are very similar in all cases. It is observed from Figure 4-16 and Table 4-12 that the minimum OFIRs are all much larger than 1.58 for the HEU fuel and 1.73 for the LEU fuel. This means that with either HEU or LEU fuel onset-of-flow-instability is precluded with a probability greater than $99.9 \%$ (see Table 3-13). 


\subsubsection{Summary}

In the maximum reactivity insertion accident, the general system behavior with LEU fuel is very similar to that with HEU fuel. The reactor power increases exponentially from $20.4 \mathrm{MW}$ at time zero due to the positive reactivity insertion of $0.005 \Delta \mathrm{k} / \mathrm{k}$ in $0.5 \mathrm{~s}$ and drops very rapidly after its peak as shim arms are inserted after a reactor trip signal. Cladding temperature rises owing to the power increase. The highest peak cladding temperature occurs in the case of the LEU fuel at EOC and it is $398.8 \mathrm{~K}$ (much lower than the expected blister temperatures) corresponding to a temperature rise of about $29 \mathrm{~K}$. Hence, no fuel damage is expected for the maximum reactivity insertion accident with either HEU or LEU fuel.

Minimum CHFR and OFIR are evaluated in all hydraulic nodes in the core region and they are all much higher than the values needed to assure no problem with a probability of $99.9 \%$.

\subsection{Loss of Flow Accidents}

\subsubsection{Loss of Offsite Power}

The accident scenario assumes all three primary pumps trip upon loss of offsite power. The three primary coolant pumps will begin to coastdown, and eventually the primary coolant flow will drop to a value where one or more of the primary coolant flow monitors will generate a scram signal. The scram occurs $0.4 \mathrm{~s}$ after flow has reached the trip value taking into account instrumentation delays.

The consequences of this flow transient are bounded by the accident with shutdown coolant pump trip as well. The shutdown pump trip in addition to the primary coolant pump trip eliminates forced flow through the core and heat must be removed through natural circulation flow of the coolant. This leads the core to more severe conditions in terms of not only fuel temperature but also CHFR due to poor heat removal from the fuel and the possibility of flow stagnation. Therefore, this accident has been analyzed with an additional assumption of shutdown pump trip.

\subsubsection{Simulation of Accident}

This accident begins with a loss of offsite power, and coastdown of the primary pumps. The reactor trip signal is generated on low primary flow with a $0.4 \mathrm{~s}$ delay and scram occurs with an additional scram actuation delay (0.09832 s). In addition, it is assumed that both the shutdown coolant pumps and all of the secondary coolant pumps also coastdown, since there has been a failure of all backup power sources. It is also assumed that at time zero the valves at the outlet of the primary pumps start being closed due to the loss of offsite power, whereas the valves at the outlet of the shutdown pumps begin opening. The primary coolant then circulates through the piping connected to the shutdown pumps by natural convection as the water heats up in the core. A RELAP5 simulation of this process is followed until the fuel reaches a relatively stable temperature, when it is being cooled by convective flow of water up through the fuel elements and down around the outside of the core. The entire inventory of water in the vessel will then be involved in a very gradual warm-up. It can be expected to take a much longer time (several 
hours) for the bulk water temperature to reach the boiling point, allowing time for shutdown cooling to be restored.

\subsubsection{Reactor Power}

Figure 4-17 and Figure 4-18 depict the reactor power responses during the transients from time zero to $300 \mathrm{~s}$ and time zero to $2 \mathrm{~s}$, respectively. As shown in the figures, the reactor power decreases very rapidly from around $1.22 \mathrm{~s}$ in all cases. The trip setpoint for low outer plenum flow $(297 \mathrm{l} / \mathrm{s})$ is reached at $0.72 \mathrm{~s}$ in all cases. A reactor trip signal is then generated after $0.4 \mathrm{~s} \mathrm{of}$ delay time and the shim arms start being inserted into the core region after additional $0.0983 \mathrm{~s}$ as shown in Figure 4-18. Table 4-13 shows the predicted reactor trip times.

It can be observed from Figure 4-17 and Figure 4-18 that the power transients with LEU fuel are very similar to those with HEU fuel. It can also be seen that the power drops more rapidly in the cases at SU compared to the cases at EOC. This results from the different initial shim arm positions (about $23^{\circ}$ at $\mathrm{SU}$ and $41^{\circ}$ at EOC) shown in Figure 3-13 and Figure 3-14 causing the larger initial negative reactivity insertion rate in the cases at $\mathrm{SU}$.

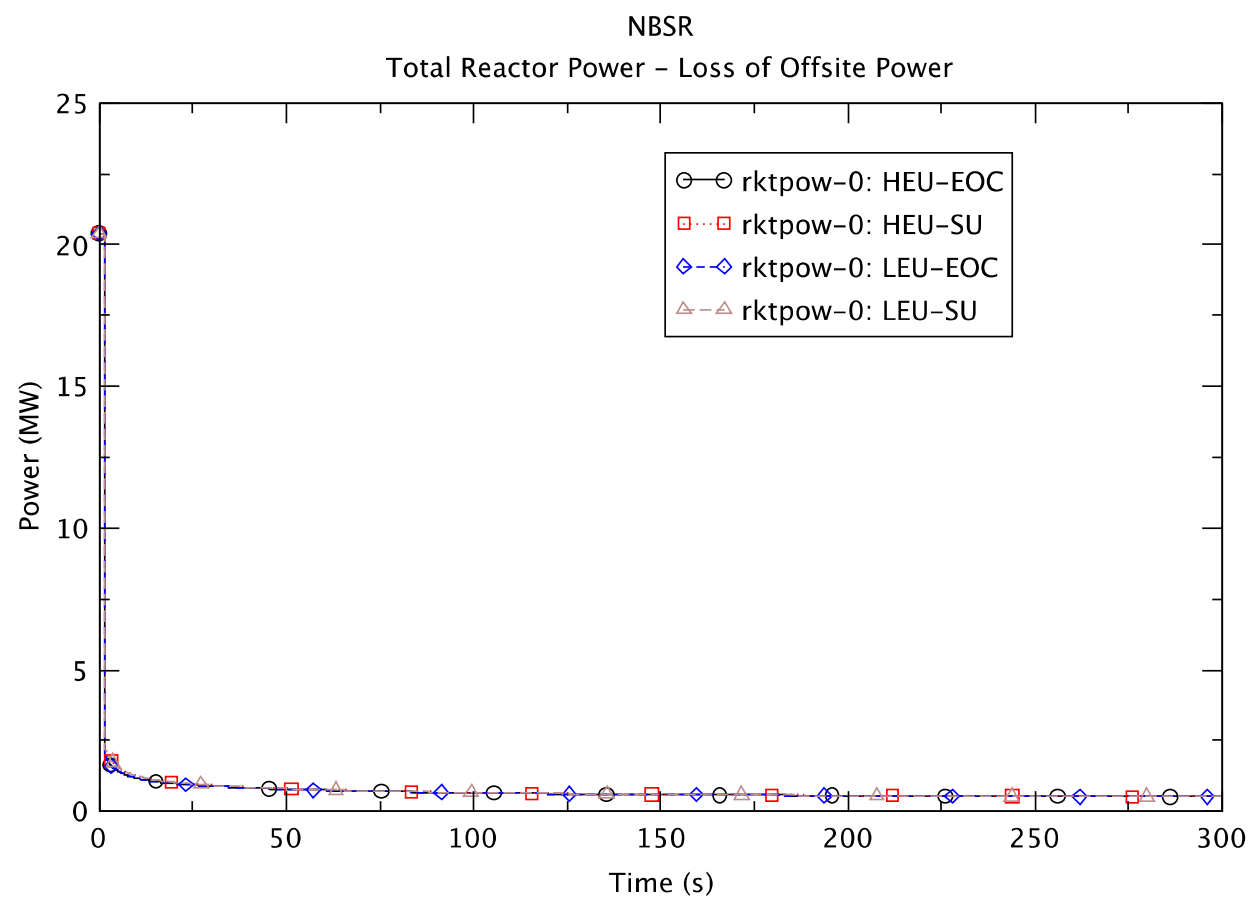

Figure 4-17 Reactor Power Responses in Accident of Loss of Offsite Power with Shutdown Pump Trip: Wide Range 


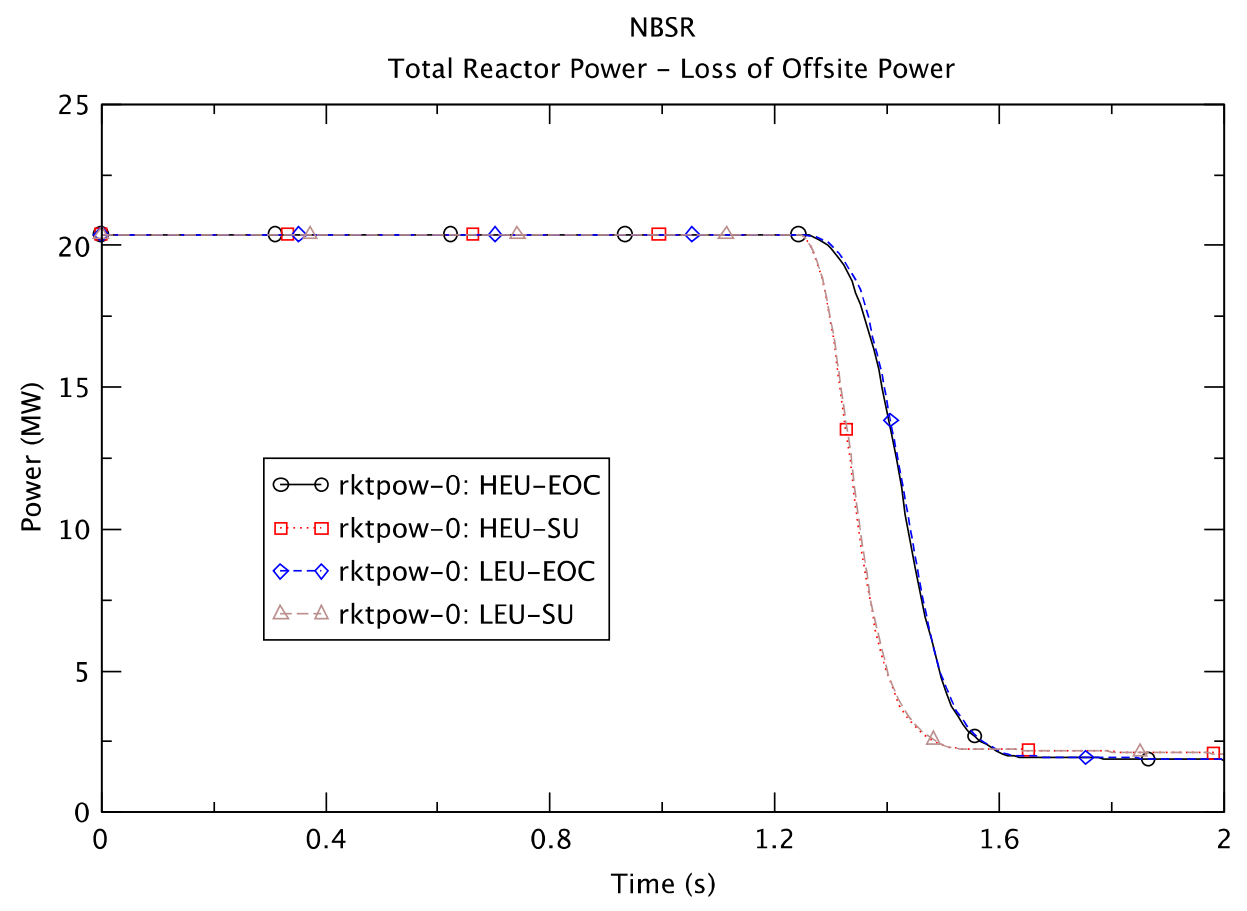

Figure 4-18 Reactor Power Responses in Accident of Loss of Offsite Power with Shutdown Pump Trip: Narrow Range

Table 4-13 Reactor Trips and Occurring Times in Accident of Loss of Offsite Power with Shutdown Pump Trip

\begin{tabular}{|c|c|l|}
\hline Case & Time $(\mathrm{s})$ & \multicolumn{1}{c|}{ Trip Type } \\
\hline HEU EOC & 1.22 & Low outer plenum flow \\
\hline HEU SU & 1.22 & Low outer plenum flow \\
\hline LEU EOC & 1.22 & Low outer plenum flow \\
\hline LEU SU & 1.22 & Low outer plenum flow \\
\hline
\end{tabular}

\subsubsection{Fuel Temperature}

Figure 4-19 and Figure 4-20 show cladding temperatures from time zero to $300 \mathrm{~s}$ and from time zero to $5 \mathrm{~s}$, respectively, in the fuel element nodes corresponding to minimum CHFR. The cladding temperatures rapidly increase due to reduced heat transfer as fluid velocity decreases after the primary pumps trip. Cladding temperature reaches a maximum value at $1.28 \mathrm{~s}$ with both HEU and LEU fuels at SU and at $1.34 \mathrm{~s}$ with both HEU and LEU fuels at EOC and then begins decreasing rapidly because of decreasing reactor power. Table 4-14 shows the peak cladding temperatures, occurring times, and temperature increases. The peak cladding temperatures and the temperature increases are less than $405 \mathrm{~K}$ (much lower than the expected blister temperatures) and $33 \mathrm{~K}$, respectively, in all cases. Hence, no fuel damage is expected as a result of this accident. 
NBSR

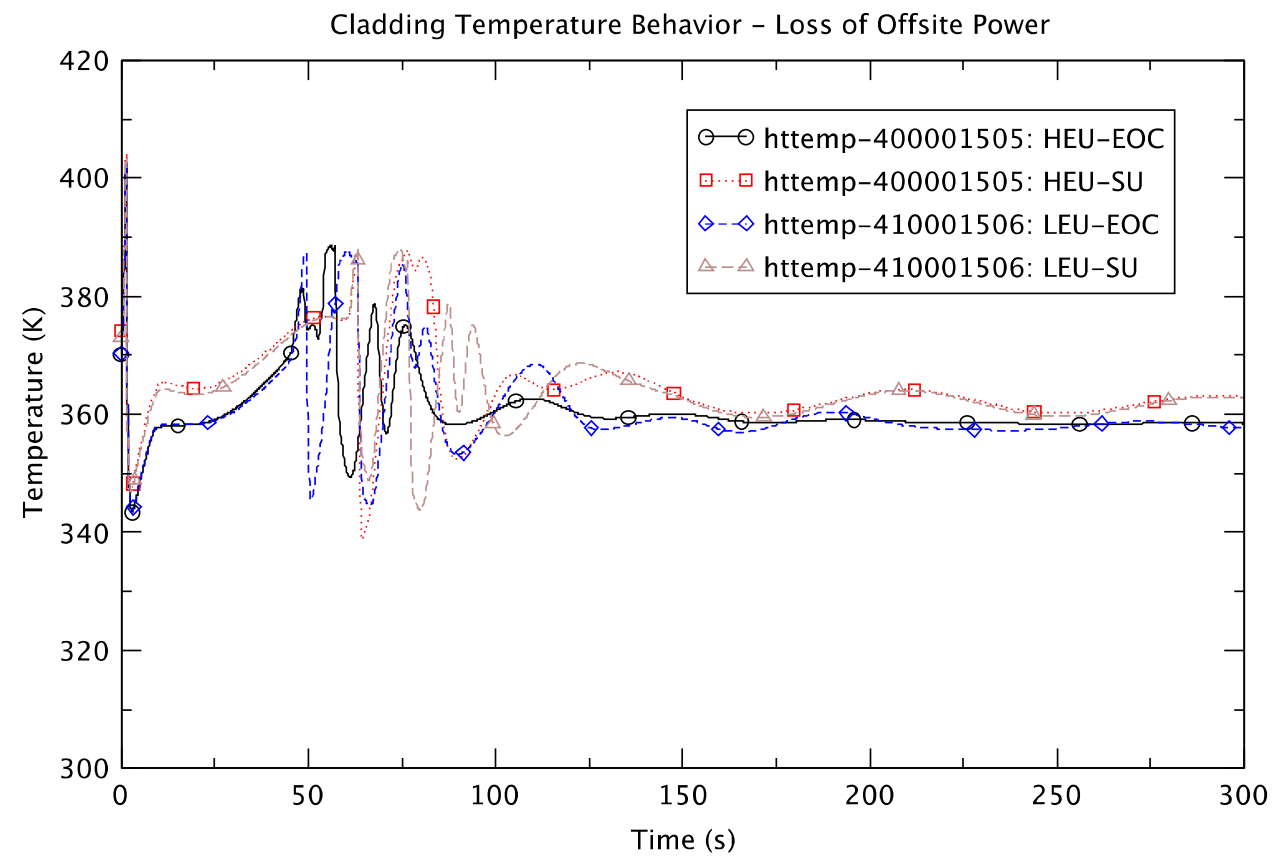

Figure 4-19 Cladding Temperatures in Accident of Loss of Offsite Power with Shutdown Pump Trip: Wide Range

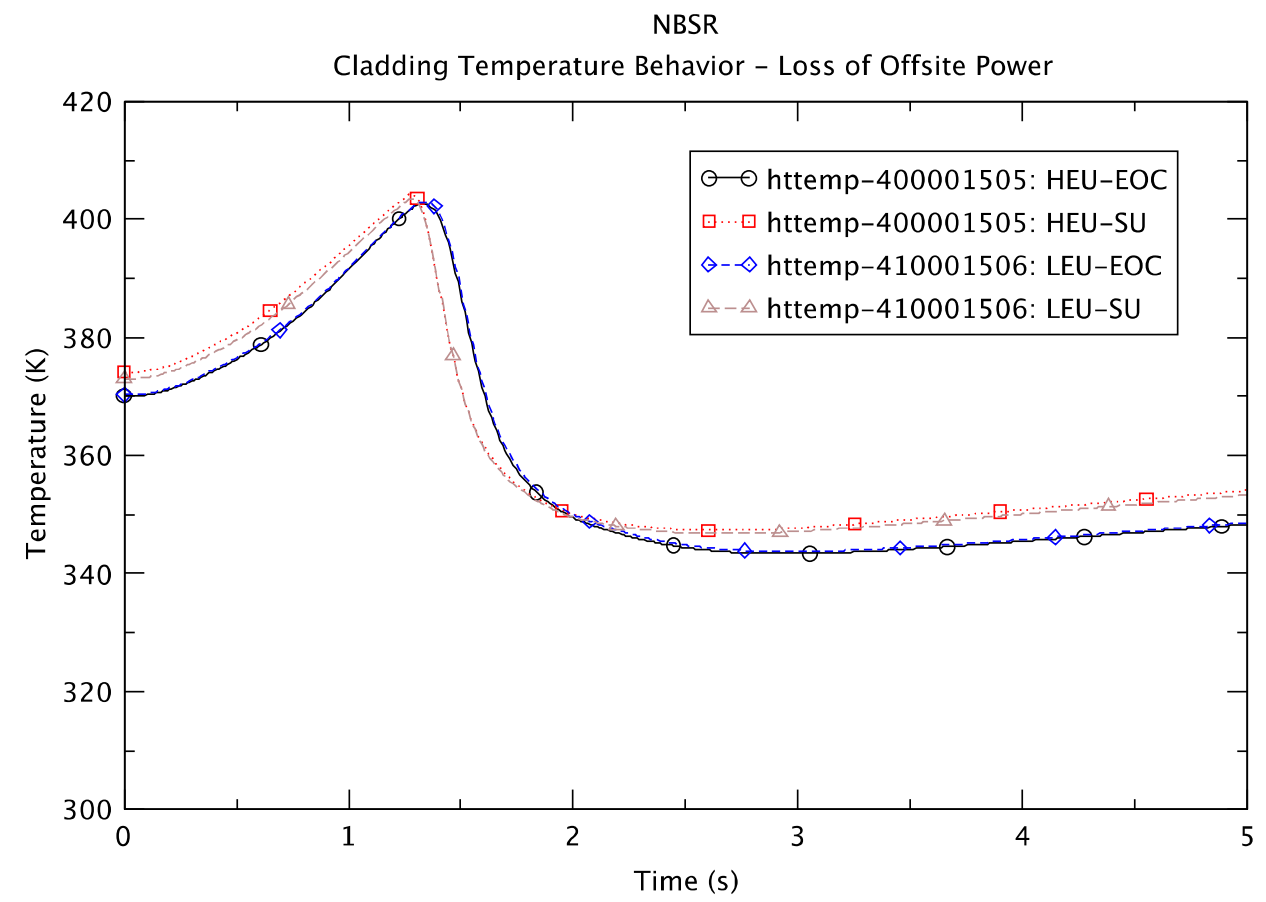

Figure 4-20 Cladding Temperatures in Accident of Loss of Offsite Power with Shutdown Pump Trip: Narrow Range 
Table 4-14 Peak Cladding Temperatures and Cladding Temperature Increases in Accident of Loss of Offsite Power with Shutdown Pump Trip

\begin{tabular}{|c|c|c|c|}
\hline Case & $\begin{array}{c}\text { Peak Cladding } \\
\text { Temperature }(\mathrm{K})\end{array}$ & Time $(\mathrm{s})$ & $\begin{array}{c}\text { Temperature } \\
\text { Increase }(\mathrm{K})\end{array}$ \\
\hline HEU EOC & 402.7 & 1.34 & 32.6 \\
\hline HEU SU & 404.2 & 1.28 & 30.1 \\
\hline LEU EOC & 403.0 & 1.34 & 32.7 \\
\hline LEU SU & 403.5 & 1.28 & 30.5 \\
\hline
\end{tabular}

Figure 4-19 shows that the cladding temperatures are oscillating between about $45 \mathrm{~s}$ and $110 \mathrm{~s}$. This is because of fluctuations of coolant flow in channels as shown in Figure 4-21. Figure 4-21 depicts the mass flow rate at the inlet of the hottest node in the outer core region. As the primary pumps coastdown, the coolant flow velocity decreases very rapidly, fluctuates around zero, and then stabilizes to natural circulation flow. During the flow fluctuations, RELAP5 predicts almost zero flow velocity several times when flow direction changes. This results in poor heat transfer from the fuel to coolant and increasing cladding temperatures. As flow velocity increases, the heat transfer becomes efficient and the cladding temperature decreases rapidly. This behavior occurs several times during the flow fluctuation in all cases as shown in Figure 4-19. However, the highest cladding temperatures during the flow fluctuations are lower than the peak cladding temperatures shown in Table 4-14.

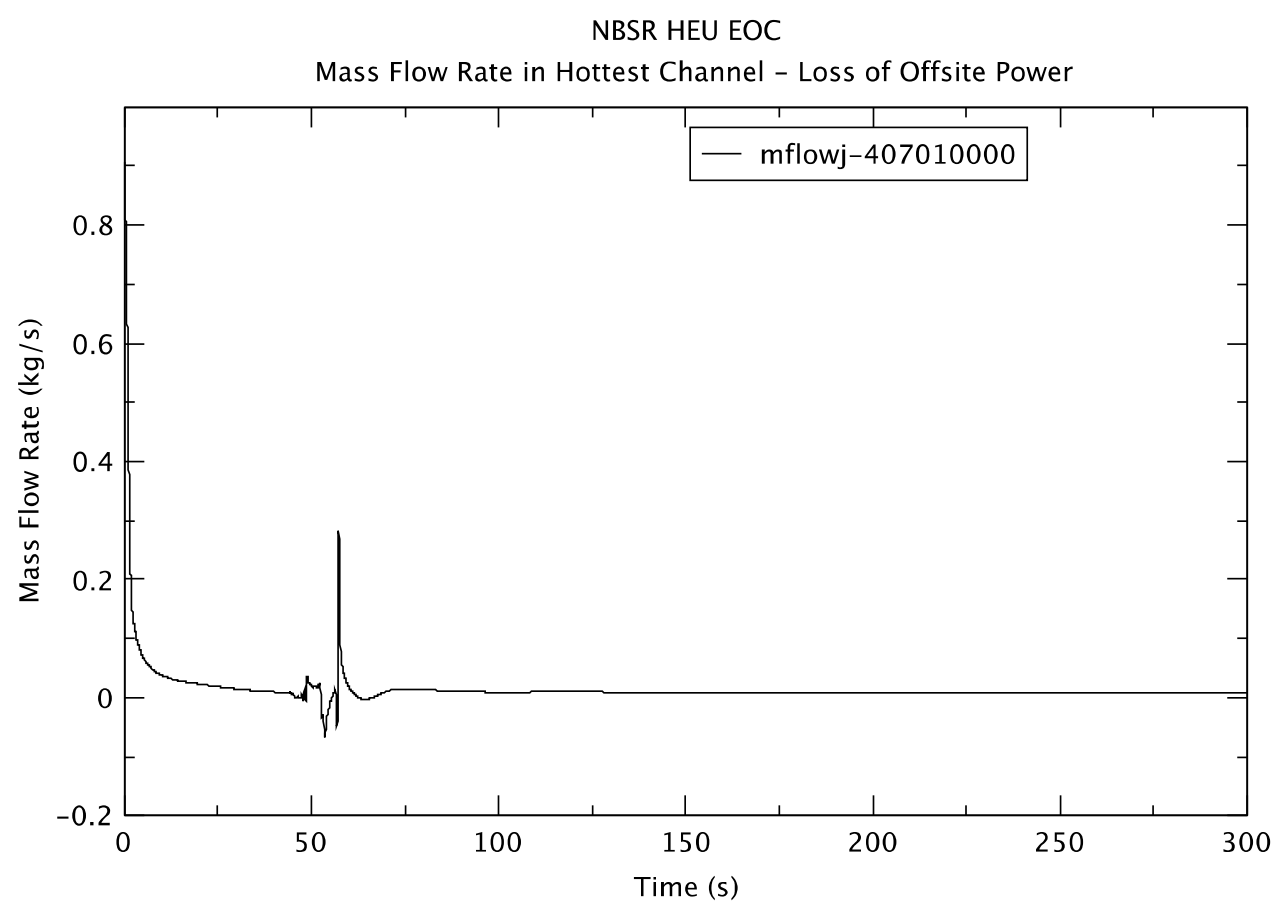

Figure 4-21 Mass Flow Rate in Hottest Channel in Accident of Loss of Offsite Power with Shutdown Pump Trip of NBSR with HEU fuel at EOC 


\subsubsection{Minimum CHFR}

Critical-heat-flux ratios are evaluated using Sudo-Kaminaga correlations (see Section 3.4.1) and the evaluated CHFR behaviors are shown in Figure 4-22 from time zero to $300 \mathrm{~s}$ and in Figure 4-23 from time zero to $2 \mathrm{~s}$. The nodes in the figures are the ones where minimum CHFR takes place among all the hydraulic nodes in the core region. As shown in the figures, the CHFR reaches a minimum value between $1.25 \mathrm{~s}$ and $1.35 \mathrm{~s}$. CHFR then increases very rapidly and becomes larger than 2.8 from $1.5 \mathrm{~s}$ in all cases. The calculated minimum CHFRs are shown in Table 4-15.

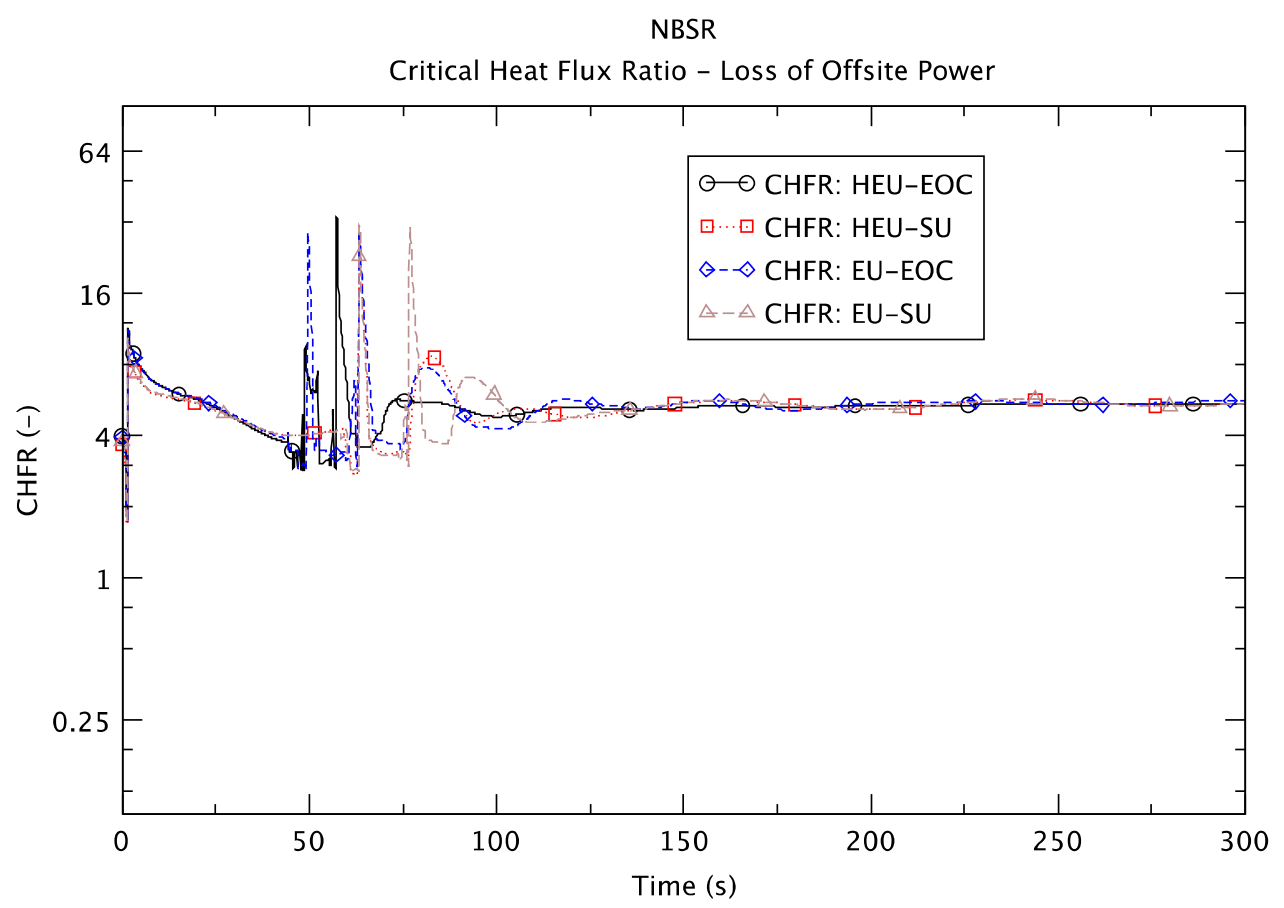

Figure 4-22 Critical Heat Flux Ratios in Accident of Loss of Offsite Power with Shutdown Pump Trip: Wide Range 
NBSR

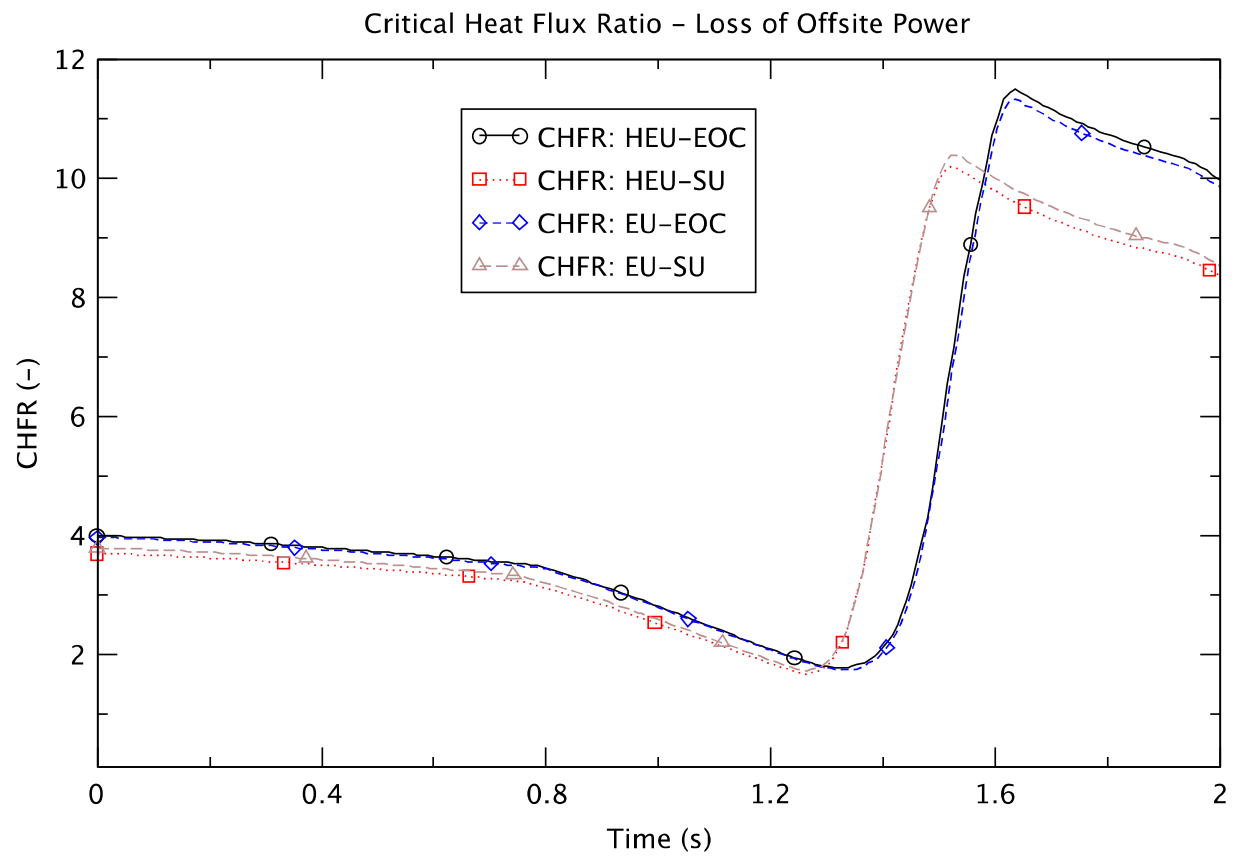

Figure 4-23 Critical Heat Flux Ratios in Accident of Loss of Offsite Power with Shutdown Pump Trip: Narrow Range

Table 4-15 Minimum CHFRs in Accident of Loss of Offsite Power with Shutdown Pump Trip

\begin{tabular}{|c|c|c|c|}
\hline Case & $\begin{array}{c}\text { Minimum } \\
\text { CHFR (-) }\end{array}$ & Time (s) & Hydraulic Node No. \\
\hline HEU EOC & 1.77 & 1.32 & $407-02^{(1)}$ \\
\hline HEU SU & 1.67 & 1.26 & $407-02^{(2)}$ \\
\hline LEU EOC & 1.74 & 1.34 & $417-02^{(3)}$ \\
\hline LEU SU & 1.73 & 1.26 & $417-02^{(4)}$ \\
\hline
\end{tabular}

Notes ${ }^{(1)}$ The minimum CHFR occurs in the node where the hottest cell (highest power cell in the core region) is located.

${ }^{(2)}$ The minimum CHFR occurs in the next heated (or powered) node above the one where the hottest cell is located.

${ }^{(3)}$ The minimum CHFR occurs in the node where the highest power cell in the hottest fuel stripe is located. This cell is different from the hottest cell among all cells in the core region.

${ }^{(4)}$ The minimum CHFR occurs in the next heated (or powered) node above the one where the highest power cell in the hottest fuel stripe is located.

Figure 4-18 and Table 4-15 illustrate that the minimum CHFR takes place shortly after reactor trip while the reactor power is still high. This indicates that the fluid conditions change rapidly 
and the critical heat flux at these conditions decreases faster with time than the decrease of heat transferred to the coolant, until the minimum CHFR occurs. Then the decrease rate of the former becomes smaller than that of the latter and the CHFR begins increasing.

It can be seen from Figure 4-23 that the CHFR responses with the LEU fuels are very similar to those with the HEU fuels, until around $2.0 \mathrm{~s}$. It is also observed from Figure 4-23 and Table 4-15 that the evaluated minimum CHFRs are 1.67 and 1.77 for the HEU fuel and 1.73 and 1.74 for the LEU fuel. This indicates that with either HEU or LEU fuel CHF is precluded with a probability greater than $95 \%$ (see Table 3-12). It should be noted that the accident considered in this analysis is the one with dual failures (loss of offsite power and shutdown pump trip) and that the probability of occurrence of this dual-failure accident is significantly small. Therefore, the actual probability of occurrence of CHF in the NBSR reactor due to this accident is also extremely small.

\subsubsection{Minimum OFIR}

Flow fluctuations around zero are predicted during this accident. When the flow velocity in a channel approaches zero because of flow fluctuations before stable natural circulation flow is established, even though the heat transfer becomes less efficient, the coolant receives a relatively large amount of heat from the fuel and is being heated up because it stays in the powered channel for a relatively long time. Vapor can be generated if heat continues to be transferred to the coolant. However, when flow velocity increases after a change of flow direction, vapor generation will stop because of the relatively cold coolant flowing in the channel.

RELAP5 predicts vapor generation in the core during this particular accident as shown in Figure 4-24. Figure 4-24 depicts the void fraction behavior predicted in the powered top node of the hottest channel with HEU fuel at EOC. As discussed in Section 3.4.2, Saha-Zuber criteria (Saha, 1974) are used to evaluate the onset of net vapor generation as a conservative threshold for onset of flow instability. Therefore, evaluation of minimum OFIR has no significant meaning in this accident analysis.

However, the fact that no fuel damage is expected can be assured by other parameters, such as peak clad temperature and minimum CHFR. It was observed that the peak cladding temperatures are all less than $405 \mathrm{~K}$ and the minimum CHFRs are all higher than 1.67 in this accident. 


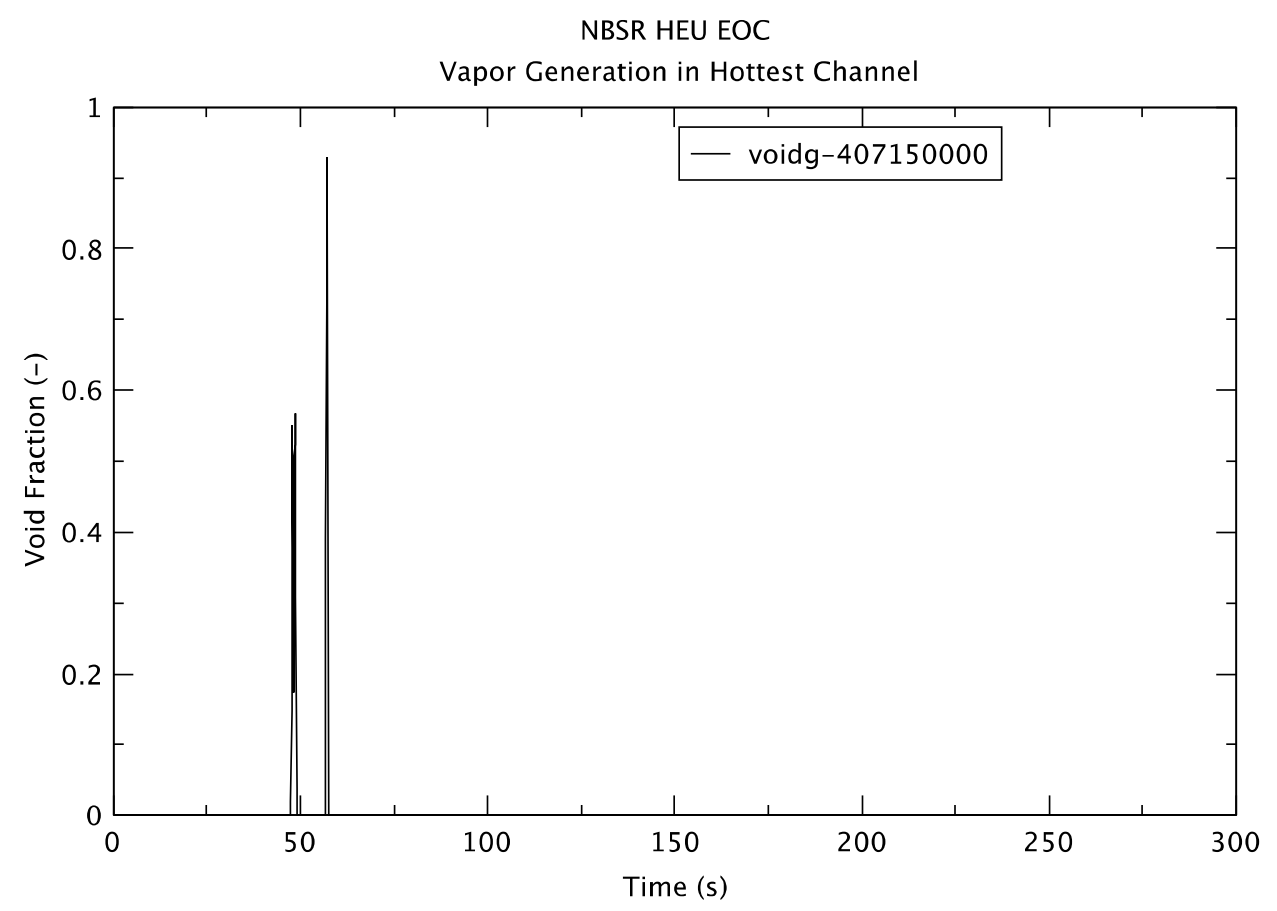

\section{Figure 4-24 Void Fraction in Powered-Top Node of Hottest Channel in Accident of Loss of Offsite Power with Shutdown Pump Trip}

\subsubsection{Summary}

For loss-of-offsite-power with shutdown pump trip, the general system behavior with LEU fuel is similar to that with HEU fuel. The reactor power starts decreasing very rapidly from $20.4 \mathrm{MW}$ after reactor trip at $1.12 \mathrm{~s}$ due to a signal from low flow to the outer plenum. Cladding temperature rises from time zero because of mass flow rate decreasing caused by the coastdown of the primary pumps. The highest peak cladding temperature occurs in the case of HEU fuel at $\mathrm{SU}$ and is $404.2 \mathrm{~K}$ (much lower than the expected blister temperatures) corresponding to a temperature rise of $30.1 \mathrm{~K}$. Hence, no fuel damage is expected with either HEU or LEU fuel for this accident. .

Minimum CHFR is always high enough to preclude fuel damage with a probability greater than $95 \%$. In addition, since the frequency of occurrence of this particular accident is very small (because dual failures are considered), the reactor is not expected to have any fuel damage either with HEU or LEU fuel.

\subsubsection{Seizure of One Primary Pump}

\subsubsection{Simulation of Accident}

It is assumed that through some failure, such as a faulty bearing, the rotor of one pump suddenly becomes locked. Because of its momentum, coolant flow through the primary loop will decrease 
over a finite time interval until the $1 / 3$ flow reduction is achieved. Since the RELAP5 model lumps all three pumps into one effective pump, the seizure of one of the pumps is modeled by an instantaneous step reduction in the pump speed to $2 / 3$ of full speed. This is conservative since the flow with only two pumps operating would actually be more than $2 / 3$ of full flow.

\subsubsection{Reactor Power}

Reactor power responses are compared during the transient from time zero to $300 \mathrm{~s}$ in Figure 4-25 and zero to $2 \mathrm{~s}$ in Figure 4-26. As shown in the figures, reactor power decreases very rapidly from around $0.8 \mathrm{~s}$ in all cases. The trip setpoint for low outer plenum flow $(297 \mathrm{l} / \mathrm{s})$ is reached at approximately $0.3 \mathrm{~s}$ in all cases. A reactor trip signal is then generated after $0.4 \mathrm{~s}$ of delay time and the shim arms start being inserted into the core after an additional $0.0983 \mathrm{~s}$ of scram actuation delay (see Section 3.3.6.2) as shown in Figure 4-26. Table 4-16 shows the predicted reactor trip times.

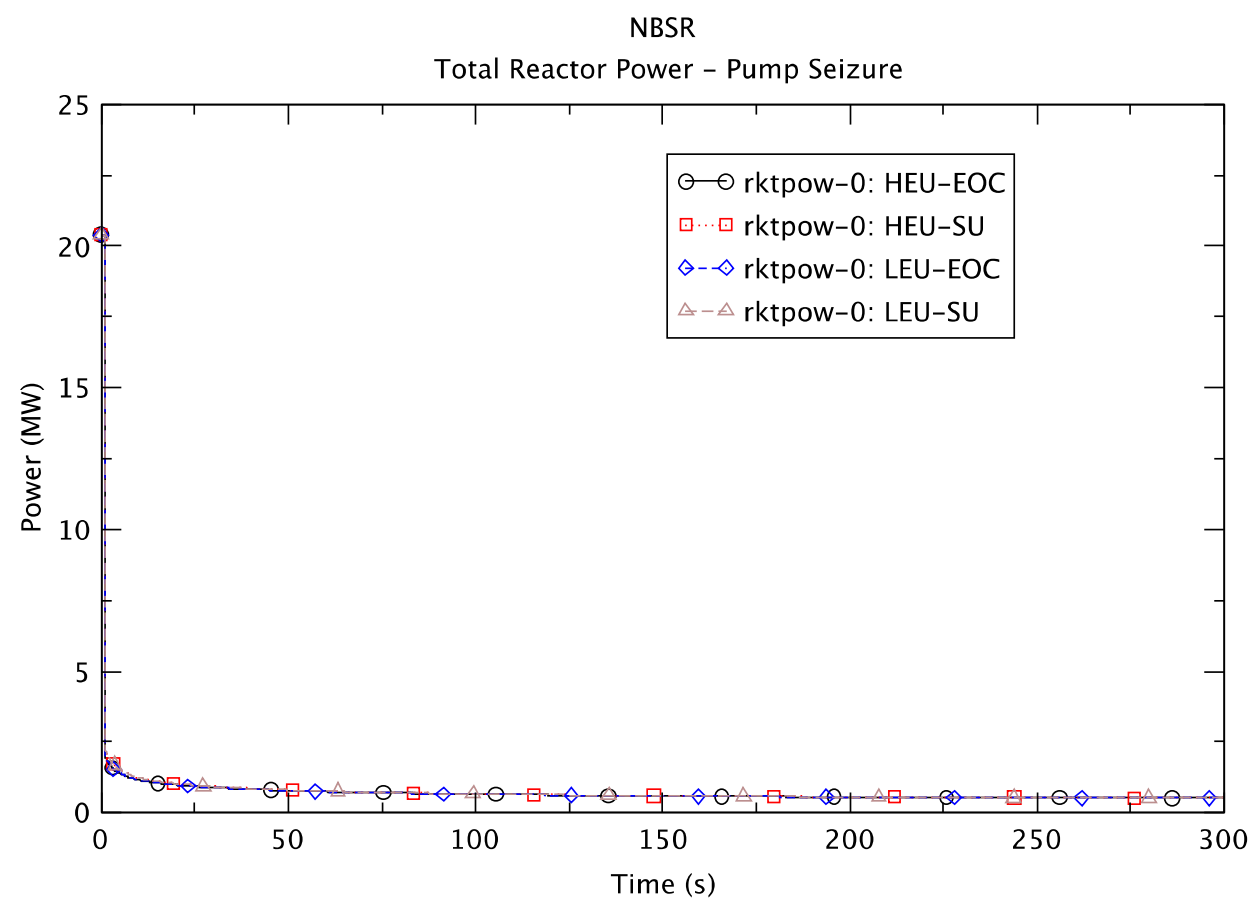

Figure 4-25 Reactor Power Responses in Accident of Seizure of One Primary Pump: Wide Range 


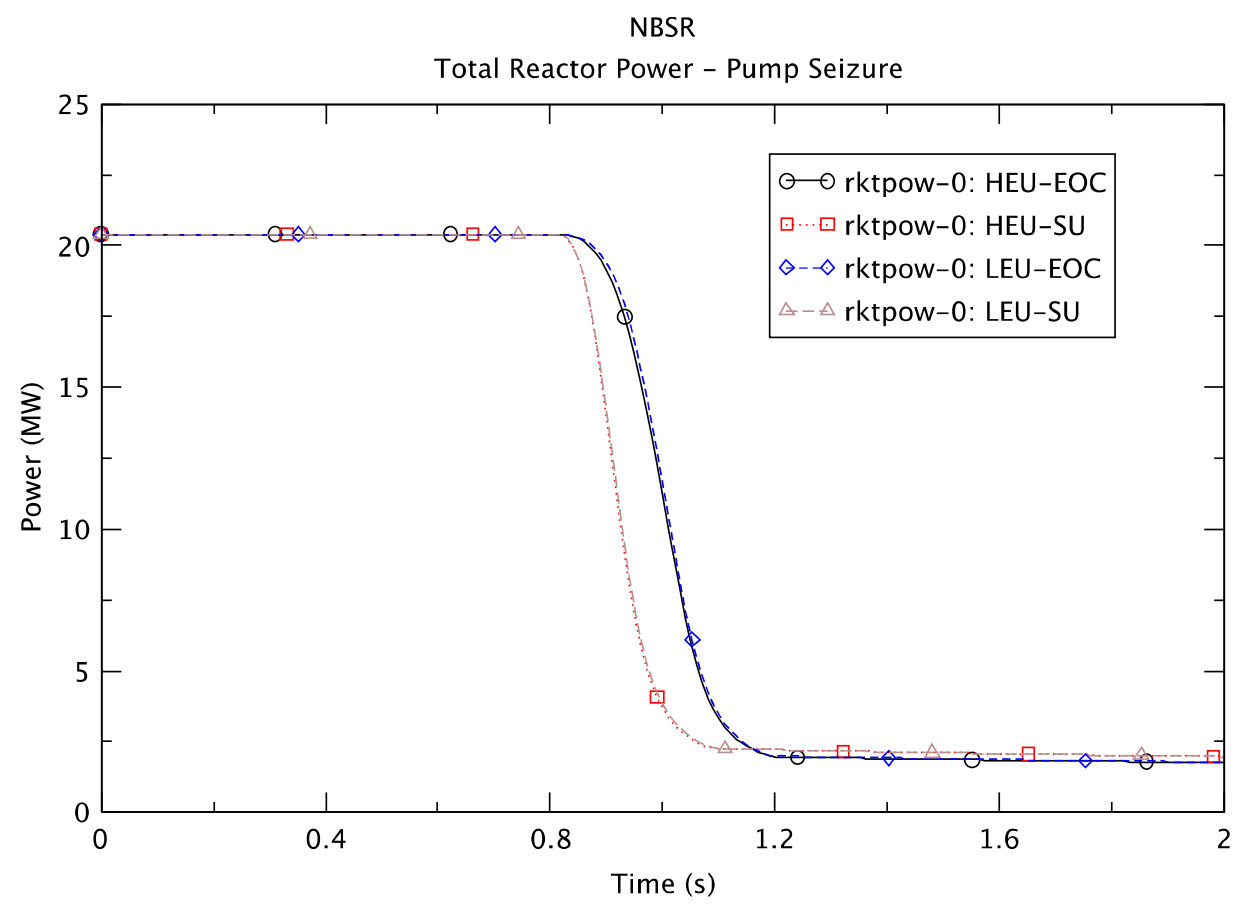

Figure 4-26 Reactor Power Responses in Accident of Seizure of One Primary Pump: Narrow Range

Table 4-16 Reactor Trips and Occurring Times in Accident of Seizure of One Primary Pump

\begin{tabular}{|c|c|l|}
\hline Case & Time (s) & \multicolumn{1}{c|}{ Trip Type } \\
\hline HEU EOC & 0.8 & Low outer plenum flow \\
\hline HEU SU & 0.8 & Low outer plenum flow \\
\hline LEU EOC & 0.8 & Low outer plenum flow \\
\hline LEU SU & 0.8 & Low outer plenum flow \\
\hline
\end{tabular}

The reactor trips occur earlier in this accident than in the accident with loss of offsite power with shutdown pump trip discussed in the previous section. This is because of the more rapid decrease in core flow early in the event in this accident relative to the loss-of-offsite-power event.

Figure 4-25 and Figure 4-26 show that the behavior of power in the LEU and HEU cores is very similar. The power drops more rapidly in the cases at SU compared to the cases at EOC. This results from the different initial shim arm positions (about $23^{\circ}$ at $\mathrm{SU}$ and $41^{\circ}$ at EOC) shown in Figure 3-13 and Figure 3-14 which causes a larger initial negative reactivity insertion rate at SU. 


\subsubsection{Fuel Temperature}

Figure 4-27 and Figure 4-28 show cladding temperatures from time zero to $300 \mathrm{~s}$ and from time zero to $2 \mathrm{~s}$, respectively, in the fuel element nodes corresponding to where minimum CHFR occurs. The cladding temperatures start increasing from time zero due to heat transfer becoming inefficient as the mass flow rate decreases because of the pump seizure. Temperature reaches a maximum shortly after reactor trip and then begins decreasing rapidly because of the reduction of reactor power. Table 4-17 gives the peak cladding temperatures, occurring times, and temperature increases from their initial values. The peak cladding temperatures and the temperature increases are less than $393 \mathrm{~K}$ (much lower than the expected blister temperatures) and $19 \mathrm{~K}$, respectively, in all cases. Hence, no fuel element damage is expected.

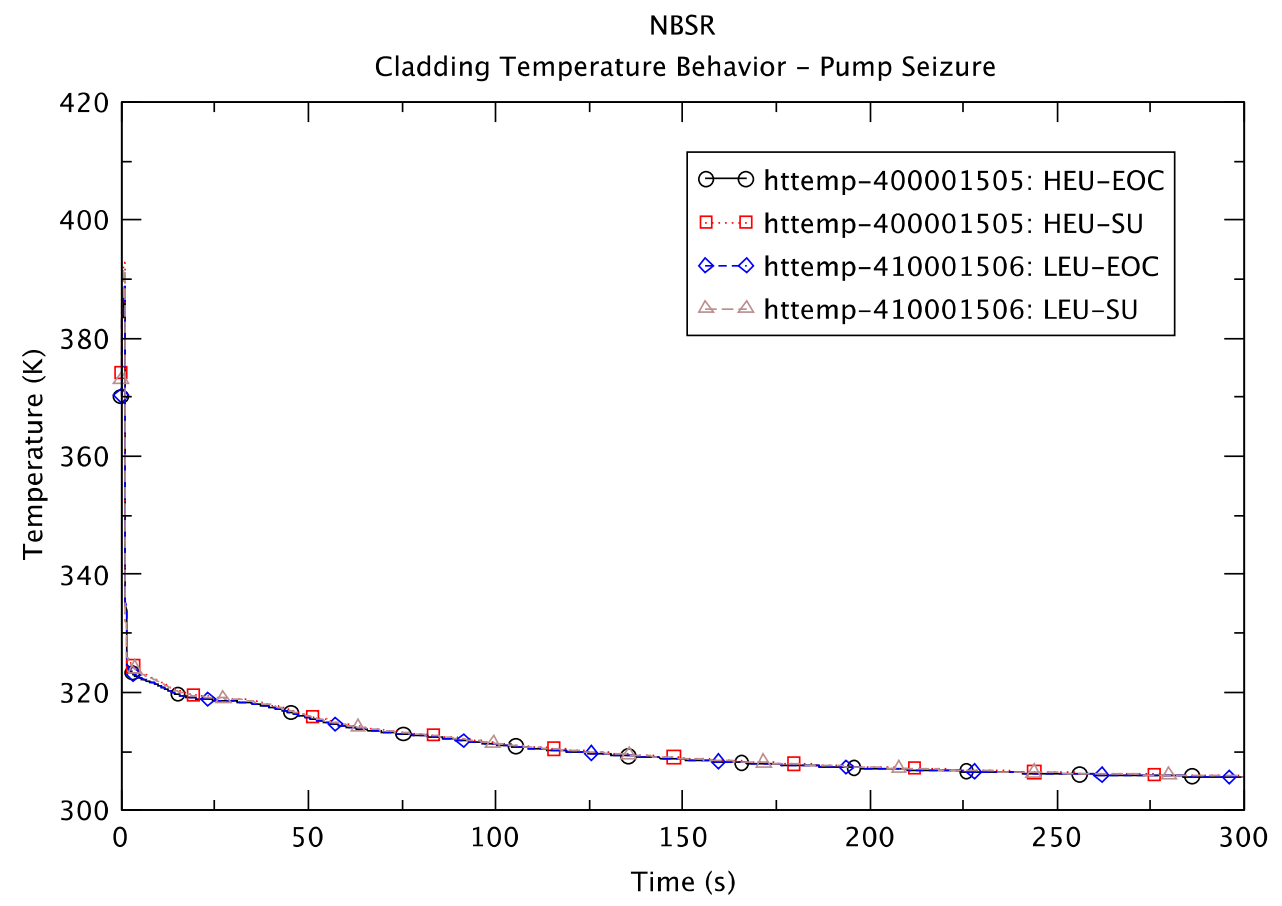

Figure 4-27 Cladding Temperatures in Accident of Seizure of One Primary Pump: Wide Range 


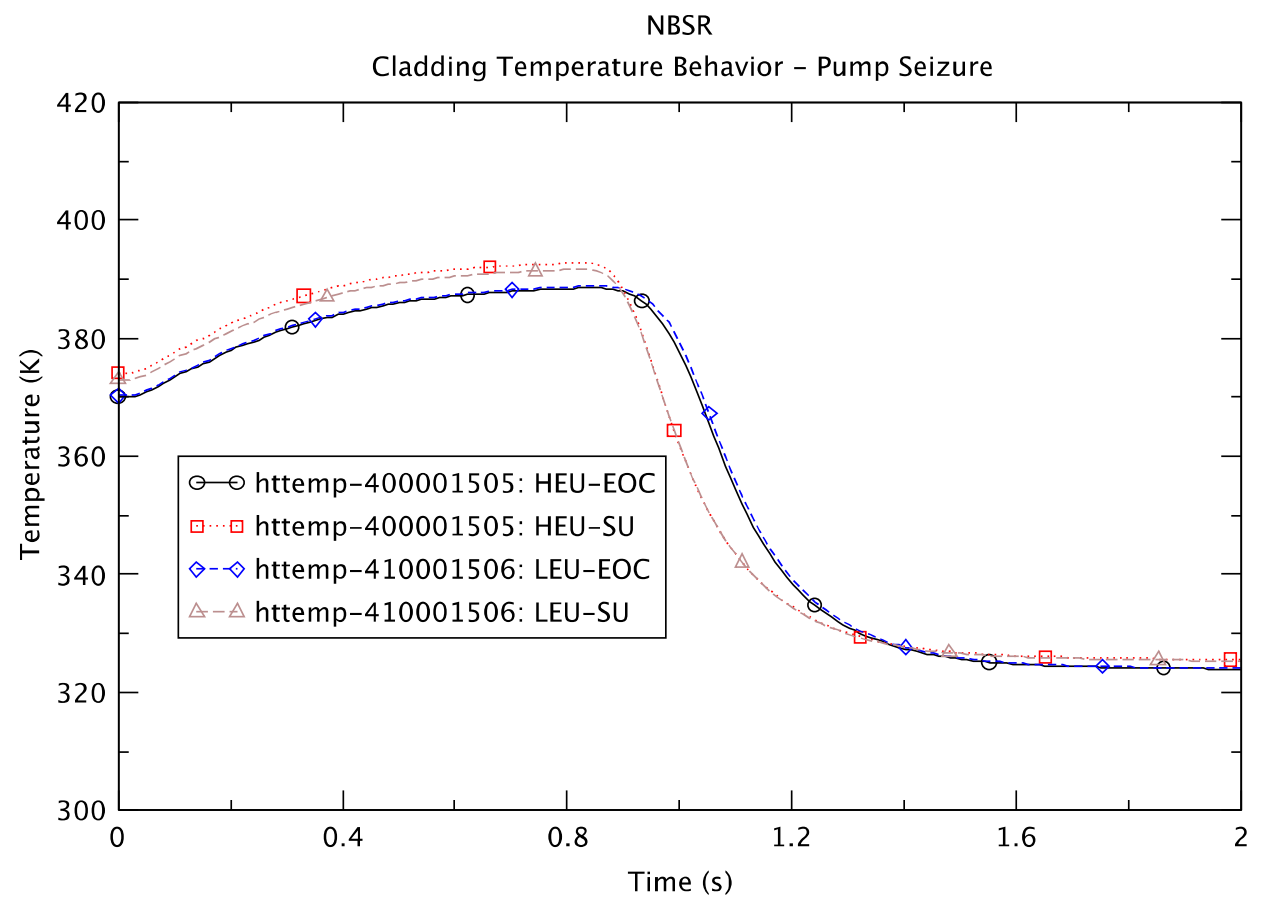

Figure 4-28 Cladding Temperatures in Accident of Seizure of One Primary Pump: Narrow Range

Table 4-17 Peak Cladding Temperatures and Cladding Temperature Increases in Accident of Seizure of One Primary Pump

\begin{tabular}{|c|c|c|c|}
\hline Case & $\begin{array}{c}\text { Peak Cladding } \\
\text { Temperature }(\mathrm{K})\end{array}$ & Time $(\mathrm{s})$ & $\begin{array}{c}\text { Temperature } \\
\text { Increase }(\mathrm{K})\end{array}$ \\
\hline HEU EOC & 388.5 & 0.85 & 18.5 \\
\hline HEU SU & 392.8 & 0.83 & 18.7 \\
\hline LEU EOC & 388.8 & 0.85 & 18.5 \\
\hline LEU SU & 391.6 & 0.83 & 18.7 \\
\hline
\end{tabular}

\subsubsection{Minimum CHFR}

Critical-heat-flux ratios are evaluated using Sudo-Kaminaga correlations (see Section 3.4.1) and they are compared in Figure 4-29 from time zero to $300 \mathrm{~s}$ and in Figure 4-30 from time zero to 2 s. The nodes in the figures are the ones where minimum CHFRs take place among all the hydraulic nodes in the core region. CHFR starts decreasing slowly from time zero and reaches a minimum at $0.81 \mathrm{~s}$ at $\mathrm{SU}$ and $0.82 \mathrm{~s}$ at EOC, as shown in Table 4-18. CHFR then increases very rapidly and becomes larger than 30 from $1.2 \mathrm{~s}$ in all cases. The calculated minimum CHFRs are shown in Table 4-18. 


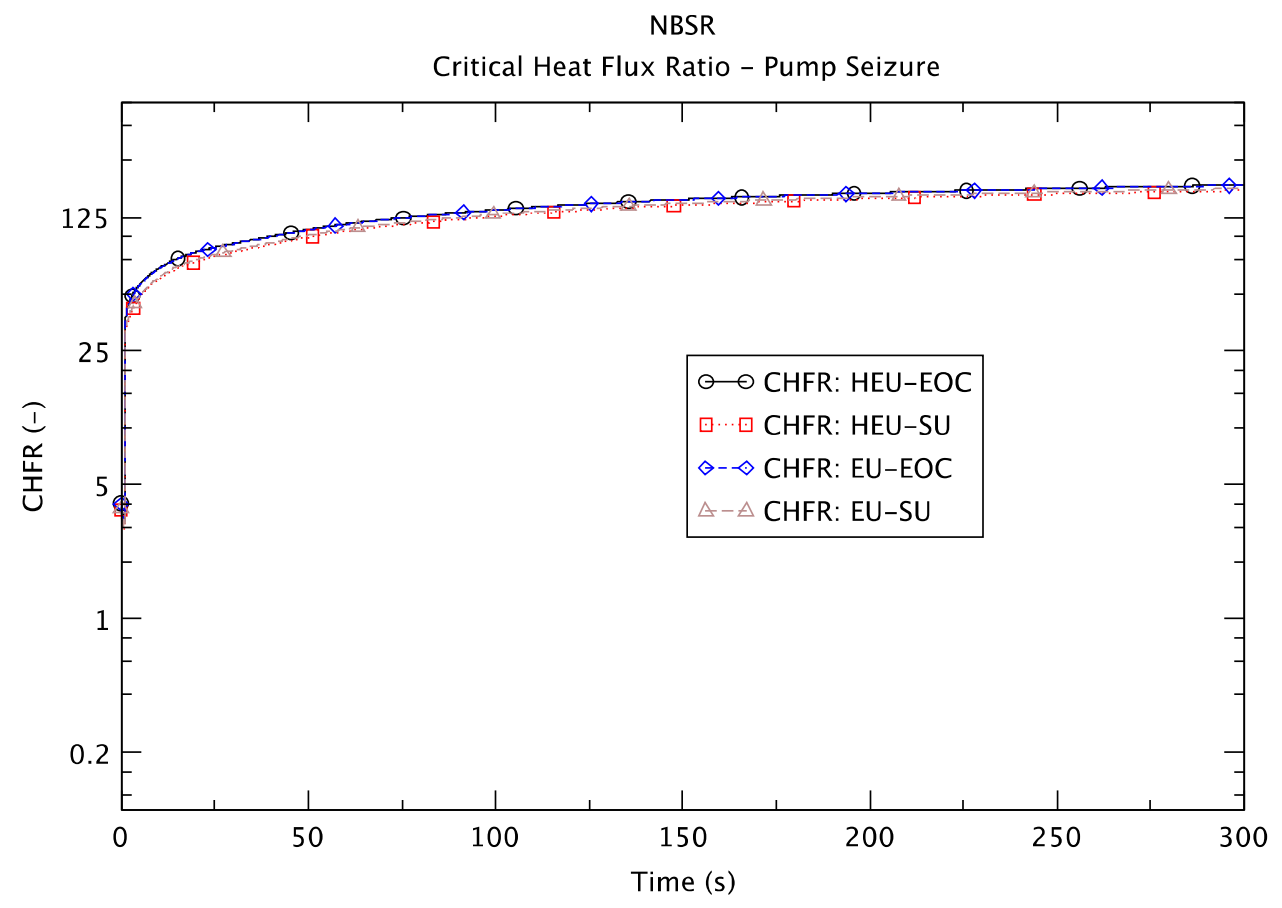

Figure 4-29 Critical Heat Flux Ratios in Accident of Seizure of One Primary Pump: Wide Range

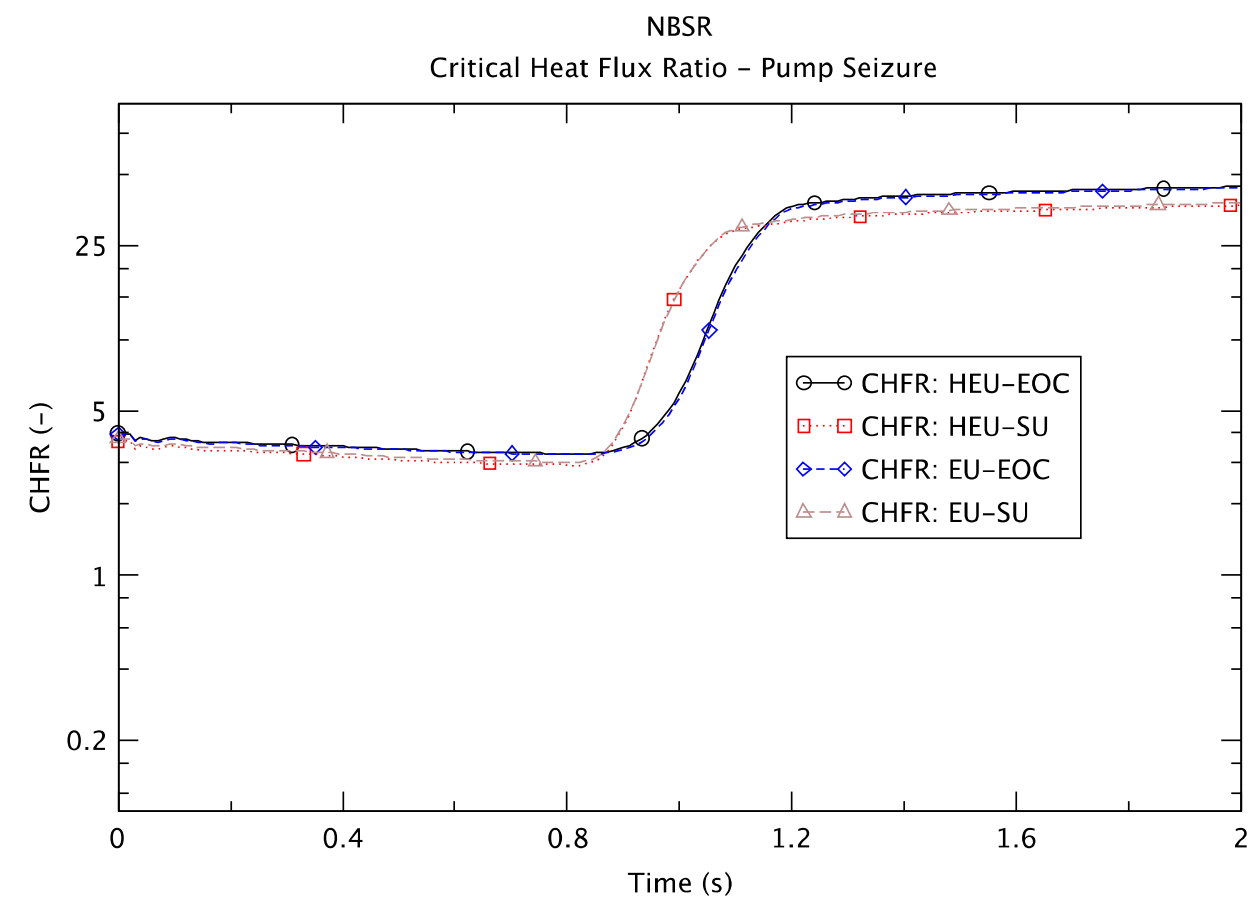

Figure 4-30 Critical Heat Flux Ratios in Accident of Seizure of One Primary Pump: Narrow Range 
Table 4-18 Minimum CHFRs in Accident of Seizure of One Primary Pump

\begin{tabular}{|c|c|c|c|}
\hline Case & $\begin{array}{c}\text { Minimum } \\
\text { CHFR (-) }\end{array}$ & Time (s) & Hydraulic Node No. \\
\hline HEU EOC & 3.28 & 0.82 & $407-02^{(1)}$ \\
\hline HEU SU & 2.94 & 0.81 & $407-02^{(2)}$ \\
\hline LEU EOC & 3.26 & 0.82 & $417-02^{(3)}$ \\
\hline LEU SU & 3.02 & 0.81 & $417-02^{(4)}$ \\
\hline
\end{tabular}

Notes ${ }^{(1)}$ The minimum CHFR occurs in the node where the hottest cell (highest power cell in the core region) is located.

${ }^{(2)}$ The minimum CHFR occurs in the next heated (or powered) node above the hottest cell.

${ }^{(3)}$ The minimum CHFR occurs in the node where the highest power cell in the hottest fuel stripe is located. This cell is different from the hottest cell among all cells in the core region.

${ }^{(4)}$ The minimum CHFR occurs in the next heated (or powered) node above the one where the highest power cell in the hottest fuel stripe is located.

Figure 4-26 and Table 4-18 show that the minimum CHFR takes place shortly after reactor tip when the reactor power is still high. This indicates that the fluid conditions change rapidly and the critical heat flux at these conditions decreases faster with time than the decrease of the heat flux to the coolant until the minimum CHFR occurs. Then the decrease of the critical heat flux becomes slower than that of the heat flux to the coolant and CHFR begins increasing.

Figure 4-29 and Figure 4-30 show that the CHFR with LEU fuel is very similar to that with HEU fuel. It is also observed from Figure 4-30 and Table 4-18 that the minimum CHFRs are 2.94 and 3.28 for the HEU cases and 3.02 and 3.26 for the LEU cases. Hence, CHF is precluded, with either HEU or LEU fuel, with a probability greater than $99.9 \%$ (see Table 3-12).

\subsubsection{Minimum OFIR}

Onset-of-flow-instability ratios are evaluated using Saha-Zuber criteria (see Section 3.4.2) and are shown in Figure 4-31 from time zero to $300 \mathrm{~s}$ and in Figure 4-32 from time zero s to $2 \mathrm{~s}$. The nodes in the figures are the ones where minimum OFIR occurs among all hydraulic nodes in the core region. As shown in those figures, OFIR starts decreasing slowly from time zero and reaches a minimum value at $0.81 \mathrm{~s}$ at EOC and at $0.83 \mathrm{~s}$ at SU. OFIR then increases very rapidly and becomes larger than 35 after $1.2 \mathrm{~s}$ in all cases. The minimum OFIR is shown in Table 4-19. 
NBSR

Ratio of Onset of Flow Instability - Pump Seizure

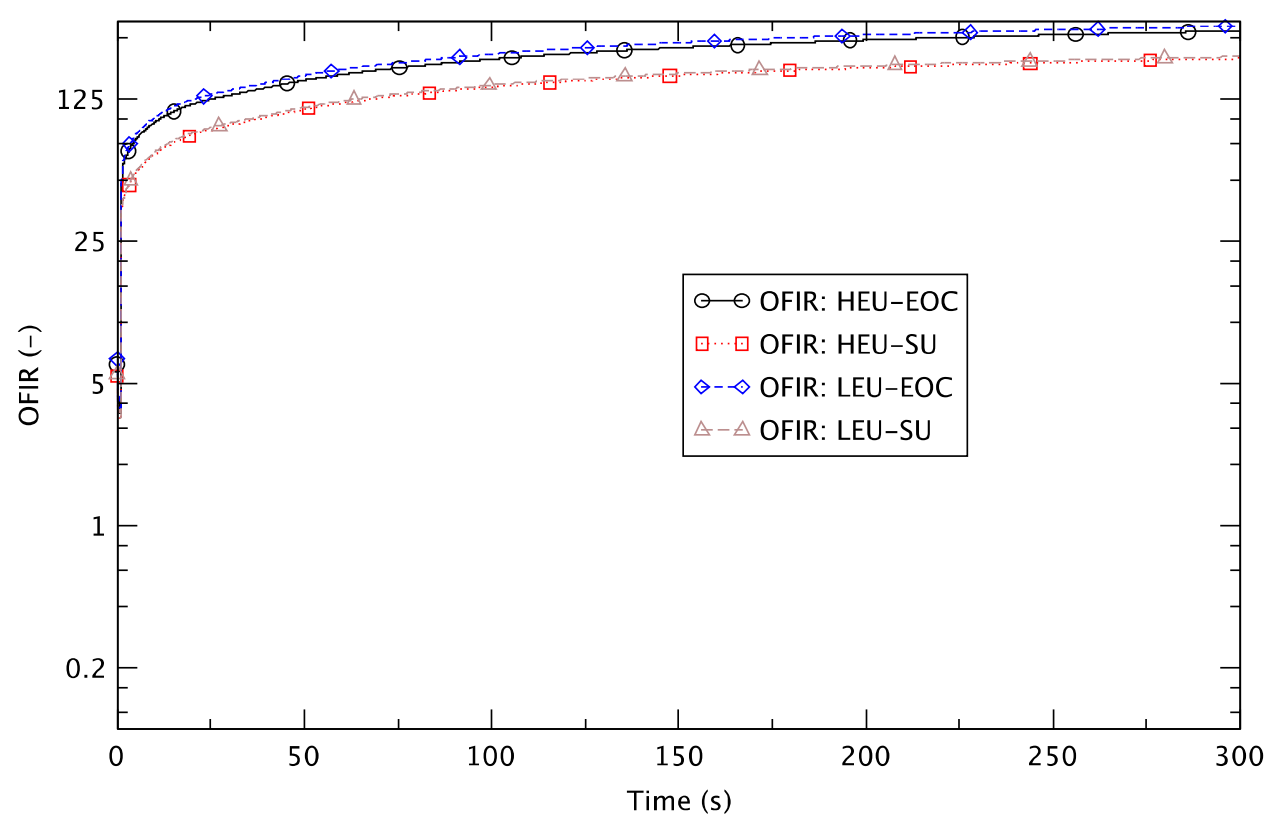

Figure 4-31 Onset-of-Flow-Instability Ratios in Accident of Seizure of One Primary Pump: Wide Range

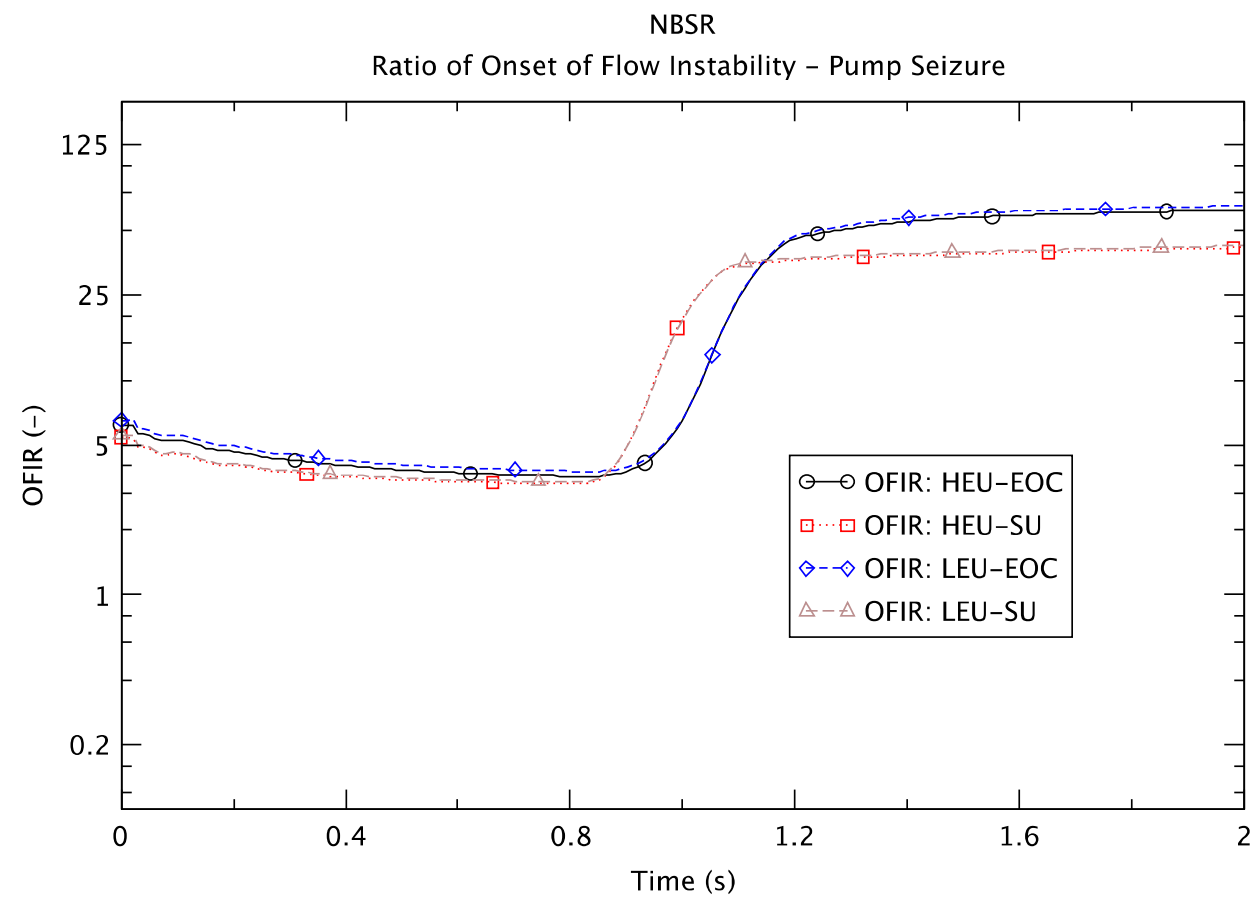

Figure 4-32 Onset-of-Flow-Instability Ratios in Accident of Seizure of One Primary Pump: Narrow Range 
Table 4-19 Minimum OFIRs in Accident of Seizure of One Primary Pump

\begin{tabular}{|c|c|c|c|}
\hline Case & $\begin{array}{c}\text { Minimum } \\
\text { OFIR (-) }\end{array}$ & Time (s) & Hydraulic Node No. \\
\hline HEU EOC & 3.56 & 0.83 & $417-15^{(1)}$ \\
\hline HEU SU & 3.29 & 0.81 & $503-15^{(2)}$ \\
\hline LEU EOC & 3.77 & 0.83 & $417-15^{(1)}$ \\
\hline LEU SU & 3.36 & 0.81 & $503-15^{(2)}$ \\
\hline
\end{tabular}

Notes ${ }^{(1)}$ The minimum OFIR occurs in the powered-top node of the flow channel corresponding to the hottest fuel stripe.

${ }^{(2)}$ The minimum OFIR occurs in the hottest node (highest power cell in the core region). The flow channel with this node has a mid-plane gap shared with the flow channel for 16 average fuel plates.

Table 4-19 shows that the minimum OFIR does not take place around the hottest node at EOC in this accident. Similar to the minimum CHFR, however, Figure 4-26 and Table 4-19 show that that the minimum OFIR occurs shortly after reactor trip when the reactor power is still high.

It can be seen from Figure 4-31 and Figure 4-32 that the OFIR with LEU fuel is very similar to that with the HEU fuel. It is also observed from Figure 4-32 and Table 4-19 that the minimum OFIR is 3.29 and 3.56 for the HEU cases and 3.36 and 3.77 for the LEU cases. Hence, fuel element damage is precluded with either HEU or LEU fuel, with a probability greater than 99.9\% (see Table 3-13).

\subsubsection{Summary}

In the accident with seizure of one primary pump the general system behavior with LEU fuel is similar to that with HEU fuel. The reactor power starts decreasing very rapidly from $20.4 \mathrm{MW}$ after a reactor trip signal caused by low flow to the outer plenum. Cladding temperature rises from time zero because of the decreasing mass flow rate due to seizure of one primary pump. The highest peak cladding temperature $(392.8 \mathrm{~K})$ occurs in the case of HEU fuel at SU and is much lower than the expected blister temperatures. Hence, fuel element damage is not expected as a result of an accident with seizure of one primary pump.

Minimum CHFR and OFIR are evaluated in all hydraulic nodes in the core region and they are all much higher than the threshold values for precluding fuel damage with a probability of $99.9 \%$.

\subsubsection{Throttling of Coolant Flow to Outer Plenum}

\subsubsection{Simulation of Accident}

In this accident scenario, the flow control valve DWV-1 is assumed to close, reducing the flow through the outer plenum, with reactor trip signal $0.4 \mathrm{~s}$ after the flow reaches the low flow trip point of $4700 \mathrm{gpm}(297 \mathrm{l} / \mathrm{s})$. A scram is activated with its actuation delay time of $0.0983 \mathrm{~s}$. The 
complete closure of the flow control valve isolates the lower plenum of the outer core and cuts off the supply of forced coolant flow. The RELAP5 calculation shows that since all coolant channels in the fuel elements in the outer core share the same inlet and outlet plenums, closed loop recirculation flow paths are established between the heated coolant channels in the outer core. Buoyancy induces upflow through the hotter coolant channels, while downflow through the cooler channels completes the closed flow loop. The recirculation flow removes heat from the core region by natural convection.

\subsubsection{Reactor Power}

Reactor power from time zero to $300 \mathrm{~s}$ is shown in Figure 4-33. The reactor power decreases very rapidly from $11.22 \mathrm{~s}$ in the HEU cases and $11.26 \mathrm{~s}$ in the LEU cases. The trip setpoint on low outer plenum flow $(297 \mathrm{l} / \mathrm{s})$ is reached at $10.72 \mathrm{~s}$ for the HEU core and at $10.76 \mathrm{~s}$ for the LEU core. Reactor trip begins after $0.4 \mathrm{~s}$ of delay time and the shim arms start to be inserted into the core after an additional $0.0983 \mathrm{~s}$ (see Section 3.3.6.2). Table 4-20 shows the predicted reactor trip times.

The power plots in Figure 4-33 show that the behavior is similar in both the LEU and HEU cores. It can also be seen that the power drops more rapidly in the cases at SU compared to the cases at EOC. This results from the different initial shim arm positions (about $23^{\circ}$ at $\mathrm{SU}$ and $41^{\circ}$ at EOC) shown in Figure 3-13 and Figure 3-14 which causes a larger initial negative reactivity insertion rate at $\mathrm{SU}$.

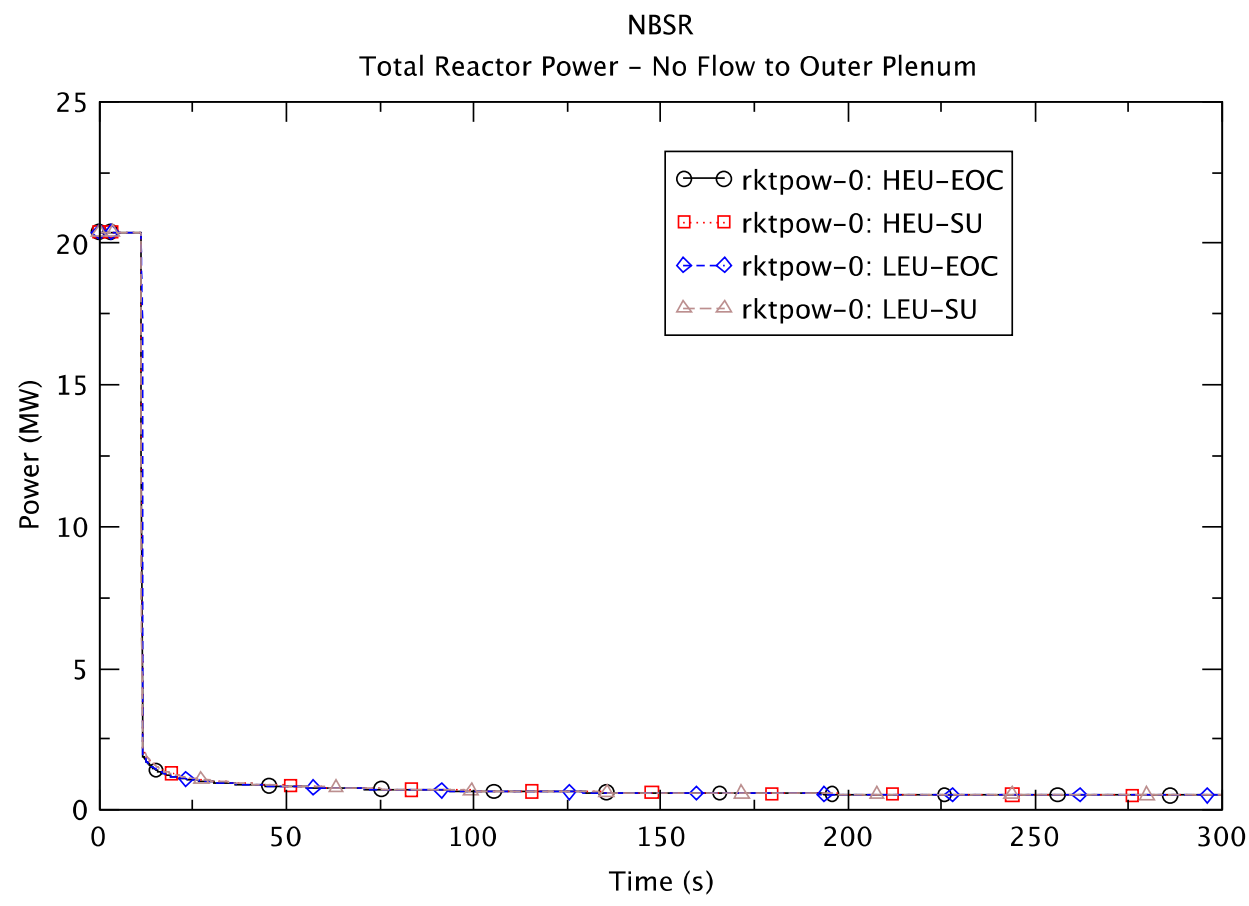

Figure 4-33 Reactor Power Responses in Accident of Throttling of Coolant Flow to Outer Plenum 


\section{Table 4-20 Reactor Trips and Occurring Times in Accident of Throttling of Coolant Flow to Outer Plenum}

\begin{tabular}{|c|c|c|}
\hline Case & Time $(\mathrm{s})$ & \multicolumn{1}{c|}{ Trip Type } \\
\hline HEU EOC & 11.22 & Low outer plenum flow \\
\hline HEU SU & 11.22 & Low outer plenum flow \\
\hline LEU EOC & 11.26 & Low outer plenum flow \\
\hline LEU SU & 11.26 & Low outer plenum flow \\
\hline
\end{tabular}

\subsubsection{Fuel Temperature}

Figure 4-34 shows cladding temperatures from time zero to $300 \mathrm{~s}$ in the fuel element nodes corresponding to the channel cell with minimum CHFR. Heat structure number 5000 in the legend indicates the fuel stripe containing the hottest fuel cell (highest cell power) in the outer core. The flow channel with this heat structure shares a mid-plane gap with 16 average fuel plates (see Table 3-3 and Table 3-10).

The general behavior of the cladding temperature for LEU fuel is very similar to that for HEU fuel. The cladding temperature starts increasing from time zero due to heat transfer becoming inefficient as the mass flow rate to the outer core decreases. The temperature reaches a first peak when reactor trip occurs and then begins decreasing rapidly because of reduction of the reactor power. The temperature starts increasing again from around $15 \mathrm{~s}$ as the mass flow rate decreases further and heat transfer from the fuel elements to the coolant becomes inefficient. The cladding temperatures show oscillatory behaviors from around $50 \mathrm{~s}$ to $85 \mathrm{~s}$ because the mass flow rates in flow channels fluctuate around zero. As the valve (DWV-1) at the inlet to the outer plenum is being closed, the coolant flow velocity decreases very rapidly, fluctuates around zero, and then stable natural circulation flow is established inside the outer core. During the flow fluctuation, RELAP5 predicts almost zero flow velocity several times when flow direction changes. This results in poor heat transfer from the fuel to coolant and increased cladding temperatures. As flow velocity increases after change of the flow direction, the heat transfer increases and the cladding temperature decreases. This behavior occurs several times during the flow fluctuations in all cases and it causes oscillations of the cladding temperature as shown in Figure 4-34. However, the highest cladding temperatures during the flow fluctuations are lower than their expected blister temperatures. 


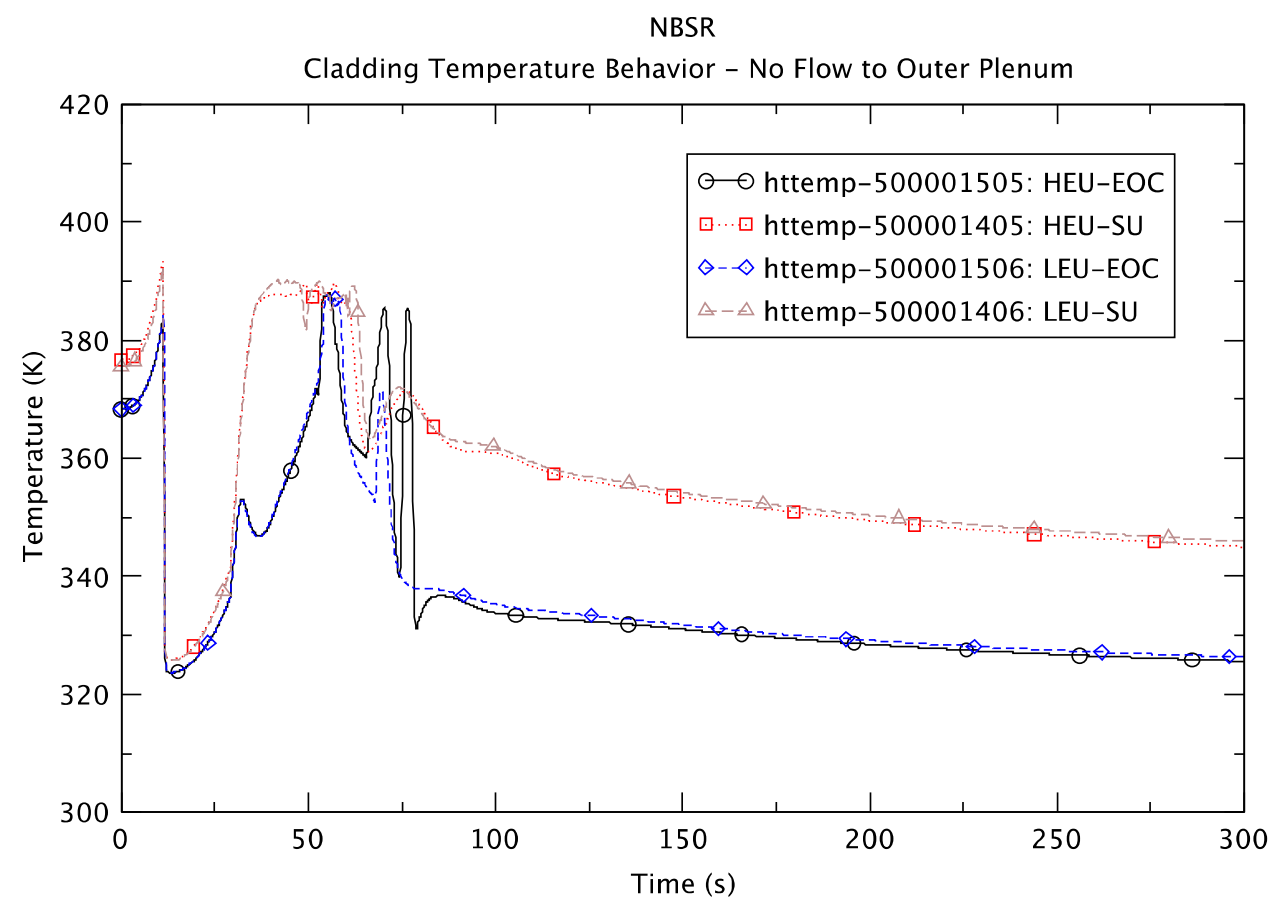

\section{Figure 4-34 Cladding Temperatures in Accident of Throttling of Coolant Flow to Outer Plenum}

Table 4-21 illustrates the peak cladding temperatures, occurring times, and temperature increases from their initial values. The peak cladding temperatures occur during the closure of DWV-1 (at $11.2 \mathrm{~s}$ and $11.3 \mathrm{~s}$ ) at SU but during flow fluctuation (at $55.7 \mathrm{~s}$ and $57.1 \mathrm{~s}$ ) at EOC. This different timing seems to be caused by different initial temperature as shown in Figure 4-34. The peak cladding temperatures and increases are less than $394 \mathrm{~K}$ (much lower than the expected blister temperatures) and $20 \mathrm{~K}$, respectively, in all cases. Hence, it is expected that there will be no fuel element damage from this event.

Table 4-21 Peak Cladding Temperatures and Cladding Temperature Increases in Accident of Throttling of Coolant Flow to Outer Plenum

\begin{tabular}{|c|c|c|c|}
\hline Case & $\begin{array}{c}\text { Peak Cladding } \\
\text { Temperature }(\mathrm{K})\end{array}$ & Time $(\mathrm{s})$ & $\begin{array}{c}\text { Temperature } \\
\text { Increase }(\mathrm{K})\end{array}$ \\
\hline HEU EOC & 388.0 & 55.7 & 19.6 \\
\hline HEU SU & 393.4 & 11.2 & 16.8 \\
\hline LEU EOC & 387.3 & 57.1 & 19.0 \\
\hline LEU SU & 392.6 & 11.3 & 17.0 \\
\hline
\end{tabular}

\subsubsection{Minimum CHFR}

Critical-heat-flux ratios are evaluated using Sudo-Kaminaga correlations (see Section 3.4.1) and are compared in Figure 4-35 from time zero to $300 \mathrm{~s}$. The nodes used for the figures are the ones 
where minimum CHFR takes place among all the hydraulic nodes in the core region. The general behavior of CHFR is similar in all cases. The CHFR starts decreasing slowly from time zero and increases suddenly at around $11.2 \mathrm{~s}$ as the power decreases rapidly after the rector trip. CHFR begins decreasing again after reaching a peak at around $12.8 \mathrm{~s}$ because the severity of flow conditions associated with CHF surpasses the effect of the power decrease. There is another sudden decrease of CHFR at around $30 \mathrm{~s}$ when VALVE-51 (simulating DWV-1) is completely closed and mass flow to the outer plenum becomes almost zero. Then the CHFR increases slowly and becomes larger than 5.5 from $100 \mathrm{~s}$ after some oscillations due to the fluctuation of mass flow rate around zero before stable natural circulation is established in the outer core.

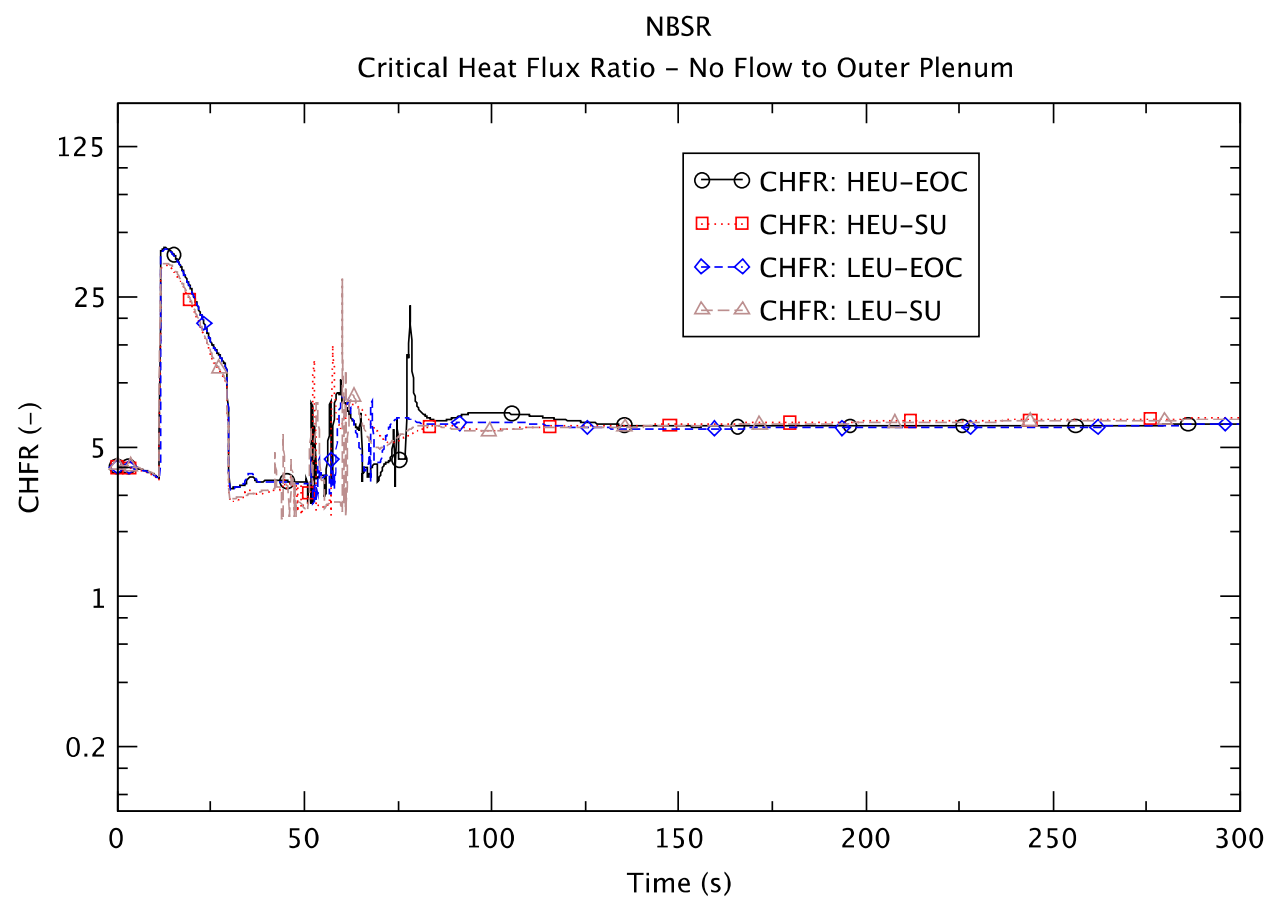

Figure 4-35 Critical Heat Flux Ratios in Accident of Throttling of Coolant Flow to Outer Plenum 
Table 4-22 shows the minimum CHFRs. From Figure 4-35 and 
Table 4-22 it can be observed that minimum CHFR occurs during the fluctuation of mass flow rate in the outer core. The minimum CHFR is higher than 2.30 in all cases. This indicates that fuel element damage is precluded in this event in both HEU and LEU cores with a probability greater than $99.9 \%$ (see Table 3-12). 
Table 4-22 Minimum CHFRs in Accident of Throttling of Coolant Flow to Outer Plenum

\begin{tabular}{|c|c|c|c|}
\hline Case & $\begin{array}{c}\text { Minimum } \\
\text { CHFR (-) }\end{array}$ & Time (s) & Hydraulic Node No. \\
\hline HEU EOC & 2.74 & 51.8 & $507-02^{(1)}$ \\
\hline HEU SU & 2.39 & 57.2 & $503-15^{(1)}$ \\
\hline LEU EOC & 2.74 & 52.4 & $507-02^{(1)}$ \\
\hline LEU SU & 2.30 & 44.2 & $503-15^{(1)}$ \\
\hline
\end{tabular}

Notes ${ }^{(1)}$ The minimum CHFR occurs in the hottest node (highest power cell in the core region). The flow channel with this node has a mid-plane gap with the flow channel representing 16 average fuel plates.

\subsubsection{Minimum OFIR}

A flow oscillation around zero flow was predicted during this accident. When the flow velocity in a channel approaches zero because of flow fluctuation, even though the heat transfer becomes less efficient, the coolant receives a relatively large amount of heat from the fuel because it stays in the powered channel for a relatively long time. Vapor can be generated if heat continues to be transferred to the coolant. However, when flow velocity increases after change of flow direction, vapor generation will stop when cooler coolant returns.

RELAP5 predicts vapor generation in the core during this particular accident. As discussed in Section 3.4.2, Saha-Zuber criteria (Saha, 1974) are used to evaluate the onset of net vapor generation as a conservative threshold for onset of flow instability. Therefore, evaluation of minimum OFIR is not relevant in this accident.

However, the fact that fuel element damage is unlikely can be assured by other parameters; namely, fuel element temperature and minimum CHFR. As discussed in the previous sections, it was observed that the peak cladding temperatures are all less than $394 \mathrm{~K}$ and the minimum CHFRs are all higher than 2.30 in this accident. Hence, it is unlikely that there would be any fuel element damage.

\subsubsection{Summary}

In the accident with throttling of coolant flow to the outer plenum, the general system behavior with LEU fuel is similar to that with HEU fuel. The reactor power starts decreasing very rapidly from 20.4 MW, after reactor trip at $11.22 \mathrm{~s}$ with HEU fuel and at $11.26 \mathrm{~s}$ with LEU fuel, due to low flow to the outer plenum. Cladding temperature in the outer core rises from time zero because the mass flow rate is decreasing due to closure of the valve (DWV-1) at the inlet to the outer plenum. The highest peak cladding temperature occurs in the case of HEU fuel at SU and is $393.4 \mathrm{~K}$ (much lower than the expected blister temperatures) with a temperature rise of about $16.8 \mathrm{~K}$. From this result it can be concluded that there is no fuel damage with either the HEU or LEU fuel in the accident initiated by throttling of coolant flow to the outer plenum.

Minimum CHFR is evaluated in all hydraulic nodes in the core region and indicates that fuel element damage is precluded with probability greater than $99.9 \%$. 


\subsubsection{Throttling of Coolant Flow to Inner Plenum}

\subsubsection{Simulation of Accident}

In this accident scenario, the flow control valve DWV-2 is assumed to close, decreasing the flow through the inner plenum, with reactor trip signal $0.4 \mathrm{~s}$ after the flow reaches the low flow trip point of $1200 \mathrm{gpm}(75.7 \mathrm{l} / \mathrm{s})$. A scram is activated with its actuation delay time of $0.0983 \mathrm{~s}$. The 8 " flow control valve is known to have a stroke time of $30 \mathrm{~s}$. The complete closure of the flow control valve isolates the lower plenum of the inner core and at the same time cuts off the supply of forced coolant flow. The RELAP5 calculation shows that since all coolant channels in the fuel elements in the inner core share the same inlet and outlet plenums, closed loop recirculation flow paths are established between the heated coolant channels in the outer core. Buoyancy induces upflow through the hotter coolant channels, while downflow through the cooler channels completes the closed flow loop. The recirculation flow removes heat from the core region by natural convection.

\subsubsection{Reactor Power}

Figure 4-36 depicts predicted reactor power during the transients from time zero to $300 \mathrm{~s}$. The reactor power decreases very rapidly from $15.6 \mathrm{~s}$ in all cases. Trip setpoint on low inner plenum flow $(75.7 \mathrm{l} / \mathrm{s})$ is reached at $15.1 \mathrm{~s}$ in all cases. Reactor scram starts as the shim arms are being inserted into the core region after $0.4 \mathrm{~s}$ instrument delay time and $0.0983 \mathrm{~s}$ of scram actuation delay time. Table 4-23 shows the predicted reactor trip times.

Figure 4-36 shows that general behavior of the power with the LEU fuel is similar to that with the HEU fuel. The power decrease occurs slightly faster in the cases at SU than in the cases at EOC. This is because differential shim arm worth is lowest when the shim arms are inserted from the fully withdrawn (EOC) position. 


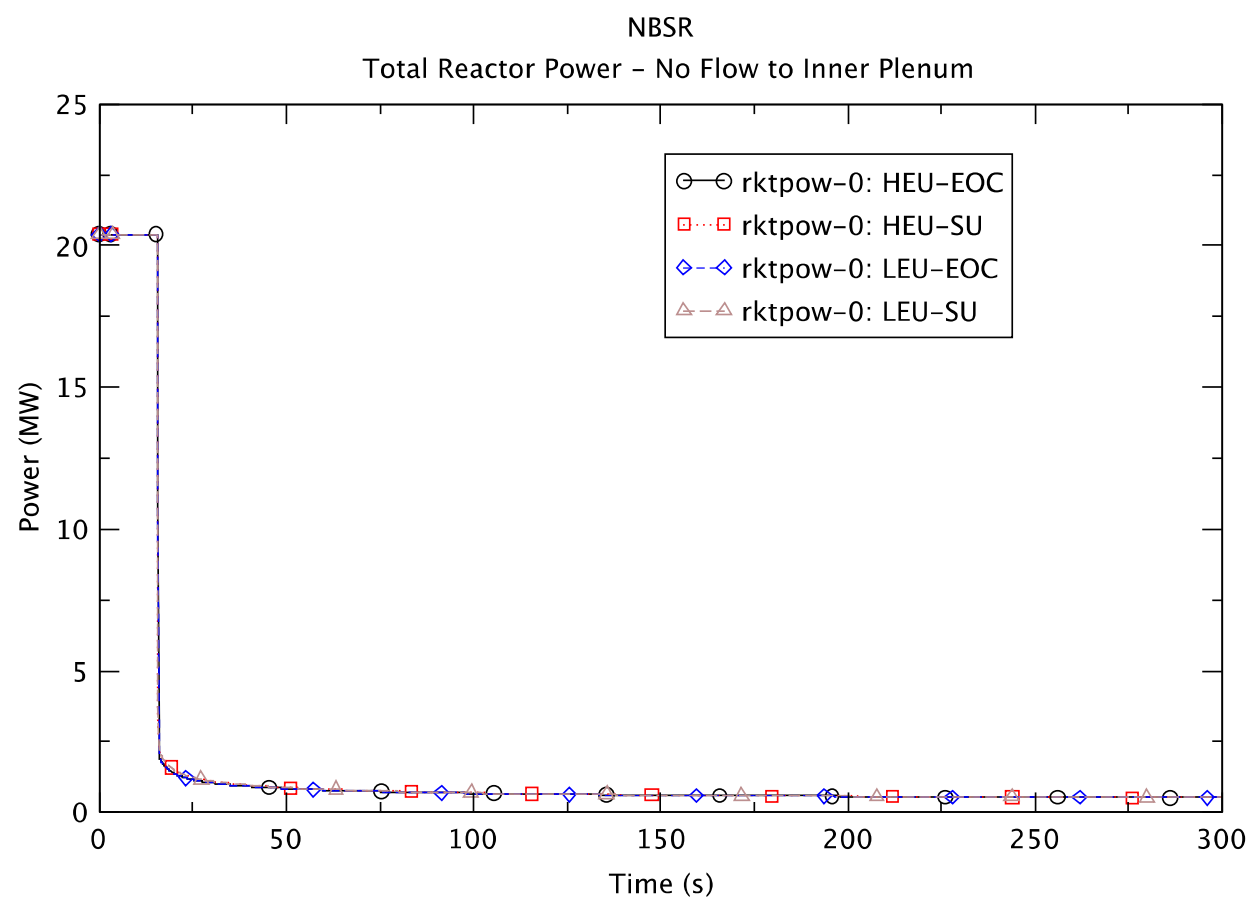

Figure 4-36 Reactor Power Responses in Accident of Throttling of Coolant Flow to Inner Plenum

Table 4-23 Reactor Trips and Occurring Times in Accident of Throttling of Coolant Flow to Inner Plenum

\begin{tabular}{|c|c|l|}
\hline Case & Time $(\mathrm{s})$ & \multicolumn{1}{c|}{ Trip Type } \\
\hline HEU EOC & 15.6 & Low inner plenum flow \\
\hline HEU SU & 15.6 & Low inner plenum flow \\
\hline LEU EOC & 15.6 & Low inner plenum flow \\
\hline LEU SU & 15.6 & Low inner plenum flow \\
\hline
\end{tabular}

\subsubsection{Fuel Temperature}

Figure 4-37 shows cladding temperatures from time zero to $300 \mathrm{~s}$ in the fuel element nodes corresponding to the channel cell with minimum CHFR. Heat structure number 2000 in the legend indicates the fuel stripe containing the hottest fuel cell (highest cell power) in the inner core. The flow channel with this heat structure shares a mid-plane gap with 16 average fuel plates (see Table 3-3 and Table 3-10).

The general behavior of the cladding temperature for LEU fuel is very similar to that for HEU fuel. The cladding temperature starts increasing from time zero due to heat transfer becoming inefficient as the mass flow rate to the inner core decreases. The temperature reaches first peak shortly after reactor trip and then begins decreasing rapidly because of reduction of the reactor power. The temperature starts increasing again from around $18 \mathrm{~s}$ as the mass flow rate decreases 
further and heat transfer from the fuel elements to the coolant becomes inefficient. The cladding temperatures show some oscillatory behaviors from around $30 \mathrm{~s}$ to $55 \mathrm{~s}$ because of fluctuations of the mass flow rates in those channels around zero. As the valve (DWV-2) at the inlet to the inner plenum is being closed, the coolant flow velocity decreases very rapidly, fluctuates around zero, and then stabilizes to natural circulation flow inside the inner core. During the flow fluctuation, RELAP5 predicts almost zero flow velocity a few times when flow direction changes. This results in poor heat transfer from the fuel to coolant and increased cladding temperatures. As flow velocity increases after change of the flow direction, the heat transfer becomes efficient again and the cladding temperature decreases. This behavior occurs a few times during the flow fluctuations in all cases and it causes oscillations of the cladding temperature as shown in Figure 4-37. However, the highest cladding temperatures during the flow fluctuations are lower than their expected blister temperatures.

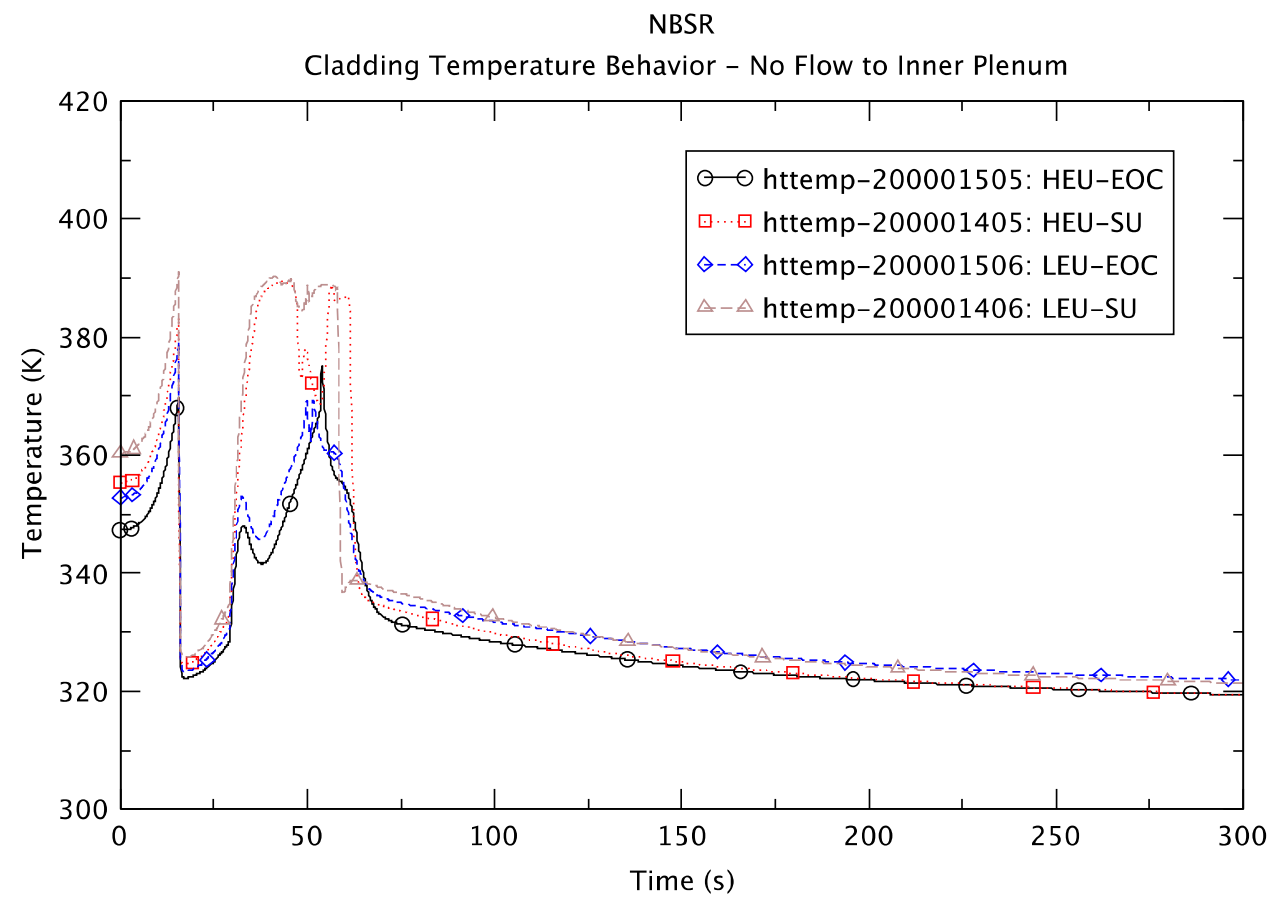

Figure 4-37 Cladding Temperatures in Accident of Throttling of Coolant Flow to Inner Plenum 
Table 4-24 illustrates the peak cladding temperatures, occurring times, and temperature increases from their initial values. The peak cladding temperatures occur during the closure of DWV-2 (at $15.6 \mathrm{~s}$ ) with LEU fuel but during flow fluctuation at $45.7 \mathrm{~s}$ and $53.8 \mathrm{~s}$ with HEU fuel. The peak cladding temperatures and increases are less than $392 \mathrm{~K}$ (much lower than the expected blister temperature) and $31 \mathrm{~K}$, respectively, in all cases. Therefore, it is expected that the integrity of fuel element is retained in this accident. 
Table 4-24 Peak Cladding Temperatures and Cladding Temperature Increases in Accident of Throttling of Coolant Flow to Inner Plenum

\begin{tabular}{|c|c|c|c|}
\hline Case & $\begin{array}{c}\text { Peak Cladding } \\
\text { Temperature (K) }\end{array}$ & Time (s) & $\begin{array}{c}\text { Temperature } \\
\text { Increase (K) }\end{array}$ \\
\hline HEU EOC & 375.2 & 53.8 & 27.9 \\
\hline HEU SU & 389.7 & 45.7 & 34.4 \\
\hline LEU EOC & 378.9 & 15.6 & 26.1 \\
\hline LEU SU & 391.1 & 15.6 & 30.7 \\
\hline
\end{tabular}

\subsubsection{Minimum CHFR}

Critical-heat-flux ratios are evaluated using Sudo-Kaminaga correlations (see Section 3.4.1) and are compared in Figure 4-38 from time zero to $300 \mathrm{~s}$. The nodes used for the figures are the ones where minimum CHFR takes place among all the hydraulic nodes in the core region. The general behavior of CHFR is similar with both HEU and LEU fuels. The CHFRs start decreasing slowly from time zero and increases suddenly at around $15.6 \mathrm{~s}$ as the power decreases rapidly after the rector trip. CHFR begins decreasing again after reaching a peak at around 16.8 $s$ because the severity of flow conditions associated with CHF surpasses the effect of the power decrease. There is another sudden decrease of CHFR at around $30 \mathrm{~s}$ when DWV-2 is completely closed and mass flow to the inner plenum becomes almost zero. Then the CHFR increases slowly and becomes larger than 6 from $100 \mathrm{~s}$ after some oscillations due to the fluctuation of mass flow rate around zero before stable natural circulation is established in the inner core.

Table 4-25 shows the minimum CHFRs. From Figure 4-38 and Table 4-25 it can be observed that minimum CHFR occurs during the fluctuation of mass flow rate in the inner core. The minimum CHFR is higher than 2.21 in all cases. This indicates that fuel element integrity is retained in both HEU and LEU cores with a probability greater than $99.9 \%$ (see Table 3-12). 


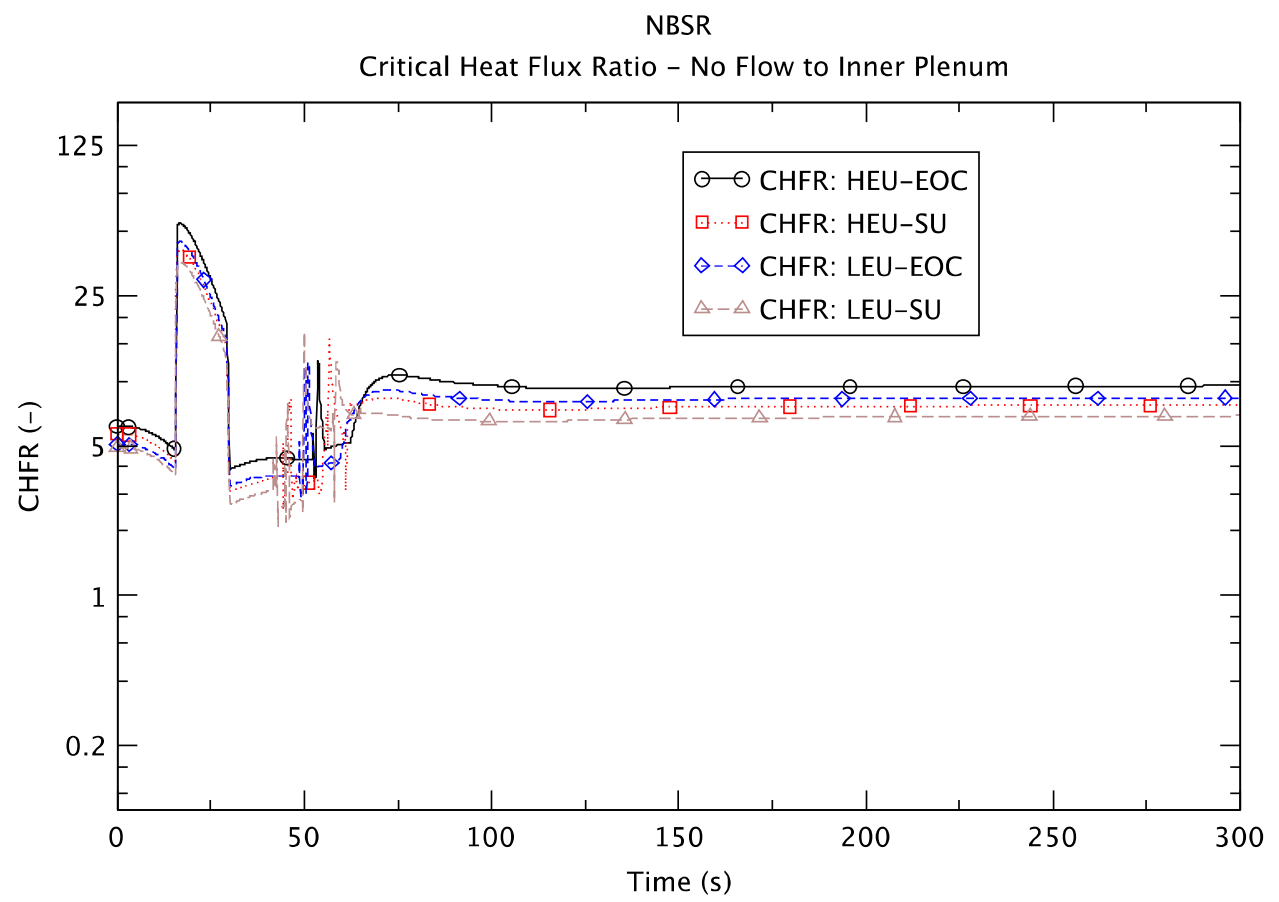

Figure 4-38 Critical Heat Flux Ratios in Accident of Throttling of Coolant Flow to Inner Plenum

Table 4-25 Minimum CHFRs in Accident of Throttling of Coolant Flow to Inner Plenum

\begin{tabular}{|c|c|c|c|}
\hline Case & $\begin{array}{c}\text { Minimum } \\
\text { CHFR (-) }\end{array}$ & Time (s) & Hydraulic Node No. \\
\hline HEU EOC & 3.51 & 52.7 & $207-02^{(1)}$ \\
\hline HEU SU & 2.54 & 44.4 & $203-15^{(1)}$ \\
\hline LEU EOC & 2.88 & 49.0 & $207-02^{(1)}$ \\
\hline LEU SU & 2.21 & 45.2 & $203-15^{(1)}$ \\
\hline
\end{tabular}

Notes ${ }^{(1)}$ The minimum CHFR occurs in the hottest node (highest power cell) in the inner core. The flow channel with this node has a mid-plane gap with the flow channel involving 16 average fuel plates.

\subsubsection{Minimum OFIR}

A flow oscillation around zero flow was predicted during this accident. When the flow velocity in a channel approaches zero because of flow fluctuation, even though the heat transfer becomes less efficient, the coolant receives a relatively large amount of heat from the fuel because it stays in the powered channel for a relatively long time. Vapor can be generated if heat continues to be transferred to the coolant. However, when flow velocity increases after change of flow direction, vapor generation will stop when relatively cold coolant returns. 
RELAP5 predicts vapor generation in the core during this particular accident. As discussed in Section 3.4.2, Saha-Zuber criteria (Saha, 1974) are used to evaluate the onset of net vapor generation as a conservative threshold for onset of flow instability. Therefore, evaluation of minimum OFIR has no significant meaning in this accident.

However, the integrity of fuel elements can be assured by other parameters: namely, fuel element temperature and minimum CHFR. As discussed in the previous sections, it was observed that the peak cladding temperatures are all less than $392 \mathrm{~K}$ and the minimum CHFRs are all higher than 2.21 in this accident. Hence, overheating of fuel element is precluded.

\subsubsection{Summary}

In the accident with throttling of coolant flow to the inner plenum, the general system behavior with LEU fuel is very similar to that with HEU fuel. The reactor power starts decreasing very rapidly from 20.4 MW after reactor trip at $15.6 \mathrm{~s}$ with both HEU and LEU fuels, due to low flow to the inner plenum. Cladding temperature in the inner core rises from time zero because the mass flow rate is decreasing due to closure of the valve (DWV-2) at the inlet to the inner plenum. The highest peak cladding temperature occurs in the LEU case at SU and it is $391.1 \mathrm{~K}$ (much lower than the expected blister temperatures) with a temperature rise of about $30.7 \mathrm{~K}$. From this result it can be concluded that there is no fuel damage with either the HEU or LEU fuel in the accident with throttling of coolant flow to the inner plenum.

Minimum CHFR is evaluated in all hydraulic nodes in the core region and the results assure that integrity of fuel element is retained with probability greater than $99.9 \%$.

\subsection{Pipe Break Events}

In the unlikely event that a break occurs in the inlet pipe between the reactor inlet valves and the inlet plenums, coolant will drain from the interior of the fuel elements. Coolant exterior to the fuel elements will continue to provide some cooling. Another source of cooling is by flow from the inner emergency cooling tank. Nozzles in the distribution pan direct flow from the inner emergency cooling tank to each individual fuel element.

Assuming heat removal is by boil-off, the makeup flow rate is determined from the decay power calculated by RELAP5 for an initial power of $20.4 \mathrm{MW}$ (allowing for a $2 \%$ uncertainty in core power). Within the first second after shutdown the core makeup flow rate drops below $1 \mathrm{~kg} / \mathrm{s}$. The required makeup flow rate for boil-off is shown in Figure 4-39. The flow from the inner emergency cooling tank is calculated as a function of time, using the analytical model described in Section 3.3.5, and is shown in Figure 4-39. The coolant in the fuel element is assumed to have drained out of the break and the tank flow is a result of the hydrostatic head. The flow from the inner emergency cooling tank decreases linearly in time as the water level drops in the tank. For at least 20 minutes after shutdown the tank flow is more than adequate to cool the fuel elements by boil-off. Coolant inventory in the inner emergency cooling tank would be replenished from the 3000-gallon main emergency cooling tank. Thus there is ample time for the operators to assess the situation and initiate additional emergency cooling as needed. 


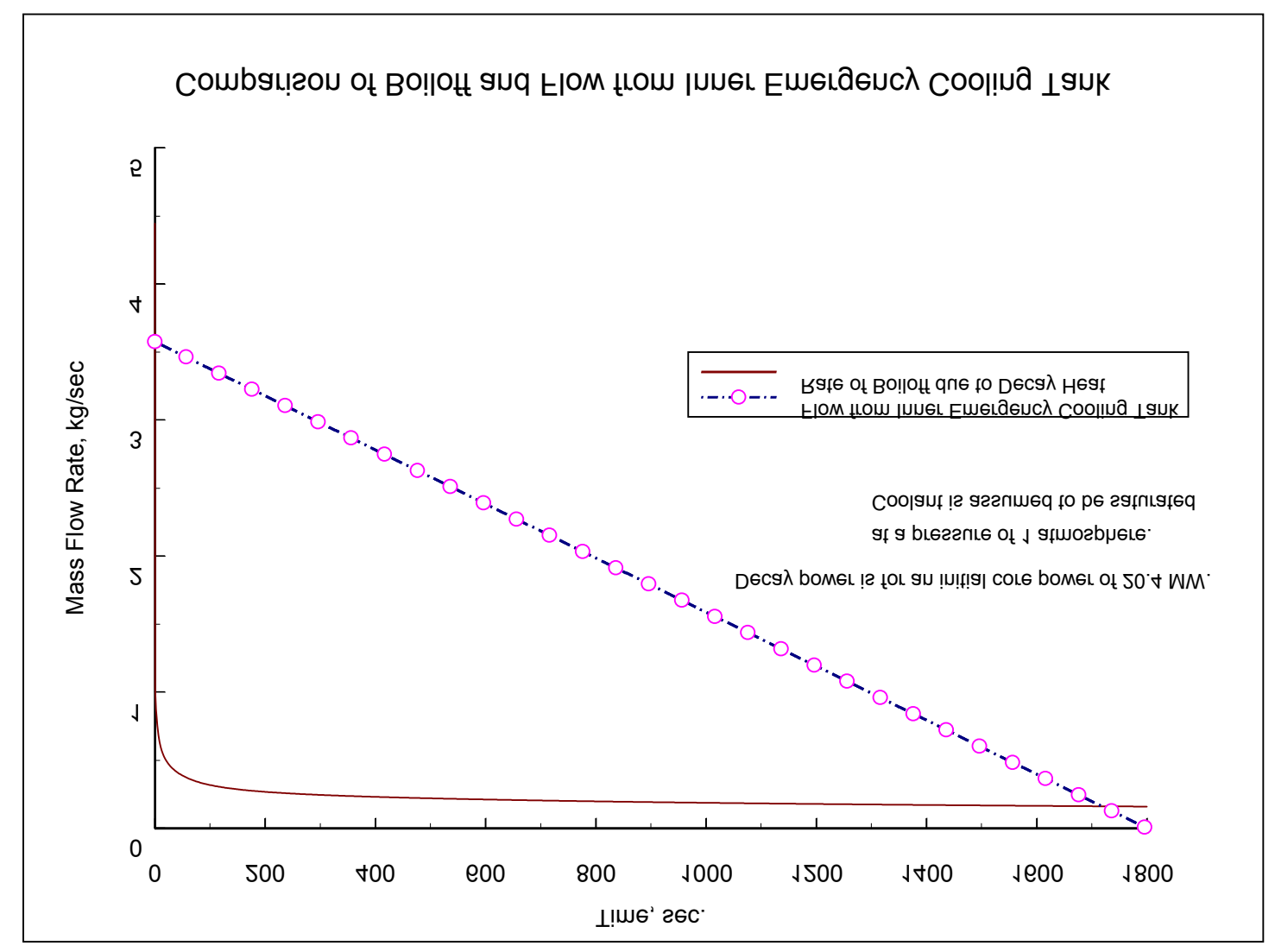

Figure 4-39 Comparison of Boil-Off and Flow from Inner Emergency Cooling Tank (Cheng, 2004)

\subsection{Natural Circulation Cooling at Low Power Operation}

\subsubsection{Simulation of Event}

A RELAP5 calculation was performed to simulate the operation of the NBSR at low power without forced flow cooling. The result indicates that operation of the NBSR with natural convection cooling would not lead to fuel element damage at a power level of $100 \mathrm{~kW}$.

The calculation starts with zero reactor power and zero primary flow in the system. The initial temperature of the primary coolant is set at $43.35^{\circ} \mathrm{C}\left(110^{\circ} \mathrm{F}\right)$. The secondary flow in the primary heat exchanger is assumed to be at an arbitrarily low value of $1 \mathrm{~kg} / \mathrm{s}$. The reactor power is then ramped linearly from zero to $100 \mathrm{~kW}$ in 60 seconds. From that point on the reactor power is maintained constant till the end of the simulation at $500 \mathrm{~s}$. 


\subsubsection{Flow Behavior in Primary System}

Results of the RELAP5 calculation show that natural circulation flow through the core reaches stable natural circulation (quasi-steady state) at about $200 \mathrm{~s}$ in all cases as shown in Figure 4-40. Figure 4-40 shows the coolant flows at the inlets to the channels that contain the hottest node in the inner and outer core (see Table 3-3). As shown in the figure, all coolant channels in the inner and outer core have stable subcooled upflow. It can also be observed that the flow rates decrease with time after around $200 \mathrm{~s}$. This is because fluid temperature increases, especially in the primary piping system, due to inefficient heat transfer to the secondary system and this results in a smaller gravity head difference between the coolant in the core and the coolant in the vessel outlet.

NBSR

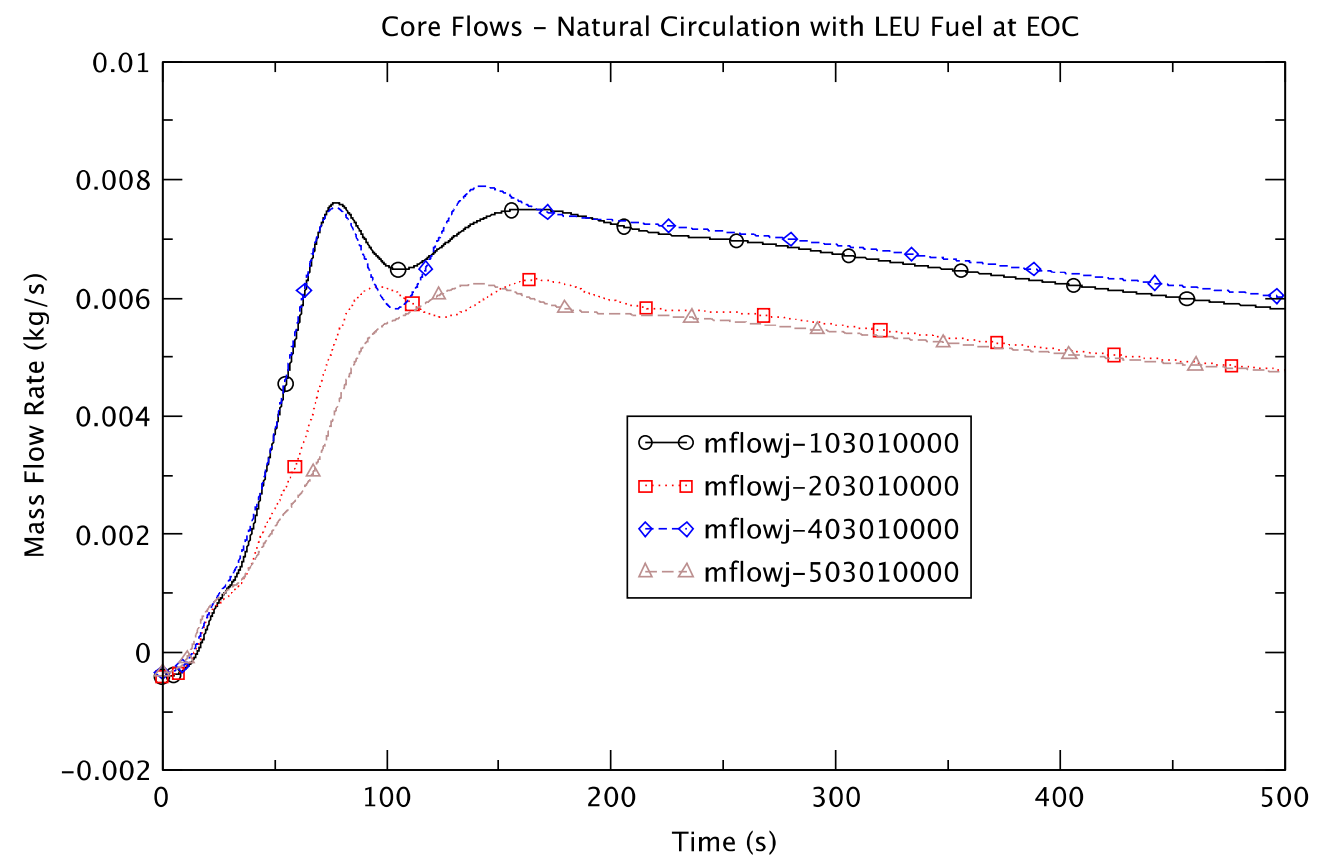

\section{Figure 4-40 Coolant Flows inside Core in Event of Natural Circulation Cooling at Low Power Operation}

\subsubsection{Fuel Temperature}

Figure 4-41 shows cladding temperatures from time zero to $500 \mathrm{~s}$ in the fuel element nodes corresponding to the minimum CHFR. Heat structure numbers 4000 and 5000 in the legend indicate the fuel channel containing the hottest fuel cell (highest power cell) in the core and the hottest fuel cell with a mid-plane gap shared with 16 average fuel channels (see Table 3-3 and Table 3-10). The general behavior of the cladding temperature with LEU fuel is similar to that with HEU fuel. The cladding temperature starts increasing from time zero due to increase of reactor power according to the event scenario. When the flow velocity increases from zero at time zero and colder coolant is flowing into the channels from the lower plena as stable natural 
circulation flow is being established due to the rise of reactor power, the rate of cladding temperature increase reduces and a peak occurs between 50 and 100 seconds. Then cladding temperature starts decreasing slightly as shown in Figure 4-41as the reactor power stays at 100 $\mathrm{kW}$ from $60 \mathrm{~s}$ and large enough amount of colder upstream coolant flows in with increase of its velocity. The cladding temperature continues increasing very slowly after $140 \mathrm{~s}$ because overall coolant is being heated up in the primary system due to inefficient heat transfer to the secondary system through the heat exchangers. As shown in Figure 4-41, however, the temperature increase is almost negligible until $500 \mathrm{~s}$ and it indicates that there is ample time for the operators to take necessary actions to protect the reactor before the cladding temperature reaches the blister temperature.

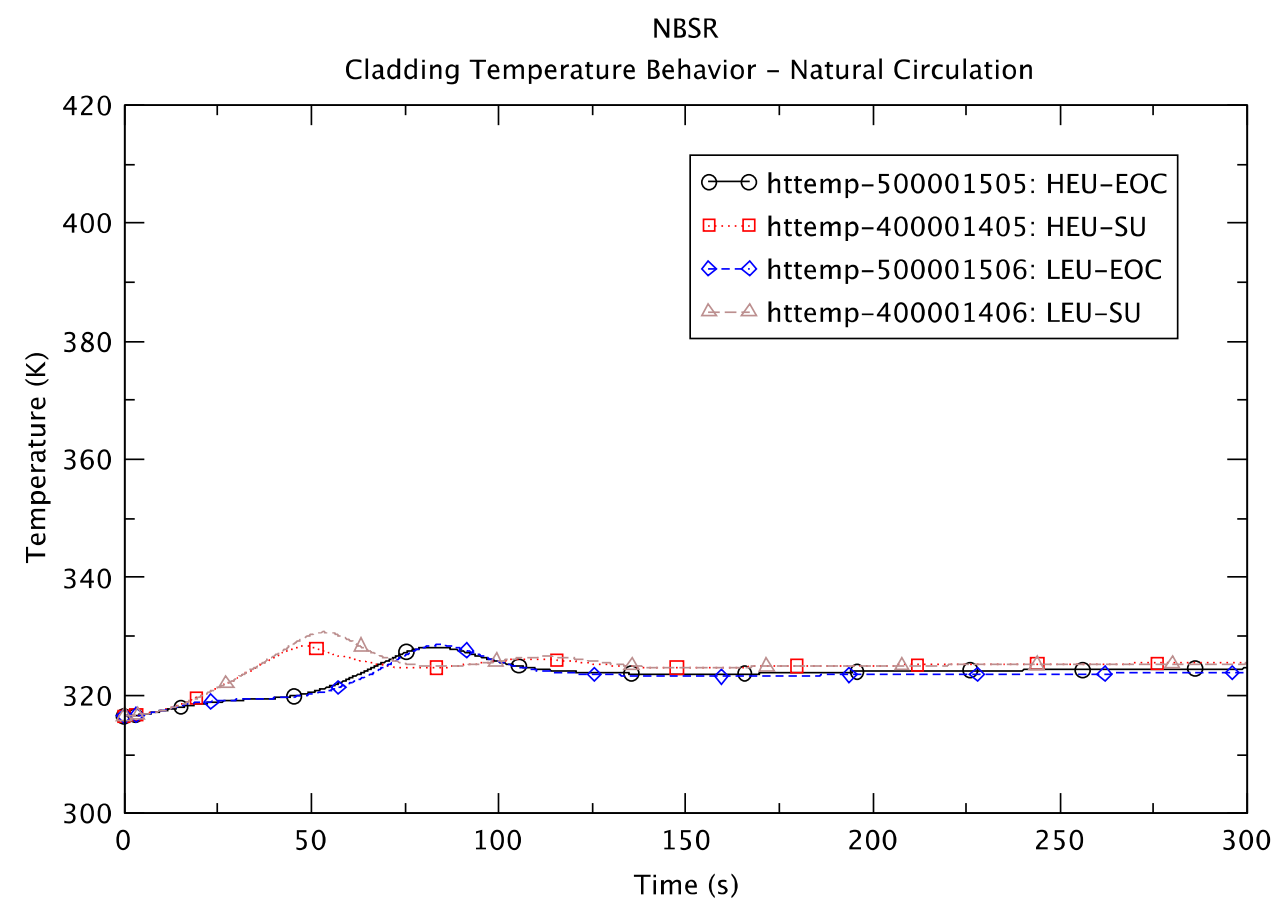

Figure 4-41 Cladding Temperatures in Event of Natural Circulation Cooling at Low Power Operation 
Table 4-26 illustrates the peak cladding temperatures, occurring times, and temperature increases from their initial values. The peak cladding temperatures and increases are less than $331 \mathrm{~K}$ (much lower than the expected blister temperatures) and $15 \mathrm{~K}$, respectively, in all cases. Hence, no fuel element damage is expected. 
Table 4-26 Peak Cladding Temperatures and Cladding Temperature Increases in Event of Natural Circulation Cooling at Low Power Operation

\begin{tabular}{|c|c|c|c|}
\hline Case & $\begin{array}{c}\text { Peak Cladding } \\
\text { Temperature }(\mathrm{K})\end{array}$ & Time $(\mathrm{s})$ & $\begin{array}{c}\text { Temperature } \\
\text { Increase }(\mathrm{K})\end{array}$ \\
\hline HEU EOC & 328.2 & 82.80 & 11.7 \\
\hline HEU SU & 328.3 & 48.31 & 11.8 \\
\hline LEU EOC & 328.5 & 84.30 & 12.0 \\
\hline LEU SU & 330.7 & 53.31 & 14.2 \\
\hline
\end{tabular}

\subsubsection{Minimum CHFR}

Critical-heat-flux ratios are evaluated using Sudo-Kaminaga correlations (see Section 3.4.1) and are compared in Figure 4-42 from time zero to $500 \mathrm{~s}$. The nodes in the figures are the ones where minimum CHFR takes place among all the hydraulic nodes in the core region. When the CHFR is larger than 1,000, it is plotted as 1,000 in Figure 4-42. The CHFR starts decreasing from time zero as the coolant begins flowing through the core and then remain higher than 28 after $60 \mathrm{~s}$ until the end of the simulation $(500 \mathrm{~s})$ in all cases after stable natural circulation flow is established. This means that fuel element damage is precluded in the HEU and LEU cores with a probability greater than $99.9 \%$ (see Table $3-12$ ).

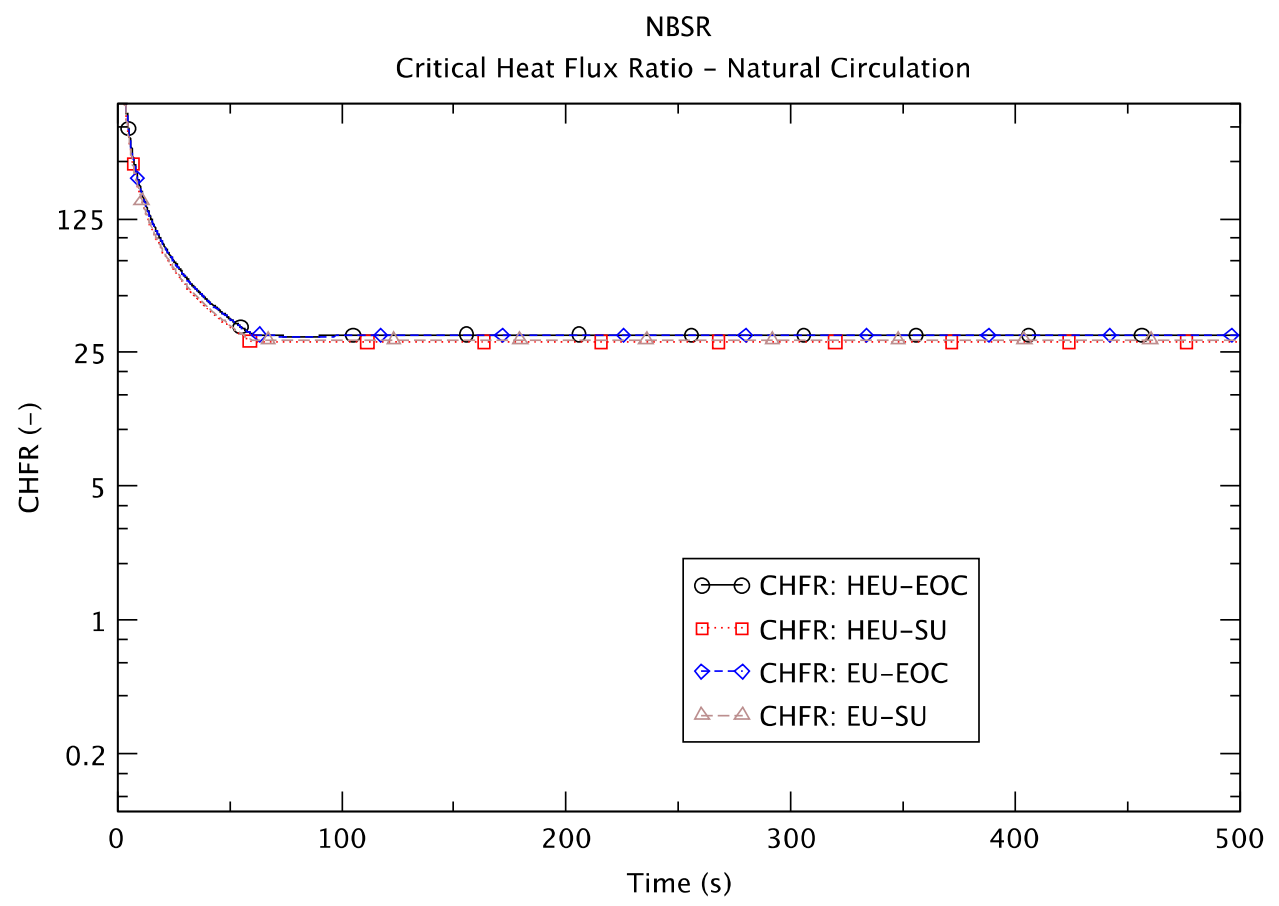

Figure 4-42 Critical Heat Flux Ratios in Event of Natural Circulation Cooling at Low Power Operation 


\subsubsection{Minimum OFIR}

Onset-of-flow-instability ratios are evaluated using Saha-Zuber criteria (see Section 3.4.2) and are shown in Figure 4-43 from time zero to $500 \mathrm{~s}$. The nodes in the figures are the ones where minimum OFIR occurs among all hydraulic nodes in the core region. When the OFIR is larger than 1,000, it is plotted as 1,000 in Figure 4-43. OFIR starts decreasing from time zero as the coolant begins flowing through the core, and reaches a minimum, and then increases slightly, remaining higher than 410 until the end of the simulation $(500 \mathrm{~s})$ in all cases. The lowest minimum OFIR of 379 occurs at around $68.2 \mathrm{~s}$ with LEU fuel at SU. This means that for both the HEU and LEU cores fuel element damage is precluded with a probability greater than $99.9 \%$ (see Table 3-13).

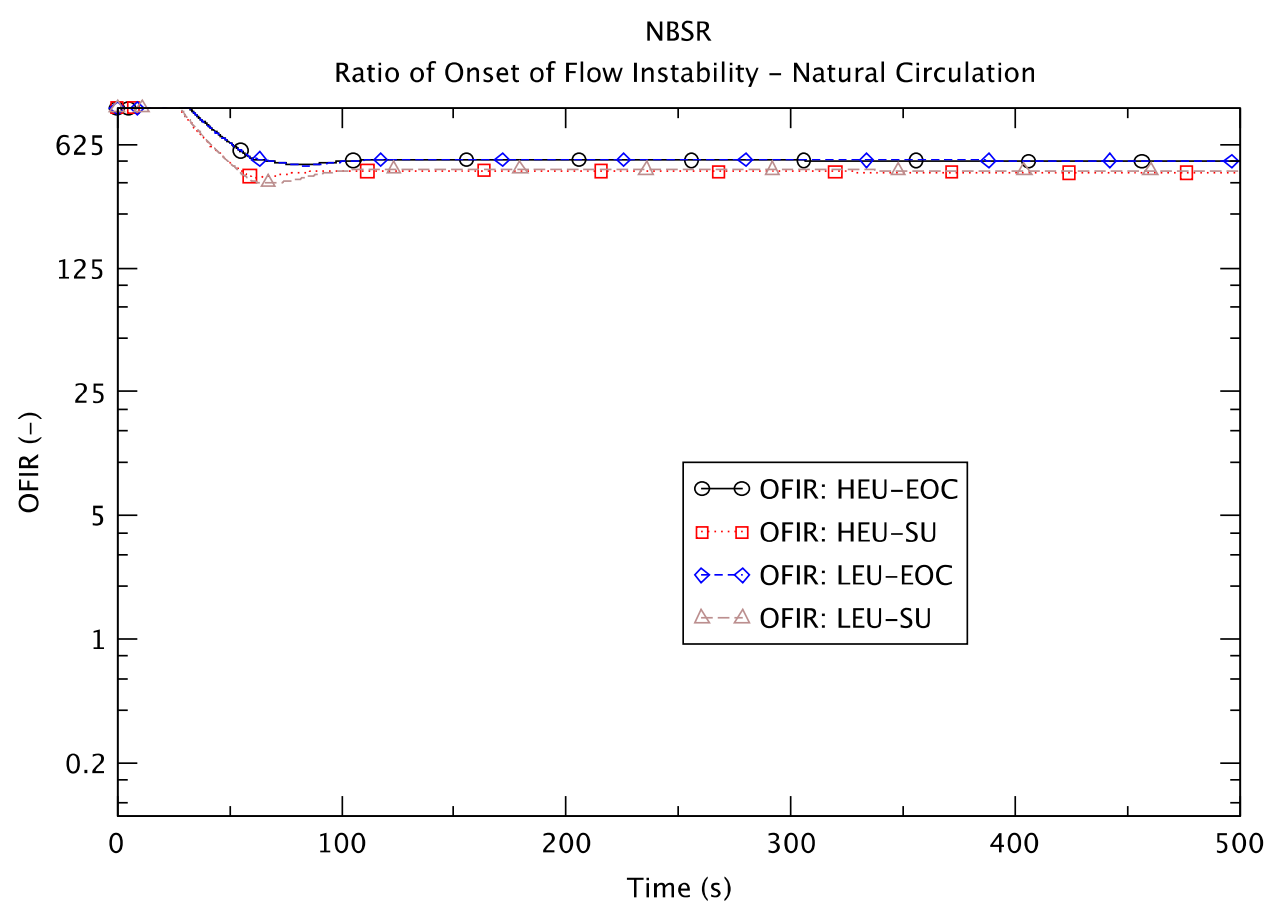

Figure 4-43 Onset-of-Flow-Instability Ratios in Event of Natural Circulation Cooling at Low Power Operation

\subsubsection{Summary}

In natural circulation cooling at $100 \mathrm{~kW}$ operation, the general system behavior with LEU fuel is similar to that with HEU fuel. Stable natural circulation flow is established in the primary system from around $200 \mathrm{~s}$. Cladding temperature rises from time zero slowly because of an increase of the reactor power. Peak cladding temperatures take place as flow velocity increases with the power while natural circulation flow is being established. The highest peak cladding temperature occurs in the LEU case at SU and is $330.7 \mathrm{~K}$ (much lower than the expected blister temperatures) with the temperature rise of about $14.2 \mathrm{~K}$. Hence, no fuel element damage is expected with either HEU or LEU fuel in the event that the reactor is brought up to a power of $100 \mathrm{~kW}$ without pumps operational. 
Minimum CHFR and OFIR are high enough so that neither CHF nor OFI would be expected with a probability greater than $99.9 \%$. 


\section{SUMMARY AND CONCLUSIONS}

The NIST research reactor (NBSR) is being converted from high-enriched uranium (HEU) fuel to low-enriched uranium (LEU) fuel. In order to perform safety analyses, a detailed RELAP5 input model has been developed. The results for the equilibrium LEU core have been compared to those obtained for the current HEU core (using the same methodology) for two state pomts during the fuel cycle, startup (SU) and end-of-cycle (EOC).

The analysis results are summarized as below.

- The general system behavior of the NBSR with LEU fuel is observed to be very similar to that with HEU fuel in all postulated accidents considered in this report.

- Reactor power starts increasing from time zero in the reactivity-initiated accidents, startup and maximum reactivity insertion, due to insertion of positive reactivity but decreases rapidly, when shim arms are inserted after generation of a reactor trip signal, and remains at decay power level until the end of the simulations.

- The initial position of the shim arms at SU or EOC dictates the short term transient response of the transient cases that include shim arm motion.

- The highest peak cladding temperature of $404 \mathrm{~K}$ occurs in the HEU core at SU in a lossof-offsite-power accident with shutdown pump trip and the largest clad temperature rise of $102 \mathrm{~K}$ occurs in the LEU core at EOC in the startup reactivity accident. The peak cladding temperatures are all much lower than the expected blister temperature in all accidents considered. This implies that the reactor will not experience fuel element damage in any event.

- Critical heat flux ratio (CHFR) has been evaluated using the Sudo-Kaminaga correlation. The results show that the minimum CHFR is high enough so that CHF is precluded with probability greater than $99.9 \%$ in all accidents with HEU or LEU fuel at SU and EOC except for one type of accident. In a loss-of-offsite-power with shutdown pump trip the minimum CHFR shows that CHF is precluded with a probability greater than $95 \%$. However, this accident is the one with dual failures (loss of offsite power and shutdown pump trip) and the frequency of occurrence of this accident is significantly small.

- The Saha-Zuber correlation is used to evaluate onset-of-flow-instability ratio (OFIR). The results show that minimum OFIR is high enough so that OFI is precluded with a probability greater than $99.9 \%$ in all accidents with HEU or LEU fuel at SU and EOC as long as there is coolant flow through the core. However, in some accidents where flow fluctuation around zero occurs as stable natural circulation flow is being established, RELAP5 predicts vapor generation in the core. In those cases evaluation of OFIR does 
have significant meaning and the integrity of the fuel elements is assured by consideration of peak clad temperature and minimum CHFR.

- From the analysis results it can be concluded that the NBSR reactor with either HEU or LEU fuel at SU and EOC is safe with respect to fuel element damage taking into account many postulated accidents. 


\section{REFERENCES}

ANS, "Decay Heat Power in Light Water Reactors," American National Standard, ANSI/ANS5.1-1994, American Nuclear Society, August 1994

Baek, J.S. and Cuadra, A., "RELAP5 Input Model for HEU Fuel," Revision 0 to Revision 9 Mod. 1, Calculation Notebooks for NBSR, BNL Internal Reports, January 2011 through August 2012a.

Baek, J.S. and Cuadra, A., "RELAP5 Input Model for LEU Fuel," Revision 0 to Revision 2 Mod. 1, Calculation Notebooks for NBSR, BNL Internal Reports, May 2011 through August $2012 b$.

Cheng, L-Y., "Heat Conduction in an NBSR Fuel Plate-Effect on Wall Heat Flux," BNL Memorandum, Brookhaven National Laboratory, Upton, NY, April 6, 2010.

Cheng, L-Y. et al., "Physics and Safety Analysis for the NIST Research Reactor," BNL-NIST0803, Rev. 1, Brookhaven National Laboratory, Upton, NY, April 2004.

Cuadra, A., and Cheng, L-Y., "Statistical Hot Channel Analysis for the NBSR," BNL Technical Report, Brookhaven National Laboratory, Upton, NY, May 27, 2011.

Hanson, A.L., and Diamond, D.J., "Calculation of Kinetics Parameters for the NBSR," BNL97007-2012, Brookhaven National Laboratory, Upton, NY, March 2012.

Hanson, A. and Diamond, D., "Calculation of Design Parameters for an Equilibrium LEU Core in the NBSR,” BNL Technical Report, Brookhaven National Laboratory, September 29, 2011.

Hanson, A. and Diamond, D., "Energy Deposition in the NBSR," BNL internal memo, Brookhaven National Laboratory, February 2, 2005.

ISL, "RELAP5/MOD3.3 Code Manual,” NUREG/CR-5535/Rev1, Information Systems Laboratories, Inc., Rockville, MD and Idaho Falls, ID, December 2001.

Kaminaga, M., Yamamoto, K., and Sudo, Y., "Improvement of Critical Heat Flux Correlation for Research Reactors using Plate-Type Fuel,” J. Nucl. Sci. Technol. 35 [12], 943-951, 1998.

NIST, "Safety Analysis Report (SAR) for License Renewal for the National Institute of Standards and Technology Reactor - NBSR; NBSR 14, Rev 4" National Institute of Standards and Technology (NIST), Gaithersburg, MD, 2010. Note that this is a modified version of the original NBSR 14 issued in 2004.

NIST, "Technical Specifications for the NIST Test Reactor (NBSR)," Appendix A to License No. TR-5, National Institute of Standards and Technology (NIST), Gaithersburg, MD, 2009. 
Saha, P., and Zuber, N., "Point of Net Vapor Generation and Vapor Void Fraction in Subcooled Boiling," Proc. $5^{\text {th }}$ Int. Heat Transfer Conf., Vol. IV, p. 175, Tokyo, Japan, September 3-7, 1974. 